
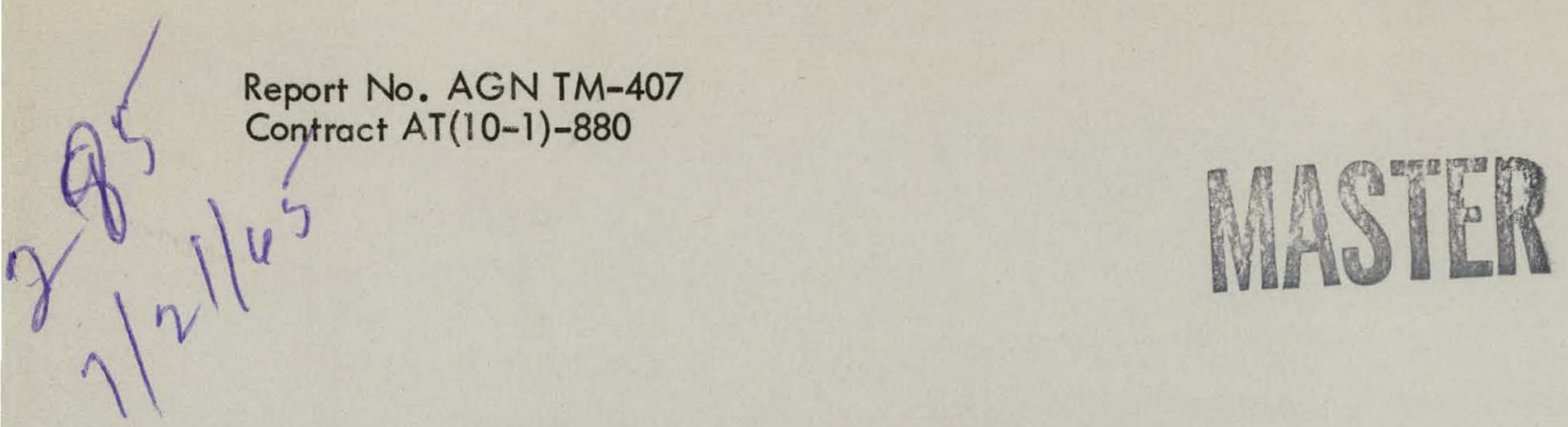

\title{
AGN
}

\section{ARMY GAS-COOLED REACTOR SYSTEMS PROGRAM \\ AGN-GAM, an IBM 7090 Code to Calculate Spectra and Multigroup Constants}

April 1965 


\section{DISCLAIMER}

This report was prepared as an account of work sponsored by an agency of the United States Government. Neither the United States Government nor any agency Thereof, nor any of their employees, makes any warranty, express or implied, or assumes any legal liability or responsibility for the accuracy, completeness, or usefulness of any information, apparatus, product, or process disclosed, or represents that its use would not infringe privately owned rights. Reference herein to any specific commercial product, process, or service by trade name, trademark, manufacturer, or otherwise does not necessarily constitute or imply its endorsement, recommendation, or favoring by the United States Government or any agency thereof. The views and opinions of authors expressed herein do not necessarily state or reflect those of the United States Government or any agency thereof. 


\section{DISCLAIMER}

Portions of this document may be illegible in electronic image products. Images are produced from the best available original document. 


\section{PAGES $\mathrm{i}$ to $\mathrm{ii}$ WERE INTENTIONALLY LEFT BLANK}


Report No. AGN TM-407

TID 4500 (37th Edition) UC-32, "Mathematics and Computers"

\section{AGN}

\section{ARMY GAS-COOLED REACTOR SYSTEMS PROGRAM}

AGN-GAM, AN IBM 7090 CODE TO CALCULATE SPECTRA

AND MULTIGROUP CONSTANTS

by

T. P. Wilcox and S. T. Perkins

April 1965

\section{Approved by: RHilieswontt/asé-}

R. H. Chesworth

Supervising Representative

Contract AT (10-1)-880

\section{AEROJET - GENERAL NUCLEONICS \\ A SUBSIDIARY OF AEROJETGENERAL CORPORATION}

Printed in USA, Price $\$ 3.00$ Available from the office of Technical Services, Department of Commerce Washington 25, D. C.

\section{OENERAL}

TIRE

iii 


\section{THIS PAGE}

\section{WAS INTENTIONALLY \\ LEFT BLANK}




\section{ARMY GAS-COOLED REACTOR SYSTEMS PROGRAM}

AGN-GAM, AN IBM 7090 CODE TO CALCULATE SPECTRA

AND MULTIGROUP CONSTANTS*

by

T. P. Wilcox and S. T. Perkins

\section{ABSTRACT}

The AGN-GAM (IBM 7090) code is discussed together with the subroutines for writing and revising the library tapes.

The code solves either the $P-1$ or $B-1$ equations for 75 quarter lethargy energy groups from $10 \mathrm{Mev}$ to $0.07 \mathrm{ev}$ to determine the slowing down fluxes and currents in a reactor core. Provision is also made to solve $\mathrm{P}-1$ equations to determine these quantities in a reflector region. Broad group constants, weighted by the flux (or current) quantities, are then derived for use in diffusion, isotropic transport or anisotropic transport calculations.

The method of Adler, Hinman and Nordheim is used to calculate resonance absorption and fission cross sections. Selfshielding factors can be included in the computations. The output cross section data can be punched directly into IBM cards for use in any of several nuclear codes.

* Published by Aerojet-General Nucleonics, San Ramon, California. 


\section{THIS PAGE \\ WAS INTENTIONALLY \\ LEFT BLANK}




\section{CONTENTS}

\section{ABSTRACT}

F. INTRODUCTION

A. SUMMARY

B. REPORT ORGANIZATION 3

II. RELATIONS AND DEFINITIONS OF THE MULTIGROUP CONSTANTS

A. IIBRARY TAPE DATA 5

1. Subgroup Cross Sections 5

2. Scattering Matrices 6

3. Resonance Data $\quad \ddots \quad 6$

B. RESONANCE EVALUATION $\quad 7$

1. Resolved Region 7

2. Un-Resolved Region 9

3. Table Interpolation 12

C. SPECTRUM GENERATION $\quad 12$

1. Method of Solution. 12

2. The $\mathrm{P}_{1}$ Equations 13

3. The $B$ Equations 16

4. The Combined $\mathrm{P}_{1}-\mathrm{B}_{1}$ Relations 17

5. Current Calculation Using a Known F1ux . 18

6. The Moment Equations .. 19

D. MULTIGROUP CONSTANTS . 20

1. The Group Structure $\quad 20$

2. Group Averaged Parameters 21

3. The Transport Cross Section and Diffusion . 21 Coefficient

4. Scattering Matrices $\quad 24$

5. $\mathrm{S}_{\mathrm{n}}$ Transport Theory Relations 25

(Continued)

vii 


\section{CONTENTS - Continued}

IIJ. USE OF THE CODE

Page

A. INPUT REQUIREMENTS

B. SAMPLE PROBLEM.

IV. OPERATION

\section{REFERENCES}

APPENDIX A - ENERGY DEPENDENT SPECTRUM GENERATION RELATIONS

APPENDIX $B$ - SCATTERING MATRIX DEVELOPMENT

B -1

APPENDIX $\mathrm{C}$ - THE MULT IGROUP TRANSPORT APPROXIMATION $\quad$. C-1

APPENDIX D - AGN-GAM DATA TAPE \#1003

D-1

APPENDIX E - UPDAT ING THE DATA TAPE

E-1

APPENDIX $F$ - AGN-GAM PROGRAM LISTING

F-1

\section{FIGURES}

Figure

Number

1

2

3

4

5

6

7

Title

Subgroup Structure

12

$\begin{array}{ll}\text { Croup Structure } & 20\end{array}$

AGN-GAM Inputs $2 \overline{8}$

Fue1 Pin Lattice for AGN-GAM Sample Problem . 38

List of Input Cards for Sample Problem . 39

Output From Sample Problem 43

Punched Card Output From Sample Problem

\section{TABLES}

Table

Number

1

2

3

4

5

6

\section{Title}

Definition of Terms

Sumary of Equations for Calculating Resonance 10 Absorption and Fission Integrals

Summary of Equations for Unresolved Region 11

$\Lambda \mathrm{CN}-\mathrm{C} \Lambda \mathrm{M}$ Problem Types and Required Inputs 29

Input for AGN-GAM Code 30

Composition of Sample Problem . 40

Calculation of Parameters for Resonance Calculation 41 


\section{INTRODUCTION}

\section{A. SUMMARY}

One of the major problems in reactor physics is obtaining good nuclear cross sections for the standard diffusion and transport theory codes. In order to obtain these constants, valid cross section data over the full energy range of reactor calculations must be available. Since most calculations are performed for relatively few energy groups, it is necessary to reduce the total body of cross section data to data pertaining to the few groups desired. This reduction is accomplished by weighting the cross sections with the system's neutron spectrum; the AGN-GAM code calculates the spectrum in a reactor core or reflector and then performs the weighting to obtain the group constants.

The code generates the macroscopic cross sections and scattering matrices for 75 quarter lethargy groups, adding together the values of each of the specified input materials. Special resonance calculations are performed to evaluate the absorption and fission cross sections of individual resonances depending upon the geometry and composition of the system. Following these operations, a slowing down spectrum is calculated by using specific values of system neutron leakages and sources. With this spectrum, broad group cross sections for use in either diffusion or transport type codes are obtained.

The organization of the code and the manner in which it functions is basically the same as for the General Atomics GAM-I code (Ref. 1). However, modifications were made to the original program to permit solution of the P-1 equations in a reflector and the entire code has been re-programmed. 
The major features of the AGN-GAM code are:

1) Core fluxes and currents are calculated by the B-1 or P-1 methods. For the P-1 solution, a reflector region or coupled core region may be simulated.

2) The seventy-five subgroups used in the calculations are established as quarter lethargy groups, from $10 \mathrm{Mev}$ to $0.07 \mathrm{ev}$.

3) Elastic scattering matrices maintain the energy-angle correlation by including both the $P_{0}$ and $P_{1}$ terms.

4) Isotropic scattering matrices for both the inelastic and ( $n, 2 n)$ processcs are included.

5) The resonance absorption and fission are calculated by a method proposed by F. T. Adler, G. W. Hirman, and L. W. Nordheim. The code calculates the effects of self-shielding in each resolved resonance as well as the volume and surface integral contributions in the unresolved regions.

6) Self-shielding factors may be specified for any component material.

7) Flux and current terms may be input, thus, eliminating the flux calculation. It is also possible to input the flux term alone to calculate the current term.

8) The moments method may be used to calculate age in an infinite homogeneous medium.

9) Using either the calculated or the input flux and current terms, macroscopic broad group constants are derived for use in either diffusion calculations, or isotropic or anisotropic transport calculations. A maximum of 32 broad groups is possible.

10) Microscopic broad-group cross sections can be obtained for any material on the data tape.

11) Both the macroscopic and microscopic cross sections can be punched directly onto cards for use in the DSN, TDC, 2DXY, DTK, DDK, PDQ-2, AIM-6, ANGIE or ZOOM codes. Space is left on these cards for thermal 
group values, for activation cross sections, and for up-scattering in the matrices when one of the transport theory codes is chosen.

12) The library data tape currently includes 182 different materials. The data for most of these materials include all 75 groups of data. Ten different source spectra are included.

13) The code is written in FORTRAN-II with sub-routines that permit easy modification.

\section{B. REPORT ORGANIZATION}

This report consists of four sections in which the code is described and six appendices in which the pertinent derivations and other supplementary information are contained. Section $I$ is an introduction. Section II provides details on subgroup library specifications, multigroup spectrum relations, and definitions of constants. The derivations germane to Section II are contained in Appendices A, B, and C; the energy dependent spectrum relations are developed in Appendix $A$, the scattering matrices are established in Appendix B, and the multigroup transport approximation is demonstrated in Appendix C.

In Scction III, the use of the code is described and a sample problem is solved. Section IV contains a discussion of the operating procedures for the code. Appendix D provides details pertaining to the library tape and Appendix $E$ gives the procedure for updating the AGN data tape. Finally, Appendix $F$ provides a simplified block diagram of the AGN-GAM Code. 
THIS PAGE

\section{WAS INTENTIONALLY LEFT BLANK}




\section{REIATIONS AND DEFINITIONS OF THE MULTIGROUP CONSTANTS}

A. LIBRARY TAPE DATA

\section{Subgroup Cross Sections}

The AGN library tape is composed of 75 quarter lethargy subgroups with zero lethargy starting at $10 \mathrm{Mev}$. (Appendix D gives a description of the data tape.) The required subgroup constants on this tape are the total-, absorption-, elastic scattering-, inelastic scattering-, $(n, 2 n)$ - and fission cross sections as well as the number of neutrons emitted per fission.

The absorption and fission cross sections are specified in two different ways. If resonance parameters are included for the material in question, these cross sections are equal to the total absorption (or fission) minus the resonance absorption (or fission); that is, to the underlying "background" cross section. If no resonance parameters are included, they are equal to the total absorption (or fission) cross section.

The $n, 2 n$ reaction is included explicitly, but due to lack of information, it may be desirable to distribute both emergent neutrons in the inelastic spectrum. In this case a new inelastic cross section is defined as:

$$
\sigma_{1 e}^{\prime}=\sigma_{1 e}+2 \sigma_{n, 2 n}
$$

and, to conserve neutrons, a new absorption cross section as:

$$
\sigma_{a}^{\prime}=\sigma_{a}-\sigma_{n, 2 n}
$$

where the primed quantities appear on the tape and $\sigma_{n, 2 n}$ is set identically equal to zero. 
Two other subgroup quantities that appear on the data tape, $L-I$ and $L-2$, are used in the transport approximation. $L-1$ is the angle average of the $l=1$ Legendre scattering polynominal; that is, $\bar{\mu}$, the average cosine of the $L$ system scattering angle. L-2 is the angle average of the $l=2$ Legendre polynominal.

\section{Scattering Matrices}

In addition to the subgroup cross section data, the subgroup transfer cross sections are required on the library tape.' These matrices are given by Eq. $(\mathrm{B}-22)$ of Appendix B. (Appendix B gives a complete specification of the elastic and inelastic scattering matrices.)

$$
\sigma_{x}{ }_{j \rightarrow i}=\frac{\int_{j} d^{\prime} f_{\ell}\left(E^{\prime}\right) \int_{i} d E \sigma_{x}^{l}\left(E^{\prime} \rightarrow E\right)}{\int_{j} d E^{\prime} f_{l}\left(E^{\prime}\right)}
$$

where:

$$
\begin{aligned}
& l=0,1 \text { for } \mathrm{x}=\mathrm{el} \text {. (elastic scattering) } \\
& \ell=0 \text { for } \mathrm{x}=\text { ie. or } \mathrm{n}, 2 \mathrm{n} \text { (inelastic scattering or } \mathrm{n}, 2 \mathrm{n} \text { reaction) }
\end{aligned}
$$

and where the $n, 2 n$ scattering kernel is normalized to one emergent neutron.

In the cruss sevtiun generating codes the flux is assumed constant across a subgroup and the integrations for elastic scattering are carried-through analytically with linear anisotropis scattering in the $M$ system. Statistical inelastic scattering is assumed and simpson's rule integration is used. The emergent $n ; 2 n$ neutrons are both distributed in the inelastic spectrum.

\section{Resonance Data ,}

For those materials that use the resonance calculation, additional (resonance) parameters are included on the library tape. These parameters include values for each individual resolved resonance and a set describing the unresolved region. The individual resolved resonances consist of the energy of the resonance; the radiative, neutron, and fission widths; the statistical weight factor; and the abundance of the isotopes that contain the specified resonance. In addition, a parameter is supplied that determines whether the resonance should be calculated with narrow-resonance or infinite-mass approximation. The unresolved region is described by a 
lower cut-off energy, the average level spacing, the average reduced neutron width, average radiative and fission widths, the potential scattering cross section of the material, and the average statistical weight factor.

B . RESONANCE EVALUAtion

The AGN-GAM code uses the method of Adler, Hinman, and Nordheim (Ref. 2 and 3) to calculate the effective absorption cross sections of materials with high resonance absorption. This method is much more efficient in obtaining correct cross sections than the normally used infinite dilution integral method. The following paragraphs present a brief description of this method and a tabulation of the equations used. A further explanation of the theory is contained in Reference 4, Chapters 3 and 5.

\section{Resolved Region}

The total integral of the absorption under any given

resonance, $i$, can be expressed as the sum of a "volume" and a "surface" term.

$$
\begin{gathered}
\mathrm{RI}_{i}=\mathrm{RI}(\text { volume })_{i}+\mathrm{RI}(\text { surface) } \\
\mathrm{RI}_{i}=\int_{-\infty}^{+\infty} \frac{\mathrm{dE}}{\mathrm{E}} \frac{\sigma_{\mathrm{a}} \sigma_{\mathrm{p}}}{\sigma_{\mathrm{t}}}+\frac{1}{\mathrm{~N} \overline{\mathrm{r}}} \int_{-\infty}^{+\infty} \frac{\mathrm{dE}}{\mathrm{E}} \frac{\sigma_{\mathrm{a}}\left(\sigma_{t}-\sigma_{\mathrm{P}}\right)}{\sigma_{t}} \mathrm{~F}
\end{gathered}
$$

where: $\quad \sigma_{a}$ and $\sigma_{t}$ are the absorption and total cross sections at the energy, $\mathrm{E}$

$\bar{r}$ is the average cord length in the absorber lump $(\bar{r}=4 \mathrm{~V} / \mathrm{s})$,

$F$ is the probability that a neutron passing into the lump suffers a collision in it,

The other terms are defined in Table 1 .

The method outlined by Adler, Hinman, and Nordheim defines the cross sections on the right side of this relationship and then solves for the resulting integrals. The results yield the following equation:

$$
R_{i}=\frac{\sigma_{p}\left(\Gamma_{\gamma}\right)_{i}}{E_{i}} J\left(\xi_{i}, \beta_{i}\right)+\frac{\sigma_{p}\left(\Gamma_{\psi}\right)_{i}}{E_{i} \beta_{i}} L\left(t, \xi_{i} \beta_{i}\right)
$$




\section{TABLE 1 - DEFINITION OF TERMS}

\begin{tabular}{|c|c|c|}
\hline i & $=$ & subscript indicating values for a specific resonance \\
\hline A & $=$ & atomic weight of absorber atom \\
\hline $\mathbf{k}$ & $=$ & Boltzmann constant; $8.6167 \times 10^{-5} \mathrm{ev} /{ }^{\circ} \mathrm{K}$ \\
\hline g & $=$ & statistical weight factor \\
\hline $\mathrm{T}$ & $=$ & material temperature, ${ }^{\circ} \mathrm{K}$ \\
\hline $\mathrm{N}$ & $=$ & number density of resonance material, $10^{24}$ atoms/cc \\
\hline a & $=$ & radius of cylinder or sphere, thickness of $\mathrm{slab}, \mathrm{cm}$ \\
\hline pot & $=$ & $\begin{array}{l}\text { potential scattering cross section of resonance material } \\
\text { barns }\end{array}$ \\
\hline $\mathrm{M}$ & $=$ & $\begin{array}{l}\text { total non-resonance scattering cross section of moderating } \\
\text { materials within pin, sphere, or slab containing resonance } \\
\text { absorber, Barns per absorber atom }\end{array}$ \\
\hline $\mathbf{P}$ & $=c$ & $\begin{array}{l}\text { total non-resonance scattering cross section of all materi- } \\
\text { als within the pin, sphere, or slab containing resonance } \\
\text { absorber. Barns per absorber atom }\end{array}$ \\
\hline$E_{i}$ & $=$ & energy of resonance, ev \\
\hline$\left(\Gamma_{n}\right)_{i}$ & $=$ & neutron width of resonance, ev \\
\hline$\left(\Gamma_{\gamma}\right)_{i}$ & $=$ & radiative width of resonance, ev \\
\hline$\left(\Gamma_{f}\right)_{i}$ & $=$ & fission width of resonance, ev \\
\hline$(\Gamma)_{1}$ & $=$ & total width $=\left(\Gamma_{n}+\Gamma_{f}+\Gamma_{\gamma}\right)_{i}$, ev \\
\hline$\left(\sigma_{0}\right)_{i}$ & $=$ & total resonance cross section at $E_{c}$, barns \\
\hline$E_{c}$ & $=$ & $\begin{array}{l}\text { cutoff energy, resonances at energies higher than this } \\
\text { will be treated as unresolved, ev }\end{array}$ \\
\hline$<\Gamma_{\mathbf{n}} 0>$ & $=$ & average reduced neutron width, $\sqrt{\text { ev }}$ \\
\hline & $=$ & average level spacing, ev \\
\hline
\end{tabular}


where (in general terms):

$\sigma_{P}$ is a measure of the non-resonance scattering in the lump,

$\xi_{i}$ is the ratio of natural to Doppler resonance widths,

$B_{i}$ is the ratio of the scattering to the total cross section.

The functions $J(\xi, \beta)$ and $L(t, \xi, \beta)$ have been computed

and are tabulated in Reference 5.

Equation (2) results if the assumption is made that the practical width of the resonance is narrow in relation to the average energy loss of a neutron when scattered. This is the so-called narrow resonance (NR) approximation. Very similar results are obtained when the narrow resonance, infinite mass (NRIA) approximation is used for wider resonances. The definitions of $\beta, \sigma_{P}$, and the width $\Gamma_{\gamma}$ are modified slightly for the latter case but the basic idea is the same. Whether the NR or the NRIA method is used depends upon the physical characteristics of the resonance.

When the NRIA method is to be used for a lump of pure metal, the "volume" term becomes small and the "surface" term does not depend upon the dimenions of the lump. For this special case, the $L(\tau, \xi, \beta)$ table is replaced by an $L^{\prime}(\xi, \beta)$ table.

Table 2 summarizes the equations for all three of the cases mentioned above. These equations include the single level fission integrals by assuming that;

$$
R I \text { (fission }_{i}=\left[\frac{\Gamma_{f}}{\left(\Gamma_{f}+\Gamma_{\gamma}\right)}\right]_{i} R I \text { (absorption) }{ }_{i}
$$

\section{Un-Resolved Region}

The previous discussion concerned the general equation with which to determine the resonance integral of a given resonance with known physical properties $\left(E, \Gamma_{n}, \Gamma_{\gamma}\right.$, etc.). For any given material there exists a so-called unresolved region, which extends above some cutoff energy $\mathrm{E}_{c}$ and in which the properties $\left(E, \Gamma_{n}, \Gamma_{\gamma}\right.$, etc.) have not been measured. To evaluate the resonance integral of this region, an estimate must be made of the resonance properties as a function of energy and these properties must then be integrated upwards from $E_{c}$ to infinity. A Porter-Thomas distribution of 
TABLE 2 SUMMARY OF EQUATIONS FOR CALCULATING RESONANCE ABSORPTION AND FISSION INTEGRALS

Resolved Region

\begin{tabular}{|c|c|c|c|}
\hline Type, basic relationships & Part & Absorption Integral & Fisston Integral \\
\hline$\frac{\text { NARROW RESONANCE (NR) }}{\xi_{1}=\frac{1}{2} \sqrt{\frac{(A+1) \Gamma_{1}^{2}}{E_{1} k T}}}$ & volume & $\frac{\sigma_{P}\left(\Gamma_{y}+\Gamma_{E_{1}}\right)}{E_{1}} J\left(B_{1}, \xi_{1}\right)$ & $\frac{\sigma_{P}\left(\Gamma_{E_{1}}\right.}{E_{1}} \mathrm{~J}\left(\theta_{1}, \xi_{1}\right)$ \\
\hline $\begin{array}{l}\beta_{1}=\sigma_{P} /\left(\sigma_{0}\right)_{1} \\
t=N \sigma_{p} a\end{array}$ & Surface & $\frac{\sigma_{P}\left(\Gamma_{Y}+\Gamma_{E_{1}}\right)}{E_{i} \beta_{1}} L\left(t, \xi_{1}, \dot{B}_{i}\right)$ & $\frac{\sigma_{P}\left(\Gamma_{f}\right)}{E_{t} \beta_{1}} L\left(t, \xi_{1}, \beta_{1}\right)$ \\
\hline $\begin{array}{l}\text { NARROW RE SONANCE- } \\
\text { INEINITE MASS (NRIA) } \\
\xi_{1} \text { same as above } \\
\vdots \\
\text { (ब) same as above }\end{array}$ & Volume & $\frac{\sigma_{\mathrm{m}} \Gamma_{i}}{E_{1}} \mathrm{~J}\left(\xi_{i}, \dot{\beta}_{1}\right)$ & $\frac{\sigma_{m} \Gamma_{1}}{E_{i}}\left(\frac{\Gamma_{f}}{\Gamma_{\gamma}+\Gamma_{f}}\right)_{1} J\left(\beta_{1}, \xi_{1}\right)$ \\
\hline $\begin{array}{l}\beta_{t}=\frac{\sigma_{m}}{\sigma} \frac{\Gamma_{1}}{\left(\Gamma_{Y}+\Gamma_{f}\right)_{i}} \\
t=N \sigma_{m}^{a}\end{array}$ & Surface & $\frac{\sigma_{m} \Gamma_{i}}{E_{i} \beta_{i}} L\left(t, \xi_{i} ; \beta_{i}\right)$ & $\frac{\sigma_{m} \Gamma_{i}}{E_{i} \beta_{i}}\left(\frac{\Gamma_{f}}{\Gamma_{\gamma}+\Gamma_{f}}\right)_{i} L\left(t, \xi_{i}, \dot{\beta}_{i}\right)$ \\
\hline$\frac{\text { NRIA-PURE METALS }}{\left(\sigma_{0}\right)_{1}, \xi_{1} \text { same as above }}$ & Volunte & $\stackrel{2}{\mathrm{~A}} \quad \sigma_{\text {pot }}$ & $\dddot{2}_{A} \quad \sigma_{\text {pot }}\left(\frac{\Gamma_{f}}{\Gamma_{f}^{+\Gamma_{\gamma i}}}\right)$ \\
\hline$t=N\left(\sigma_{3}\right)_{1}\left(\frac{\Gamma y}{\Gamma}\right)_{1}^{a}$ & Surface & $\frac{\left(\sigma_{0}\right)_{1}\left(\Gamma_{\gamma}+\Gamma_{f}\right)_{1}}{E_{1}} L^{\prime}\left(t, \xi_{1}\right)$ & $\frac{\left(\sigma_{0}\right)_{1}\left(\Gamma_{E}\right)_{1}}{E_{i}} L^{\prime} \quad\left(t, \xi_{i}\right)$ \\
\hline
\end{tabular}


TABLE 3 - SUMMARY OF EQUATIONS FOR UNRE SOLVED REGION

Volume $\quad$ absorption $=\frac{\sigma_{P}\left(\Gamma_{\gamma}+\Gamma_{E}\right)}{D} \int_{E_{C}}^{\infty} \overline{J(E)} \frac{d E}{E}$

fission $=\frac{\sigma_{P} \Gamma_{F}}{D} \int_{E_{c}}^{\infty} \overline{J(E)} \frac{d E}{E}$

Surface $\quad$ absorption $=\frac{\sigma_{P}\left(\Gamma_{\gamma}+\Gamma_{E}\right)}{D} \int_{E_{c}}^{\infty} \frac{\overline{L(E)}}{\beta} \frac{d E}{E}$

$$
\text { fission }=\frac{\sigma_{P} \Gamma_{f}}{D} \int_{E_{c}}^{\infty} \overline{\frac{L(E)}{\beta}} \frac{d E}{E}
$$

\section{Definition of Terms}

$$
\begin{aligned}
& \left.H=\frac{1}{2} \sqrt{\frac{A}{k T}}\left(<\Gamma_{n} 0\right\rangle\right) \\
& B=\frac{1}{2} \sqrt{\frac{A}{k T E}}\left(\Gamma_{\gamma}+\Gamma_{f}\right) \\
& C=\frac{\sigma_{p} E}{2.6 \times 10^{6}} \quad y=\frac{\Gamma_{n} 0}{<\Gamma_{n} 0^{>}} \\
& \xi=\mathrm{Hy}+\mathrm{B} \quad \beta(\xi)=\frac{\mathrm{C} \xi}{\xi-\mathrm{B}} \\
& \overline{J(E)}=\frac{1}{\sqrt{2 \pi H}} \int_{B}^{\infty} \frac{\mathrm{d} \xi}{\sqrt{\xi-B}} J(\xi, \beta(\xi)) e^{-(\xi-B) / 2 H} \\
& \overline{\frac{L(E)}{B}}=\frac{1}{\sqrt{2 \pi H}} \int_{B}^{\infty} \frac{d \xi}{\xi C} \quad \sqrt{\xi-B} L(t, \xi, \beta(\xi)) e^{-(\xi-B) / 2 H}
\end{aligned}
$$


neutron widths and the NR approximations are used to derive the equations shown in Table 3 .

Within the AGN-GAM code, the infinite limit of an upper integral is replaced with an energy bound so that there are 18 fine groups in the unresolved region. For this energy range the total integral is calculated by a Simpson's rule integration and subsequently divided into the 18 fine groups.

\section{Table Interpolation}

Several different methods are used to interpolate the tabular values of the $\mathrm{J}, \mathrm{L}$, and $\mathrm{L}^{\prime}$ tables. In the $\xi$ direction, interpolation is accomplished by a four point fit with Lagrange's formula. In the region between the last given point and infinity (still in the $\xi$ direction) an exponential fit of the form, $y=a+b e^{-c \xi}$ is used. The constants $a, b$ and $c$ are found from three given points in the table. In the $\beta$ direction, the fit is linear with $\beta$; because the tables are $\log$ functions of $\beta$, a linear fit takes the form of an exponential curve. In the $z$ direction in the $L$ tables, a fit is made with Lagrange's equation to fit the quantity $\mathrm{L} / \mathrm{z}$. All checks of these routines have shown results as accurate as the tables are themselves.

\section{SPECTRIM GENERATION}

\section{Method of Solution}

Either the $\mathrm{P}_{1}$ or $\mathrm{B}_{1}$. relations (Appendix $\mathrm{A}$ ) may be used for spectrum generation. The $\mathrm{P}_{1}$ equations, which are evolved from volume integrations over the region of interest, are applicable to either a core or a reflector region. The $\mathrm{B}_{1}$ equations, the usual Fourier transform relations, are only applicable to a bare normal-mode core. In either case, the equations are solved by the usual subgroup treatment (Figure 1 ).

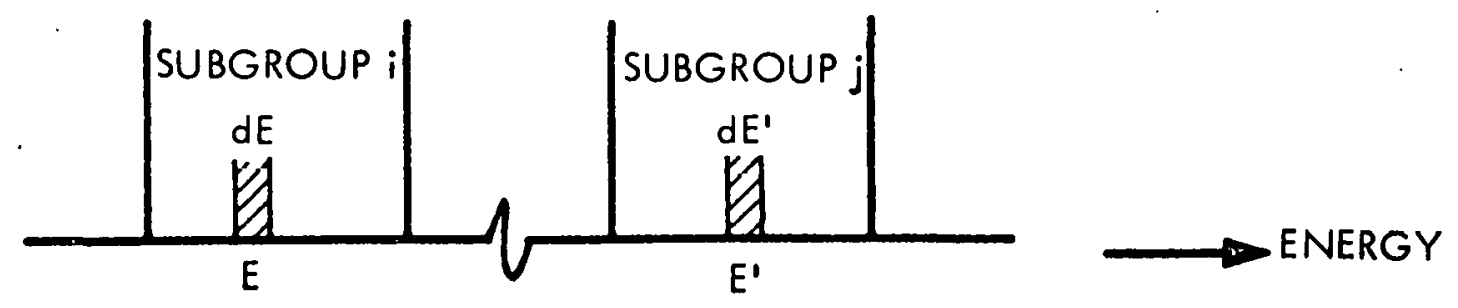

FIGURE 1. SUBGROUP STRUCTURE 


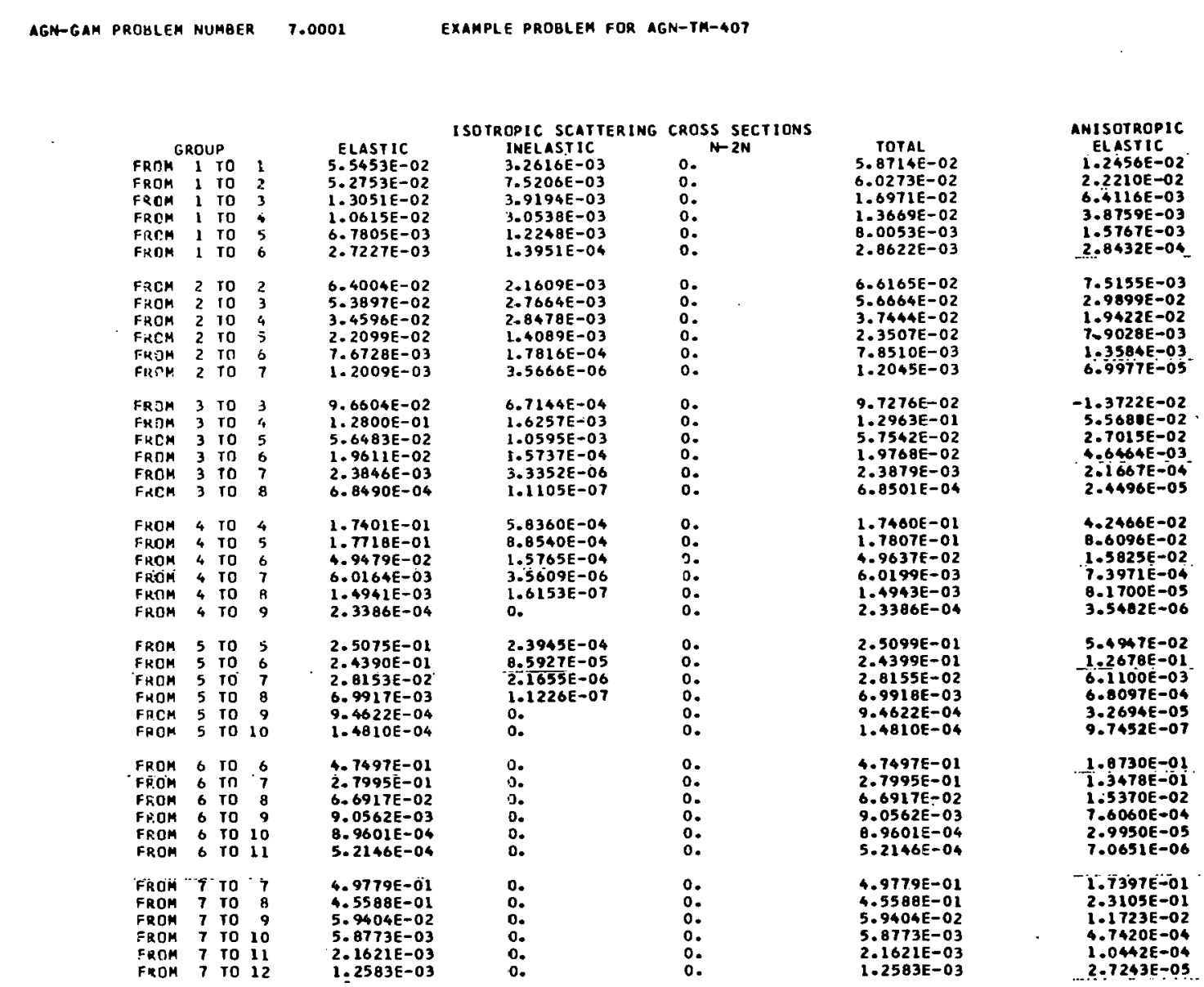

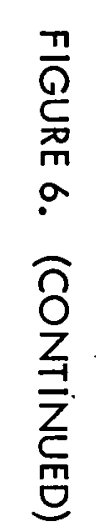

AGN-GAM PROBLEM NUMBER T.0001 EXAMPLE PROBLEM FOR AGM-TH-407

\begin{tabular}{|c|c|c|c|c|}
\hline 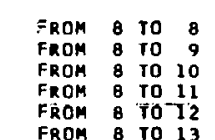 & 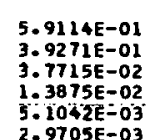 & $\begin{array}{l}0: \\
0 . \\
0 . \\
0 . \\
0 .\end{array}$ & $\begin{array}{l}0: \\
0 . \\
0: \\
0: \\
0 .\end{array}$ & 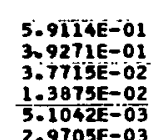 \\
\hline 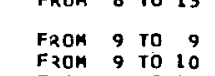 & 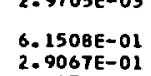 & 0. & $0:$ & 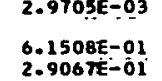 \\
\hline 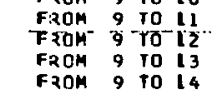 & 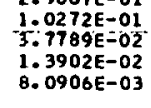 & $\begin{array}{l}0 . \\
0 . \\
0 . \\
0 .\end{array}$ & $\begin{array}{l}0: \\
0: \\
0 . \\
0 .\end{array}$ & 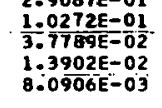 \\
\hline 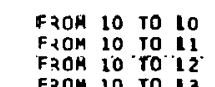 & 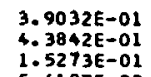 & 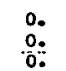 & $\begin{array}{l}0: \\
0:\end{array}$ & 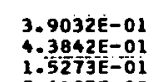 \\
\hline 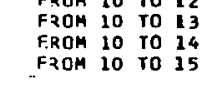 & 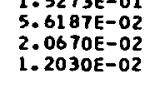 & $\begin{array}{l}0: \\
0 . \\
0 .\end{array}$ & $\begin{array}{l}0: \\
0: \\
0:\end{array}$ & 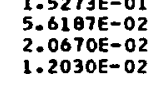 \\
\hline 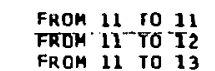 & 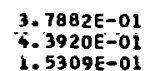 & $\begin{array}{l}0 . \\
0 . \\
0 .\end{array}$ & $\begin{array}{l}0: \\
0: \\
0 .\end{array}$ & 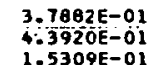 \\
\hline 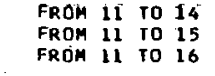 & 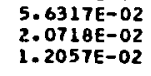 & $\begin{array}{l}0: \\
0 . \\
0 .\end{array}$ & $\begin{array}{l}0: \\
0: \\
0 .\end{array}$ & 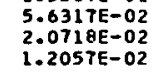 \\
\hline 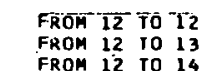 & 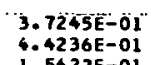 & 0. & : & 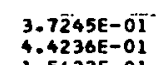 \\
\hline & 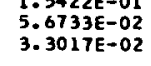 & $\begin{array}{l}0 . \\
0 . \\
0 .\end{array}$ & $\begin{array}{l}0: \\
0:\end{array}$ & 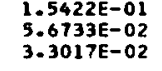 \\
\hline 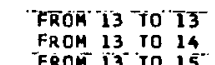 & 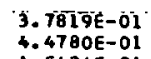 & 0. & 0 & \\
\hline & 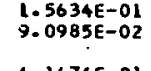 & 0. & 足: & \\
\hline 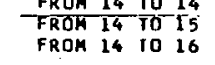 & 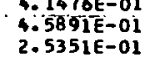 & $\begin{array}{l}0 . \\
0 . \\
0 .\end{array}$ & 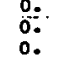 & 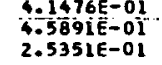 \\
\hline$\left\{\begin{array}{l}15 \\
16\end{array}\right.$ & 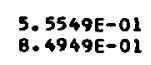 & :. & : & E-oi \\
\hline
\end{tabular}

AGN-GAM PROBLEM NUMBER T.0002 EXAMPLE PROBLEM FOR AGN-TM-407

BROAD GROUP MICROSCOPIC CROSS SECTIONS FOR MATERIAL NUMBER 43 MANGANESE
IAVERAGED FOR USE IN ANI SOTROPIC TRANSPORT COOES)

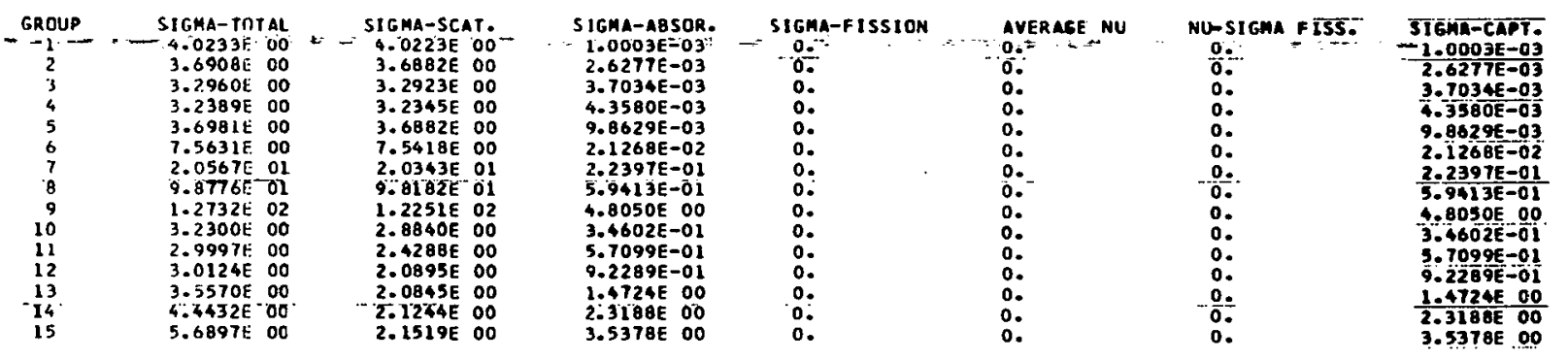

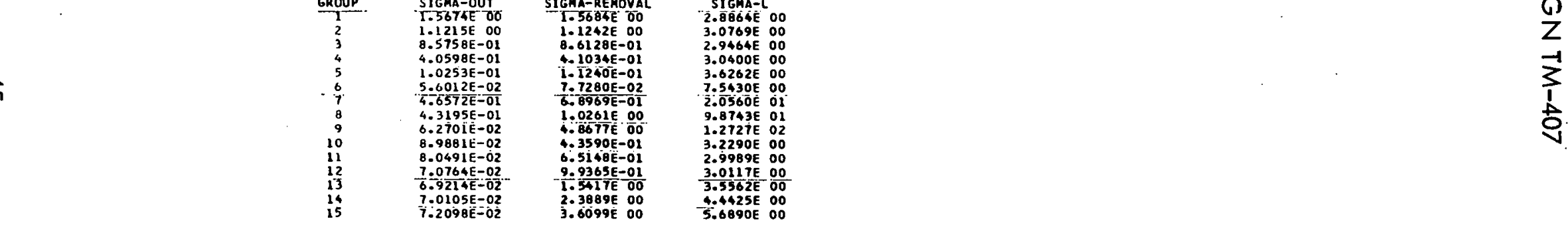




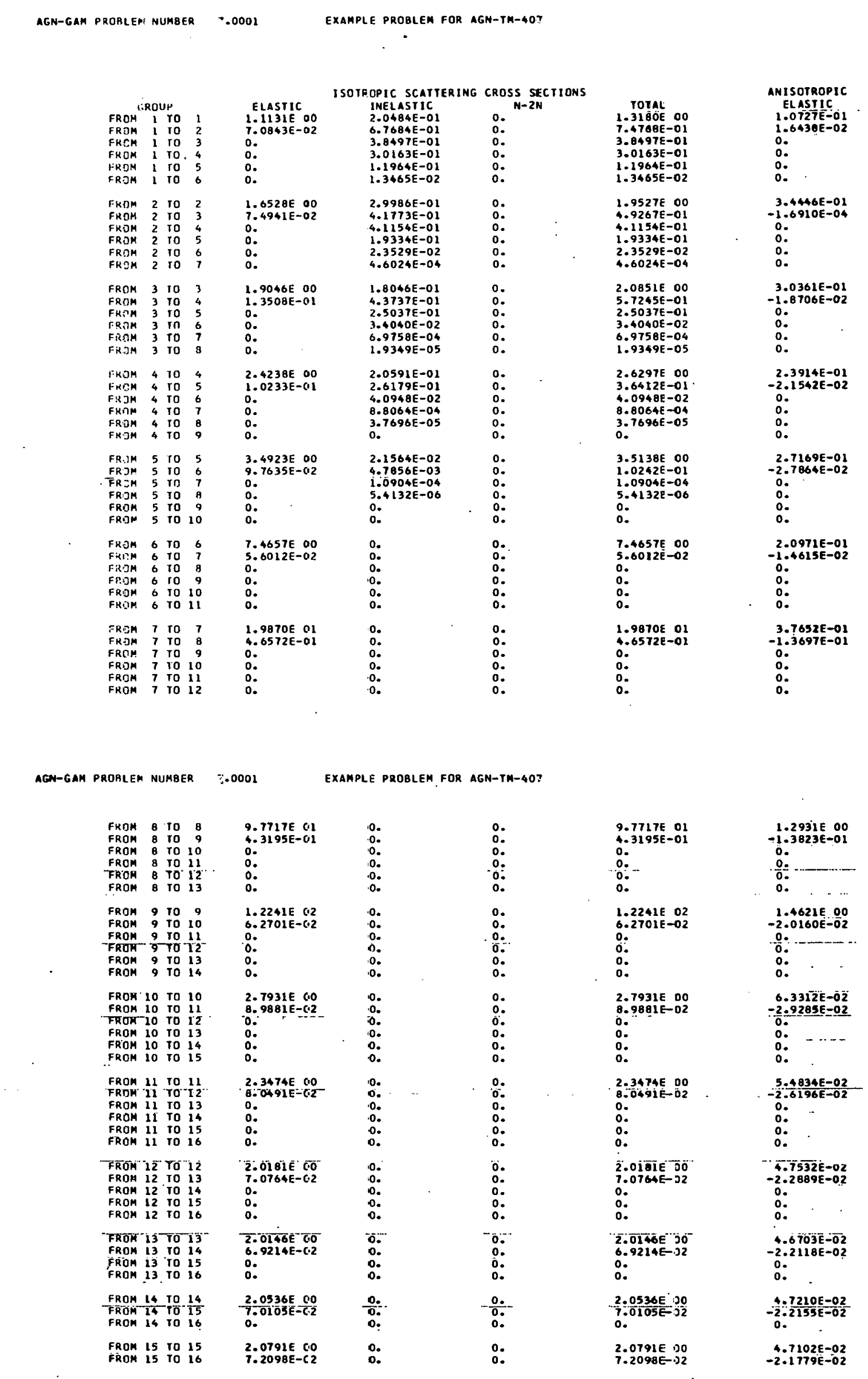

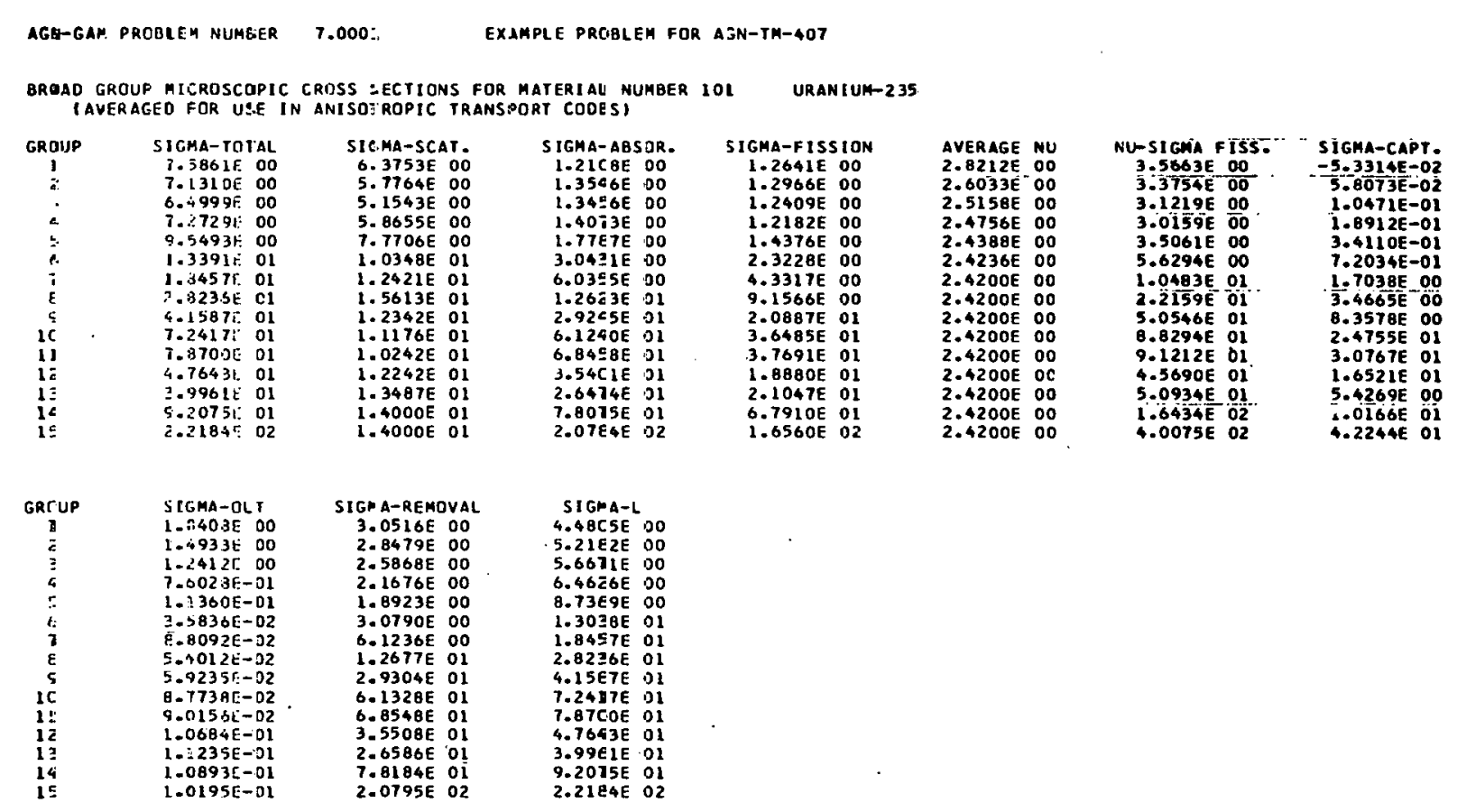




\begin{tabular}{|c|c|c|c|c|c|}
\hline 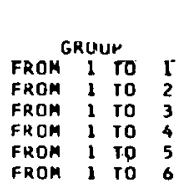 & $\begin{array}{l}\text { ELASTIC } \\
1.2481 E \text { OD } \\
1.3260 E-02 \\
0 . \\
0 . \\
0 . \\
0 .\end{array}$ & 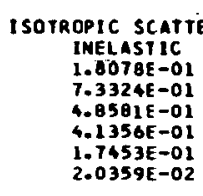 & $\begin{array}{l}\text { CROSS sECTHONS } \\
0.2 N={ }^{2 N} \\
0: \\
0: \\
0: \\
0:\end{array}$ & 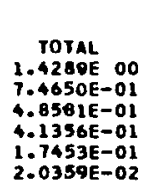 & 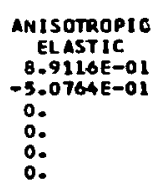 \\
\hline 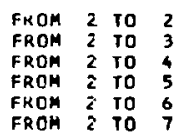 & $\begin{array}{l}2.0489 E 00 \\
2.5302 E-02 \\
0 . \\
0: \\
0: \\
0 .\end{array}$ & $\begin{array}{l}3.2144 E-01 \\
5.3043 E-01 \\
5.9227 E-01 \\
3.0529 E-01 \\
3.9163 E-02 \\
7.9403 E-04\end{array}$ & $\begin{array}{l}0 . \\
0: \\
0: \\
0: \\
0:\end{array}$ & $\begin{array}{l}2.3703 E \text { 00 } \\
5.5513 E-01 \\
5.9227 E-01 \\
3.0529 E-01 \\
3.9163 E-02 \\
7.9403 E-04\end{array}$ & $\begin{array}{l}7.1096 \mathrm{E} \rightarrow 01 \\
-2.0292 \mathrm{O}-01 \\
0: \\
0: \\
0: \\
0 .\end{array}$ \\
\hline 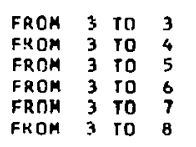 & $\begin{array}{l}2.8343 E \text { OO } \\
4.1155 E-02 \\
0 . \\
0: \\
0 . \\
0 .\end{array}$ & $\begin{array}{l}2.4596 E-01 \\
6.8857 E-01 \\
4.4519 E-01 \\
6.4844 E-02 \\
1.3603 E-03 \\
4.5968 E-05\end{array}$ & $\begin{array}{l}0 . \\
0: \\
0: \\
0: \\
0 .\end{array}$ & $\begin{array}{l}3.0803 E 00 \\
7.2973 E-01 \\
4.4510 E-01 \\
6.4044 E-02 \\
1.3603 E-03 \\
9.5968 E-05\end{array}$ & $\begin{array}{l}8.1929 E-01 \\
-2.4594 E-01 \\
0: \\
0: \\
0: \\
0:\end{array}$ \\
\hline 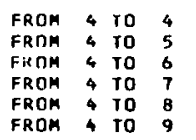 & $\begin{array}{l}\text { 3. 8876E } 00 \\
3.4084 E-02 \\
0.0 \\
0 . \\
0 . \\
0 .\end{array}$ & $\begin{array}{l}4.0739 E-01 \\
6.1745 E-01 \\
1.062 \mathrm{BE}-01 \\
2.3632 E-03 \\
1.0618 E-04 \\
0 .\end{array}$ & $\begin{array}{l}0 . \\
0: \\
0: \\
0: \\
0:\end{array}$ & $\begin{array}{l}4.2950 E \text { OO } \\
6.5153 E-01 \\
1.0620 E-01 \\
2.3632 E-03 \\
1.0616 E-04 \\
0 .\end{array}$ & $\begin{array}{l}7.6009 E-01 \\
-1.3703 E-01 \\
0 . \\
0: \\
0: \\
0 .\end{array}$ \\
\hline 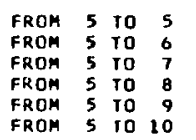 & $\begin{array}{l}6.6534 E \text { OO } \\
4.4747 E-02 \\
0 . \\
0: \\
0 . \\
0 .\end{array}$ & $\begin{array}{l}1.9123 E-01 \\
6.7106 E-02 \\
1.6589 E-03 \\
8.5608 E-05 \\
0 . \\
0 .\end{array}$ & $\begin{array}{l}0: \\
0: \\
0: \\
0: \\
0:\end{array}$ & $\begin{array}{l}0.8446 E \text { OD } \\
1.1185 E-01 \\
1.6589 E-03 \\
8.5608 E-05 \\
0 . \\
0 .\end{array}$ & $\begin{array}{l}3.6331 E-01 \\
-6.1069 E-02 \\
0: \\
0: \\
0: \\
0:\end{array}$ \\
\hline 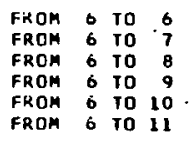 & $\begin{array}{l}9.9594 E \text { O0 } \\
\text { 3.5B36E-02 } \\
0 . \\
0 . \\
0 . \\
0 .\end{array}$ & $\begin{array}{l}0 . \\
0 . \\
0 . \\
0 . \\
0 . \\
0 .\end{array}$ & $\begin{array}{l}0: \\
0: \\
0: \\
0: \\
0 .\end{array}$ & $\begin{array}{l}9.9594 E \text { OD } \\
3: 5836 E-02 \\
0: \\
0: \\
0: \\
0 .\end{array}$ & $\begin{array}{l}2.4414 E-01 \\
-1.1875 E-02 \\
0: \\
0: \\
0: \\
0:\end{array}$ \\
\hline 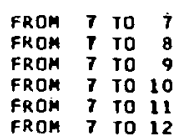 & $\begin{array}{l}1.2333 E \text { OI } \\
8.8092 E=-02 \\
0 . \\
0 . \\
0 . \\
0 .\end{array}$ & $\begin{array}{l}0 . \\
0: \\
0: \\
0: \\
0: \\
0 .\end{array}$ & $\begin{array}{l}0 . \\
0: \\
0: \\
0: \\
0 .\end{array}$ & $\begin{array}{l}1.2333 E 01 \\
8.8092 E-02 \\
0 . \\
0: \\
0 . \\
0 .\end{array}$ & $\begin{array}{l}6.8246 E-02 \\
-2.3387 E-02 \\
0 . \\
0: \\
0 . \\
0 .\end{array}$ \\
\hline
\end{tabular}

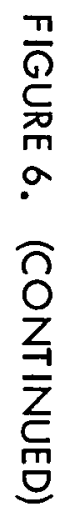

\begin{tabular}{|c|c|c|c|c|c|}
\hline 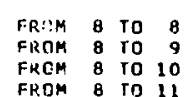 & 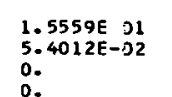 & $\begin{array}{l}0: \\
0 . \\
0 .\end{array}$ & $\begin{array}{l}0: \\
0 . \\
0 .\end{array}$ & 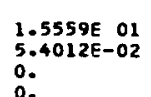 & 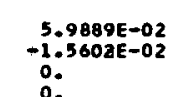 \\
\hline 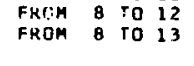 & : & . & :. & & \\
\hline 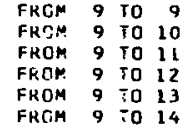 & 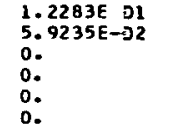 & $\begin{array}{l}0: \\
0: \\
0: \\
0:\end{array}$ & $\begin{array}{l}0: \\
0 . \\
0 . \\
0 . \\
0 .\end{array}$ & 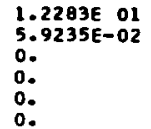 & \\
\hline 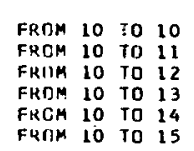 & 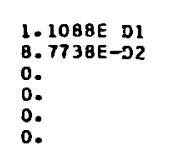 & $\begin{array}{l}0 . \\
0 . \\
0 . \\
0 . \\
0 .\end{array}$ & $\begin{array}{l}0: \\
0: \\
0: \\
0 . \\
0 .\end{array}$ & 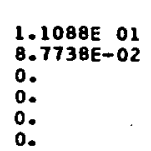 & \\
\hline 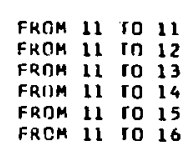 & 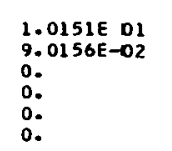 & $\begin{array}{l}0 . \\
0 . \\
0: \\
0 .\end{array}$ & $\begin{array}{l}0 . \\
0: \\
0 . \\
0 . \\
0 .\end{array}$ & 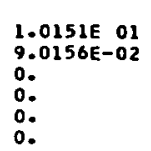 & \\
\hline 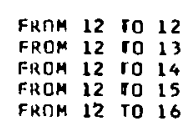 & 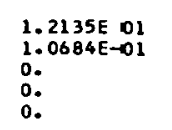 & $\begin{array}{l}0: \\
0: \\
0: \\
0:\end{array}$ & $\begin{array}{l}0: \\
0: \\
0:\end{array}$ & 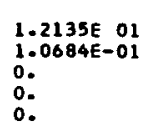 & 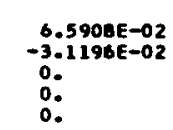 \\
\hline 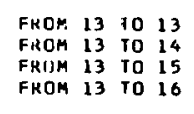 & $\begin{array}{l}1:-3335501 \\
10.1235 \in-01 \\
0 . \\
0 .\end{array}$ & $\begin{array}{l}0 . \\
0: \\
0 .\end{array}$ & $\begin{array}{l}\text { : } \\
0.0 \\
0 .\end{array}$ & 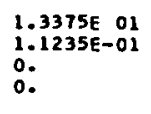 & 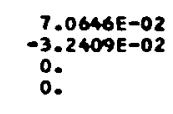 \\
\hline 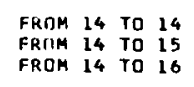 & 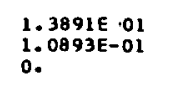 & $\begin{array}{l}0 . \\
0 .\end{array}$ & $\begin{array}{l}0: \\
0 . \\
0 .\end{array}$ & 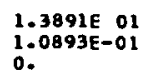 & 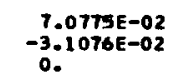 \\
\hline 4,15 To & $\begin{array}{l}1: 39868 \text {. } 01 \\
1.00195 E-01\end{array}$ & : & $\because:$ & 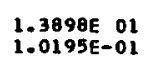 & 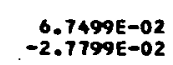 \\
\hline
\end{tabular}




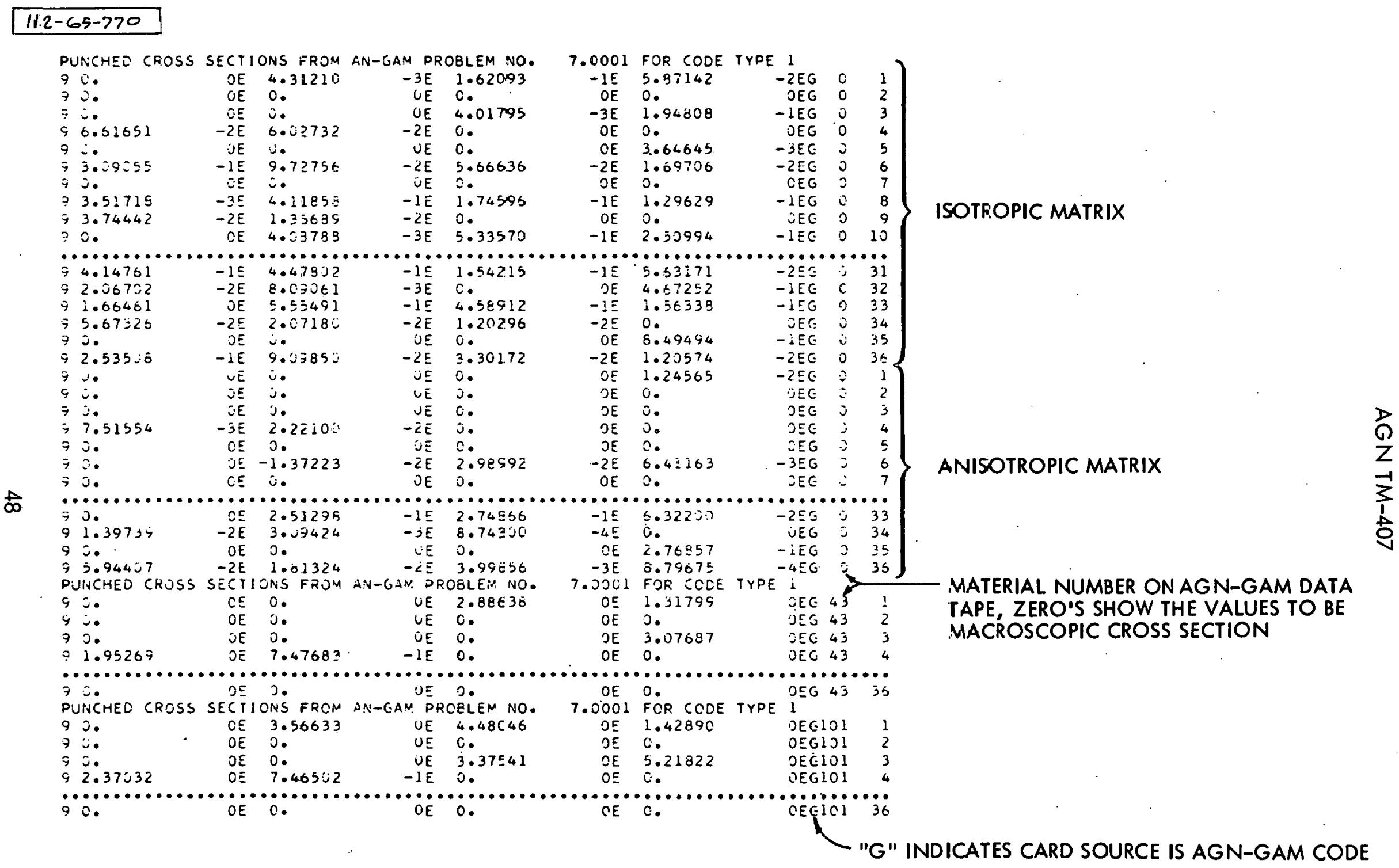

FIGURE 7. PUNCHED CARD OUTPUT FROM SAMPLE PROBLEM 
IV. OPERATION

The AGN-GAM code was written for the IBM-7090 or 7094 machine. The source program is in FORTRAN and MONITOR control is assumed. Since the program uses all but a few words of the $32 \mathrm{~K}$ core storage, the binary program deck includes all program sub-routines. This prevents difficulties when changes are made in one of the minor control sub-routines.

Logical tape requirements for operation of the program are:

Tape 5 - Erasable (TU B6)
Tape 6 - AGN-GAM Data Tape (TU B7)
Tape 7 - Erasable (TU B8)
Tape 8 - Punched Card Output (TU B4)
Tape 9 - Input (TU A2)
Tape 10 - Printed Output (TU A3)

There are a number of error routines built into the code that produce printed off-line comments describing the error discovered. After the error has been stated, most routines skip to the next problem. However, one routine causes a machine pause when an incorrect data tape is placed on Tape Unit 6. On-line comments are printed describing the corrective action which should be taken.

One extra card must always accompany the data. This card is placed immediately after the data card and supplies the following information:

Col.1-12 (E12.4) ID number of the AGN-GAM Data Tape which is to be used.

Col. 13-24 (E12.4) Matcrial ID number uf flrst macerial which contains the resonance parameters. 
Co. 25-36 (E12.4) Material ID number of the last material which contained the resonance parameters. Every material between these two must be a resonance material.

The extra card is needed only once in the program deck and is followed by the AGN-GAM problems as specified in Section $V$. As many problems as desired may be stacked, one behind the other.

The operating times depend on the number of materials considered in each problem, the presence of resonance materials, and the output required. From one to one and one-half minutes are required for the sample problem (this length of time is typical). 


\section{REFERENCES}

1: Joanou, G. D.; Gudek, J.S., "GAM-1, A Consistant P-1 Multigroup Code for the Calculation of Fast Neutron Spectra and Multigroup Constants", General Atomics, GA-1850, 28 June 1961.

2. Adler, F.T.; Hinman; G.W., Nordheim, L.W., "The Quantative Evaluation of Resonance Integrals", General Atomics, GA-350, 1958, also Geneva Paper P/1988 Vo1 16, P. 155.

3. Nordheim, L. W., "The Theory of Resonance Absorption", General Atomics, GA-638, 29 May 1959.

4. Dresner, L., "Resonance Absorption in Nuclear Reactors, Pergamon Press, New York, 1960.

5. Adler, F. T., Nordheim, L.W., "Tables for the Computation of Resonance Integrals", General Atomics, GA-377, 2 June 1958. 


\section{APPENDIX A \\ ENERGY DEPENDENT SPECTRUM GENERATION RELATIONS}

In this appendix the relations for the energy dependent $P_{1}$ and $B_{1}$ approximations, as well as those for the second moment calculation, are developed. The description of the $\mathrm{P}_{1}$ method is given in considerable detail and includes the effects of leakage from external regions. The $B_{1}$ routine and the second moment calculation are in the usual formulation and are only discussed briefly to preserve continuity.

I. THE VOLUME INTEGRATED $\mathrm{P}_{1}$ EQUATIONS

A. SPECIFICATION OF THE PROBLEM

In the original version of the GAM (Ref. A-1) code, volume integrated $P_{1}$ relations were generated for a bare core with isotropic volume source. This method will be extended here to include regions of arbitrary $P_{1}$ source description, e.g., reflected cores and reflector regions.

In a complete system, the flux specification is solved by taking the inter-regional coupling into account with a multiregion analysis. If, for any arbitrary portion of the system, the inflow of neutrons through its surface as well as its volume source is assumed to be known, this particular portion can be considered as isolated and non-re-entrant; that is, as if surrounded by a pure black absorber. In such a region, the transport equation contains the inhomogeneous volume source term and also inhomogeneous boundary conditions which describe the inflow of neutrons. In the method that follows, the transport equation through the use of a delta function surface source, will incorporate these boundary conditions directly. The resultant equation 
will then involve the homogeneous zero-inflow boundary condition.

The geometry of the isolated non-re-entrant region in question is shown in Figure $A-1$.

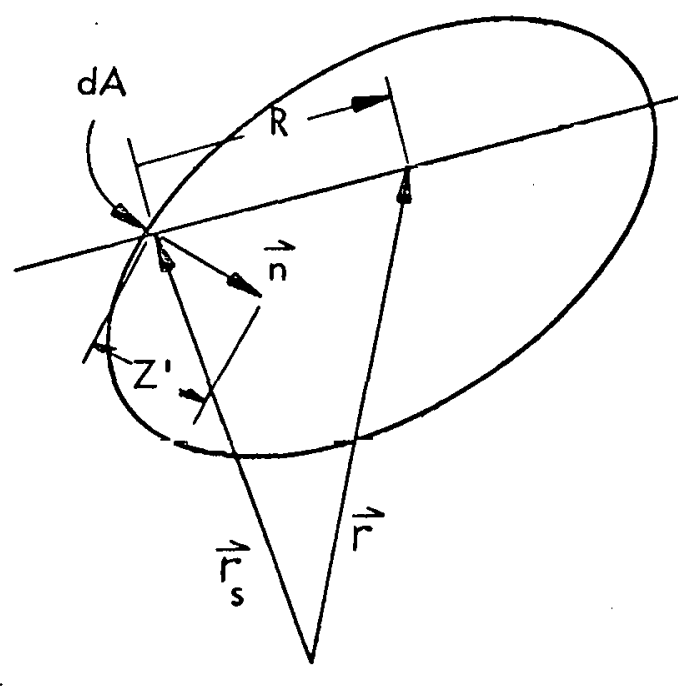

$\vec{\Omega}$

$\vec{r}_{s}$ is a vector to the differential element of area, dA, on the surface.

$\vec{r}$ is a vector within the region.

$R$ is a coordinate alnng the unit vector $\vec{\Omega}$, starting, at the surface, e.g., $R=\left|\vec{r}-\overrightarrow{r_{s}}\right|$.

$Z^{\prime}$ is the projection of $R$ onto the inward normal $\vec{n}, e . g$. , $Z^{\prime}=\vec{\Omega} \cdot \vec{n} R$.

\section{FIGURE A-I. ISOIATED NON-RE-ENTRANT REGION}

The volume element is

$$
\mathrm{dV}=\vec{\Omega} \cdot \overrightarrow{\mathrm{n}} \mathrm{d} \operatorname{RdA}=\mathrm{d} \mathrm{Z}^{\prime} \mathrm{dA} \text { for } \vec{\Omega} \cdot \overrightarrow{\mathrm{n}}>0
$$

Subscript e refers to conditions on the exterior of the surface while subscript $i$ refers to conditions on the interior.

The transport equation in this region, including both volume and Eurface source components, is

$$
\begin{aligned}
{\left[\vec{\Omega} \cdot \operatorname{grad}+\Sigma_{t}(E, \vec{r})\right] f(E, \vec{\Omega}, \vec{r}) } & =\int \mathrm{d} E^{\prime} \int^{\prime} \mathrm{d} \Omega^{\prime} \Sigma\left(E^{\prime} \rightarrow E, \vec{\Omega}^{\prime}-\vec{\Omega}, \vec{r}\right) f\left(E^{\prime}, \vec{\Omega}^{\prime}, \vec{r}\right)+s_{v}(E, \vec{\Omega}, \vec{r}) \\
& +s_{s}\left(E, \vec{\Omega}, \vec{r}_{s}\right) \delta\left(z^{\prime}\right)
\end{aligned}
$$

In the following discussion, the medium is assumed to be isotropic and homogeneous, i.e., scattering azimuthally symetric with cross sections that are spatially independent. 


\section{B. THE SURFACE COMPONENT OF THE SOURCE}

The surface source may be expressed in terms of assumed known flux conditions at the surface. To obtain the desired description, Equation $(A-1)$ is integrated across an infinitely thin volume which includes the surface. Since $\vec{s} \iota . g r a d=\partial / \partial R$, and with the volume integrals going to zero, the following expression is developed:

$$
\int \frac{\partial}{\partial R} \mathrm{f}(E, \vec{\Omega}, \vec{r}) \mathrm{d} z^{\prime}=\int s_{s}\left(E, \vec{\Omega}, \vec{r}_{s}\right) \delta\left(z^{\prime}\right) \mathrm{d} z^{\prime}
$$

when integrations over $\mathrm{d}^{\prime}$ are performed:

$$
\vec{\Omega} \cdot \vec{n}\left[f_{i}\left(E, \vec{\Omega}, \vec{r}_{s}\right)-f_{e}\left(E, \vec{\Omega}, \vec{r}_{s}\right)\right]=s_{s}\left(E, \vec{\Omega}, \vec{r}_{s}\right)
$$

The surface source thus introduces a discontinuity in the normal angular vector current at the surface.

For the specific case under consideration, the surface is a free boundary with no neutrons coming in frcm exterior sources and therefore, the following boundary conditions may be formulated.

$$
\begin{aligned}
& f_{e}\left(E, \vec{\Omega}, \vec{r}_{s}\right)=0 \text { for } \vec{\Omega} \cdot \vec{n}>0 \\
& F_{i}\left(E, \vec{\Omega}, \vec{x}_{s}\right)-g\left(E, \vec{B}, \vec{r}_{s}\right) \text { for } \vec{D}_{i} \vec{n}>0 \\
& \mathrm{f}_{i}\left(\mathrm{E}, \vec{\Omega}, \vec{r}_{\mathrm{s}}\right)=\mathrm{E}_{\mathrm{e}}\left(\mathrm{E}, \vec{\Omega}, \vec{r}_{\mathrm{s}}\right) \quad \text { for } \quad \vec{\Omega} \cdot \overrightarrow{\mathrm{n}}<0
\end{aligned}
$$

The assumed known surface distribution is $g\left(E, \vec{\Omega}, \vec{r}_{s}\right)$. When these conditions are incorporated into Equation (A-2) the following equation evolves:

$$
S_{s}\left(E, \vec{\Omega}, \vec{r}_{s}\right)=\vec{\Omega} \cdot \vec{n} H(\vec{\Omega} \cdot \vec{n}) g\left(E, \vec{\Omega}, \vec{r}_{s}\right)
$$

where $H(\vec{\Omega} \cdot \vec{n})$ is the Heaviside step function, which is defined as:

$$
\begin{array}{lll}
\mathrm{H}(\vec{\Omega} \cdot \vec{n})=1 & \text { for } & \vec{\Omega} \cdot \vec{n}>0 \\
\mathrm{H}(\vec{\Omega} \cdot \vec{n})=0 & \text { for } & \vec{\Omega} \cdot \overrightarrow{\mathrm{n}}<0
\end{array}
$$




\section{THE SPATIALLY DEPENDENT $P_{1}$ EQUATIONS}

The $P_{1}$ relations are obtained as shown in Chapter 9 , Reference $(A-2)$. First the transference function in Equation (A-1) is expanded in Legendre polynomials of the cosine of the $L$ system scattering angle.

$$
\Sigma\left(E^{\prime}-E, \vec{\Omega}^{\prime}-\vec{S}\right)=\sum_{\ell=0}^{\infty} s_{\ell}\left(E^{\prime} \rightarrow E\right) P_{\ell}\left(\mu_{0}\right)
$$

where

$$
s_{\ell}\left(E^{\prime} \rightarrow E\right)=\frac{2 \ell+1}{2} \int_{-1}^{+1} \Sigma\left(E^{\prime} \rightarrow E, \vec{\Omega}^{\prime}-\vec{\Omega}\right) P_{\ell}\left(\mu_{0}\right) d \mu_{0}
$$

The resulting expression is multiplied by $\mathrm{P}_{l m}^{*}(\vec{\Omega})$ (Ref. A-2) and integrated over. $\vec{\Omega}$.

$$
\begin{aligned}
& \int^{P} \ell_{m}^{*}(\vec{\Omega}) d \overrightarrow{\sigma_{\sigma}}\left\{\left[\vec{\Omega} \cdot \operatorname{grad}+\Sigma_{t}(E)\right] \mathrm{f}(E, \vec{\Omega}, \vec{r})-\mathrm{s}_{\mathrm{v}}(E, \vec{\Omega}, \overrightarrow{\mathrm{r}})\right. \\
& \left.-\sum_{\ell=0}^{\infty} \int d E^{\prime} s_{\ell}\left(E^{\prime} \rightarrow E\right) \int d \Omega^{\prime} P_{\ell}\left(\mu_{0}\right) f\left(E^{\prime}, \vec{\Omega}^{\prime}, \vec{r}\right)\right\} \\
& =\delta\left(z^{\prime}\right) \vec{n} \cdot \int \vec{\Omega}_{H}(\vec{S} \cdot \vec{n}) g\left(E, \vec{\Omega}, \vec{r}_{s}\right) P_{\ell m}^{*}(\vec{\Omega}) d \Omega
\end{aligned}
$$

The angular flux is expanded in spherical harmonics:

$$
f(E, \vec{\Omega}, \vec{r})=\sum_{l=0}^{\infty} \sum_{m=-l}^{+l} f_{l m}(E, \vec{r}) P_{l m}(\vec{\Omega})
$$

where

$$
\pm_{\ell \mathrm{m}}(E, \vec{r})=\frac{2 \ell+1}{4 \pi} \int f(E, \vec{\zeta}, \vec{r}) \vec{P} \ell_{m}^{*}(\vec{\Omega}) \mathrm{d} \Omega
$$

A similar expansion is performed for the volume source term. Finally, using the addition theorem, the left hand side of Equation (A-7) reduces to the time independent form of Equation (9.6) of Reference A-2. The right hand side of Equation $(A-7)$ is expanded as follows: 


$$
H(\vec{\Omega} \cdot \vec{n}) g\left(E, \vec{s}, \vec{r}_{s}\right)=\sum_{l=0}^{\infty} g_{\ell m}\left(E, \vec{r}_{s}\right) P_{\ell m}(\vec{\Omega})
$$

where

$$
g_{l m}\left(E, \vec{r}_{s}\right)=\frac{2 l+1}{4 \pi} \int H(\vec{\Omega}, \vec{n}) g\left(E, \vec{\Omega}, \vec{r}_{s}\right) P_{l m}^{*}(\vec{\Omega}) \mathrm{d} \Omega
$$

The expansion coefficients, $g_{\ell m}$, are made independent of $\vec{\Omega} \cdot \vec{n}$ by choosing $\vec{n}$ as the polar direction at each surface point. The right hand side of Equation $(A-7)$ then becomes equal to

$$
\begin{aligned}
& \delta\left(Z^{\prime}\right) \overrightarrow{\mathrm{n}} \cdot \int \vec{\Omega} \mathrm{H}(\vec{\Omega} \cdot \overrightarrow{\mathrm{n}}) \mathrm{g}\left(\mathrm{E}, \vec{\Omega} \cdot \overrightarrow{\mathrm{r}}_{\mathrm{s}}\right) \mathrm{P}_{\ell \mathrm{m}}^{*}(\vec{\Omega}) \mathrm{d} \Omega \\
& =\delta\left(z^{\prime}\right) \sum_{\ell^{\prime}=0}^{\infty} \sum_{\mathrm{m}^{\prime}=\ell^{\prime}}^{+\ell^{\prime}} \mathrm{g}_{\ell^{\prime} \mathrm{m}^{\prime}}\left(\mathrm{E}, \overrightarrow{\mathrm{r}}_{\mathrm{s}}\right) \overrightarrow{\mathrm{n}} \cdot \int_{\mathrm{J}^{\prime} \mathrm{P}_{\ell^{\prime} \mathrm{m}^{\prime}}(\vec{\Omega}) \mathrm{P}_{\ell \mathrm{m}}^{*}(\vec{\Omega}) \mathrm{d} \Omega}
\end{aligned}
$$

As could have been seen directly from Equation (A-7) and the subsequent reduction of its left hand side, $\overrightarrow{\mathrm{n}} \cdot \int \vec{S} \mathrm{P}_{\ell^{\prime} \mathrm{m}}^{\prime}(\vec{\Omega}) \mathrm{P}_{\ell \mathrm{m}}^{*}(\vec{\Omega}) \mathrm{d} \Omega$ is equa1 to the integral involved in the reduction of the streaming term (Equation (9.6c), Ref: A-2) if the grad operator is replaced by $\vec{n},\left(\partial / \partial x^{-}\right.$by $n_{x}$, etci). Thus, the $P_{l m}$ equations of interest here are equal to Equation (9.6) of Ref. A-2 plus this additional term which accounts for the reduction of the surface source.

$$
\begin{aligned}
& \text { The } l=0, m=0 \text { equation is } \\
& {\left[-\frac{1}{3 \sqrt{2}} \frac{\partial f_{11}}{\partial x}-\frac{i}{3 \sqrt{2}} \frac{\partial f_{11}}{\partial y}+\frac{1}{3 \sqrt{2}} \frac{\partial f_{1,-1}}{\partial x}-\frac{i}{3 \sqrt{2}} \frac{\partial f_{1,-1}}{\partial y}+\frac{1}{3} \frac{\partial f_{10}}{\partial z}\right]} \\
& =4 \pi \int f_{00} s_{0}\left(E^{\prime} \rightarrow E\right) d E^{\prime}-\sum_{t} f_{00}+S_{v_{00}} \\
& \therefore \\
& +\delta\left(Z^{\prime}\right)\left[-\frac{1}{3 \sqrt{2}} n_{x} g_{11}-\frac{i}{3 \sqrt{2}} n_{y} g_{11}+\frac{1}{3 \sqrt{2}} n_{x} g_{1,-1} \frac{-i}{3 \sqrt{2}} n_{y} g_{1,-1}+\frac{1}{3} n_{z} g_{10}\right]
\end{aligned}
$$


The $l=1, \mathrm{~m}=0$ relation is:

$$
\frac{\partial f_{00}}{\partial z}=\frac{4 \pi}{3} \int f_{10} s_{1}\left(E^{\prime} \rightarrow E\right) d E^{\prime}-\Sigma_{t} f_{10}+s_{v_{10}}+\delta\left(z^{\prime}\right) n_{z} g_{00}
$$

Equivalent relations exist for the other $\mathrm{P}_{1 \mathrm{~m}}$ equations, (the $\ell=1, \mathrm{~m}=-1$ and $\ell=1, \mathrm{~m}=1$ expressions).

Using the relevant relations between the $\mathrm{f}_{\mathrm{lm}}$ 's and the flux and current components (Equation (9.5) through (9.5b), Ref. A-2) in Equation (A-11) yields the $P_{0}$ relation.

$$
\begin{aligned}
\operatorname{div} \vec{J}(E, \vec{r})+\Sigma_{t}(E) \varphi(E, \vec{r}) & =\int d E^{\prime} \Sigma^{0}\left(E^{\prime} \rightarrow E\right) \varphi\left(E^{\prime}, \vec{r}\right) \\
& +s_{v}(E, \vec{r})+\delta\left(z^{\prime}\right) \vec{n} \cdot \vec{J}^{+k}\left(E, \vec{r}_{s}\right)
\end{aligned}
$$

Similarly for the $P_{10}$ relation (Equation $(A-12)$ :

$$
\begin{aligned}
\frac{\partial \varphi(E, \vec{r})}{\partial z}+3 \Sigma_{t}(E) J_{z}(E, \vec{r}) & =\int d E^{\prime} \Sigma^{1}\left(E^{\prime} \rightarrow E\right) J_{z}\left(E^{\prime}, \vec{r}\right) \\
& +3 S_{v_{z}}(E, \vec{r})+\delta\left(z^{\prime}\right) n_{z} \varphi^{+}\left(E, \vec{r}_{s}\right)
\end{aligned}
$$

Combining Equation (A-14) with the other corresponding $\mathrm{P}_{\ell m}$ equations yields the vector $P_{1}$ equation:

$$
\begin{aligned}
\operatorname{grad} \varphi(E, \vec{r})+3 \Sigma_{t}(E) \vec{J}(E, \vec{r}) & =\int d E^{\prime} \Sigma^{1}\left(E^{\prime} \rightarrow E\right) \vec{J}\left(E^{\prime}, \vec{r}\right) \\
& +3 \vec{S}_{v}(E, \vec{r})+\delta\left(Z^{\prime}\right) \vec{n} \varphi^{+}\left(E, \vec{r}_{s}\right)
\end{aligned}
$$

where:

$$
\begin{aligned}
& \text { the neutron flux is } \varphi(E, \vec{r})=\int d \Omega f(E, \vec{\Omega}, \vec{r}) \\
& \text { the vector current is } \vec{J}(E, \vec{r})=\int d \vec{\Omega} f(E, \vec{\Omega}, \vec{r})
\end{aligned}
$$

$\varphi^{+}$and $\vec{J}^{+}$are defined with Equation $(A-16)$ but with $H(\vec{\Omega} \cdot \vec{n}) g\left(E, \vec{\Omega}, \vec{r}_{s}\right)$ replacing the angular flux. $S_{v}$ and $\vec{S}_{v}$ are also defined with Equation $(A-16)$, but, the angular volume source replaces the angular flux term. 
The $e^{\text {th }}$ mode transfer cross section is defined as:

$$
\Sigma^{\ell}\left(E^{\prime} \rightarrow E\right)=4 \pi s_{\ell}^{\left(E^{\prime} \rightarrow E\right)}
$$

D. THE VOLUME INTEGRATED $P_{1}$ EQUATIONS

To obtain the volume integrated $\mathrm{P}_{0}$ equation, one integrates Equation ( $A-13$ ) across the volume. (The volume integrations include the contribution across the surface as well as that through the volume.) The contribution from the surface source in the isolated region in question is

$$
\begin{aligned}
\int \mathrm{dV} \overrightarrow{\mathrm{n}} \cdot \mathrm{J}^{+}\left(E, \overrightarrow{\mathrm{r}}_{\mathrm{s}}\right) \delta\left(\mathrm{z}^{\prime}\right) & =\int \mathrm{dA} \overrightarrow{\mathrm{n}} \cdot \overrightarrow{\mathrm{J}}^{+}\left(E, \overrightarrow{\mathrm{r}}_{s}\right) \int \delta\left(z^{\prime}\right) \mathrm{d} \mathrm{z}^{\prime} \\
& =\int \mathrm{dA} \overrightarrow{\mathrm{n}} \cdot \overrightarrow{\mathrm{J}}^{+}\left(E, \vec{r}_{s}\right)
\end{aligned}
$$

In the actual system, this is equal to the neutrons per second leaking in from other regions. Equation $(A-13)$ then becomes the usual expression for the conservation of neutrons.

$$
\begin{gathered}
\int \operatorname{div} \vec{J}(E, \vec{r}) d V+\Sigma_{t}(E) \int \varphi(E, \vec{r}) d V=\int \Sigma^{0}\left(E^{\prime} \rightarrow E\right) d E^{\prime} \int \varphi\left(E^{\prime}, \vec{r}\right) d V \\
+\int S_{v}(E, \vec{r}) d V+\int J^{+-}\left(E, \vec{r}_{s}\right) \cdot \vec{n} d A
\end{gathered}
$$

The equivalent volume integrated $\mathrm{P}_{1}$ equation is obtained by integrating the divergence of Equation (A-15) across the volume. The following integral now emerges:

$$
I=\int \operatorname{dV} \operatorname{div}\left[\vec{n}^{+}\left(E, \vec{r}_{s}\right) \delta\left(z^{\prime}\right)\right]
$$

Because the divergence term can be expressed as:

$$
\begin{aligned}
\operatorname{div}\left[\vec{n} \varphi^{+}\left(E, \vec{r}_{s}\right) \delta\left(z^{\prime}\right)\right] & =\vec{i}^{\prime} \cdot \frac{\partial}{\partial X}\left(\vec{n} \varphi^{+} \delta\left(z^{\prime}\right)\right)+\vec{j}^{\prime} \cdot \frac{\partial}{\partial Y}\left(\vec{n} \varphi+\delta\left(z^{\prime}\right)\right) \\
& +\vec{k}^{\prime} \cdot \frac{\partial}{\partial z^{\prime}}\left(\vec{n} \varphi^{+} \delta\left(z^{\prime}\right)\right)
\end{aligned}
$$


And,

$$
\begin{aligned}
& \vec{i}^{\prime} \cdot \vec{n}=\vec{j}^{\prime} \cdot \vec{n}=0 \text { and } \vec{k}^{\prime} \cdot \vec{n}=1 \text {. The integral becomes } \\
& I=\int d V \frac{d}{d z^{\prime}}\left[\delta\left(z^{\prime}\right) \varphi^{+}\left(E, \vec{r}_{s}\right)\right.
\end{aligned}
$$

and since $\varphi^{+}$is independent of $z^{\prime}$

$$
I=\int_{d A C p}^{+}\left(E, \vec{r}_{s}\right) \int \frac{d}{d z^{\prime}} \delta\left(z^{\prime}\right) d z^{\prime}
$$

and performing the $z^{\prime}$ integration yields

$$
I=0 \text {, }
$$

The volume integrated $P_{1}$ equation is then:

$$
\begin{gathered}
\int \operatorname{div} \operatorname{grad} \varphi(E, \vec{r}) d v+3 \Sigma(E) \int \operatorname{divJ}(E, \vec{r}) d v=3 \int d i \vec{S}(E, \vec{r}) d v \\
+\int d E^{\prime} \Sigma^{1}\left(E^{\prime} \rightarrow E\right) \int \operatorname{div} \vec{J}(E, \vec{r}) d v
\end{gathered}
$$

Since the volume integrals include going across the region boundary, the use of the divergence theorem will pertain to conditions on the exterior surface of the region. And, since there was no inflow of neutrons from exterior regions in this isolated system, the current term becomes

$$
\int \operatorname{div} \vec{J}(E, \bar{r}) d v=-\Gamma_{\bar{J}_{e}}\left(E, \bar{r}_{s}\right) \cdot \vec{n}_{d A}
$$

which is the leakage out of the region and is always positive. Similarly for the $\operatorname{grad} \varphi$ term

$$
\int \operatorname{div} \operatorname{grad} \varphi(E, \vec{r}) \mathrm{dV}=-\int_{\operatorname{grad}} \varphi_{e}\left(E, \vec{r}_{s}\right) \cdot \vec{n} \mathrm{dA}
$$

This is the normal gradient at the surface of the outward directed component of the flux and this component is continuous across the boundary.

To further simplify the volume integrated expressions, we assume only an isotropic volume source and the following definitions will be made. 


$$
\begin{aligned}
& \tilde{J}(E)=\int \operatorname{div} \vec{J}(E, \vec{r}) d V \\
& \varphi(E)=\int \varphi(E, \vec{r}) d V \\
& S_{v}(E)=\int_{v}(E, \vec{r}) d V \\
& S_{S}(E)=\int \vec{J}^{+}\left(E, \vec{r}_{s}\right) \cdot \vec{n} d A \\
& \mathcal{L}(E)=\frac{\int \operatorname{div} \operatorname{grad} \varphi(E, \vec{r}) d V}{\int \varphi(E, \vec{r}) d V}
\end{aligned}
$$

The $\mathrm{P}_{0}$ expression, Equation $(\mathrm{A}-19)$, becomes

$$
\begin{aligned}
\widetilde{J}(E)+\Sigma_{t}(E) \varphi(E) & =\int_{j} \Sigma^{0}\left(E^{\prime} \rightarrow E\right) \varphi\left(E^{\prime}\right) d E^{\prime} \\
& +S_{v}(E)+S_{s}(E)
\end{aligned}
$$

Similarly for the $\mathrm{P}_{1}$ expression, Equation $(\mathrm{A}-20)$

$$
\mathcal{L}(E) \varphi(E)+3 \Sigma_{t}(E) \widetilde{J}(E)=\int d E^{\prime} \Sigma^{1}\left(E^{\prime} \rightarrow E\right) \widetilde{J}\left(E^{\prime}\right)
$$

These two relations may be solved for $\widetilde{J}(E)$ and $\varphi(E)$ with the known data being the cross sections, sources and $\mathcal{L}(E)$.

E. THE TRANSPORT CROSS SECTION AND DIFFUSION COEFFICIENT

The transport cross section (an extensive parameter) is defined by Fick's law as

$$
\vec{J}(E, \vec{r})=\frac{1}{3 \Sigma_{t r}(E)} \operatorname{grad} \varphi(E, \vec{r})
$$

The diffusion coefficient is defined as

$$
D(E)=\frac{1}{3 \Sigma_{\operatorname{tr}}(E)}
$$


If the divergence of Equation $(\mathrm{A}-26)$ is integrated over the volume, the following expression emerges:

$$
\Sigma_{t r}(E)=-\frac{\mathcal{L}(E) \varphi(E)}{3 \tilde{J}(E)}
$$

Substituting for $\mathcal{L}(E) \varphi(E)$ from Equation $(A-25)$,

$$
\Sigma_{t r}(E)=\Sigma_{t}(E)-\frac{\int d E^{\prime} \Sigma^{1}\left(E^{\prime} \rightarrow E\right) \widetilde{J}\left(E^{\prime}\right)}{3 \widetilde{J}(E)}
$$

Because this last relation is linear in the cross sections, it can also be used for the corresponding microscopic quantities. 


\section{TILE B APPROXIMATION}

\section{A. TIE $B_{\ell}$ EQUATIONS}

The derivation of the $\mathrm{B}_{\ell}$ equations is based on the transport relation, Equation $(A-1)$. In addition, the process considers only an isotropic volume source and a one-dimensional azimuthally-symmetric slab geometry with cross sections independent of position. When the transference function is expanded in Legendre polynomials as in Equation $(A-6)$ and when integration is performed over the azimuthal angle, the pertinent slab equation emerges when the addition theorem for the Legendre polynomials is used.

$$
\begin{aligned}
{\left[\mu \frac{\partial}{\partial z}+\Sigma_{t}(E)\right] f(E, \mu, z)=} & \sum_{\ell=0}^{\infty} 2 \pi j d E^{\prime} s_{\ell}\left(E^{\prime} \rightarrow E\right) P_{\ell}(\mu) \int_{-1}^{+1} d \mu^{\prime} P_{\ell}\left(\mu^{\prime}\right) f\left(E^{\prime}, \mu^{\prime}, z\right) \\
& +\frac{S(E, z)}{4 \pi}
\end{aligned}
$$

The Fourier transform of Equation $(\mathrm{A}-30)$ is taken, which involves multiplying by $e^{i k z}$ and integrating over $d z$. from - $\infty$ to $+\infty$. If the Fourier transform of the wave equation, $\nabla^{2} \varphi+B^{2} \varphi=0$ is also taken, it is seen that the tiansform variable $k$ is equal to $B$, the square root of the buckling of the system. Equation (A-30) becomes,

$$
\begin{gathered}
\Sigma_{t}(E)\left[1-\eta_{\mu}\right] f(E, \mu, B)=\sum_{\ell=0}^{\infty} 2 \pi \int d E^{\prime} s_{\ell}\left(E^{\prime} \rightarrow E\right) P_{\ell}(\mu) \int_{-1}^{+1} d \mu^{\prime} P_{\ell}\left(\mu^{\prime}\right) f\left(E^{\prime}, \mu^{\prime}, B\right) \\
+\frac{S(E, B)}{4 \pi}
\end{gathered}
$$


where

$$
\eta \equiv \eta(E, B)=\frac{i B}{\Sigma_{t}(E)}
$$

The angular flux is expanded in Legendre polynomials to:

$$
f(E, \mu, B)=\sum_{\ell=0}^{\infty} f_{\ell}(E, B) P_{\ell}(\mu)
$$

with

$$
f_{\ell}(E, B)=\frac{2 \ell+1}{2} \int_{-1}^{+1} d \mu P e_{\ell}(\mu) f(E, \mu, B)
$$

When the above expansions aje made in Equation ( $A-31$ ), and the resulting equation is divided by $\left[1-\eta_{\mu}\right]$, multiplied by $P_{f}(\mu)$ and integrated over $d \mu$, the $\mathrm{B}_{\ell}$ equations are obtained:

$$
\begin{aligned}
\frac{1}{2 j+1} \Sigma_{t}(E) f_{j}(E, B) & =\sum_{\ell=0}^{\infty} \frac{4 \pi}{2 \ell+1} A_{j \ell !} r^{\prime} d E^{\prime} s_{\ell}\left(E^{\prime} \rightarrow E\right) f_{\ell}\left(E^{\prime}, B\right) \\
& +\frac{1}{4 \pi} A_{j 0} S(E, B)
\end{aligned}
$$

where:

the symmetric functions, $\mathrm{A}_{j l}$, are

$$
\begin{aligned}
A_{j \ell} \equiv A_{j \ell}(E, B)= & \frac{1}{2} \int_{-i}^{+1} \frac{d \mu P_{\ell}(\mu) P_{j}(\mu)}{1-\eta_{\mu}} \\
& =\frac{1}{\eta} Q_{j}\left(\frac{1}{\eta}\right) P_{\ell}\left(\frac{1}{\eta}\right) \text { with } \ell \leq j
\end{aligned}
$$

The $Q_{j}$ 's are the Legendre polynomials of the second kind. A few of the symmetric functions ( $A_{j \ell}$ 's) are: 


$$
\begin{aligned}
& A_{00}=\frac{\tan ^{-1} x}{x} \\
& A_{01}=A_{10}=\frac{i\left(1-A_{00}\right)}{x} \\
& A_{11}=-\frac{i A_{01}}{x}=\frac{\left(1-A_{00}\right)}{x^{2}}
\end{aligned}
$$

where

$$
x \equiv x(E, B)=\frac{\eta(E, B)}{i}=\frac{B}{\Sigma_{t}(E)}
$$

B. THE $B_{1}$ EQUATIONS

The $\mathrm{B}_{\mathrm{L}}$ approximation is obtained by setting the sum over $\mathrm{L}$ equal to zero for $\ell>L$. In the case $L=1$, one obtains the following two equations :

$$
\begin{aligned}
\Sigma_{t}(E) f_{0}(E, B) & =\frac{A_{00}}{4 \pi} S(E, B)+4 \pi A_{00} \int d E^{\prime} s_{0}\left(E^{\prime} \rightarrow E\right) f_{0}\left(E^{\prime}, B\right) \\
& +\frac{4 \pi}{3} A_{01} \int d E^{\prime} s_{1}\left(E^{\prime} \rightarrow E\right) f_{1}\left(E^{\prime}, B\right) \\
\frac{1}{3} \Sigma_{t}(E) f_{1}(E, B) & =\frac{A_{10}}{4 \pi} s(E, B)+4 \pi A_{10} d E^{\prime} s_{0}\left(E^{\prime} \rightarrow E\right) f_{0}\left(E^{\prime}, B\right) \\
& +\frac{4 \pi}{3} A_{11} d^{\prime} E^{\prime} s_{1}\left(E^{\prime} \rightarrow E\right) f_{1}\left(E^{\prime}, B\right)
\end{aligned}
$$

To obtain the $B_{1}$ equations, Equation $(A-36)$ is used to specify the $A_{j l}$ 's all in terms of $\mathrm{A}_{00}$; the transfer cross sections are defined with Equation $(A-17)$, i $J=\frac{4 \pi}{3} f_{1}, \varphi=4 \pi f_{0}$.

The $B_{1}$ relations are:

$$
\begin{aligned}
\Sigma_{t}(E) \varphi(E, B) & =A_{00} S(E, B)+A_{00} \int d E^{\prime} \Sigma^{0}\left(E^{\prime} \rightarrow E\right) \varphi\left(E^{\prime}, B\right) \\
& -\frac{\left(1-A_{00}\right)}{X} \int_{J} E^{\prime} \Sigma^{1}\left(E^{\prime} \rightarrow E\right) J\left(E^{\prime}, B\right)
\end{aligned}
$$




$$
\begin{aligned}
\Sigma_{t}(E) J(E, B) & =\frac{\left(1-A_{00}\right) S(E, B)}{x}+\frac{\left(1-A_{00}\right)}{x} \int d E^{\prime} \Sigma^{0}\left(E^{\prime} \rightarrow E\right) \varphi\left(E^{\prime}, B\right) \\
& +\frac{\left(1-A_{00}\right)}{x^{2}} j d^{\prime} \Sigma^{1}\left(E^{\prime}-E\right) J\left(E^{\prime}, B\right)
\end{aligned}
$$

Multiplying Equation $(A-42)$ by $X$ and adding to Equation (A-41) yields the $B_{0}$ expression.

$$
\mathrm{BJ}(\mathrm{E}, \mathrm{B})+\Sigma_{t}(E) \varphi(E, B)=\hat{\vdots} \mathrm{d}^{\prime} \Sigma^{0}\left(E^{\prime} \rightarrow E\right) \varphi\left(E^{\prime}, B\right)+S(E, B)
$$

Multiplying Equation $(A-43)$ by $-\frac{\left(1-A_{00}\right)}{X}$ and adding to Equation $(A-42)$ yields the $B_{1}$ expression.

where

$$
-B \varphi(E, B)+3 \Sigma_{t}(E) \alpha(E, B) J(E, B)=j_{j} d E^{\prime} \Sigma^{1}\left(E^{\prime} \rightarrow E\right) J\left(E^{\prime}, B\right)
$$

$$
\alpha(E, B)=\frac{x^{2} A_{00}}{3\left(1-A_{00}\right)}
$$

Equations $(A-43)$ and $(A-44)$ are the usual form of the $B_{1}$ equations.

C. THE TRANSPORT CROSS SECTION

The transport cross section is defined by Fick's law, Equation $(A-26)$ which will be written here as

$$
f_{1}(E, z)=-\frac{1}{\Sigma_{t r}(E)} \frac{\partial}{\partial z} f_{0}(E, z)
$$

Taking the Fourier transform of this equation yields

$$
f_{1}(E, B)=\frac{1 B}{\sum_{t r}(E)} f_{0}(E, B)
$$

Using Equation (A-40), and solving for $\Sigma_{t r}(E)$

$$
\Sigma_{t r}(E)=\frac{B Q P(E, B)}{3 J(E, B)}
$$


Substituting for $B \varphi$ from Equation $(A-44)$

$$
\Sigma_{t r}(E)=\alpha(E, B) \Sigma_{t}(E)-\frac{\int d E^{\prime} \Sigma^{l}\left(E^{\prime} \rightarrow E\right) J\left(E^{\prime}, B\right)}{3 J(E, B)}
$$

The diffusion coefficient is again defined by Equation (A-27).

If $\alpha$ is treated as an extensive quantity of the medium, Equation $(A-49)$ is linear in the cross sections and a microscopic transport cross section for a given material can be defined as:

$$
\sigma_{t r}(E)=\alpha(E, B) \sigma_{t}(E)-\frac{\int d E^{\prime} \sigma^{1}\left(E^{\prime} \rightarrow E\right) J\left(E^{\prime}, B\right)}{3 J(E, B)}
$$


III. THE SECOND MOMENT CALCULATION

A. THE $\mathrm{M}_{\mathrm{n} \ell}$ EQUATIUNS

The development of the moment relations, is based on Equation (A-30) with an isotropic plane source at the origin in an infinite medium.

$$
\begin{gathered}
{\left[\mu \frac{\partial}{\partial z}+\Sigma_{t}(E)\right] f(E, \mu, z)=\sum_{j=0}^{\infty} 2 \pi \int_{j} d E^{\prime} s_{j}\left(E^{\prime} \rightarrow E\right) P_{j}(\mu) \int_{-1}^{+1} d \mu^{\prime} P_{j}\left(\mu^{\prime}\right) f\left(E^{\prime}, \mu^{\prime}, z\right)} \\
+S(E) \delta(z)
\end{gathered}
$$

Using Equation (A-33), the angular flux is expanded in Legendre polynomials, the resulting equation is multiplied by $P_{\ell}(\mu)$ and integrated over $d \mu$. The $P_{b}$ relations that result are:

$$
\begin{aligned}
\frac{l+1}{2 \ell+3} \frac{\partial}{\partial z} f_{\ell+1} & (E, z)+\frac{\ell}{2 \ell-1} \frac{\partial}{\partial z} f_{\ell-1}(E, z)+\Sigma_{t}(E) f_{\ell}(E, z) \\
= & \frac{4 \pi}{2 \ell+1} \int d E^{\prime} s_{\ell}\left(E^{\prime}-E^{\prime}\right) f_{\ell}\left(E^{\prime}, z\right)+S(E) \delta_{\ell 0} \delta(z)
\end{aligned}
$$

The plane moments are defined as:

$$
M_{n \ell}(E)=\frac{1}{n !} \int z^{n} f_{\ell}(E, z) d z \quad \text { where } n \geq 0
$$

Equation (A-52) is multiplied by $z^{n} / n !$ and integrated over all space, to obtain the $M_{n \ell}$ relations 


$$
\begin{aligned}
\Sigma_{t}(E) M_{n \ell}(E) & =\frac{1}{2 \ell+1} \int \mathrm{d} E^{\prime} \Sigma^{\ell}\left(E^{\prime} \rightarrow E\right) M_{n \ell}\left(E^{\prime}\right)+\delta_{l 0} \delta_{n 0} S(E) \\
& +\frac{l+1}{2 \ell+3} M_{n-1, l+1}+\frac{l}{2 \ell-1} M_{n-1, l-1}
\end{aligned}
$$

In the $M_{n \ell}$ relations, the terms involving spatial derivatives were integrated by parts with the contribution at $\pm{ }^{\infty}$ vanishing due to the assumption that $f_{\ell}$ vanishes, at least exponentially, at $\pm{ }^{\infty}$. The definitions of the transfer cross sections were again obtained from Equation (A-17).

B. THE RELATIONS FOR THE SECOND MOMENT

The only relation that gives a nontrivial solution for $n=0$ is the inhomogeneous equation for ${ }^{M_{00}}$

$$
\Sigma_{t}(E) M_{00}(E)=\int d E^{\prime} \Sigma^{0}\left(E^{\prime} \rightarrow E\right) M_{00}\left(E^{\prime}\right)+S(E)
$$

For $\mathbf{n}=1$, the only nontrivial relation is for $M_{11}$

$$
\Sigma_{t}(E) M_{11}(E)=\frac{1}{3} \int d E^{\prime} \Sigma^{1}\left(E^{\prime} \rightarrow E\right) M_{11}\left(E^{\prime}\right)+M_{00}(E)
$$

For $\mathrm{n}=2$, the only nontrivial relations are those for $M_{20}$ and $M_{22}$. For ${ }_{20}$ :

$$
\Sigma_{t}(E) M_{20}(E)=\int d E^{\prime} \Sigma^{0}\left(E^{\prime} \rightarrow E\right) M_{20}\left(E^{\prime}\right)+\frac{1}{3} M_{11}(E)
$$

The relation for $M_{22}$ is of no immediate interest since the so-called second moment, or age, in this geometry is

$$
T(E)=\frac{\int_{-\infty}^{+\infty} z^{2} f_{0}(E, z) d z}{2 \int_{-\infty}^{+\infty} f_{0}(E, z) d z}=\frac{M_{20}(E)}{M_{00}(E)}
$$

We can further conclude that since the flux components are even spatial functions for $l$ even and odd spatial functions for $l$ odd, $M_{n}$ is zero unless $\mathrm{n}+\ell$ is even. In addition, the condition $\ell \leq \mathrm{n}$ must exist to obtain the pertinent nontrivial solutions. 
IV. SIMPLE APPROXIMATIONS TO THE P LEAKACE TERM, $\mathcal{L}(E)$

A. $\quad \dot{L}(E)$ IN TIL DIFFUSION APPROXIMATILIN

$\mathcal{L}(E)$ is defined by Equation $(A-23)$ as:

$$
\mathcal{L}(E)=\frac{\int d i v \operatorname{grad} \varphi(E, \vec{r}) d V}{\int \varphi(E, \vec{r}) d V}
$$

Using the divergence theorem on the numerator (Equation (A-22)) yields:

$$
S .(E)=-\frac{\tilde{j} \cdot \vec{n} \cdot \operatorname{grad} \varphi_{e}\left(E, \vec{r}_{s}\right) d A}{\int \varphi(E, \vec{r}) d V}
$$

Fick's law may he written ae:

$$
\vec{J}_{e}\left(E, \vec{r}_{s}\right)=-\frac{1}{3 \sum_{t r}(E)} \operatorname{grad} \varphi_{e}\left(E, \dot{r}_{s}\right)
$$

Using this result in Equation $(A-60)$ gives:

$$
\mathcal{L}(E)=3 \Sigma_{t r}(E) \frac{\int \overrightarrow{\mathrm{n}} \cdot \vec{J}_{e}\left(E, \vec{r}_{s}\right) \mathrm{d} A}{\int \varphi(E, \vec{r}) \mathrm{d} V}
$$

This provides an expression for $\mathcal{L}(E)$ in terms of the leakage out of the region. Since $\vec{n} \cdot \vec{J}_{e}<0$ always, the important result is that in the diffusion approximation, $\mathcal{L}(E) \leq 0$ always.

Returning to Equation (A-59), the divergence theorem can be used to express $\mathcal{L}(E)$ as follows: 


$$
\mathcal{L}(E)=\frac{\int \nabla^{2} \varphi(E, \vec{r}) \mathrm{d} V}{\int \varphi(E, \vec{r}) \mathrm{d} V}+\frac{\int \overrightarrow{\mathrm{n}} \cdot \operatorname{grad} \varphi_{i}\left(E, \vec{r}_{s}\right) \mathrm{dA}-\int \overrightarrow{\mathrm{n}} \cdot \operatorname{grad} \varphi_{e}\left(E, \vec{r}_{s}\right) \mathrm{dA}}{\int \varphi(E, \vec{r}) \mathrm{dV}}
$$

The integral in the numerator of the first term is the usual volume integral up to the surface.

Fick's law can be used on the numerator of the second term,

$$
\begin{aligned}
& \int \vec{n} \cdot \operatorname{grad} \varphi_{i}\left(E, \vec{r}_{s}\right) d A-\int \vec{n} \cdot \operatorname{grad} \varphi_{e}\left(E, \vec{r}_{s}\right) d A \\
& =-3 \Sigma_{t r}(E) \int \vec{n} \cdot \vec{J}_{i}\left(E, \vec{r}_{s}\right) d A+3 \Sigma_{t r}(E) \int \vec{n}_{0} \vec{J}_{e}\left(E, \vec{r}_{s}\right) d A
\end{aligned}
$$

However, with the assistance of the boundary conditions indicated by Equation $(\mathrm{A}-3)$

$$
\vec{n}_{i} \cdot \vec{J}_{i}\left(E, \vec{r}_{s}\right)-\vec{n} \cdot \vec{J}_{e}\left(E, \vec{r}_{s}\right)=\vec{n}_{\vec{J}} \vec{J}^{+}\left(E, \vec{r}_{s}\right)
$$

Here, $\overrightarrow{\mathrm{n}} \cdot \overrightarrow{\mathrm{J}}^{+}$is the direct contribution from the surface source (see comments after Equation (A-16)). Combining these last two expressions with Equation (A-63) gives

$$
\mathcal{L}(E)-\frac{\int \nabla^{2} \varphi(E, \vec{r}) d V}{\int \varphi(E, \vec{r}) d V}-3 \Sigma_{t r}(E) \frac{\int \vec{n} \cdot J^{+}\left(E, \vec{r}_{s}\right) d A}{\int \varphi(E, \vec{r}) d V}
$$

The integral ratio in the first term is either positive or negative while the one in the second term is inherently positive.

\section{B. MONOENERGETIC DIFFUSTON VALUES OF $\mathcal{L}$}

In the monoenergetic diffusion model, one assumes that the spatial flux dependence satisfies the wave equation. In the core, this givés:

$$
\nabla^{2} \varphi(\vec{r})+B^{2} \varphi(\vec{r})=0
$$

A similar equation applies in the reflector,

$$
\nabla^{2} \varphi(\vec{r})-x^{2} \varphi(\vec{r})=0
$$


It would be expected that a first approximation to $\mathcal{L}$ in a core region would be equal to $-\mathrm{B}^{2}$ (by neglecting the second term in Equation $(A-66)$ ). Such an approach would lead to trouble in a reflector region; taking $\mathcal{L}=+x^{2}$ is a serious error, because Equation $(A-62)$ states that $\mathcal{L}<0$ always. Better values are obtained by using the solutions of Equation (A-67) or Equation $(A-68)$ in the equation for $\mathcal{L}$ and performing the necessary integrations.

\section{One Dimensional Cores}

The fluxes (symmetrical solutions) and $\mathcal{L}$ values for one dimensional cores are tabulated below.

$\begin{array}{lll}\text { Geometry } & \frac{\varphi(r)}{\underline{L}} & \frac{-B^{2}}{2}\left[1+\left(\frac{1}{2 B D}\right) \cot (B R)\right] \\ \text { Slab } & A \cos B x & \frac{-B^{2}}{2}\left[\frac{\left(\frac{1}{2 B D} J_{0}(B R)+J_{1}(B R)\right.}{J_{1}(B R)}\right] \\ \text { Cylinder } & A J_{0}(B r) & \frac{-B^{2}}{2}\left[\frac{\left(\frac{R+2 D}{2 D}\right) \sin B R-B R \cos B R}{\sin B R-B R \cos B R}\right]\end{array}$

where:

$\mathbb{R}$ is the core half thickness or radius

$D$ is the diffusion coefficient.

\section{One Dimenoional Reflectors}

The case under consideration is a core surrounded by a single reflector of thickness, $T$. The flux is assumed to go to zero at an extrapolation distance, $d$, outside the reflector.

For a slab reflector, the solution to Equation $(A-68)$ is:

$$
\varphi(x)=C \sinh x(R+T+d-x)
$$

and

$$
\mathcal{L}=-x^{2}\left[\frac{1}{2 D} \frac{\left(\frac{1}{2 x}\right) \sinh x(T+d)+D \cosh x(T+d)}{\cosh x(T+d)-\cosh x d}\right]
$$

This is the only geometry for which $\mathcal{L}$ is not a function of $R$. 
The case of usual reflector interest is that in which the absorption is zero. The flux in the reflector then satisfies Laplaces equation. The flux (solutions going to zero at the extrapolated boundary) and $\mathcal{L}$ values under these conditions are tabulated below.

$\begin{array}{lll}\text { Geometry } & & \underline{L(\vec{r})} \\ \text { Slab } & C\left(\frac{R+T+d-X}{R+T+d}\right) & -\frac{1}{2 D T} \frac{(T+d+2 D)}{(T+2 d)} \\ \text { Cylinder } & C\left(1-\frac{1 n r}{\ln (R+T+d)}\right) & -\frac{R}{D} \frac{\left[\frac{1}{2} \ln \frac{R+T+d}{R}+\frac{D}{R}\right]}{\left[T(T+2 R)\left(\ln \left(\frac{R+T+d}{R+T}\right)+\frac{1}{2}\right)-R^{2} \ln \left(\frac{R+T}{R}\right)\right]} \\ \text { Sphere } & C\left(\frac{R+T+d}{r}-1\right) . & -\frac{3}{2 D T} \frac{R(T+d)+2 D(R+T+d)}{T(T+3 R+3 d)+6 R d}\end{array}$

A-1 GAM-1, A Consistent Multigroup Code for the Calculation of Fast Neutron Spectra and Multigroup Constants, General Atomic Report GA-1850, June 1961, G.D. Joanou and J. S. Dudek

A-2 Weinberg, A. M. and E. P. Wigner, The Physical Theory of Neutron Chain Reactors, University of Chicago Press, 1958 
APPENDIX B

SCATTERING MATRIX DEVELOPMENT

In this appendix, expressions for the multigroup transfer matrices are developed. First, the multigroup formulation is obtained to get the expression for the transfer cross section. The kernel for inelastic scattering to a specific level and the domain of integration of the transfer cross section are established. Next, inelastic scattering in the statistical approximation and a simple recipe for the $n, 2 n$ reaction are stated. Finally, the pertinent information for elastic scattering is shown to be just a special case of the more general inelastic results and the domain is relatively simple so that the integrals may be explicitly expressed.

\section{THE MULTIGROUP EQUATION}

The quantity of immediate interest in the multigroup relations is the definition of the group transfer cross sections. Therefore, the form of the Boltzmann equation is investigated in which the transference function has been expanded in Legendre polynomials, but, where the treatment of the angular flux has been left arbitrary. (Except in the collision integral, where it has been expanded in spherical harmonics.)

The process is started with Equation $(A-1)$ for the case of a volume source only, and the transference function is expanded in Legendre polynomials of the $I$ system scattering angle with Equation $(A-6)$. After using the addition theorem for the spherical harmonics to express $\mathrm{P}_{\ell}\left(\mu_{0}\right)$ in terms of $\vec{\Omega}$ and $\vec{\Omega}^{\prime}$, the integral over $d \Omega^{\prime}$ is expressed in terms of the angular flux expansion (see Equation $(A-8)$ ) and the desired equation is obtained: 


$$
\begin{aligned}
{\left[\vec{\Omega} \cdot \operatorname{grad}_{x}+\Sigma_{t}(E)\right] f(E, \vec{\Omega}, \vec{r})=} & \sum_{l=0}^{\infty} \frac{1}{(2 \ell+1)} \int \mathrm{dE}^{\prime} \Sigma^{\ell}\left(E^{\prime} \rightarrow E\right) \sum_{\mathrm{m}=-l}^{+\ell} \mathrm{P}_{\ell \mathrm{m}}(\vec{\Omega}) \mathrm{f} \mathrm{lm}_{\mathrm{m}}\left(\mathrm{E}^{\prime}, \overrightarrow{\mathrm{r}}\right) \\
& +\mathrm{S}(\mathrm{E}, \vec{\Omega}, \overrightarrow{\mathrm{r}})
\end{aligned}
$$

The transfer cross section, $\Sigma^{\ell}\left(E^{\prime} \rightarrow E\right)$, is defined in terms of the cocfficients $s_{\ell}\left(E^{\prime} \rightarrow E\right)$ by Equation $(A-17)$ of Appendix $A$ and is given explicitly by

$$
\Sigma^{\ell}\left(E^{\prime} \rightarrow E\right)=4 \pi\left(\frac{2 \ell+1}{2}\right) \int_{-1}^{+1} \Sigma\left(E^{\prime} \rightarrow E, \vec{\Omega}^{\prime} \rightarrow \vec{\Omega}\right) P_{\ell}\left(\mu_{0}\right) d \mu_{0}
$$

The multigroup version of Equation $(B-1)$ is obtained by multiplying by $\mathrm{dE}$ and integrating over $\mathrm{g}^{\text {th }}$ group.

$$
\begin{gathered}
{\left[\vec{\Omega} \cdot \operatorname{grad}_{\mathbf{x}}+\Sigma_{t_{\mathrm{g}}}\right]_{\mathrm{f}}(\vec{\Omega}, \overrightarrow{\mathrm{r}})=\sum_{\ell=0}^{\infty} \sum_{\mathrm{g}^{\prime} \leq \mathrm{g}} \frac{1}{(2 \ell+1)} \Sigma_{\mathrm{g}^{\prime} \rightarrow \mathrm{g}}^{\ell} \sum_{\mathrm{m}=-\ell}^{+\ell} \mathrm{P}_{\ell \mathrm{m}}(\vec{\Omega}) \mathrm{f}_{\ell \mathrm{m}_{\mathrm{g}^{\prime}}}} \\
+\mathrm{s}_{\mathrm{g}}(\vec{\Omega}, \overrightarrow{\mathrm{r}})
\end{gathered}
$$

When it is assumed that the intragroup spectrum is independent of direction, the group total cross section can be defined by the mean value theorem. In addition, the integral over $\mathrm{dE}^{\prime}$ was replaced by a sum of integrals over the $g^{\prime}$ th group. The concept of a transfer cross section dependent on $l$ only has also been applied to the multigroup equations. This is done by using the mean value theorem on the various m modes and then arithmetically averaging over all $\mathrm{m}$. The resultant transfer cross section is:

$$
\Sigma_{g^{\prime} \rightarrow g}^{\ell}=\frac{\int_{\dot{g}^{\prime}} d E^{\prime} \sum_{m=-\ell}^{+l} P_{\ell m}(\vec{\Omega}) f_{l m}\left(E^{\prime}, \vec{r}\right) \int_{g} d E^{\prime} \Sigma^{\ell}\left(E^{\prime} \rightarrow E\right)}{\int_{g} d E^{\prime} \sum_{m=-l}^{+l} P_{l m}(\vec{\Omega}) f_{\ell m}\left(E^{\prime}, \vec{r}\right)}
$$

where, in effect, suitable spatial flux averages are employed over the region of interest. 
Equation $(B-4)$ as it stands is a function of $\vec{\Omega}$. To remove this dependence $i t$ is assumed that over the $g^{\prime}$ th group, the spectral shapes are the same for all $\mathrm{m}$; that is, that $f_{\ell m}\left(E^{\prime}\right)=a_{\ell m} f_{\ell}\left(E^{\prime}\right)$ where a $l m$ is not a function of energy. The directional dependence then cancels out and the usual form of the multigroup transfer cross section is obtained

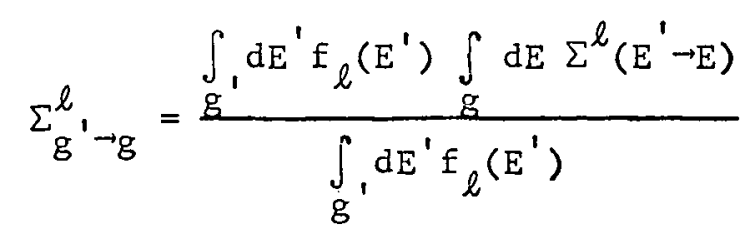

The cross section $\Sigma^{l} g^{\prime} \rightarrow g$ is the one on the library tape and is used in the spectrum generating routines of this code. However, the cross section that is actually used in multigroup neutronic analysis, is the one defined by

$$
\Sigma_{\ell_{g^{\prime} \rightarrow g}}=\frac{1}{(2 \ell+1)} \Sigma_{g^{\prime} \rightarrow g}^{l}
$$

It is this cross section that is the output of the spectral averaging routine. 


\section{INELASTIC SCATTERING}

\section{A. EIVERGELLCS UE' I'HE KEAC'LIUN}

The expressions for the scattering kernel are developed for arbitrary $Q$ values. This includes inelastic scattering to a specific level, when $Q=-W$ and where $W$ is the level excitation energy and also elastic scattering, when $Q=0$.

The $Q$ equation, is obtained by conservation of energy and momentum in the I system; for the case of inelastic scattering (Ref. B-1):

$$
E^{\frac{1}{2}}=\frac{E^{J_{2}}}{(A+1)} \mu_{0} \pm\left[\frac{F^{\prime}}{(A+1)^{2}} \mu_{0}^{2}+\frac{A}{(A+1)} Q+\left(\frac{A-1}{A+1} E^{\prime}\right]^{\frac{1}{2}}\right.
$$

The reaction becomes possible when the term inside the brackets is zero. The lowest possible incident neutron energy, $E^{\prime}{ }_{t h}$, occurs at $\theta=0^{\circ}$ and is.

$$
E_{t h}^{\prime}=-\left(\frac{A+1}{A}\right) Q
$$

As the incident neutron energy is increased, other scattering angles become possible. According to Equation (B-7), two values of $E$ are possible at each angle and given incident energy. When particles appear at $90^{\circ}$, the required incident energy is

$$
E_{900}^{\prime}-\left(\frac{A}{A-1}\right) Q
$$

At $E^{\prime} 900$, the final neutron energy is zero. Above this incident energy, only the + sign is possible in Equation ( $B-7)$ and the final neutron energy is, thus, single valued for all scattering angles. 
The $Q$ equation is rewritten in terms of the cosine of the scattering angle in the I system, $\mu_{0}$,

$$
\mu_{0}\left(E^{\prime}, E\right)=\frac{(A+1)}{2}\left(\frac{E}{E^{\prime}}\right)^{\frac{1}{2}}-\frac{(A-1)}{2}\left(\frac{E^{\prime}}{E}\right)^{\frac{1}{2}}-\frac{A}{2\left(E^{\prime} E\right)^{\frac{1}{2}}} Q
$$

A similar relation may be obtained for the cosine of the scattering angle in the $\mathrm{CM}$ system, $\eta_{0}$, by using the appropriate conservation relations and then converting back to the $\mathrm{L}$ system.

$$
\eta_{0}\left(E^{\prime}, E\right)=\frac{\gamma}{2}\left[(A+1)^{2} \frac{E}{E^{\top}}-\left(1+\frac{1}{\gamma^{2}}\right)\right]
$$

where:

$\gamma$ is the ratio of the velocity of the CM in the $L$ system to that of the emergent neutron in the CM system:

$$
Y=\frac{1}{A}\left[1+\frac{(A+1)}{A} \frac{Q}{E}\right]^{-\frac{1}{2}}
$$

B. THE SCATTERING KERNEL

If the transference function is assumed to be azimuthaliy independent, the scattering kernel, expressed by Equation (B-2) is:

$$
\Sigma^{\ell}\left(E^{\prime}-E\right)=(2 b+1) \int_{-1}^{+1} \Sigma\left(E^{\prime} \rightarrow E, \mu_{0}\right) P_{\ell}\left(\mu_{0}\right) d \mu_{0}
$$

The final neutron energy is uniquely determined by the scattering angle in the $\mathrm{CM}$ system with Equation (B-11). In the previous section it has been shown that this is generally nọt true in the $L$ system, and the transference function will therefore, contain a delta function in the CM system.

$$
\Sigma\left(E^{\prime} \rightarrow E, \mu_{0}\right)=2 \pi \Sigma\left(E^{\prime}, \mu_{0}\right) \delta\left(E-E\left(\eta_{0}\right)\right)
$$

where:

$E\left(\eta_{0}\right)$ is the solution of Equation $(B-11)$ for $E$ and $\Sigma\left(E^{\prime}, \mu_{0}\right)$ is the differential scattering cross section per unit solid angle in the $I$ system. 
By conservation of neutrons in both systems

$$
\Sigma\left(E^{\prime}, \mu_{0}\right) \mathrm{d} \mu_{0}=\Sigma\left(E^{\prime}, \eta_{0}\right) \mathrm{d} \eta_{0}
$$

Equation (B-14) becomes

$$
\Sigma\left(E^{\prime} \rightarrow E, \mu_{0}\right)=2 \pi \Sigma\left(E^{\prime}, \eta_{0}\right) \frac{d \eta_{0}}{d \mu_{0}} \delta\left(E-E\left(\eta_{0}\right)\right)
$$

A scattering probability in the CM system is defined by:

$$
\Sigma\left(E^{\prime}, \eta_{0}\right)=\Sigma_{i e_{.}}\left(E^{\prime}\right) f\left(E^{\prime}, \eta_{0}\right)
$$

where:

$$
\begin{aligned}
& \Sigma_{i e}\left(E^{\prime}\right) \text { is the inelastic scattering cross section to the specific } \\
& \text { level in question; } f\left(E^{\prime}, \eta_{0}\right) \text { is now expanded in Legendre poly- } \\
& \text { nomials }
\end{aligned}
$$

where

$$
f\left(E^{\prime}, \eta_{0}\right)=\sum_{\ell^{\prime}=0}^{\infty} \frac{2 \ell^{\prime}+1}{4 \pi} g_{\ell^{\prime}}\left(E^{\prime}\right) P_{\ell^{\prime}}\left(\eta_{0}\right)
$$

$$
\left.g_{\ell^{\prime}}\left(E^{\prime}\right)=\frac{2 \pi}{\Sigma_{i e .}\left(E^{\prime}\right)} \int_{-1}^{+1} \Sigma\left(E^{\prime}, \eta_{0}\right) P_{\ell^{\prime}}\left(\eta_{0}\right) d \eta_{0}\right\}
$$

Using these relations, Equation (B-16) becomes

$$
\Sigma\left(E^{\prime} \rightarrow E, \mu_{0}\right)=\delta\left(E-E\left(\eta_{0}\right)\right) \frac{\mathrm{d} \eta 0}{\mathrm{~d} \mu_{0}} \Sigma_{i e}\left(E^{\prime}\right) \sum_{\ell^{\prime}=0}^{\infty} \frac{2 l^{\prime}+1}{2} g_{\ell^{\prime}}\left(E^{\prime}\right) P_{\ell^{\prime}}\left(\eta_{0}\right)
$$

If Equation ( $B-19$ ) is substituted into ( $B-13$ ), and the variable of integration is changed to $\eta_{0}$, the integration yields the scattering kernel:

$$
\Sigma^{\ell}\left(E^{\prime} \rightarrow E\right)=\frac{(2 \ell+1)(A+1)^{2}}{4 E^{\prime}} \gamma\left(E^{\prime}\right) \Sigma_{i c .}\left(E^{\prime}\right) P_{\ell}\left(\mu_{0}\left(E^{\prime}, E\right)\right) \sum_{\ell^{\prime}=0}^{\infty}\left(2 \ell^{\prime}+1\right) g_{\ell^{\prime}}\left(E^{\prime}\right) P_{\ell^{\prime}}\left(\eta_{0}\left(E^{\prime}, E^{\prime}\right)\right)
$$

where (Ref. B-2):

$$
\int_{-\alpha}^{+\alpha} \delta(b-a x) \varphi(x) d x=\frac{1}{a} \varphi\left(\frac{b}{a}\right)
$$




\section{THE DOMAIN OF THE SCATTERING INTEGRAIS}

The group scheme for the definition of the scattering matrices is shown in Figure $B-1$.

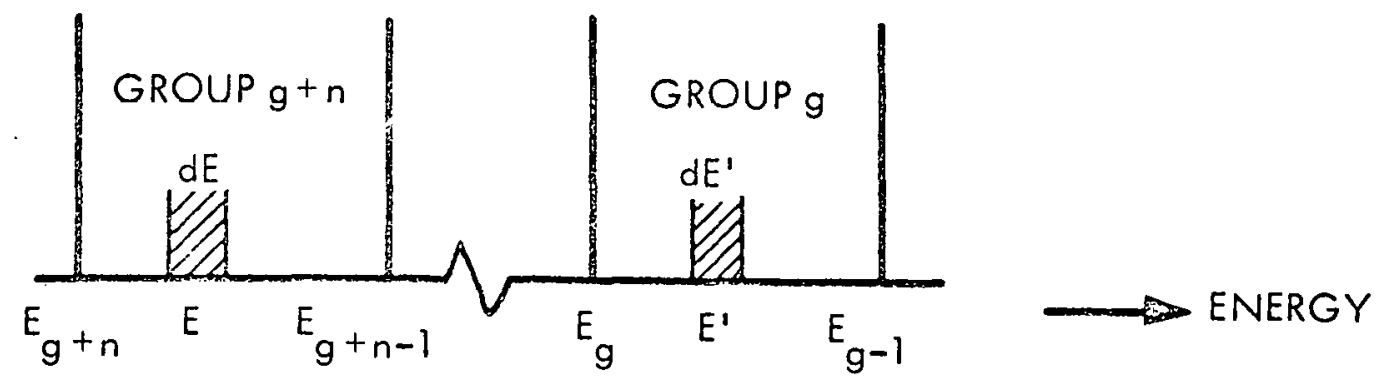

FIGURE B-1. GROUP SCHEME FOR DEFINITION OF SCATTERING MATRICES

Neutrons are transferred from group $g$ to group $g+n$ and the transfer cross section of Equation $(B-5)$ is written as:

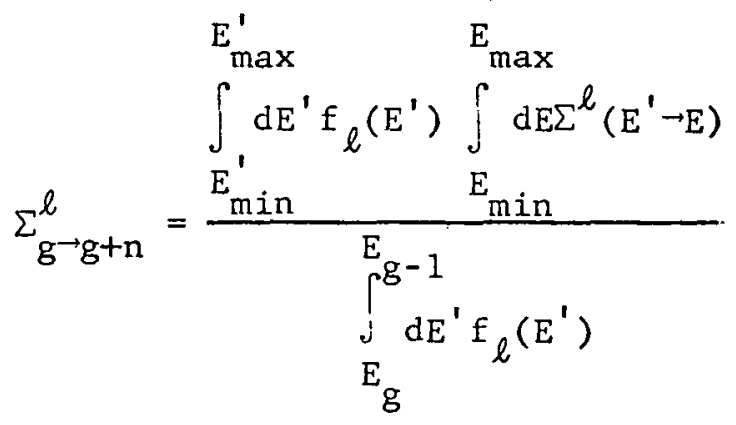

The group scheme will now be resketched on the two-dimensional $E, E^{\prime}$ plane, but first, the range of neutron scattering must be established. The maximum or minimum final neutron energy for a particular incident neutron energy, $E_{\max }\left(E^{\prime}\right)$, will occur when $\eta_{0}$ is equal to +1 or -1 , respectively, in $\min$

Equation $(B-11)$.

$$
\mathrm{E}_{\min }\left(E^{\prime}\right)=\frac{E^{\prime}}{(A+1)^{2}}\left[A\left(1-\frac{E_{t h}^{\prime}}{E}\right) \pm 1\right]^{2}
$$

where the + sign is used for $E_{\max }\left(E^{\prime}\right)$ and the - sign for $E_{\min }\left(E^{\prime}\right)$. 
To obtain the corresponding incident neutron energy, Equation (B-23) is solved backwards:

$$
\begin{gathered}
E^{\prime}\left(E_{\max }\right)=\frac{E_{\max }}{(A-1)^{2}}\left\{2\left[1 \pm A\left(1+\left(\frac{A-1}{A+1}\right) \frac{E_{t h}^{\prime}}{E_{\max }}\right)^{\frac{1}{2}}\right]\right. \\
\left.+(A+1)(A-1)\left[1+\left(\frac{A}{A+1}\right)^{2} \frac{E_{t h}^{\prime}}{E_{\max }}\right]\right\}
\end{gathered}
$$

where the - sign is used for $E^{\prime}\left(E_{\max }\right)$ and alsn for $E^{\prime}\left(E_{\min }\right)<E^{\prime}{ }_{90}$. The $+\operatorname{sign}$ is used for $E^{\prime}\left(E_{\min }\right)>E^{\prime}{ }_{900^{\circ}}$

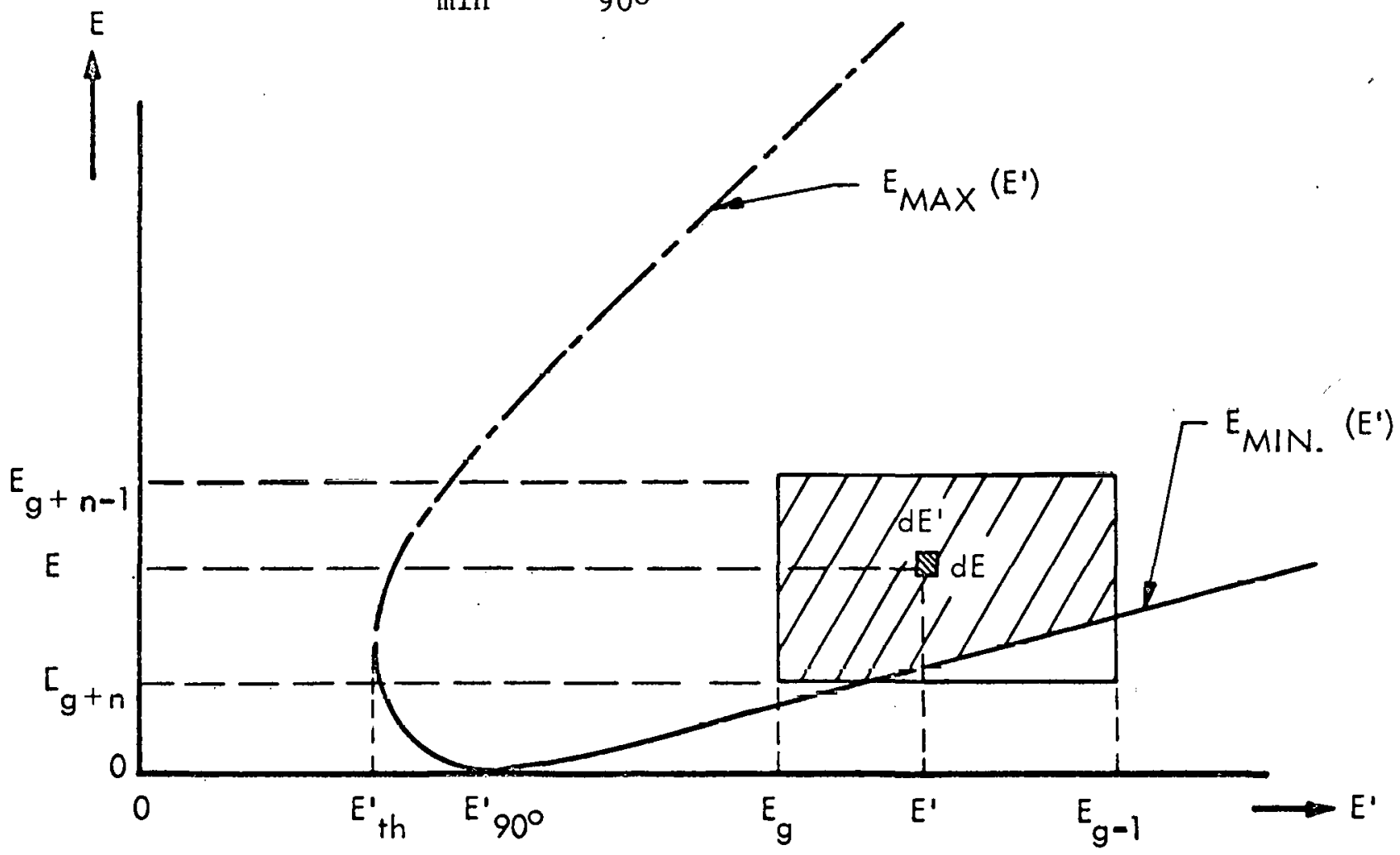

FIGURE B-2. TWO-DIMENS IONAL E-E' PLANE

In the two-dimensional E, E' plane (Figure B-2), the domain of integration of the transfer cross section is the shaded area between $E_{\max }\left(E^{\prime}\right)$ and $E_{\min }\left(E^{\prime}\right)$. The limits for the differential area integration ( $d E ' d E$ ) over the domain, are (from Equation $B-22$ ) $E_{\min } \leq E \leq E_{\max }$ and $E_{\min }^{\prime} \leq E^{\prime} \leq E_{\max }^{\prime}$, and, since neutrons only scatter down in energy, $E \leq E^{\prime}$. 
The domain is integrated upwards in energy for both $E^{\prime}$ and $E$. For a given $E^{\prime}$, all possible values for $E$ are integrated, then, on to the next higher $\mathrm{E}$, etc. The limits in this order, are then:

$$
\begin{aligned}
& E_{\min }^{\prime}=\max \left(E_{g} ; E_{t h^{\prime}}^{\prime} E_{E^{\prime}\left(E_{\min }=E_{g+n-1}\right) \text { if } E_{g+n-1}<E_{\min }\left(E^{\prime}=E_{t h}^{\prime}\right)}=E_{g+n}\right) \text { if } E_{\max }\left(E^{\prime}=E_{t h}^{\prime}\right)<E_{g+n} \\
& E_{\min }=\max \left(E_{g+n} ; E_{\min }\left(E^{\prime}\right)\right) \\
& E_{\max }=\min \left(E_{g+n-1} ; E_{\max }\left(E^{\prime}\right)\right) \\
& E_{\max }^{\prime}=\min \left(E_{g-1} ; E^{\prime}\left(E_{\min }=E_{g+n-1}\right)\right)
\end{aligned}
$$

The limits as specified by Equation ( $B-25)$ for use in Equation (B-22) along with the kernel defined by Equation (B-20), completely specify the multigroup transfer matrix for inelastic scattering to a specific level. The total transfer cross section due to inelastic scattering is then, the sum over all levels.

D. STATISTICAL THEORY - THE EVAPORATION MODEL

When many levels are available for excitation, the isotropic statistical theory is used (Ref. B-3). Neglecting the conversion between the $\mathrm{CM}$ and $\mathrm{L}$ systems, the scattering kernel is obtained:

$$
\Sigma^{0}\left(E^{\prime} \rightarrow E\right)=\Sigma_{i e .}\left(E^{\prime}\right) K\left(E^{\prime}\right) E e^{-E / \theta\left(E^{\prime}\right)}
$$

where:

$\Sigma_{i e .}$ is the total inelastic cross section; e.g., the sum over all levels. The compound nucleus temperature is assumed to be a function of the incident neutron energy

$$
\theta\left(E^{\prime}\right)=C E^{1^{\frac{1}{2}}}
$$


If no other information is available, $C$ is taken as (Ref. B-3):

$$
\mathrm{C} \simeq \frac{2}{0.62 \sqrt{\mathrm{A}}} \quad\left(\mathrm{Mev}^{\frac{1}{2}}\right)
$$

The normalization parameter, $K\left(E^{\prime}\right)$, is determined from the conservation relation

$$
\int_{0}^{E^{\prime}} \Sigma^{0}\left(E^{\prime}-E\right) d E=\Sigma_{i e}\left(E^{\prime}\right)
$$

which yields

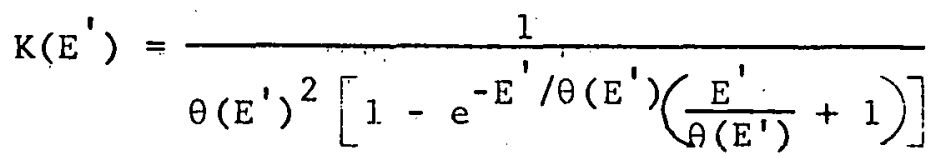

With this statistical kernel, the group transfer cross section may be written as

$$
\Sigma_{g \rightarrow g+n}^{0}=\frac{\int_{g}^{E_{g-1}} \sum_{i=}\left(E^{\prime}\right) \varphi\left(E^{\prime}\right) K\left(E^{\prime}\right) d E^{\prime} \int_{E_{g+n}}^{E+n-1} E e^{-E / \theta\left(E^{\prime}\right)} d E}{\int_{E_{g}}^{E_{g-1}} \varphi\left(E^{\prime}\right) d E^{\prime}}
$$

where we define

$$
E_{g+n-1}(n=0) \equiv E^{\prime}
$$

This. is not to be confused with $E_{g-1}$ which is the upper energy limit in the $g^{\text {th }}$ group. The integration over $d E$ may be performed analytically to yield

$$
\left.\left.\int_{E_{g+n}}^{E} E e^{-E / \theta\left(E^{\prime}\right)} d E=\theta\left(E^{\prime}\right)^{2}\left[e^{-E} g+n^{/ \theta\left(E^{\prime}\right)} \cdot \frac{E_{g-n}}{\theta\left(E^{\prime}\right)}+1\right)-e^{-E g+n-1 / \theta\left(E^{\prime}\right)} \frac{E_{g+n-1}}{\left(\theta\left(E^{\prime}\right)\right.}+1\right)\right]
$$

Substituting this result into Equation (B-30) gives the group transfer cross section for inelastic scattering in the statistical approximation. 


\section{E. THE $(n, 2 n)$ REACTION}

Because there is 1 ittle information available about the decay modes of the $(n, 2 \pi)$ reaction, the simple approach of placing both emergent neutrons in the statistical inelastic spectrum can be used. Thus, a new inelastic cross section, $\Sigma_{i e}^{\prime}\left(E^{\prime}\right)$, is defined as:

$$
\Sigma_{i e .}^{\prime}\left(E^{\prime}\right)=\Sigma_{i e_{e}}\left(E^{\prime}\right)+2 \Sigma_{n, 2 n}\left(E^{\prime}\right)
$$

This new definition is used both in the group constants and in the transfer matrix, Equation $(B-30)$. Then, to conserve neutrons, a new absorption cross section, $\Sigma_{a}^{\prime}\left(E^{\prime}\right)$ is defined by

$$
\Sigma_{a}^{\prime}\left(E^{\prime}\right)=\Sigma_{a}\left(E^{\prime}\right)-\Sigma_{n, 2 n}\left(E^{\prime}\right)
$$

When this approach is taken, the primed quantities are those which appear on the library tape. 


\section{ELASTIC SCATTERING}

A. THE 3CATTERING KERNEL

As mentioned earlier, the elastic scattering kernel is obtained as a special case of the more generai inelastic formulation, Equation (B-20) with $Q=0$.

$\Sigma^{\ell}\left(E^{\prime} \rightarrow E\right)=(2 \ell+1) \frac{(A+1)^{2}}{4 A E^{\prime}} \Sigma_{e l} .\left(E^{\prime}\right) P_{\ell}\left(\mu_{0}\left(E^{\prime}, E\right)\right) \sum_{\ell^{\prime}=0}^{\infty}\left(2 \ell^{\prime}+1\right) g_{\ell^{\prime}}\left(E^{\prime}\right) P_{l^{\prime}}\left(\eta_{0}\left(E^{\prime}, E\right)\right)$

The normalization integral of the kernel over all final energies is obtained by changing the integration variable to $\mu_{0}$.

$\int_{\alpha E^{\prime}}^{E^{\prime}} \Sigma^{\ell}\left(E^{\prime}-E\right) d E=(2 l+1) 2 \pi \int_{-1}^{+1} P_{\ell}\left(\mu_{0}\right) \Sigma\left(E^{\prime}, \mu_{0}\right) d \mu_{0}=(2 \ell+1) \Sigma_{c l} .\left(E^{\prime}\right) f_{\ell}\left(E^{\prime}\right)$

where $f_{\ell}\left(E^{\prime}\right)$ is the equivalent expression to Equation (B-18) in the L system:

In actual practice, the sum over $l^{\prime}$ is terminated at a finite value to make the normalization integral a function of the selected maximum value of $l^{\prime}$. For example, if the series had been carried through $l^{\prime}=1$, the normalization integral for $l=I$ would have been equal to

$$
\int_{\alpha E^{\prime}}^{E^{\prime}} \Sigma^{1}\left(E^{\prime} \rightarrow E\right) d E=3 \Sigma_{e l}\left(E^{\prime}\right)\left[\frac{2}{3 A}+\bar{\eta}_{0}\left(E^{\prime}\right)\left(1-\frac{3}{5 A^{2}}\right)\right]
$$


The term in the square brackets is the expression for $\overline{\mu_{0}}\left(E^{\prime}\right)$ if there is no scattering of a higher order than $\mathrm{p}$ scattering, but is not necessarily equal to the experimental value of $\overline{\mu_{0}}\left(E^{\prime}\right)$.

Another formulation of the kernel is possible for elastic scattering since, for this case, the cosine of the scattering angle in either system uniquely determines the final neutron energy. Thus, if instead of carrying the analysis through in the $\mathrm{CM}$ system, as was done for the results leading up to Equation (B-33), the equivalent $L$ system relations had been used, the following series expansion over the L system coefficients would have been obtained:

$\Sigma^{l}\left(E^{\prime} \rightarrow E\right)$

$=\frac{(2 b+1)}{8 E} \sum_{e 1}\left(E^{\prime}\right)\left[(A+1)\left(\frac{E}{E^{\prime}}\right)^{\frac{1}{2}}+(A-1)\left(\frac{E^{\prime}}{E}\right)^{\frac{1}{2}}\right] P_{l}\left(\mu_{0}\left(E^{\prime}, E\right)\right) \sum_{l^{\prime}=0}^{\infty}\left(2 l^{\prime}+1\right) E_{l^{\prime}}\left(E^{\prime}\right) P_{l^{\prime}}$ $\left(\mu_{0}\left(E^{\prime}, E\right)\right)$

B. THE DOMAIN OF THE SCATTERING INTEGRAL

The two-dimensional $\mathrm{E}, \mathrm{E}^{\prime}$ plane is much simpler for elastic scattering since the two bounds from the energetics, $E_{\max }\left(E^{\prime}\right)$ and $E_{\min }\left(E^{\prime}\right)$, are straight lines from the origin.

$$
\begin{aligned}
& E_{\max }\left(E^{\prime}\right)=E^{\prime} \\
& E_{\min }\left(E^{\prime}\right)=\alpha E^{\prime}
\end{aligned}
$$

where

$$
\alpha=\left(\frac{A-1}{A+1}\right)^{2}
$$

According to Equation $(B-25)$, the following limits are obtained for elastic scattering:

$$
\begin{aligned}
& E_{\min }^{\prime}=E_{g} \\
& E_{\min }=\max \left(E_{g+n} ; \alpha E^{\prime}\right)
\end{aligned}
$$




$$
\begin{aligned}
& E_{\max }=\min \left(E_{g+n-1} ; E^{\prime}\right) \\
& E_{\max }^{\prime}=\min \left(E_{g-1} ; \frac{E_{g+n-1}}{\alpha}\right)
\end{aligned}
$$

However, for elastic scattering, there is a small enough number of cases to permit the integrals to be explicitly specified. These integrals are easily obtained visually from the scattering domain on the $E, E^{\prime} \mathrm{plane}$, but the actual form of the limits will depend on whether the $E^{\prime}$ integration or the $\mathrm{E}$ integration is performed first.

For the integral limits, the curve number refers to the corresponding $E_{\min }\left(E^{\prime}\right)$ curve on the $E, E^{\prime} p l a n e ;$ the $E_{\min }\left(E^{\prime}\right)$ bounds are given after the curve number. The kernels of the integrals have been omitted from the tables to save space.

\section{Ingroup Scattering}

There are only two possible cases for ingroup scattering since $E_{\max }\left(E^{\prime}\right)$ is fixed and $E_{\min }\left(E^{\prime}\right)$ can only cut the square in two ways as shown in Figure $B-3$.

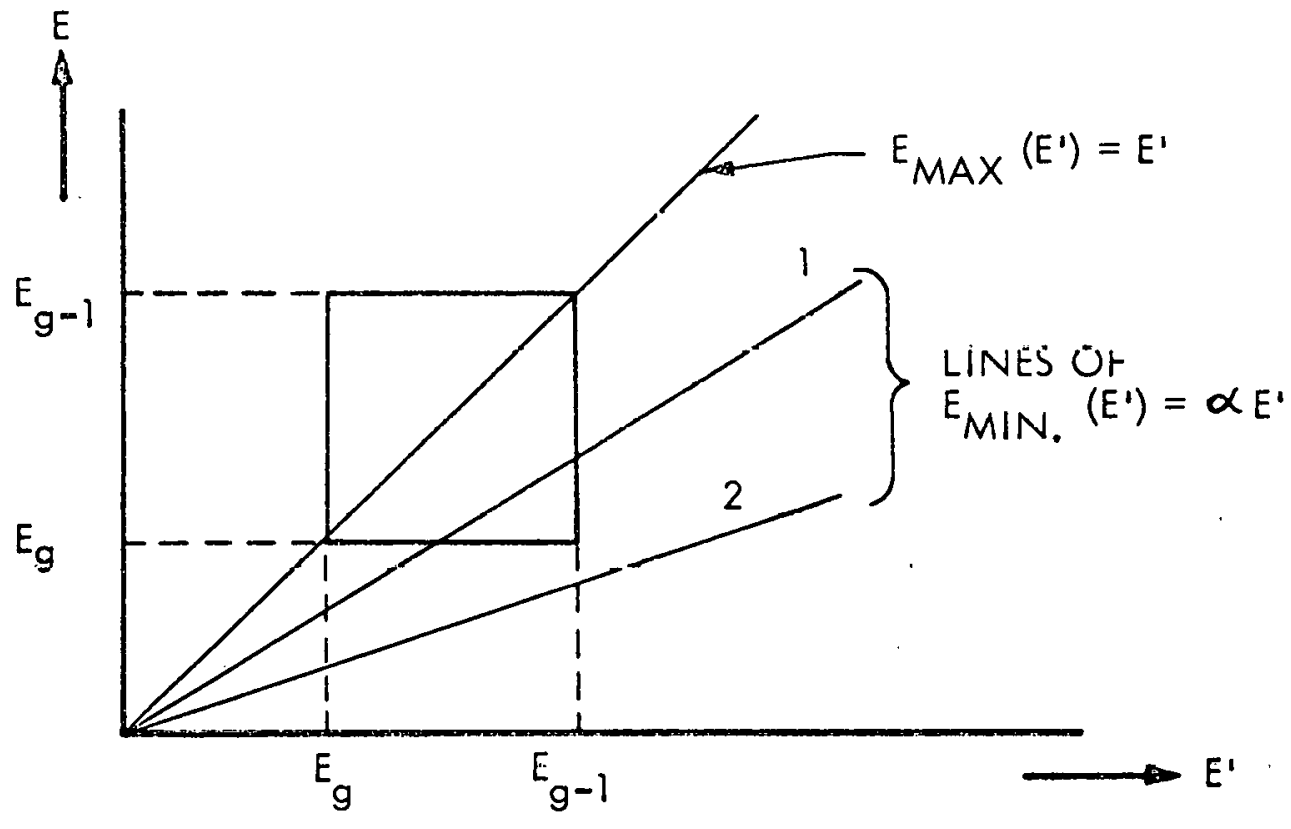

FIGURE B-3. THE TWO POSSIBLE CASES FOR IN-GROUP SCATTERING 


\begin{tabular}{|c|c|c|}
\hline $\begin{array}{l}\text { Curve No. } \\
\left(E_{\min }\left(E^{\prime}\right) \text { bounds) }\right.\end{array}$ & $\int d E^{\prime} E_{\ell}\left(E^{\prime}\right) \int d E \Sigma^{\ell}\left(E^{\prime} \rightarrow E\right)$ & $\int d E_{j} d E^{\prime} f_{l}\left(E^{\prime}\right) \Sigma^{\ell}\left(E^{\prime} \rightarrow E\right) \quad(B-38)$ \\
\hline$\left(\alpha E_{g}<E_{g}<\alpha E_{g-1} \leq E_{g-1}\right)$ & $\begin{array}{lll}E_{g} / \alpha E^{\prime} & E_{g-1} & E^{\prime} \\
\int_{g} d E^{\prime} & \int_{g} d E+\int_{g} d E^{\prime} & \int_{\alpha E^{\prime}} d E\end{array}$ & $\int_{E_{g}}^{\alpha E_{g-1}} \int_{E}^{E / \alpha} d E^{\prime}+\int_{\alpha E_{g-1}}^{E} d E j_{g-1}^{E} d E^{\prime}$ \\
\hline$\left(\alpha E_{g} \leq \alpha E_{g-1} \leq E_{g} \leq E_{g-1}\right)$ & $\begin{array}{ll}\int_{g-1} & E^{\prime} \\
E_{g} & \int_{g} d E\end{array}$ & $\int_{E_{g}}^{E} d E \int_{E}^{E-1} d E^{\prime}$ \\
\hline
\end{tabular}

\section{Out-of-Group Scattering}

For out-of-group scattering, the line $E_{\max }\left(E^{\prime}\right)$ is always above the rectangle and there are only six ways in which $E_{\text {min }}$ (E') can cut the rectangle. (Figure $\mathrm{B}-4$ )

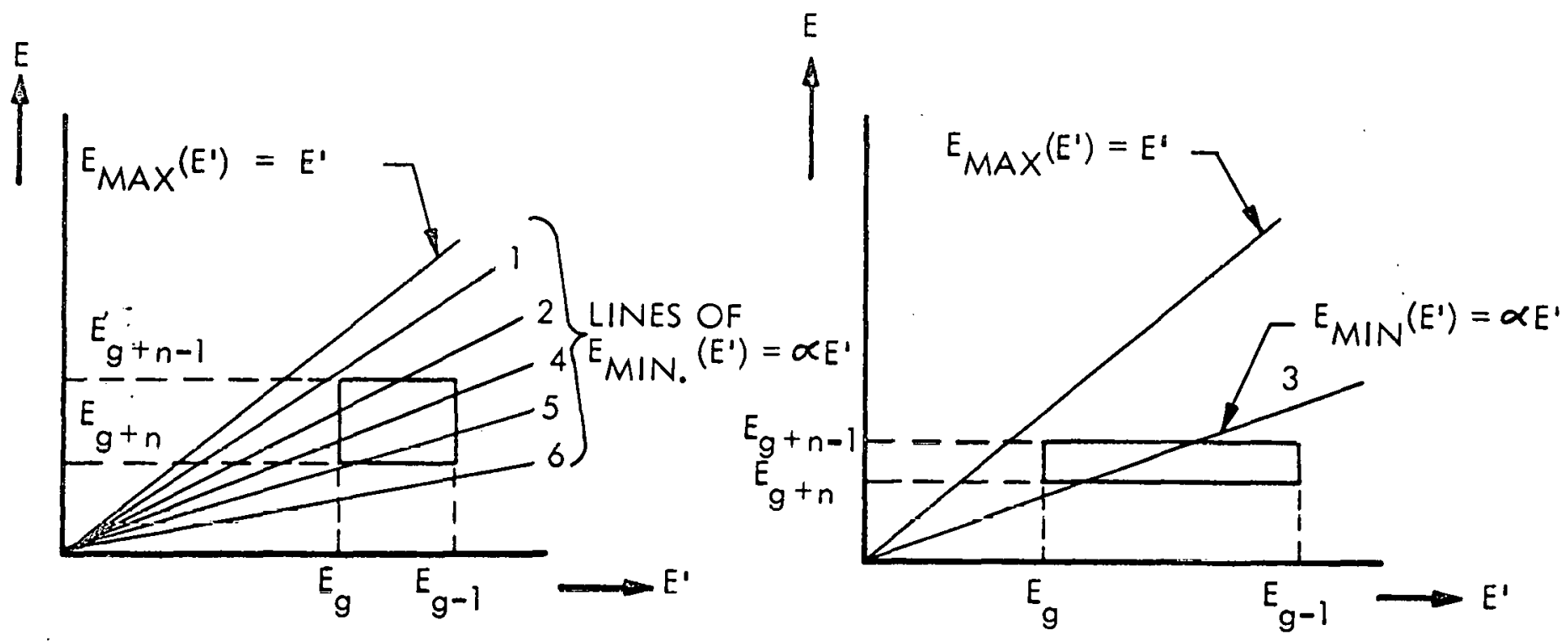

FIGURE B-4. THE SIX POSSIBLE CASES FOR OUT-OF-GROUP SCATTERING 


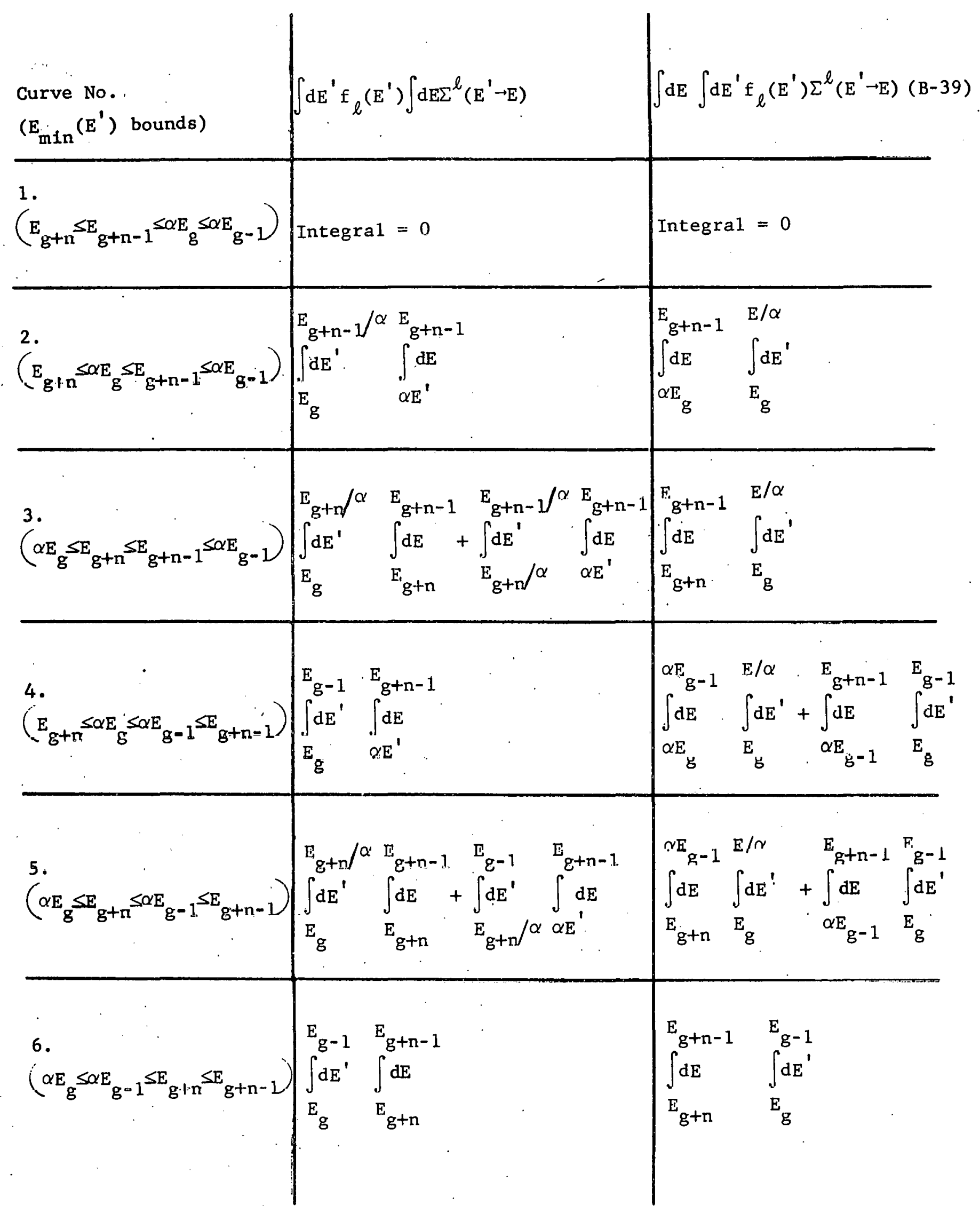




\section{REFERENCES - APPENDIX B}

B-1 Evans, R.D., The Atomic Nucleus, McGraw-Hi11, 1955, Ch. 12

B-2 Friedman, B., "Principles and Techniques of Applied Mathematics," Ch. 3, John Wiley and Sons (1956)

B-3 Weinberg, A.M. and E.P. Wigner, The Physical Theory of Neutron Chain Reactors, University of Chicago Press, 1958 


\section{APPENDIX C \\ THE MULTIGROUP TRANSPORT APPROXIMATTON}

When the series expansion is terminated at a finite value the transport approximation is used to include the effects of higher order scattering. This approximation has been investigated extensively for the energy dependent (Ref. C-1) and multigroup (Ref. C-2, C-3) cases jn the isotropic approximation;much less extensively in the linear anisotropic approximation (Ref. C-4). G. Hansen (Ref. C-5) has expressed the general multigroup approximation with arbitrary termination of the scattering expansion.

In this appendix, the multigroup transport approximation is developed and then simplified to the monogroup case. Next, the resultant scattering law is investigated; and finally, the results for the isotropic and linear anisotropic cases are explicitly given as these approximations are programmed in this code.

\section{DEVELOPMENT OF THE TRANSPORT APPROXIMATION}

A. THE DERIVATION

The transport approximation is the correction to the cross sections that is used to allow for the effects of higher order scattering in transport theory when the scattering expansion is terminated at a given $\ell^{\text {th }}$ mode. This development starts with the multigroup expression for the transport equation, Equation (B-3), in conjunction with Equation (B-6).

$$
\begin{gathered}
{\left[\vec{\Omega} \cdot g_{x}+\Sigma_{t}\right]_{f}(\vec{\Omega})=\sum_{\ell=0}^{\infty} \sum_{g^{\prime} \leq g} \Sigma_{l_{g^{\prime}} \rightarrow g} \sum_{m=-l}^{+\ell} P_{\ell m}(\vec{\Omega}) f_{l m_{g}}} \\
+s_{g}(\vec{\Omega}) \\
c-1
\end{gathered}
$$


The term, $\Sigma_{l_{0}} \sum_{g}^{\infty} \sum_{l=0}^{+l} P_{l m}{ }_{l m}^{(\vec{\Omega}) f_{\ell m}}$ is substracted from this equation, where $\Sigma_{\ell_{0}}$ is as yet undefined. The result is

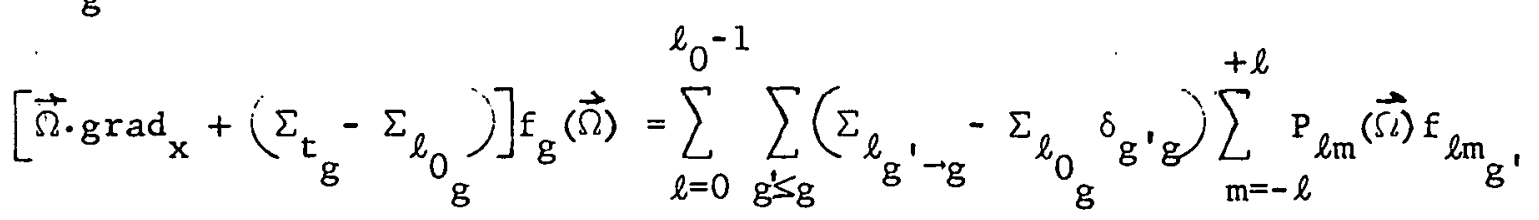

$$
\begin{aligned}
& +S_{g}(\vec{\Omega})+R
\end{aligned}
$$

where ${ }^{{ }_{g}} \mathrm{~g}^{\prime} \mathrm{g}$ is the Kronecker delta and the remainder, $\mathrm{R}$, is equal to

$$
R=\sum_{l=l_{0}}^{\infty} \sum_{g^{\prime} \leq g^{\prime} g^{\prime} \rightarrow g} \sum_{m=-l}^{+l} \mathrm{P}_{\ell m}(\vec{\Omega}) \mathrm{f}_{\ell \mathrm{m}_{g^{\prime}}}-\Sigma_{l_{0}} \sum_{g}^{\infty} \sum_{\ell=l_{0}}^{+l} \mathrm{P}_{\ell=-l}(\vec{\Omega}) \mathrm{f}_{\ell m_{g}}
$$

To put Equation (C-2) into the usual multigroup format in which $l$ is terminated at $\ell_{0}-1, R$ is required to be equal to zero. This then defines the unknown cross section, $\Sigma_{l_{0}}$.

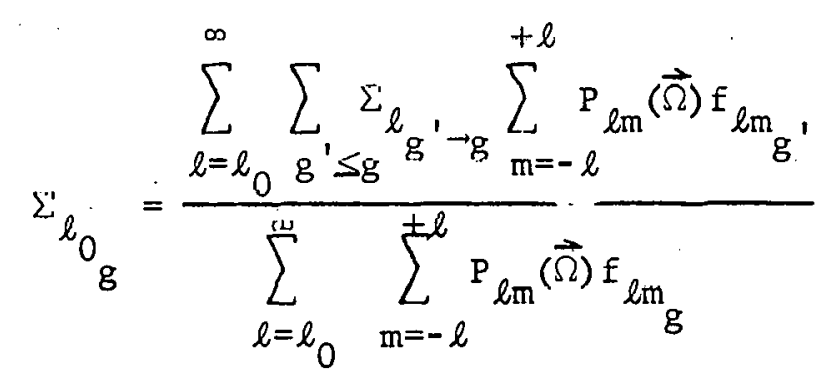

Equation (C-2) with $R$ equal to zero, is therefore, equal to the exact multigroup expression, Equation $(\mathrm{C}-1)$, if $\Sigma_{\ell_{0}}$ is defined by Equation (C-4). Thus, $\Sigma_{\ell_{0}}$ is the "transport correcting" cross section which introduces the higher scattering moments into the equation where $l$ is terminated at $\ell=\ell_{0}-1$. Actually, $\Sigma_{\ell_{0}}$ from Equation $(\mathrm{C}-4)$ is in an unusable form as 
it requires the complete solution of the multigroup equation and because it is a function of direction as well as energy. The simplifications of this expression lead to the transport approximation.

The multigroup transport approximation is obtained by rewriting Equation (C-4) in the form

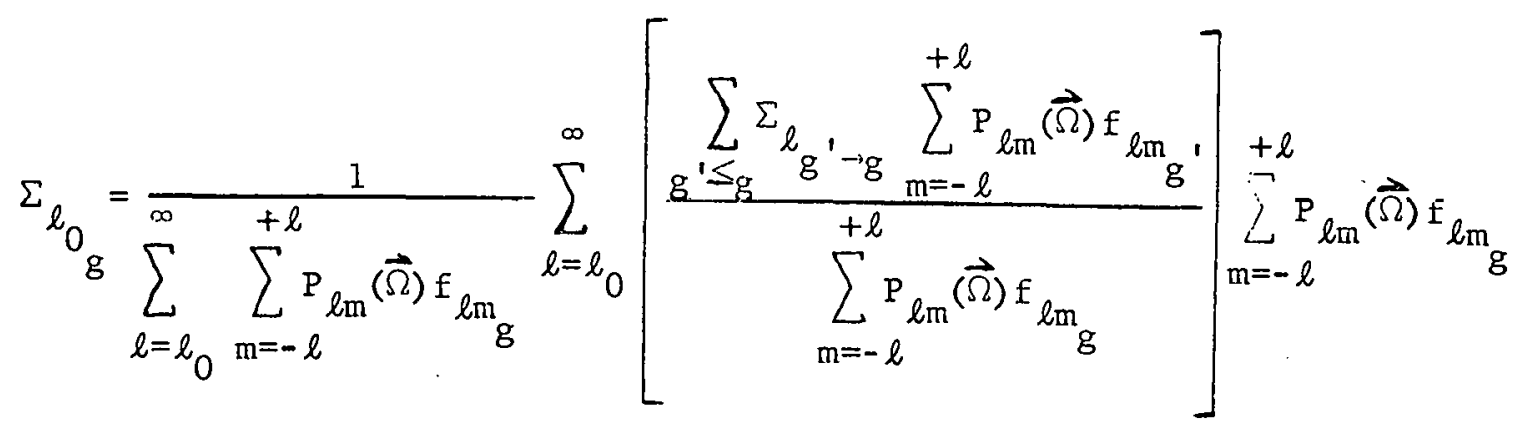

If it is assumed that the term inside the square brackets is independent of $l$ and is equal to its value at $l=l_{0}$, this term may be taken outside of the summation

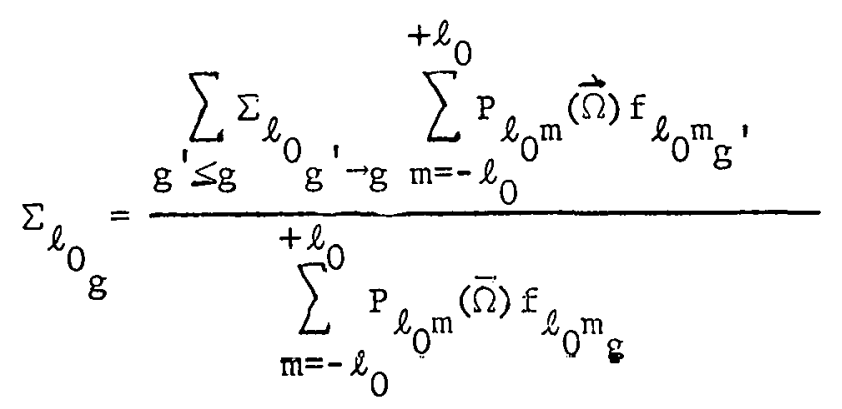

If in Equation ( $C-5$ ) the term in square brackets is a decreasing monotonic function of $l$, then $\Sigma_{l_{0}}$, as given by Equation $(C-6)$, furnishes an upper bound to the exact function. However, this last expression is still a function of direction. To remove this dependence, the assumption is made that over the entire energy range $g{ }^{\prime} \leq g$ such that $\Sigma_{l_{0}}$ is non-zero,

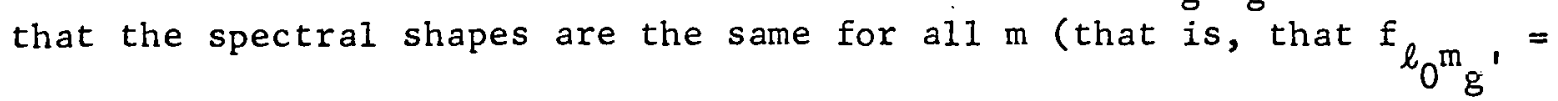
${ }^{a}{ }_{\ell_{0}}{ }^{f}{ }_{l_{0}}$, where $a_{\ell_{0} m}$ is not a function of the energy groups). Under this assumption the directional dependence cancels out to yield the multigroup $l_{0}$ type transport approximation: 


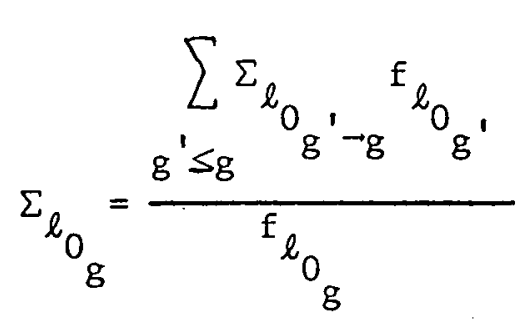

Now, Equation ( $\mathrm{C}-7$ ) may be simplified further by considering the case in which the only anisotropic scattering is elastic. (This approach also holds for anisotropic inelastic scattering.) It is assumed that over the energy range of interest (e.g., over the groups $g^{\prime}$ ), both the $l_{0}^{\text {th }}$ mode lethargy scattering density, $\Sigma_{s}\left(u^{\prime}\right) f_{\ell_{U}}\left(u^{\prime}\right)$ and the angular distribution coefficients $g_{\ell^{\prime}}\left(u^{\prime}\right)$, are constants. Under these assumptions, the numerator on the right hand side of Equation ( $\mathrm{C}-7)$ becomes

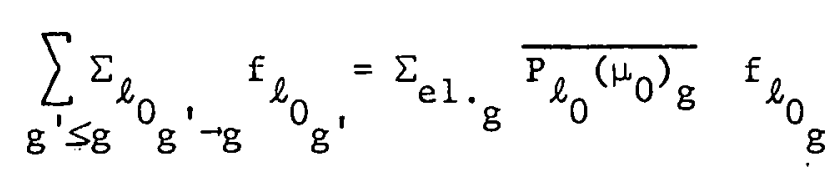

where

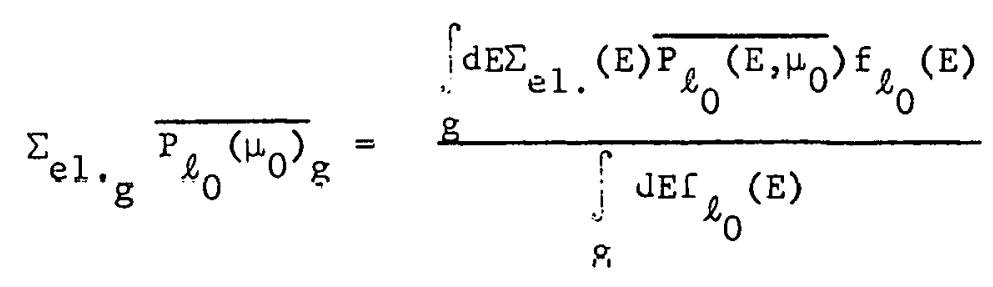

and where $\overline{\mathrm{P}_{l_{0}}\left(E, \mu_{0}\right)}$ is identical with the angular distribution coefficients in the L system, $f_{\ell_{0}}(E)$ (Equation $(B-34)$ ). By substituting Equation (C-8) into Equation ( $\mathrm{C}-7$ ) the usual monogroup $\ell_{0}$ type transport approximation is obtained

$$
\Sigma_{\ell_{0}}=\Gamma_{\mathrm{el}} \frac{\mathrm{P}_{\ell_{0}}\left(\mu_{\mathrm{o}}\right)_{\mathrm{g}}}{}
$$

The group transport correcting cross section can be postulated as a $l_{0} f l u x$ average of an energy dependent counterpart:

$$
\Sigma_{\ell_{0}}=\frac{\int \mathrm{dEF}_{\ell_{0}}(E) \Sigma_{\ell_{0}}(E)}{\int_{\mathrm{g}} \mathrm{dEf}_{\ell_{0}}(E)}
$$


This indicates that; in the multigroup approximation:

$$
\Sigma_{\ell_{0}}(E)=\frac{\int d E^{\prime} f_{\ell_{0}}\left(E^{\prime}\right) \Sigma_{\ell_{0}}\left(E^{\prime-E}\right)}{f_{\ell_{0}}(E)}
$$

and in the monogroup approximation:

$$
\Sigma_{\ell_{0}}(E)=\Sigma_{e l .}(E) \overline{P_{\ell_{0}}\left(E, \mu_{0}\right)}
$$

\section{B. THE CORRESPONDING SCÁTTERJNG LAW}

In the development of the multigroup transport relation, Equation $(C-1)$, the transference function was expressed as an expansion in Legendre polynomials. It is therefore advantageous to determine the resultant form for the transference function after making the transport approximation. This requires working backwards from the pertinent multigroup equations to the energy dependent case.

Now, the multigroup transport equation with transport approximation is equal to Equation $(\mathrm{C}-2)$ with $\mathrm{R}=0$. The terms in this relation that correspond to the collision integral, are:

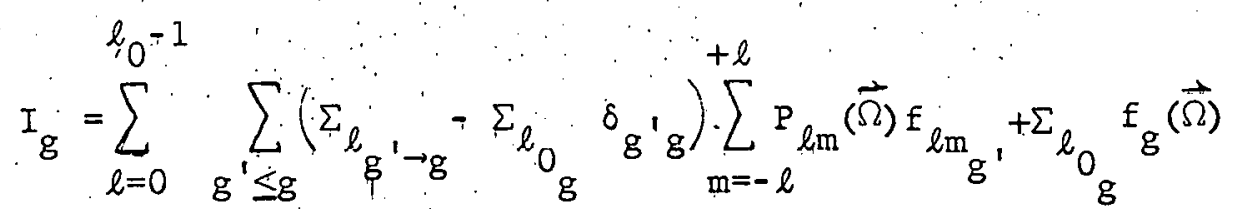

which may also be written as

$$
\begin{aligned}
& \ell_{0} \div 1+l+l
\end{aligned}
$$

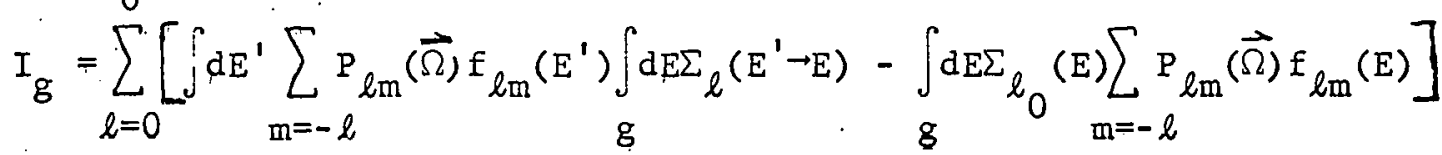

$$
\begin{aligned}
& +\sum_{l=0}^{\infty} \int_{g} \mathrm{dE} \Sigma_{\ell_{0}}(E) \sum_{\mathrm{m}=-l}^{+\ell} \mathrm{P}_{\ell \mathrm{m}}(\vec{\Omega}) \mathrm{f}_{\ell \mathrm{m}}(E)
\end{aligned}
$$


where in the first term, the assumptions regarding the spectral averaging of the group transfer cross section has been neglected (see Equations (B-4) and $(B-5))$. In addition, $\Sigma_{\ell_{0}}(E)$, as expressed in Equation (C-15), corresponds to this term as previously mentioned in Equation (C-11), but only, if the various $l^{\text {th }}$ mode spectra differ from the spectrum of the $l_{0}^{\text {th }}$ mode by constant factors.

The multigroup collision integral is defined by the relation

$$
I_{g}=\int_{g} d E I(E)
$$

Therefore:

$$
\begin{aligned}
& I(E)=\sum_{\ell=0}^{\ell_{0}-1} \int \mathrm{d} E^{\prime}\left[\Sigma_{\ell}\left(E^{\prime}-E\right)-\Sigma_{\ell}\left(E^{\prime}\right) \delta\left(E^{\prime}-E\right)\right] \sum_{\mathrm{m}=-\ell}^{+\mathrm{P}_{\ell}}(\vec{\Omega}) \mathrm{E}_{\ell \mathrm{m}}\left(E^{\prime}\right) \\
& +\sum_{l=0}^{\infty} \int \mathrm{d} E^{\prime} \Sigma_{\ell_{0}}\left(E^{\prime}\right) \delta\left(E^{\prime}-E\right) \sum_{m=-l}^{+\ell} P_{\ell m}(\vec{\Omega}) E_{\ell m}\left(E^{\prime}\right)
\end{aligned}
$$

Next the integral form of the angular flux components (see Equation A-8)) and the addition theorem for the spherical harmonics are used to obtain

$$
\begin{aligned}
I(E)= & \sum_{\ell=0}^{\ell_{0}-1}\left(\frac{2 \ell+1}{4 \pi}\right) \int \mathrm{d} E^{\prime}\left[\Sigma_{\ell}\left(E^{\prime} \rightarrow E\right)-\Sigma_{\ell_{0}}\left(E^{\prime}\right) \delta\left(E^{\prime}-E\right)\right] \int \mathrm{d} \Omega^{\prime} f\left(E^{\prime}, \vec{\Omega}^{\prime}\right) P_{\ell}\left(\mu_{0}\right) \\
& +\int d E^{\prime} \Sigma_{\ell}\left(E^{\prime}\right) \delta\left(E^{\prime}-E\right) \int d \Omega^{\prime} f\left(E^{\prime}, \vec{\Omega}^{\prime}\right) \sum_{\ell=0}^{\infty}\left(\frac{2 \ell+1}{4 \pi}\right) P_{\ell}\left(\mu_{0}\right) P_{\ell}(1)
\end{aligned}
$$

where the identity, $\mathrm{P}_{\ell}(1)=1$, has been used.

The expansion of the delta function. in Legendre polynomials yields

$$
\delta_{2}\left(\vec{\Omega} \cdot \vec{\Omega}^{\prime}\right)=\frac{\delta\left(\mu_{0}-1\right)}{2 \pi}=\sum_{\ell=0}^{\infty}\left(\frac{2 \cdot l+1}{4 \pi}\right) \mathrm{P}_{\ell}(1) \mathrm{P}_{\ell}\left(\mu_{0}\right)
$$


where the angular delta function, $\delta_{2}\left(\vec{\Omega} \cdot \vec{\Omega}^{\prime}\right)$, has the property

$$
\int \delta_{2}\left(\vec{\Omega} \cdot \vec{\Omega}^{\prime}\right) \mathrm{f}\left(\vec{\Omega}^{\prime}\right) \mathrm{d} \Omega^{\prime}=\mathrm{f}(\vec{\Omega})
$$

If this result is substituted into Equation $(C-16)$ and compared with the collision integral in the energy dependent Boltzmann equation, the expression for the transference function, after use of the transport approximation, is obtained.

$$
\begin{aligned}
\Sigma\left(E^{\prime} \rightarrow E, \vec{\Omega} \rightarrow \vec{\Omega}\right) & =\sum_{\ell=0}^{\ell_{0}^{-1}} \frac{2 \ell+1}{4 \pi}\left[\Sigma_{\ell}\left(E^{\prime} \rightarrow E\right)-\Sigma_{\ell_{0}}\left(E^{\prime}\right) \delta\left(E^{\prime}-E\right)\right] P_{\ell}\left(\mu_{0}\right) \\
& +\Sigma_{\ell_{0}}\left(E^{\prime}\right) \delta\left(E^{\prime}-E\right) \delta_{2}\left(\vec{\Omega} \cdot \vec{\Omega}^{\prime}\right)
\end{aligned}
$$

The $\ell_{0}$ type transport approximation is thus equivalent to replacing the actual anisotropic scattering distribution by a finite expansion up through $\ell_{0}-1$, plus a forward directed component. The energy transfer moments are defined by Equation (B-2) in conjunction with the energy dependent form of Equation (B-6), and if the transference function from Equation ( $C-17)$ is used in these relations, the following is obtained:

$$
\begin{array}{ll}
\Sigma_{\ell}\left(E^{\prime} \rightarrow E\right) & =2 \pi j_{\text {trans. approx. }}^{+1} \Sigma\left(E^{\prime} \rightarrow E, \vec{\Omega}^{i}-\vec{\Omega}\right) P_{\ell}\left(\mu_{0}\right) d \mu_{0}=\Sigma_{\ell}\left(E^{\prime} \rightarrow E\right) \\
-1
\end{array}
$$

Thus, all moments up through $\ell=\ell_{0}-1$ are preserved and used. The inclusion of the $\ell_{0}^{\text {th }}$ moment is through $\Sigma_{\ell_{0}}(E)$.

If the scattering distribution is a forward directed delta function, or if the expansion coefficients vanish for $l \geq l_{0}$, the $l_{0}$ type transport approximation is exact. For the first case; one has $\Sigma_{\ell}\left(E^{\prime} \rightarrow E\right)=\Sigma_{s}\left(E^{\prime}\right) \delta\left(E^{\prime}-E\right)$ and $\Sigma_{\ell_{0}}\left(E^{\prime}\right)=\Sigma_{s}\left(E^{\prime}\right)$. The second case is easily verified in Equation (C-17) since then, $\Sigma_{\ell_{0}}\left(E^{\prime}\right)=0$. 
II. USE OF THE TRANSPORT APPROXIMATION

A. THE MULTIGROUP RELATION AS USED

The transport approximation finds its major use in $S_{n}$ transport codes (Ref. C-6). The general multigroup $s_{n}$ type of equation, with the angular description left open as not of interest is

$$
\left[\vec{\Omega} \cdot \operatorname{grad}_{x}+\Sigma_{g}\right] f_{g}(\vec{\Omega})=s_{g}+\sum_{g^{\prime} \leq g} s_{s^{\prime}} s_{g}
$$

where the scattering source term $\sum_{g^{\prime} s g} s_{s_{g}}{ }^{\prime} \rightarrow g$ involves the usual finite sum T.egendre expansion.

B. CASES OF IMMEDIATE INTEREST

The cases of immediate interest are those of isotropic and 1 inear anisotropic sçattering since these scattering options are available in the LASL family of $S_{n}$ programs (Ref. $C-7$ ). The form of the group cross section, $\Sigma_{g}$, and of the scattering matrices, are primarily of interest.

A comparison of Equation (C-19) with Equation (C-2) gives for the isotropic $\left(l_{0}=1\right)$ transport approximation: 


$$
\begin{aligned}
& \Sigma_{g}=\Sigma_{t}-\Sigma_{1_{g}} \\
& s_{s_{g^{\prime} \rightarrow g}}=\Sigma_{0} g_{g^{\prime} \rightarrow g} \varphi_{g^{\prime}} \quad\left(g^{\prime} \neq g\right) \\
& s_{s_{g \rightarrow g}}=\left(\Sigma_{0}-\Sigma_{l_{g}}\right) \varphi_{g} .
\end{aligned}
$$

Similarly, for the linear anisotropic $\left(\ell_{0}=2\right)$ case:

$$
\begin{aligned}
& \Sigma_{g}=\Sigma_{t_{g}}-\Sigma_{2} \\
& \mathrm{~S}_{\mathrm{s}_{\mathrm{g}^{\prime} \rightarrow \mathrm{g}}}=\Sigma_{0_{\mathrm{g}^{\prime} \rightarrow \mathrm{g}^{\prime}}} \varphi_{\mathrm{g}^{\prime}}+\Sigma_{\mathrm{g}^{\prime}-\mathrm{g}}\left(3 \vec{\Omega} \cdot \vec{J}_{\mathrm{g}^{\prime}}\right) \ldots \quad\left(\mathrm{g}^{\prime} \neq \mathrm{g}\right) \\
& \mathrm{s}_{\mathrm{s}_{\mathrm{g} \rightarrow \mathrm{g}}}=\left(\Sigma_{0}-\Sigma_{\mathrm{g} \rightarrow \mathrm{g}}\right) \varphi_{\mathrm{g}}+\left(\Sigma_{1_{\mathrm{g} \rightarrow \mathrm{g}}}-\Sigma_{2}\right)\left(3 \vec{\Omega} \cdot \overrightarrow{\mathrm{J}}_{\mathrm{g}}\right)
\end{aligned}
$$

The transport correcting cross sections are given either by Equation (C-7) in the multigroup approximation or by Equation $(C-10)$ in the monogroup approximation. 


\section{REFERENCES - APPENDTX C}

C-1 G. Rakavy and Y. Yeivin, "The Transport Approximation of the EnergyDependent Boltzmann Equation," Nuclear Science Eng., 15, 158 (1963)

C-2 G. D. Joanou, and A. Halim Kazi. "The Validity of the Trancport Approximation in Fast-Reactor Calculations," Trans. Amer. Nuclear Soc., $\underline{6}$, No. 1, p. 17, (1963)

C-3 E. D. Pendlebury and L. H. Underhill, "The Validity of the Transport Approximation in Critical-Size and Reactivity Calculations," Physics of Fast and Intermediate Reactors, Vol. 2, IAEA, p. 73 (1961)

C-4 Anisotropic Scattering in the Transport Equation, LAMS-2873, Apr. 1963, K. D. Lathrop

C-5 Transport Approximation and Anisotropic Sources, Tnterna1 T.A.ST Memerandum N-2-1511, Oct. 1959, G. E. Hansen

C-6 The Discrete S Approximation to Transport Theory, LA-2595, March 1962, C. E. Lee

C-7. The DSN and TDC Neutron Transport Codes, LAMS-2346, Feb 1960, B. Carlson, et al., Also interial LASL documents on the DTK and DDK codes. 


\section{APPENDIX D}

AGN-GAM DATA TAPE \#1003

A library data tape has been written for use with the AGN version of. the GAM fast cross section code. This appendix explains what data is available on the tape and the source of this information.

The AGN-GAM library tape contains three types of information; the resonance tables which permit calculation of resonance integrals from basic parameters and input geometry; source spectra of neutrons as a function of energy; and material cross section data.

Resonance tables containing approximately 13,500 numbers are provided for spherical, cylindrical and slab geometries.

Ten source spectra are included on the present library tape. These permit the GAM code to calculate fluxes, currents, and the Fermi age for both delayed and prompt U-235; for U-235, Plutonium, and Californium fission; and for $\mathrm{Po}-\mathrm{Be}$ and $\mathrm{Ra}-\mathrm{Be}$ sources.

Nuclear cross section data, for a total of 182 different materials, are included on tape number 1003. These data include the microscopic absorption, elastic scattering, inelastic scattering, $n-2 n$ reaction, fission, and $\nu$ for each of seventy-five groups of one-quarter lethargy unit in width in the energy range from $10 \mathrm{Mev}$ to $0.07 \mathrm{ev}$. Complete scattering matrices are included for the elastic (both the $P_{0}$ and $P_{1}$ terms), inelastic, and ( $n-2 n$ ) reactions. Of the matextals present on the data tape, 36 are naturally occurring elements, 26 are mixtures (i.e., water and stainless steel), 7 are 
fission product groupings, 104 are specific individual isotopes, and 9 are elements which have been added for the special resonance absorption and fission calculations. Room for thirty-one additional entries has been left for future additions.

The microscopic cross sections on this data tape have been obtained from physical measurements of cross sections. They have not been normalized to any specific reactor system, but they do produce good results when used properly.

\section{ENERGY GROUPS}

The present library tape has been established with 75 fine groups. Each group is one-quarter-lethargy unit wide with the top energy at $10 \mathrm{Mev}$. Table D-1 lists the energy and lethargy limits of each group .

\section{RESONANCE TABLES}

The resonance tables on the AGN-GAM data tape were taken from the GAM data tape (101) supplied to AGN by General Atomic. The data from the original tape were transferred to cards by an IBM machine, to eliminate manual keypunching and data transcribing errors, and then added to the AGN tape. Tabular data thus obtained have been compared with published GA documents (Ref. D-1, D-2) to check their validity. No errors were found but the tables included on the data tape are more extensive than those published in the reference documents.

\section{SOURCES}

Ten sources (1isted in Table D-2) are available for use in the AGN-GAM data tape. Eight sources came from the original GA tape while two were added from data generated at AGN. The two added sources, numbers 1 and 3 , are for the delayed neutron spectrum from U-235 fission products (Ref. D-3), and the delayed plus prompt U-235 fission spectrum. The latter source is a combination of spectra 2 and 3 . 
TABLE D-1

AGN-GAM FAST CROSS SECTIION LIBRARY TAPE 1003 FINE GROUP BOUNDKIES

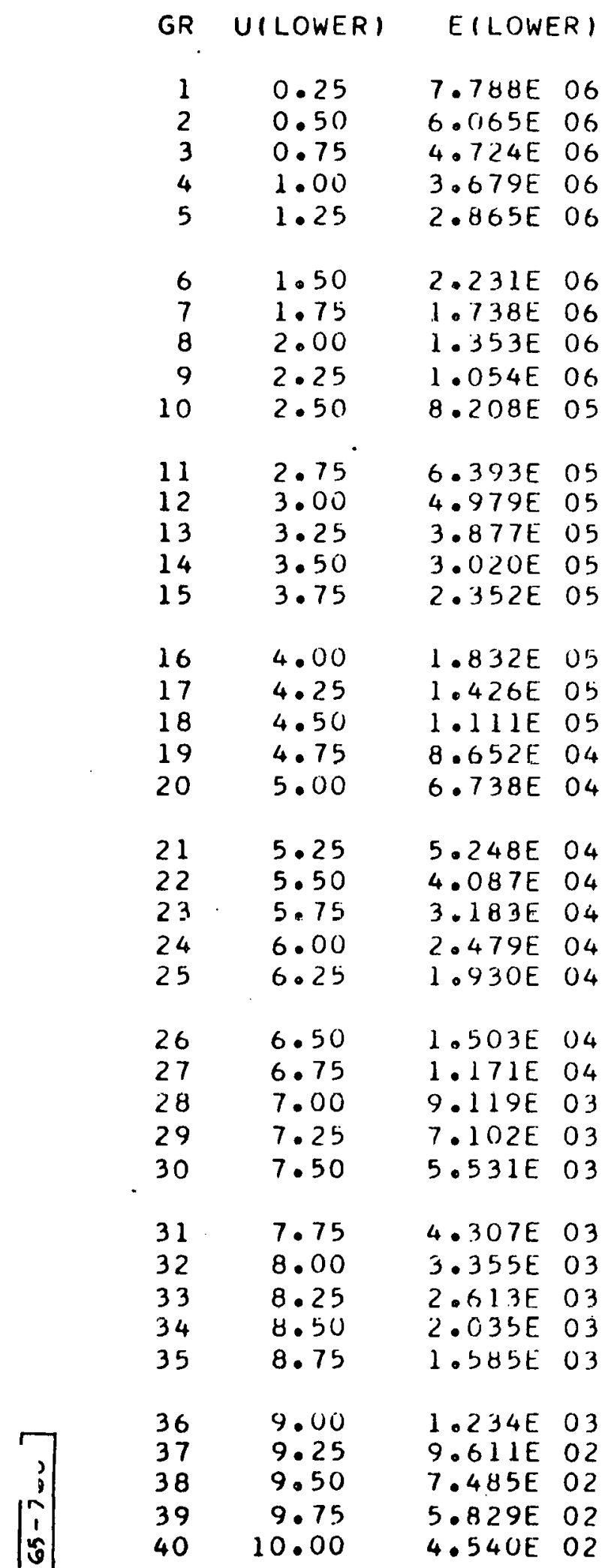

GR U(LOWER) E(LOWER)

$\begin{array}{llll}41 & 10.25 & 3.536 E & 02 \\ 42 & 10.50 & 2.754 E & 02 \\ 43 & 10.75 & 2.145 E & 02 \\ 44 & 11.00 & 1.670 E & 02 \\ 45 & 11.25 & 1.301 E & 02 \\ & & & \\ 46 & 11.50 & 1.013 E & 02 \\ 47 & 11.75 & 7.889 E & 01 \\ 48 & 12.00 & 6.144 E & 01 \\ 49 & 12.25 & 4.785 E & 01 \\ 50 & 12.50 & 3.727 E & 01\end{array}$

$\begin{array}{llll}51 & 12.75 & 2.902 E & 01\end{array}$

$\begin{array}{lll}52 & 13.00 \quad 2.260 E & 01\end{array}$

$53 \quad 13.25 \quad 1.760 E \quad 1$

$54 \quad 13.50 \quad 1.371 E \quad 1$

$\begin{array}{lll}55 & 13.75 \quad 1.068 E & 01\end{array}$

$56 \quad 14.00 \quad 8.315 E \quad 00$

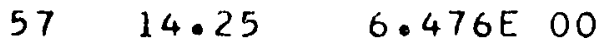

$58 \quad 14.50 \quad 5.043 E \quad 00$

$59 \quad 14.75 \quad 3.928 E 00$

$60 \quad 15.00 \quad 3.059 E 00$

$61 \cdot 15.25 \quad 2.382 \mathrm{E} 00$

$62 \quad 15.50 \quad 1.855 E 00$

$63 \quad 14.75 \quad 1.445 \mathrm{E} 00$

$64 \quad 16.00 \quad 1.125 \mathrm{E} 00$

$65 \quad 16.25 \quad 8.764 E-01$

$66 \quad 16.50 \quad 6.826 E-01$

$67 \quad 16.75 \quad 5.316 E-01$

$68 \quad 17.00 \quad 4.140 E-01$

$69 \quad 17.25 \quad 3.224 E-01$

$70 \quad 17.50 \quad 2.511 E-01$

$71 \quad 17.75 \quad 1.956 E-01$

$7218.00 \quad 1.523 E-01$

$73 \quad 18.25 \quad 1.186 E-01$

$74 \quad 18.50 \quad 9.237 E-02$

$75 \quad 18.75 \quad 7.194 E-02$ 
TABLE D-2

AGN-GAM FAST CROSS SECTIUN LIBKARY TANE 1003

1 JULY 1964

SOURCES

$\begin{array}{lll}1 & U-235 & \text { PROMPT + DELAYED } \\ 2 & U-235 & \text { PROMPT } \\ 3 & U-235 & \text { DELAYED (CRANBERG) } \\ 4 & U-233 & \text { (SMITH) } \\ 5 & \text { (KUEPIN) } & \\ & & \\ 6 & \text { (NERESON) } & \\ 7 & \text { CF }-252 & \text { (SMITH) } \\ 8 & \text { PO-BE } & \text { (SMITH) } \\ 9 & \text { PO-BE } & \text { (WHITMORE AND BAKER) } \\ 10 & \text { RA-BE } & \text { (HILLI) }\end{array}$


IV. MATERIAL CONSTANTS

A. GENERAL

The material constants on the AGN-GAM data tape were compiled from a number of different sources. Each of these sources is discussed and sufficient information is provided to describe the data obtained for each material. Complete data for each material is not provided in this document (a complete printout of the tape would take 800 full pages).

The materials on the library tape are listed in alphabetic order in Table $\mathrm{D}-3$ and by numerical and type-of-use arrangement in Table $\mathrm{D}-4$.

B. DATA ORIGINATED AT AGN

The cross section data for 33 elements have been generated at AGN, and thirty-one of these are listed in Table D-5. The other two are free and bound hydrogen.

The inelastic scattering matrix was generated for these materials by the solution of the statistical inelastic scattering model. A full description of this solution is contained in Appendix B. Appendix E explains the use of the INSECT code to calculate the required numerical results. The one input required to these equations, a constant $C$, is listed for each material in Table D-5.

The $P_{0}$ and $P_{1}$ elastic scattering matrices were based on the solution of the standard equations as given in the GAM-I report (Ref. D-4, Appendix $B)$. The matrices were calculated and punched directly onto cards, by the POP 1 program (Appendix E). Table D-6 1ists the values of $\eta\left(\eta=\bar{\mu}^{\prime}\right.$, the average cosine of the scattering angle in the CM system), used for each material. Due to the lack of angular data, for several elements $\eta$ 's from adjacent materials were used. Thus, for mercury the data of lead were used, for silver those of cadmium, for manganese those of chromium, and for europium, samarium, and gadolinium those of tungsten.

Because of the fact that the $(n, 2 n)$ reaction in AGN cross sections is treated by a change in the absorption and inelastic cross sections, the absence of a specific $(n, 2 n)$ cross section does not lignify neglect of this reaction. 
TABLE D-4

AGN-GAM FAST CROSS SECTION LIBRARY TAPE 1003 I JULY 1964

MODERATOR MATERIALS

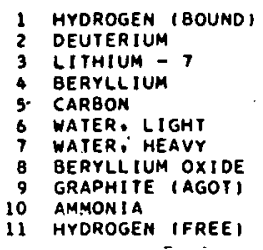

FUEL MATERIALS

13 URANIUM - 233

14 URANIUM - 234
15 URANIUM -235 IINF.DIL

16 URANIUM - 236

7 URANIUM - 238 IINF. OIL.1

PROTACTINIUM-233

9 NEPTUNIUM - 239

PLUTONIUM - 239

2 PLUTONIUM - 241

PLUTONIUM - 242

4 THORIUM IINF. DIL.

25 URANIUM - NATURAL

26 URANIUM-FULLY ENRICHEO (ML-1)

27 URANIUM DIOXIDE-FULLY ENRICHED

STRUCTURAL MATERIALS

ELEMENIS

30 LITHIUM

32 OXYGEN

34 MAGNESIUM

36 SILICON

40 TITANIUM

42 CHROMIUM

43 MANGANE
44 IRON

45 COBALT

46 NICKEL

47 COPPER

SO YTTRIUM

II ZIRCONIUM

52 NIOBTUM (COLUMBIUM)

S3 MOLYBOENUM IINF. DIL

54 TUNGSTEN

\begin{tabular}{l}
55 \\
56 \\
$5 E S I U M A$ \\
\hline
\end{tabular}

57 LEAD

ST LEAD

SIRUCTURAL MATERIALS

MIXTURES

39 GTAlMLESS GTCEL - THE 904

60 STAINLESS STEEL - TYPE 316

61 STAINLESS STEEL - TYPE 321

62 STAINLESS STEEL - TYPE 347

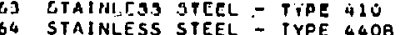

64 STAINLESS STEE

66 HASTELLOY

67 INCONEL -

68 FECRAL

69 ALUMINUM - TYPE 6061

1 HAYNES - 25

72 ALIUMINIJY OXINF

73 MAGNESIUM OXIDE

75 REFRASIL

POISON MATERIALS

a1 BORON

82. CADMIUM IINF OILI

83 EUROPIUM IINF DIL

B4 SAMARIUM IINF DIL

85 INDIUM IINF OIL)

B6 SILVER IINF. OILI

98 CóNPROL BLADE

91 GADOLINIUM

FISSION PRODUCTS

93 FISS. PROD. - TOIAL $(U-235)$

94 FISS. PROD. - NON-SAT. (U-235

95 FISS. PROD. - SLOW SAT IU-235

96 FISS. PQOD. - GD-1ES

97 FISS. PROD. - XE-13

98 FISS. PROD. - SM-1S9
RESONANCE MATERIALS

100 THORIUM

101 URANIUM-235

102 URANIUM-238

103 TUNGSTEN

104 MOLYBOENUM

105 SILVER

107 INDIUM

108 SAMARIUM

INOIVIOUAL I SOTOPES

121 SELENIUM - O2

22 BROMINE - 82 IABS

122 BROMINE - 81 TABS

KRAPTON = B4 IABSI

25 KRYPTON - O5 (ABS

126 . RUYPION - 86 TABSI

128 RUBIDIUM - 87 IABSI

129 STRONTIUM - B8 (ABS)

130 STRONTIUM - 90 (ABS)

131 IIRCONIUM - 90 (ABSI

132 ZIRCONIUM - 91 (ABS)

133 ZIRCONIUM - 92 (ABSI

34 ZIRCONIUM - 93 (ABS)

35 ZIRCONIUM - 94 (ABS)

136 ZIRCOHIUM - 96 (ABS)

137 MOLYBOENUM - 95 (ABS)

138 MULYHOENUM - Y6 (ABS)

139 MOLYBDENUM - 97 (ABSI

140 MOLYBDENUM - 98 (ABS)

141 MOLYBDENUM - 100 (ABS)

142 TECHNETIUM - 99 (ABS)

143 RUTHENIUM - 100 - (ABS)

144 RUTHENIUM - 101 (ABS)

145 RUTHENIUM - 102 (ABS)

146 . RUIHENIUM - 104 (ABS)

147 RHODIUM - 103 (ABS)

49 PALLADIUM - 105 (ABSI

150 PALLAOIUM - 100 LABSI

51 PALLADIUM - 107 (ABS)

152 PALLADIUM - 108 (ABS)

PALLADIUM - 110 IABSI

155 INDIUM - 115 (ABS)

156 CADMIUM - 110 (ABS)

157 CADMIUM - 111 (ABS)

150 CADMIUM - 112 (ABS)

159 CAOMIUM - 113 (ADS)

160 CADMIUM - 114 TABSI

161 TELLURIUMA - 126 (ABS)

163 TELLURIUM - 130 (ABS)
(ABS)

164 IODINE -127 (ABS)

165 IODINE - 129 (ABS)

166 XENON - 128 (ABS)

167 XENON - 130 (ABS)

XENON - 131 (ABS)

169 XENON - 132 (ABS)

171 XENON - 139 (ABS)

172 CESIUM - 133 (ABSI

173 CESIUM - 135 IABS

174 CESIUM - 137 (ABS)

175 BARIUM - 134 (ABS)

176 BARIUM - 136 IABS

177 BARIUM - 137 (ABS

178 BARIUM - I38 (ABSI

179 LANTHANUM - 139 (ABS)

ISU CENIUM - 1WU (ADS)

102 PRASEODYMIUM - 141 (ABSI

183 NEODYMIUM - 142 . IABS

184 MEODYMIUM - 143

105 NEODYMIUM - 144

186 NEODYMIUM - 145

187 NEODYMIUM - 146

188 NEOOYMIUM - 148 (ABS)

189 NEODYMIUM - 150 (ABS)

190 PROMETHIUM - 147 (ABS)

191 SAMARIUM - 147 (ABS)

192 SAMARIUM - 148 (ABBS)

193 SAMARIUM - 150 (ABS)

194 SAMARIUM - 15I (ABS)

195 SAMARIUM - 152 (ABS)

196 SAMARIUM - 154 (ABS)

197 EUROPIUM - 151 (AUS)

190 EUROPIUM - 153 (ABS)

199 EUROPIUM - 154 (ABS)

1 GADOLIMIUM ISS IABSI

202 GADOLINIUM - 155 (ADS)

203 GADOLINIUM - 156 (ABSI

204 GADOLINIUM = 157 (ABS)

205 GADOLINIUM - 158 (ABSI

206 TERAIUM - 159 (ABS)

207 GOLD - 197 (ABS)

YITRIUM - 89 (ABS)

209 SAMARIUM = 149 IABSI

$2101.0 / \mathrm{V}-2$ BARN AT $2200 \mathrm{~m} / 5 E C$

211 TUNGSTEN - 182 IINF DILI

212 TUNGSTEN - 183 INF DIL

213 TUNGSTEN - 184 IINF OIL) 
TABLE D-3

AGN-GAM FAST CROSS SECTION LIBRARY TAPE 1003 I JULY 1964

ALUMINUM

ALUMINUM - TYDE 6061

ALUMINUM OXIDE

AMMONI A

35
69
12

BARIUM - 134 (ABS)

BARIUM - 136 (ABS

$\begin{array}{ll}\text { BARIUM - } 137 & \text { (ABS) } \\ \text { BARIUM - 138 } & \text { (ABS }\end{array}$

BARIUM - 13

BERYLLIUM OXIDE

BERYLLIUM OXIDE

BISTI

BROMINE - 81 LABS

CADMIUM IINF DILI

CADMIUM

CADMIUM - 110 IABSI

CADMIUM - 111 (ABSI

CADMIUM - 112 (ABSI

CADMIUM - 113 (ABS)

CARBON

CERIUM - 140 (ABS)
CERIUM - 142 (ABS)

CESIUM

CESIUIM - 133 (ABS

CESIUM $=135$ (ABS)
CESIUM -137 (ABS)

CHROMIUM

CHROMIUM

CONTROL BLADE (AG-IN-CD)

COLUMBIUM

COPPER

DEUTERIUM

EUROPIUM IINF DIL)

EUROPIUM - 151 (ABS)

EUROPIUM - 153 (ABS).

EUROPIUM - 154

ABS

(ABS)

FECRAL

FECRAL PROD - GD-1SS

FISS. PROD. - NON-SAT. $1 U-235$

FISS. PROD. - SLOW SAT IU-235I

FISS. PROD. - SM-149

FISS. PROD. - TOIAL (U-235)

FISS. PROD. - XE-135

GADOLINIUM

GADOLINIUM - 154 (ABS)

GADOLINIUM - 155 (ABS)

GADOLINIUM - 156 (ABS)

$\begin{array}{ll}\text { GADOLINIUM - } 157 & \text { (ADS) } \\ \text { GADOLINIUM - } 158 & \text { (ABS) }\end{array}$

GOLO 197 (ABS

HASTELLOY - $x$

HAYNES - 25

HYDROGEN (FREE)

I ITCUURL

INDIUM IINF DIL,

INDIUM

INDIUM - 115 IABS

I.NDIUM $=115$ IABS
IODINE -127 IABS:

IODINE = 129 IABS:

IRON

KRYPTON - 83 (ABS)

KRYPTON - 84 (ABS)

KRYPTON $=85$ (AES)
KRYPTON -86 (ABS)

LANTHANUM - 139 IAUSI

LEAD

LITHIUM

LITHIUM $=6$
LITHIUM -7

MAGNESIUM

MAGNESIUM OXIDE

MANGANESE

MERCURY

MOLYBDENUM IINF. OIL

MOL YBDENUM

MOLYBDENUM - 95 (ABS

MOLYBDENUM - 96 (ABS

MOLYEDENUM = 97 (ABS

MOLYBDENUM - 98 IABS

NEODYMIUM - 142 (ABS)

$\begin{array}{ll}\text { NEODYMIUM }-142 & \text { (ABS) } \\ \text { NEODYMIUM }-143 & \text { (ABS) }\end{array}$

$\begin{array}{ll}\text { NEODYMIUM }=143 & \text { (ABS } \\ \text { NEODYMIUM }=144 & \text { (ABS }\end{array}$

NEODYMIUM $=144$ (ABS

NEODYMIUM - 146 (ABS)

NEODYMIUM - i4B (ABS

NEODYMIUM - 150 IABS

NEPTUNIUM - 330

NICKEL

NIOBIUM IINF OIL

NITROGEN$$
\begin{aligned}
& 183 \\
& 184 \\
& 185 \\
& 186 \\
& 187 \\
& 188 \\
& 189 \\
& 19 \\
& 46 \\
& 52 \\
& 31
\end{aligned}
$$

OXYGEN

PALLADIUM - 104 (ABSS)

PALLADIUM - 105 (ABS)

PALLADIUM = 106 (AABS

PALLAOIUM - 108 (ABS)

PALLAOIUM - 110 (AABS

PLUTONIUM - 239

PLUTONIUM - 24

PLUTONIUM - 241

PRASEODYMIUM -141 (ABS

PROTACTINIUM - 141 TABS

PROMETHIUM - 147 (ABS)

REFRASIL

RHODUM - 103 (AAS)

RUBIOIUM - 85 (ABS)

HUTHENIUM - 100 (ABS)

RUTHENIUM - 101 (ABS)

RUTHENIUM - 102 (ABSI

RUTHENIUM - 104 (ABS)

SAMARIUM (INF DIL)

SAMARIUM

SAMARIUM - 147 IAHSI

SAMARIUM - 148 (ABS)

SAMARIUM - 140 (ABSI

SAMARIUM - 150 (ABS)

SAMARIUM - 151 (ABSI

SAMARIUM - 152 (ABS)

SELENIUM - 82 (ABSI

SILICON

SILVER (INF. DIL)

SILVER

SILVER - 109 (ABS)

STAINLESS STEEL - TYPE 304

STAINLESS STEEL - TYPE 316

STAINLESS STEEL - TYPE 32

SIAINLESS STEEL - TYPE 34

STAINLESS STEEL - TYPE 410

STAINLESS STEEL - TYPE $440 \mathrm{OB}$

SIRONTIUM - 8.8 IASSI
SIRONTIUM - 90

TECHNETIUM - 99 (ABS

TELLURIIJM - 126 (ABS)

TELLURIUM - 128 IABS

IELLURIUM - 130 IAUS

TERBIUM - 159 . (ABS)

THORIUM IINF DIL

THORIUM (INF. DIL)

THOR IUM

THTANIUM

TUNGSTEN IINF DIL)

- 182 IINF DILI

IUNGSTEN - 183 IINF DILI

URANIUAM - 233

URANIUM - 234

IIRAN IIIM =239 IINE DII

URANIUM - 235

URANIUM - 236

URANIUM - 238 IINF DILI

URANIUM - 230

URANIUM - NATURAL

URAN IUM-FULLY ENRICHED IML-1)

URANIUM DIOXIDE-FULLY ENRICHED

WATER, LIGHT

$\begin{array}{ll}X E N O N & -128 \\ X E N O N & 120 \\ X E N S I & 166\end{array}$

XENON - 130 (ABS) 167

XENON $=131$ (ABS) . 168

$\begin{array}{lll}X E N O N=134 & \text { (ABS) } & 179 \\ X E N O N=136 & \text { (ABS) } & 170\end{array}$

YTTRIUM

YTTRIUM - 89 (ABS) 208

ZIRCONIUM

ZIRCONIUM - 90 (ABS) 51

ZIRCONIUM - 91 (ABS)

IIRCONIIIM - 92 IAOSI 132

IIRCONIUM - 93 (ABS) 134

$\begin{array}{lll}\text { ZIRCONIUM - } 96 & \text { (ABS) } & 135 \\ & \text { (ABS) } & 136\end{array}$

1.ON - 1 BARN AT $2200 \mathrm{M} / \mathrm{SEC}$

148

150

53$$
\text { "10 }
$$ 
TABLE D-5 - CONSTANT "C" * USED IN CALCULATION OF INELASTIC SCATTERING MATRIX

\begin{tabular}{|c|c|c|c|c|c|}
\hline Number & Material & C & Number & Material & C \\
\hline & & & 50 & Yttrium & 0.3421 \\
\hline 3 & Lithium -7 & 1.2177 & 51 & Zirconium & 0.3377 \\
\hline 4 & Beryllium & 1.0745 & 52 & Niobium & 0.3347 \\
\hline 5 & Carbon & 0.9308 & 53 & Molybdenum & 0.3293 \\
\hline 15 & Uranium-235 & 0.3750 & 54 & Tungsten & 0.2379 \\
\hline 17 & Dran1um-238 & 0.2090 & 55 & Cesium & 0.2798 \\
\hline 31 & Nitrogen & 0.8619 & 56 & Mercury & 0.2277 \\
\hline 32 & Oxygen & 0.8065 & 57 & Lead & 0.3162 \\
\hline 35 & Aluminum & 0.6210 & 81 & Boron & 0.9807 \\
\hline 36 & St11con & 0.6090 & 82 & Cadmium & 0.3043 \\
\hline 40 & Titanium & 0.4661 & 83 & Europium & 0.2616 \\
\hline 42 & Chromium & 0.4473 & 84 & Samarium & 0.2631 \\
\hline 43 & Manganese & 0.4352 & 85 & Indium & 0.3010 \\
\hline 44 & Iron & 0.4316 & 86 & 3ilver & 0.3100 \\
\hline 45 & Cobalt & 0.4202 & 90 & Lithium - 6 & 1.3151 \\
\hline 46 & Nickel & 0.4210 & 91 & Gadolinium & 0.2572 \\
\hline
\end{tabular}

* $\mathrm{C}$ is the compound nucleus temperature parameter and is defined by:

$$
\theta=C E^{\prime \frac{1}{2}}
$$

where

$$
\begin{aligned}
& \theta=\text { compound nucleus temperature (Mev) } \\
& E^{\prime}=\text { incident neutron energy (Mev) }
\end{aligned}
$$


TABLE D-6 - VALUES OF $\eta$ USED IN THE CALCULATION

OF THE ELASTIC SCATTERING MATRICES

\begin{tabular}{|c|c|c|c|c|c|c|c|c|c|}
\hline $\begin{array}{l}\text { Sub- } \\
\text { group }\end{array}$ & $\mathrm{H}$ & $\mathrm{Li}-7$ & Be & $\mathrm{C}$ & $\mathrm{U}$ & $\mathbb{N}$ & 0 & $\mathrm{~A} 1$ & Si \\
\hline 1 & 0.000 & 0.243 & 0.640 & 0.350 & 0.750 & 0.390 & 0.650 & 0.620 & 0.578 \\
\hline 2 & & 0.224 & 0.588 & 0.207 & 0.798 & 0.365 & 0.490 & 0.590 & 0.566 \\
\hline 3 & & 0.194 & 0.500 & 0.110 & 0.800 & 0.340 & 0.300 & 0.530 & 0.538 \\
\hline 4 & & 0.158 & 0.470 & 0.038 & 0.825 & 0.295 & 0.091 & 0.450 & 0.450 \\
\hline 5 & & 0.120 & 0.364 & -0.009 & 0.810 & 0.250 & 0.079 & 0.260 & 0.290 \\
\hline 6 & & 0.076 & 0.214 & 0.003 & 0.720 & 0.200 & 0.065 & 0.342 & 0.326 \\
\hline 7 & & 0.038 & 0.114 & 0.032 & 0.635 & 0.160 & 0.065 & 0.378 & 0.326 \\
\hline 8 & & 0.019 & 0.205 & 0.060 & 0.420 & 0.082 & 0.158 & 0.311 & 0.270 \\
\hline 9 & & -0.007 & 0.188 & 0.070 & 0.400 & 0.057 & 0.000 & 0.254 & 0.270 \\
\hline 10 & & -0.050 & 0.131 & 0.071 & 0.350 & 0.043 & 0.000 & 0.220 & 0.308 \\
\hline 11 & & -0.109 & 0.088 & 0.064 & 0.320 & 0.038 & 0.109 & 0.193 & 0.107 \\
\hline 12 & & -0.200 & 0.029 & 0.058 & 0.300 & 0.031 & 0.260 & 0.182 & 0.166 \\
\hline 13 & & -0.275 & 0.031 & 0.039 & 0.280 & 0.025 & 0.160 & 0.118 & 0.089 \\
\hline 14 & & -0.281 & 0.033 & 0.032 & 0.240 & 0.019 & -0.240 & 0.088 & 0.071 \\
\hline 15 & & 0.015 & 0.039 & 0.032 & 0.180 & 0.015 & -0.170 & 0.070 & 0.032 \\
\hline 16 & & 0.325 & 0.021 & 0.021 & 0.100 & 0.011 & -0.102 & 0.077 & 0.013 \\
\hline 17 & & 0.240 & 0.018 & 0.010 & 0.095 & 0.010 & 0.006 & 0.045 & 0.008 \\
\hline 18 & & 0.110 & 0.012 & 0.006 & 0.090 & 0.008 & -0.023 & 0.020 & 0.000 \\
\hline 19 & & 0.049 & 0.000 & 0.002 & 0.080 & 0.005 & 0.000 & 0.000 & \\
\hline 20 & & 0.000 & 0.014 & -0.003 & 0.074 & 0.001 & & & \\
\hline 21 & & -0.025 & 0.019 & -0.005 & 0.070 & 0.000 & & & \\
\hline 22 & & 0.060 & 0.015 & -0.003 & 0.060 & & & & \\
\hline 23 & & 0.000 & 0.010 & -0.0025 & 0.045 & & & & \\
\hline 24 & & & 0.008 & -0.002 & 0.030 & & & & \\
\hline 25 & & & 0.005 & -0.0015 & 0.020 & & & & \\
\hline 26 & & & 0.002 & -0.001 & 0.010 & & & & \\
\hline 27 & & & 0.001 & 0.000 & 0.005 & & & & \\
\hline$\approx$ & & & & & & & & & \\
\hline 75 & . & 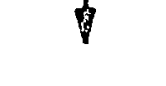 & $\checkmark$ & & & & $\checkmark$ & 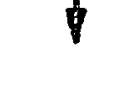 & \\
\hline
\end{tabular}


TABLE $D-6$ (Continued)

\begin{tabular}{|c|c|c|c|c|c|c|c|c|c|}
\hline $\begin{array}{l}\text { Sub- } \\
\text { group }\end{array}$ & $\mathrm{Cr}$ & $\mathrm{Fe}$ & Co & $\mathrm{Ni}$ & $\mathrm{Y}$ & $\mathrm{Zr}$ & $\mathrm{Nb}$ & Mo & W \\
\hline 1 & 0.615 & 0.820 & .672 & 0.950 & 0.600 & 0.750 & 0.528 & 0.700 & 0.870 \\
\hline 2 & 0.594 & 0.8125 & .0647 & 0.880 & 0.550 & 0.708 & 0.510 & 0.610 & 0.830 \\
\hline 3 & 0.565 & 0.746 & 0.597 & 0.790 & 0.500 & 0.603 & 0.495 & 0.550 & 0.790 \\
\hline 4 & 0.530 & 0.549 & 0.555 & 0.578 & 0.465 & 0.500 & 0.475 & 0.450 & 0.756 \\
\hline 5 & 0.490 & 0.500 & 0.509 & 0.448 & 0.338 & 0.333 & 0.453 & 0.480 & 0.707 \\
\hline 6 & 0.450 & 0.387 & 0.447 & 0.320 & 0.301 & 0.370 & 0.432 & 0.437 & 0.598 \\
\hline 7 & 0.395 & 0.260 & 0.384 & 0.230 & 0.264 & 0.340 & 0.406 & 0.406 & 0.181 \\
\hline$\because$ & 0.340 & 0.22( & 0.306 & 0.170 & 0.205 & 0.320 & 0.380 & 0.381 & 0.393 \\
\hline 9 & 0.285 & 0.19 & 0.193 & 0.129 & 0.140 & 0.300 & 0.350 & 0.371 & 0.342 \\
\hline 10 & 0.219 & $0.1 \mathrm{co}$ & 0.122 & 0.095 & 0.075 & 0.305 & 0.315 & 0.360 & 0.290 \\
\hline 11 & 0.154 & $0.1+5$ & 0.108 & 0.114 & 0.000 & 0.269 & 0.289 & 0.346 & 0.220 \\
\hline 12 & 0.153 & 0.170 & 0.095 & 0.127 & & 0.242 & 0.264 & 0.310 & 0.120 \\
\hline 13 & 0.108 & 0.124 & 0.070 & 0.105 & & 0.194 & 0.228 & 0.270 & 0.055 \\
\hline 14 & 0.096 & 0.088 & 0.057 & 0.082 & & 0.138 & 0.182 & 0.230 & 0.020 \\
\hline 15 & 0.099 & 0.072 & 0.049 & 0.070 & & 0.111 & 0.152 & 0.180 & 0.000 \\
\hline 16 & 0.075 & 0.058 & 0.036 & 0.053 & & 0.103 & 0.119 & 0.150 & \\
\hline 17 & 0.051 & 0,045 & 0.019 & 0.034 & .. & 0.077 & 0.079 & 0.120 & \\
\hline 18 & 0.038 & 0.023 & 0.008 & 0.019 & & 0.0475 & 0.057 & 0.090 & \\
\hline 19 & 0.031 & 0.019 & 0.003 & 0.011 & & 0.026 & 0.049 & 0.070 & \\
\hline 20 & 0.025 & 0.009 & -0.001 & 0.007 & & 0.013 & 0.043 & 0.060 & \\
\hline 21 & 0.022 & 0.005 & -0.004 & 0.005 & & 0.005 & 0.020 & 0.055 & \\
\hline 22 & 0.018 & 0.000 & -0.010 & 0.000 & & 0.000 & 0.000 & 0.050 & \\
\hline 23 & 0.013 & & -0.017 & & & & & 0.040 & \\
\hline 24 & 0.010 & & 0.000 & & & & & 0.030 & \\
\hline 25 & 0.0075 & & & & & & & 0.020 & \\
\hline 26 & 0.003 & & & & & & & 0.010 & \\
\hline 27 & 0.001 & & & & & - & & 0.000 & \\
\hline 28 & 0.000 & & & & & & & & \\
\hline$\approx$ & & & & & & & & & \\
\hline 75 & & & & & & & & & \\
\hline
\end{tabular}


TABLE D-6 (Continued)

\begin{tabular}{|c|c|c|c|c|c|c|c|}
\hline $\begin{array}{l}\text { Sub- } \\
\text { group }\end{array}$ & Cs & $\mathrm{Ph}$ & $\mathrm{B}$ & $\mathrm{Cd}$ & In & $L i-6$ & $\mathrm{Ti}$ \\
\hline 1 & 0.690 & 0.626 & 0.444 & 0.790 & 0.690 & 0.240 & 0.726 \\
\hline 2 & 0.665 & 0.607 & 0.400 & 0.740 & 0.665 & 0.200 & 0.677 \\
\hline 3 & 0.630 & 0.559 & 0.000 & 0.670 & 0.630 & 0.169 & 0.630 \\
\hline 4 & 0.584 & 0.577 & 0.000 & 0.600 & 0.584 & 0.140 & 0.605 \\
\hline 5 & 0.526 & 0.466 & 0.000 & 0.440 & 0.526 & 0.120 & 0.636 \\
\hline 6 & 0.460 & 0.480 & 0.000 & 0.390 & 0.460 & 0.105 & 0.612 \\
\hline 7 & 0.420 & 0.350 & 0.003 & 0.380 & 0.420 & 0.095 & 0.470 \\
\hline 8 & 0.384 & 0.261 & 0.009 & 0.385 & 0.384 & 0.112 & 0.361 \\
\hline 9 & 0.375 & 0.191 & 0.0148 & 0.394 & 0.375 & 0.140 & 0.320 \\
\hline 10 & 0.358 & 0.200 & 0.117 & 0.395 & 0.358 & 0.162 & 0.248 \\
\hline 11 & 0.380 & 0.151 & 0.119 & 0.380 & 0.380 & 0.142 & 0.168 \\
\hline 12 & 0.382 & 0.118 & 0.143 & 0.360 & 0.382 & 0.121 & 0.176 \\
\hline 13 & 0.322 & 0.175 & 0.119 & 0.340 & 0.322 & 0.120 & 0.125 \\
\hline 14 & 0.294 & 0.149 & 0.119 & 0.300 & 0.294 & 0.063 & 0.099 \\
\hline 15 & 0.272 & 0.149 & 0.0076 & 0.250 & 0.272 & 0.040 & 0.000 \\
\hline 16 & 0.208 & 0.135 & 0.0143 & 0.210 & 0.208 & -0.065 & \\
\hline 17 & 0.177 & 0.104 & 0.011 & 0.170 & 0.177 & -0.133 & \\
\hline 18 & 0.152 & 0.070 & 0.0105 & 0.140 & 0.152 & -0.120 & \\
\hline 19 & 0.135 & 0.058 & 0.0102 & 0.120 & 0.135 & -0.117 & \\
\hline 20 & 0.119 & 0.037 & 0.010 & 0.110 & 0.119 & -0.115 & \\
\hline 21 & 0.107 & 0.028 & 0.000 & 0.100 & 0.107 & -0.115 & \\
\hline 22 & 0.092 & 0.019 & & 0.085 & 0.092 & 0.050 & \\
\hline 23 & 0.071 & 0.010 & & 0.065 & 0.071 & 0.000 & \\
\hline 24 & 0.050 & 0.005 & & 0.050 & 0.050 & & \\
\hline 25 & 0.032 & 0.000 & & 0.030 & 0.032 & & \\
\hline 26 & 0.016 & & & 0.030 & 0.016 & & \\
\hline 27 & 0.005 & & & 0.010 & 0.005 & & \\
\hline 28 & 0.000 & & & 0.000 & 0.000 & & \\
\hline$\approx$ & & & & & & & \\
\hline 75 & & & & & & & \\
\hline
\end{tabular}


C. DATA OBTAINED FROM GA TAPE 101

A number of materials, for which cross sections were not available at AGN but which were on the original GAM tape, have been saved and placed on the AGN data tape. A 1ist of these is given in Table D-7. Like the resonance tables, the data on these materials were transferred directly from the old tape to cards to avoid errors. Some of the scattering matrices were reduced in size to eliminate zeros and very small terms.

No references are available on the original sources for these data.

\section{DATA OBTAINED DY MDXING MATERIALB}

Twenty-six materials on the AGN-GAM library tape were formed by mixing pure elements. This was done to generate data on materials that are most often required such as water, or for materials of specific reference composition such as stainless steel. The cross sections were combined using the SCRIBBLE code (Appendix E), in much the same way as AGN-GAM code functions. Equations were used that calculated the average cross section per atom present. This means that the number density to be used with mixtures is the sum of all atoms present in one cubic centimeter of the mixture. The atomic weight is chosen so that the proper number density results when the physical density of the material is input.

Table D-8 lists the mixtures present, the atomic weights, and the assumed weight as well as the atom percents of the components.

\section{E. INDIVIDUAL ISOTOPE DATA}

The data on the 1ndividual 1sotopes (material numbers 121 to 213) were obtained from GA data tape (No. 101) with the exception of yttrium-89. (material 208), tungsten-182, 183, and 184 (materials 211 through 213), and the special $1 / v$ cross section addition. These GA materials apparently came from evaluations of the fission product cross sections (Ref. D-5). Except for materials 211 and 213 these constants include only absorption and no other. processes.

The original data tape contained only 68 groups of information. To extend this data to 75 groups, it was assumed that a 1/v dependence existed. This is a valid assumption for all but a few of the materials considered 


\section{TABLE D-7 - MATERIALS FOR WHICH ALL CONSTANTS}

WERE OBTA INED FROM GENERAL ATOMICS' DATA

ID NUMBER

\section{2}

13

14

16

18

19

20

21

22

23

24

34

47

58

100
MATERTAL

Deuterium

Uranium-233

Uranium-234

Uranium-236

Protactinium-233

Neptunium-239

P1utonium-239

Plutonium-240

Plutonium-241

P1utonium-242

Thorium (inf dil)

Magnesium

Copper

Bismuth

Thorium 
TABLE D-8 - COMPOSITION OF MIXED MATERIALS

\begin{tabular}{|c|c|c|c|c|c|c|}
\hline No. & Name & * & $\begin{array}{l}\text { Atomic } \\
\text { Weight }\end{array}$ & Components & $\begin{array}{l}\text { Weight } \\
\text { Percent }\end{array}$ & $\begin{array}{l}\text { Atom } \\
\text { Percent }\end{array}$ \\
\hline 6 & Water, 1 ight & $\mathbf{a}$ & 6.005 & $\begin{array}{l}\text { Hydrogen } \\
\text { Oxygen }\end{array}$ & $\begin{array}{l}11.19 \\
88.81\end{array}$ & $\begin{array}{l}66.67 \\
33.33\end{array}$ \\
\hline 7 & Water, heavy & $\mathbf{a}$ & 6.677 & $\begin{array}{l}\text { Deuterium } \\
\text { Oxygen }\end{array}$ & $\begin{array}{l}20.12 \\
79.88\end{array}$ & $\begin{array}{l}66.67 \\
33.33\end{array}$ \\
\hline 8 & Beryllium oxide & $\mathbf{a}$ & 12.507 & $\begin{array}{l}\text { Bery } 11 \text { ium } \\
\text { Oxygen }\end{array}$ & $\begin{array}{l}36.03 \\
63.97\end{array}$ & $\begin{array}{l}50.00 \\
50.00\end{array}$ \\
\hline 9 & Graphite (AGOT) & $\mathrm{c}$ & 12.013 & $\begin{array}{l}\text { Carbon } \\
\text { Iron } \\
\text { Boron }\end{array}$ & $\begin{array}{l}99.98 \\
0.02 \\
0.6 \mathrm{ppm}\end{array}$ & $\begin{array}{r}99.99 \\
0.01 \\
-\quad-\quad-\end{array}$ \\
\hline 10 & Ammonia & $\mathrm{a}$ & 4.258 & $\begin{array}{l}\text { Nitrogen } \\
\text { Hydrogen }\end{array}$ & $\begin{array}{l}82.25 \\
17.75\end{array}$ & $\begin{array}{l}25.00 \\
75.00\end{array}$ \\
\hline 25 & Uranium-natural & $b$ & 238.100 & $\begin{array}{l}U-234 \\
U-235 \\
U-238\end{array}$ & $\begin{array}{c}0.006 \\
0.72 \\
99.274\end{array}$ & $\begin{array}{r}0.006 \\
0.729 \\
99.265\end{array}$ \\
\hline 26 & $\begin{array}{l}\text { Uranium-fully } \\
\text { enriched } \\
(M-1)\end{array}$ & d & 235.280 & $\begin{array}{l}U-235 \\
U-236 \\
U-238\end{array}$ & $\begin{array}{r}93.15 \\
0.13 \\
5.82\end{array}$ & $\begin{array}{r}93.22 \\
0.13 \\
5.75\end{array}$ \\
\hline 27 & $\begin{array}{l}\mathrm{UO}_{2} \text {-fully } \\
\text { enriched }\end{array}$ & $a$ & 89.096 & $\begin{array}{l}\text { U-fully enriched } \\
\text { Oxygen }\end{array}$ & $\begin{array}{l}88.03 \\
11.97\end{array}$ & $\begin{array}{l}33.33 \\
66.67\end{array}$ \\
\hline 30 & Lithium & $\mathrm{b}$ & 6.932 & $\begin{array}{l}\mathrm{Li}-6 \\
\mathrm{LI}-7\end{array}$ & $\begin{array}{r}7.50 \\
92.50\end{array}$ & $\begin{array}{r}8.64 \\
91.36\end{array}$ \\
\hline 59 & $\begin{array}{l}\text { Stainless Steel- } \\
304\end{array}$ & $\mathbf{e}$ & 54.618 & $\begin{array}{l}\text { Chromium } \\
\text { Nicke } 1 \\
\text { Silicon } \\
\text { Manganese } \\
\text { Iron } \\
\text { Carbon }\end{array}$ & $\begin{array}{r}19.00 \\
9.50 \\
1.00 \\
2.00 \\
68.42 \\
0.08\end{array}$ & $\begin{array}{r}19.95 \\
8.84 \\
1.95 \\
1.99 \\
66.91 \\
0.36\end{array}$ \\
\hline 60 & $\begin{array}{c}\text { Stainless Steel- } \\
316\end{array}$ & $\mathbf{e}$ & 55.289 & $\begin{array}{l}\text { Chromium } \\
\text { Nickel } \\
\text { Silicon } \\
\text { Manganese } \\
\text { Irun } \\
\text { Molybdenum } \\
\text { Carbon }\end{array}$ & $\begin{array}{r}17.00 \\
12.00 \\
1.00 \\
2.00 \\
65.40 \\
2.50 \\
0.10\end{array}$ & $\begin{array}{r}18.07 \\
11.30 \\
1.97 \\
2.01 \\
64.74 \\
1.44 \\
0.46\end{array}$ \\
\hline
\end{tabular}


TABLE D-8 (Continued)

\begin{tabular}{|c|c|c|c|c|c|c|}
\hline No. & Name & $*$ & $\begin{array}{l}\text { Atomic } \\
\text { Weight }\end{array}$ & Components & $\begin{array}{l}\text { Weight } \\
\text { Percent }\end{array}$ & $\begin{array}{l}\text { Atom } \\
\text { Percent }\end{array}$ \\
\hline 61 & $\begin{array}{c}\text { Stainless Stee1- } \\
321\end{array}$ & e & 54.658 & $\begin{array}{l}\text { Chromium } \\
\text { Nicke1 } \\
\text { Silicon } \\
\text { Manganese } \\
\text { Iron } \\
\text { Carbon }\end{array}$ & $\begin{array}{r}18.00 \\
9.50 \\
1.00 \\
2.00 \\
69.42 \\
0.08\end{array}$ & $\begin{array}{r}18.92 \\
8.84 \\
1.95 \\
1.99 \\
67.94 \\
0.36\end{array}$ \\
\hline 62 & $\begin{array}{c}\text { Stain1ess } \\
347\end{array}$ & e & 54.684 & $\begin{array}{l}\text { Chromium } \\
\text { NickeI } \\
\text { Silicon } \\
\text { Manganese } \\
\text { Iron } \\
\text { Carbon }\end{array}$ & $\begin{array}{r}18.00 \\
10.50 \\
1.00 \\
2.00 \\
68.42 \\
0.08\end{array}$ & $\begin{array}{r}18.93 \\
9.78 \\
1.95 \\
1.99 \\
66.99 \\
0.36\end{array}$ \\
\hline 63 & $\underset{410}{\operatorname{Stain1ess}}$ Stee $1-$ & & 54.500 & $\begin{array}{l}\text { Chromium } \\
\text { Silicon } \\
\text { Manganese } \\
\text { Iron } \\
\text { Carbon }\end{array}$ & $\begin{array}{r}12.50 \\
1.00 \\
1.00 \\
85.35 \\
0.1 .5\end{array}$ & $\begin{array}{r}13.10 \\
1.94 \\
0.99 \\
83.29 \\
0.68\end{array}$ \\
\hline 64 & $\begin{array}{c}\text { Stainless stee } 1- \\
440 \mathrm{~B}\end{array}$ & & 53.165 & $\begin{array}{l}\text { Chromium } \\
\text { Silicon } \\
\text { Manganese } \\
\text { Iron } \\
\text { Molybdenum } \\
\text { Carbon }\end{array}$ & $\begin{array}{r}17.00 \\
1.00 \\
1.00 \\
79.40 \\
0.75 \\
0.85\end{array}$ & $\begin{array}{r}17.38 \\
1.90 \\
0.97 \\
75.58 \\
0.42 \\
3.76\end{array}$ \\
\hline 65 & Hastelloy $X$ & $\mathbf{f}$ & 58.627 & $\begin{array}{l}\text { Chromium } \\
\text { Manganese } \\
\text { Iron } \\
\text { Nickel } \\
\text { Molybdenum } \\
\text { Tungsten } \\
\text { Cobalt }\end{array}$ & $\begin{array}{c}22.37 \\
0.75 \\
18.41 \\
48.0 \\
8.73 \\
0.31 \\
1.30\end{array}$ & $\begin{array}{r}25.22 \\
0.80 \\
19.33 \\
47.93 \\
5.33 \\
0.10 \\
1.29\end{array}$ \\
\hline 66 & Incone 1 & $\mathrm{~g}$ & 58.461 & $\begin{array}{l}\text { Chromium } \\
\text { Iron } \\
\text { Nickel }\end{array}$ & $\begin{array}{r}16.34 \\
9.50 \\
72.00\end{array}$ & $\begin{array}{r}18.36 \\
9.94 \\
71.70\end{array}$ \\
\hline 67 & Incone $1-X$ & $g$ & 59.132 & $\begin{array}{l}\text { Alumium } \\
\text { Chromium } \\
\text { Iron } \\
\text { Nickel } \\
\text { Niobium } \\
\text { Cobalt }\end{array}$ & $\begin{array}{r}0.70 \\
15.50 \\
7.00 \\
71.81 \\
0.95 \\
0.50\end{array}$ & $\begin{array}{r}1.53 \\
17.62 \\
7.41 \\
72.33 \\
0.61 \\
0.50\end{array}$ \\
\hline
\end{tabular}


TABLE D-8 (Continued)

\begin{tabular}{|c|c|c|c|c|c|c|}
\hline No. & Name & $*$ & $\begin{array}{l}\text { Atomic } \\
\text { Weight }\end{array}$ & Components & $\begin{array}{l}\text { Weight } \\
\text { Percent }\end{array}$ & $\begin{array}{l}\text { Atom } \\
\text { Percent }\end{array}$ \\
\hline 68 & FeCrAl & $\mathrm{h}$ & 52.774 & $\begin{array}{l}\text { Aluminum } \\
\text { Chromium } \\
\text { Iron } \\
\text { Yttrium }\end{array}$ & $\begin{array}{r}4.00 \\
25.00 \\
70.20 \\
0.80\end{array}$ & $\begin{array}{r}7.82 \\
24.37 \\
66.33 \\
0.48\end{array}$ \\
\hline 69 & Aluminum- 6061 & $\mathbf{i}$ & 27.180 & $\begin{array}{l}\text { Silicon } \\
\text { Iron } 1 \\
\text { Copper } \\
\text { Manganese } \\
\text { Chromium } \\
\text { Aluminum }\end{array}$ & $\begin{array}{r}0.60 \\
0.85 \\
0.50 \\
0.15 \\
0.25 \\
96.75\end{array}$ & $\begin{array}{r}0.58 \\
0.41 \\
0.21 \\
0.07 \\
0.13 \\
97.47\end{array}$ \\
\hline 71 & Haynes - 25 & $\mathbf{j}$ & 64.101 & $\begin{array}{l}\text { Nickel } \\
\text { Cohalt } \\
\text { Chromlum } \\
\text { Tungsten } \\
\text { Iron } \\
\text { Manganese }\end{array}$ & $\begin{array}{r}10.00 \\
50.40 \\
20.00 \\
15.00 \\
2.30 \\
1.50\end{array}$ & $\begin{array}{r}10.92 \\
54.81 \\
24.65 \\
5.23 \\
2.64 \\
1.75\end{array}$ \\
\hline 72 & $\begin{array}{l}\text { Aluminum } \\
\text { Oxide }\end{array}$ & $\mathbf{a}$ & 20.392 & $\begin{array}{l}\text { Aluminum } \\
\text { Oxygen }\end{array}$ & $\begin{array}{l}52.92 \\
47.08\end{array}$ & $\begin{array}{l}40.00 \\
60.00\end{array}$ \\
\hline 73 & $\begin{array}{l}\text { Magnesium } \\
\text { Oxide }\end{array}$ & a & 20.160 & $\begin{array}{l}\text { Magncoium } \\
\text { Oxygeu }\end{array}$ & $\begin{array}{l}60.32 \\
39.68\end{array}$ & $\begin{array}{l}50.00 \\
50.00\end{array}$ \\
\hline 74 & Thermof lex & $\mathrm{k}$ & 20.201 & $\begin{array}{l}\text { Aluminum } \\
\text { Silicon } \\
\text { Boron } \\
\text { Oxygon }\end{array}$ & $\begin{array}{r}16.78 \\
31.74 \\
0.02 \\
51.13\end{array}$ & $\begin{array}{r}12.56 \\
22.85 \\
0.04 \\
04.55\end{array}$ \\
\hline 75 & Refrasil & $\mathrm{k}$ & 19.963 & $\begin{array}{l}\text { Silicon } \\
\text { Boron } \\
\text { Oxygen }\end{array}$ & $\begin{array}{r}46.22 \\
0.01 \\
53.78\end{array}$ & $\begin{array}{r}32.88 \\
0.02 \\
67.10\end{array}$ \\
\hline 89 & $\begin{array}{l}\text { Control Blade } \\
(\mathrm{ML}-1)\end{array}$ & 1 & 109.900 & $\begin{array}{l}\text { Silver } \\
\text { Cadmium } \\
\text { Indium }\end{array}$ & $\begin{array}{r}80.00 \\
5.00 \\
15.00\end{array}$ & $\begin{array}{r}80.90 \\
4.85 \\
14.25\end{array}$ \\
\hline
\end{tabular}

SOURCE MATERIAL - TABLE D-8

a. Fixed Chemical Composition

b. Natural occuring analysis taken from W. M. Sullivan's "Trilinear Chart of Nuclides", 1957.

c. H. Etherington; Nuclear Engineering Handbook; Mc-Craw Hi11, New York; 1958 p. 10-55 (NOTE: Iron was used to represent the impurities for which the fast cross-sections were not available.) 


\section{SOURCE MATERIAL (Continued)}

d. Analysis of fuel used in ML-1-I reactor.

e. H. Etherington; op. crit. p. 10-60.

f. Analysis of ML-1-I fuel pins performed by Haynes Stellite Company, 3 June 1960. Cobalt content increased to represent average Hastelloy-X content.

g. Technical Bulletin T-38, Huntington Alloy Products Division, International Nickel Company. Note that several materials were omitted from the mixture since fast cross-sections were not available.

h. Composition typical of present FeCrAl.

i. H. Etherington; op crit; p. 10-47.

j. Data from information sheet published by Haynes Stellite Company, Union Carbide Corporation, June 1962.

k. Analysis of material used in M-1 system.

1. Reference M-1 control blade composition. 
and for those few, 75 groups of data are given in Ref. D-5. This reference also indicates how these data were obtained.

\section{F. FISSION PRODUCTS}

Materials 93 through 99 are labeled fission products. The data on these materials was obtained from Ref. D-5. They were not the GA data tape combined fission products. Only absorption is considered. Material 93 is the sum of the cross section data times the yield for all $\mathrm{fission}$ products except Xe-135 and Sm-149, expressed in units of barns per fission. Material 94 is the sum of all the "non-saturating" fission products, which build up Independent of power or time and are listed in Table D-9. Material 95 is the "slowly saturating" group. Both materials 94 and 95 are also expressed in units of barns per fission. The atomic weights of materials 93, 94, and 95 have been set equal to that of $\mathrm{U}-235$; if the densities of these materials are set equal to the density of U-235 times the fraction burnup, the correct macroscopic cross section will result.

Materials 96, 97, 98 and 99 (Gd-155, Xe-135, Sm-149, and Sm-151) are the principal four of the six "rapidly-saturating" fission products. The atomic weight of each of these materials has been set equal to that of U-235 divided by the yield of the given fission products. A correction term permits calculation of the macroscopic data when this value is used. The cross sections for the four materials are expressed in barns per atom.

The production of $\mathrm{U}-236$ is not considered in the fission product cross section block.

G. RESONANCE MATERIALS

On the current tape the resonance parameters for nine materials are included in a form suitable for the full resonance calculations. The resonance parameters for one of these materials, thorium, were obtained direct1y from the old GAM data tape. The parameters for each of the other eight were generated from AGN data. It is to be noted that these nine materials are also on the library tape with infinite dilution cross sections. The infinite dilution cross sections should be used, where appropriate, in order to save computational time. Table D-5 lists the nine materials. 


\section{H. FUTURE ADDITIONS}

There are material numbers in the present AGN-GAM library tape that are not in Tables $D-3$ and $D-4$. These represent locations that have been left open for future additions. Table D-10 lists some of these positions and the materials that are expected to occupy them (12, 28, 29 and 76-80). Positions 109 through 120 are available for additional materials with resonance parameters. An almost infinite number of positions is available beyond location 213 .

\section{REFERENCES - APPENDIX D}

D-1 Adler, F. T., Hinman, G.W., Nordheim, L.W., "The Quantitative Evaluation of Resonance Integrals," GA-350, 1958.

D-2 Adler, F.T., Nordheim, L.W., "Tables for the Computation of Resonance Integrals, "GA-377, 2 June 1958.

D-3 Keepin, G.R., "Neutron Data for Reactor Kinetics," Nucleonics, 20, 8, p 152 (1962).

D-4 Joanou, G.D., Budek, J. W., "CAM-1, A Consistant P-1 Multigroup Code for the Calculation of Fast Neutron Spectra and Multigroup Constants," GA-1850, 28 June 1961 .

D-5 - Garrison, J.D., Roose, B.W., "Tission-Product Capture Cross Sections," Nuclear Science and Engineering 12, 115-134 (1962). 


\section{TABLE D-9 - FISSION PRODUCTS}

NON-SATURATING FISSION PRODUCTS

$$
\begin{aligned}
& \mathrm{Br}-81, \mathrm{Se}-82, \mathrm{Kr}-83, \mathrm{Kr}-84, \mathrm{Kr}-85, \mathrm{Kr}-86, \mathrm{Rb}-85, \mathrm{Rb}-87, \mathrm{Sr}-88, \\
& \mathrm{Sr}-90, \mathrm{Y}-89, \mathrm{Zr}-91, \mathrm{Zr}-92, \mathrm{Zr}-93, \mathrm{Zr}-94, \mathrm{Zr}-96, \mathrm{Mo}-97, \mathrm{Mo}-98, \\
& \mathrm{Mo}-100, \mathrm{Ru}-101, \mathrm{Ru}-102, \mathrm{Ru}-104, \mathrm{Pd}-105, \mathrm{Pd}-106, \mathrm{Pd}-107, \mathrm{Pd}-108, \\
& \mathrm{Pd}-110, \mathrm{Ag}-109, \mathrm{Cd}-111, \mathrm{Cd}-112, \mathrm{Cd}-114, \mathrm{In}-115, \mathrm{le}-126, \mathrm{Te}-128, \\
& \mathrm{Te}-130, \mathrm{I}-127, \mathrm{I}-129, \mathrm{Xe}-132, \mathrm{Xe}-134, \mathrm{Xe}-136, \mathrm{Cs}-135, \mathrm{Cs}-137, \\
& \mathrm{Ba}-138, \mathrm{La}-139, \mathrm{Ce}-140, \mathrm{Ce}-142, \mathrm{Pr}-141, \mathrm{Nd}-144, \mathrm{Nd}-146, \mathrm{Nd}-148 \\
& \mathrm{Nd}-150, \mathrm{Sm}-154, \mathrm{Gd}-156, \mathrm{Gd}-153, \mathrm{~Tb}-159 .
\end{aligned}
$$

SLOWLY-SATURATING FISSION PRODUCTS

Mo-95, Tc-99, Rh-103, Xe-131, Cs-133, Nd-143, Nd-145, Pm-147, Sm-152, Eu-153.

RAPIDLY-SATURATING FISSION PRODUCTS

Cd-113, Sm-149, Sm-151, Gd-155, Gd-157, Xe-135.

\section{TABLE D-10 - PROBABLE FUTURE ASS IGNMENTS}

FOR CURRENTLY UNASS IGNED NUMBERS

$\begin{array}{ll}33 & \text { Sodium } \\ 37 & \text { Sulfur } \\ 38 & \text { Potassium } \\ 39 & \text { Calcium } \\ 40 & \text { Vanadium } \\ 48 & \text { Zinc } \\ 49 & \text { Rubidium } \\ 70 & \text { Zircaloy } \\ 87 & \text { Hafnium } \\ 88 & \text { Dysprosium } \\ 92 & \text { Gold }\end{array}$




\section{APPENDIX E}

UPDATING THE DATA TAPE

To generate or update an AGN-GAM data tape, it is necessary to perform large amounts of numerical work. The part of this work that is related to the elastic and inelastic scattering matrix and to the mixing of cross sections has largely been automated. This saves computational time and ensures greater accuracy.

The inelastic scattering matrix, as defined by previously stated equations, is generated by the INSECT code. Inputs to, and the use of, this code are described in Paragraph I of this Section. A code entitled POP1 (Paragraph II) was written to generate the $P_{0}$ and $P_{1}$ elastic scattering matrices. The actual updating of the data tape is accomplished by the SCRIBBLE code. This code also mixes element cross sections to form the cross sections for mixed materials (such as the stainless steels) and produces a printed 1 isting of the tape itself. The required inputs to this code are described in Paragraph III.

The listings of the above mentioned codes are not included because of their length and low level of interest. However, they are available, along with the punched Fortran source cards and program binary cards, from the Argonne Code Center.

I. INEI_ASTIC SCATTERING MATRIX - THE INSECT CODE

In order to generate the inelastic scattering matrix, the equations derived in Appendix $B$ were programmed to form the INSECT code. This routine calculates the scattering matrix, $\left(\Sigma_{g \rightarrow g+n}^{0} / \Sigma_{g}^{0}\right)$, for the first twenty-five quarter-lethargy groups. As many down scattering groups are kept as are needed to include all values of the matrix larger than $10^{-5}$. Final results 
are printed and punched in a form suitable as input to the routines which write the AGN-GAM data tape.

The basic equation solved is (B-30). A Simpson's rule technique is used to evaluate the integral. As a check on the accuracy of the method, the matrix is summed and the result indicated in the print-out. The correct result should be exactly one.

Input data needed for INSECT includes two cards per material.

Card \#1 Co1. 1-12

Col . 13-24

Card 非

Col. 47-48
Atomic weight of material

Constant " $C$ " of equation (B-27) in Mev. $\frac{1}{2}$ If input as zero, " $C$ " will be calculaled frum eyuallul $(B-28)$.

Hollerith description of the material

Two letter Hollerith symbol for the material. This will be used to identify the punched cards.

Problems may be stacked. Operation is standard under the MONITOR program. 


\section{II, ELASTIC SCATTERING MATRIX - THE POR1 CODE}

The elastic scattering matrices needed for the AGN-GAM data tape are generated from the general equations presented in Appendix B, Section III. For these calculations, the exact integrations were performed and programmed into the POP1 code. This code, like its counterpart for inelastic scattering, prints the calculated values and punches them in a form suitable for addition to the data tape. Scattering values from all 75 fine groups are calculated. All scattering to energies below the 75 th group are combined into a 76 th group.

A list of the exact equations solved is not given in this document. The equations are straight-forward, although somewhat involved. (The tabulation of these equations in the original version of the GAM code (Reference $E-1$ ) contains typographical errors.)

Input Requirements are

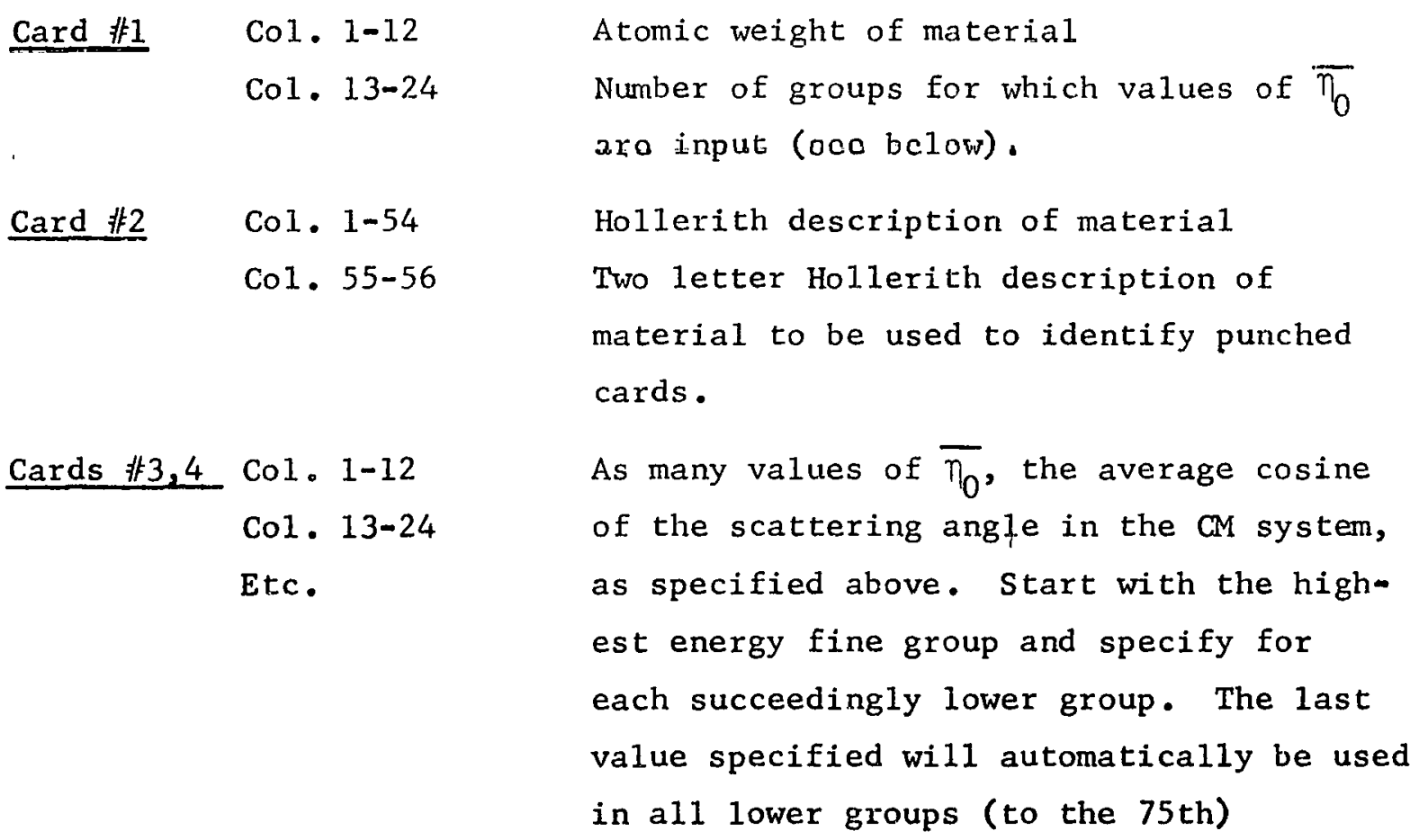

Problems may be stacked. Operation is under MONITOR control. 


\section{THE SCR BBBLE PROGRAM}

\section{A. INTRODUCTION}

The SCRIBBLE program was written to update the AGN-GAM data tape. Besides correcting the existing cross-section data, it is able to add new materials to the tape and to prepare lists of the data on the library tape.

As an added feature, this program was designed to also mix crosssection data to form mixed materials. This permits the data tape to include materials which would normally have to be specified in any one AGN-GAM problem as several separate elements. Water is the most frequently required mixed material and is fairly simple to include; the various kinds of stainless steels require more work because of the larger number of constituent elements. By placing mixtures on the library tape, a saving in the running time per problem is obtained, since fewer materials need be read from this tape. In addition, consistency is secured in the properties of the various mixtures because a reference composition is defined.

The mixing relationships are used to find the cross-section and the atomic weight of an "average" atom of the mixture. The cross-section for water, obtained by this method, is one third of the (commonly-thought-of) value based on the cross-section per molecule. The water mixture atomic weight by this definition is 6 .

Materials using the special resonance treatment can not be mixed with this routine.

The description of the input to this code will describe its operation more fully. 


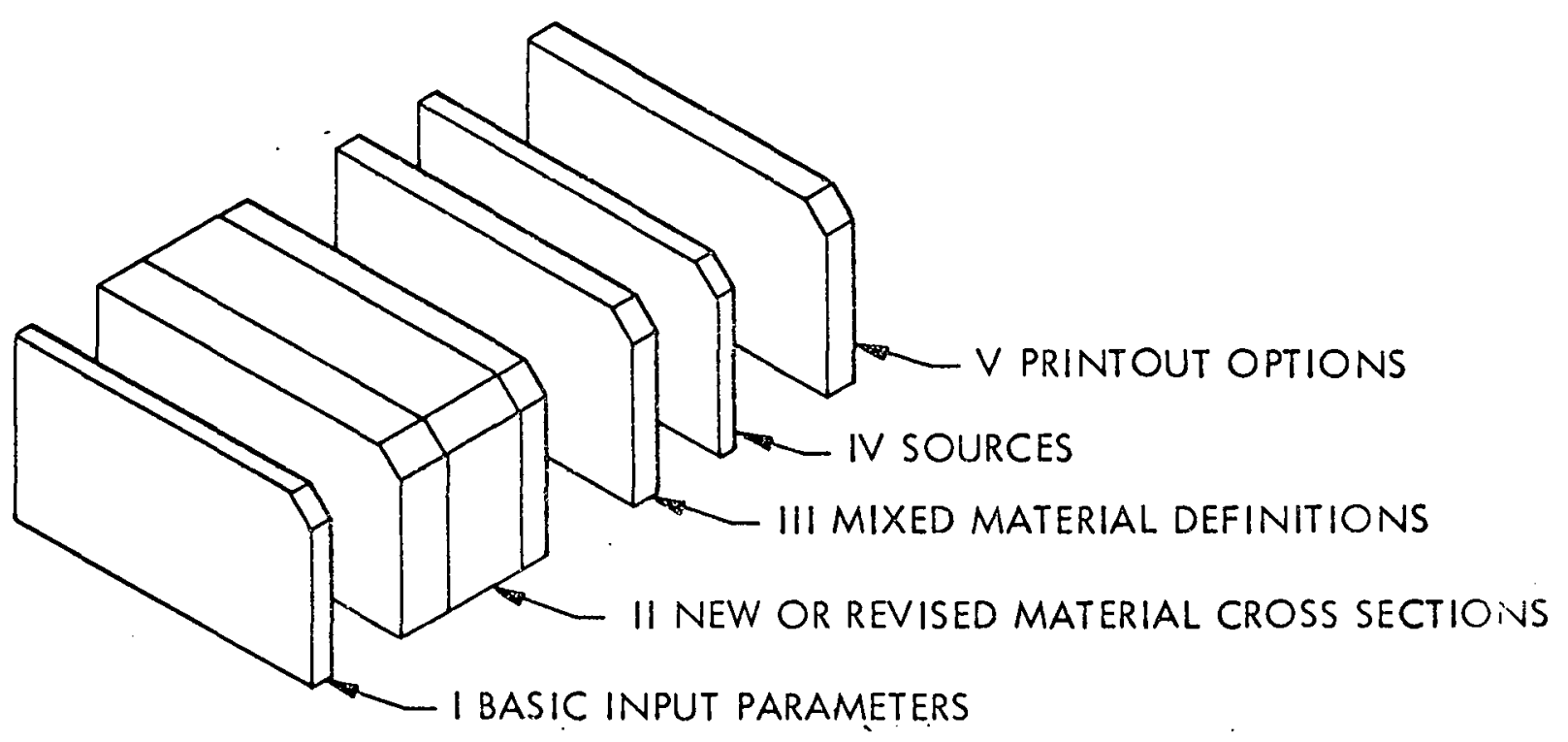

FIGURE E-1. SCRIBBLE INPUT

The input to the SCRIBBLE code consists of five major groups of data as illustrated in Figure E-1. The first of these, the basic input parameters, must always be present. Any of the following four groups may be omitted if the basic parameters do not indicate a need for the data contained within them. Each of these groups is described in detail below.

\section{GROUF I, BAEIC INPUT PARAMETERS}

These two cards must be supplied in all problems.

Card 非1001 Col. I-12
Number of materials for which cross section data are supplied. These can be either new materials to be added to the tape (either at the end of the present data or in one of the "blank" positions) or revisions of data existing on the present tape. Revisions are made by adding the corrected material to the tape in the same position as the old material. If this number is zero, no materials will be supplied in the Section II input. 
Col $\cdot 13-24$

Co1. 25-36

Co1. $37-48$

Co1. 49-60

Col. $61-72$

Card 非1002 Col. 1-72
Number of materials to be formed by mixing together cross-sections. These mixed materials are formed by specifying the material composition of the mixture. Both the cross-section data already on an ex- . isting data tape and those added in Section II can be used. If this number is zero, omit the section III input.

The new ID number for the tape which is to be written. If this number is set equal to zcro, no new laye w111 be written. This would be done only if it is desired to have SCRIBBLE just print an existing tape.

Total number of materials to be on the new data tape.

Total number of sources to be on the new data tape.

Set equal to zero if the new data tape is to Include the same sources as the old data tape (omit Secliun IV Input). Utherwise set equal to +1.0 and supply all sources as defined in section IV.

Hollerith description of data tape. Give tape name, date, source of data, etc.

\section{GROUP II, NEW OR REVISED MATERIAL CROSS-SECTIONS}

The input discussed in this section consists of a number of sets of crosssection data. Each input material will have its own set of data. As many sets must be supplied as are specified in Col. 1-12 of Card 非1001. Whether the material is a revision of existing data or the addition of an entirely new macerial, there is no difference in the composition of these sets. (The only difference would be the ID number assigned to the material). The sets of data are stacked one behind the other without any particular order or sequence. 
Each set of data consists of four basic parameter cards followed by the required cross-sections and scattering matrices. An end card (containing a +99999.0 in the first field) is included after each material as a check to ensure the proper input.

Figure E-2 indicates the composition of the four parameter cards. The ID designations in colums 73 through 79 are for identification only and have no input significance. Included in this same figure is a check 1 ist which indicates the order in which cross-sections must be supplied. If certain data are not required for a specific material, no special cards need be substituted for those that would have given this information; the cards can simply be omitted. Lines are drawn between the key blocks and the check list summary to indicate the placement of the check list items. Definition of a scattering matrix with zero length automatically indicates that that process is not appropriate and that all input can be neglected. When the basic parameter cards are filled out to indicate the absence of a particular set of input cards, the corresponding blocks in the check 1ist should be crossed out. Figure E-3 shows a typical form when filled out.

Each cross section block (i.e., $\sigma_{a}, \sigma_{f}, \nu$, etc) includes 75 values, one for each of the fine groups. Because six values are given per card starting with the highest energy group (非1), thirteen cards are needed per block. A11 values of cross-sections are expressed in barns.

The scattering matrices are provided in a compressed form. If each element in these matrices is designated as $A_{i \rightarrow j}$, which means the scattering value from group $i$ to group $j$, the input takes the form of:

$$
\begin{aligned}
& A_{1 \rightarrow 1} ; A_{1 \rightarrow 2}, A_{1 \rightarrow 3}, \ldots, A_{1 \rightarrow 1}+J, A_{2 \rightarrow 2}, \\
& A_{2 \rightarrow 3}, \ldots . A_{2 \rightarrow 2}+J, \cdots . A_{I \rightarrow I}+J
\end{aligned}
$$

In this example, $J$ is the number of groups downscatter and $I$ is the total number of groups considered. Values representing scattering to any group with a higher number than 76 , are omitted from the list. The length of the matrix is defined as the total number of values in the matrix. Because six numbers are punched on each input card and since the matrix is input exactly as shown 
FOR QUESTIONS; YES $=1.0$, NO $=0.0$ (IF NO, STRIKE OUT CORRESPONDING BLOCK IN CHECK LIST).

\begin{tabular}{|c|c|c|c|c|}
\hline & & & & \\
\hline
\end{tabular}

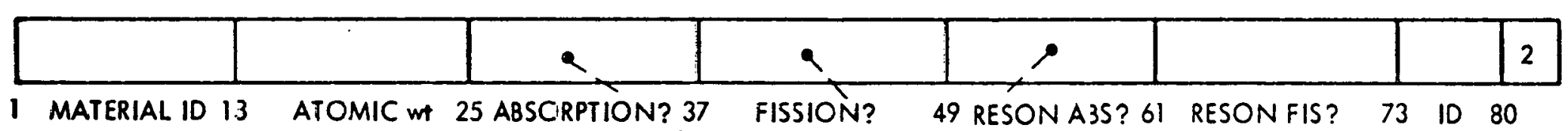

1 MATERIAL ID 13 ATOMIC $w+25$ ABSCRPTION? 37 FIS5ION? 49 RESON A35? 6I RESONFIS? 73 ID 80

$\stackrel{m}{\infty}$
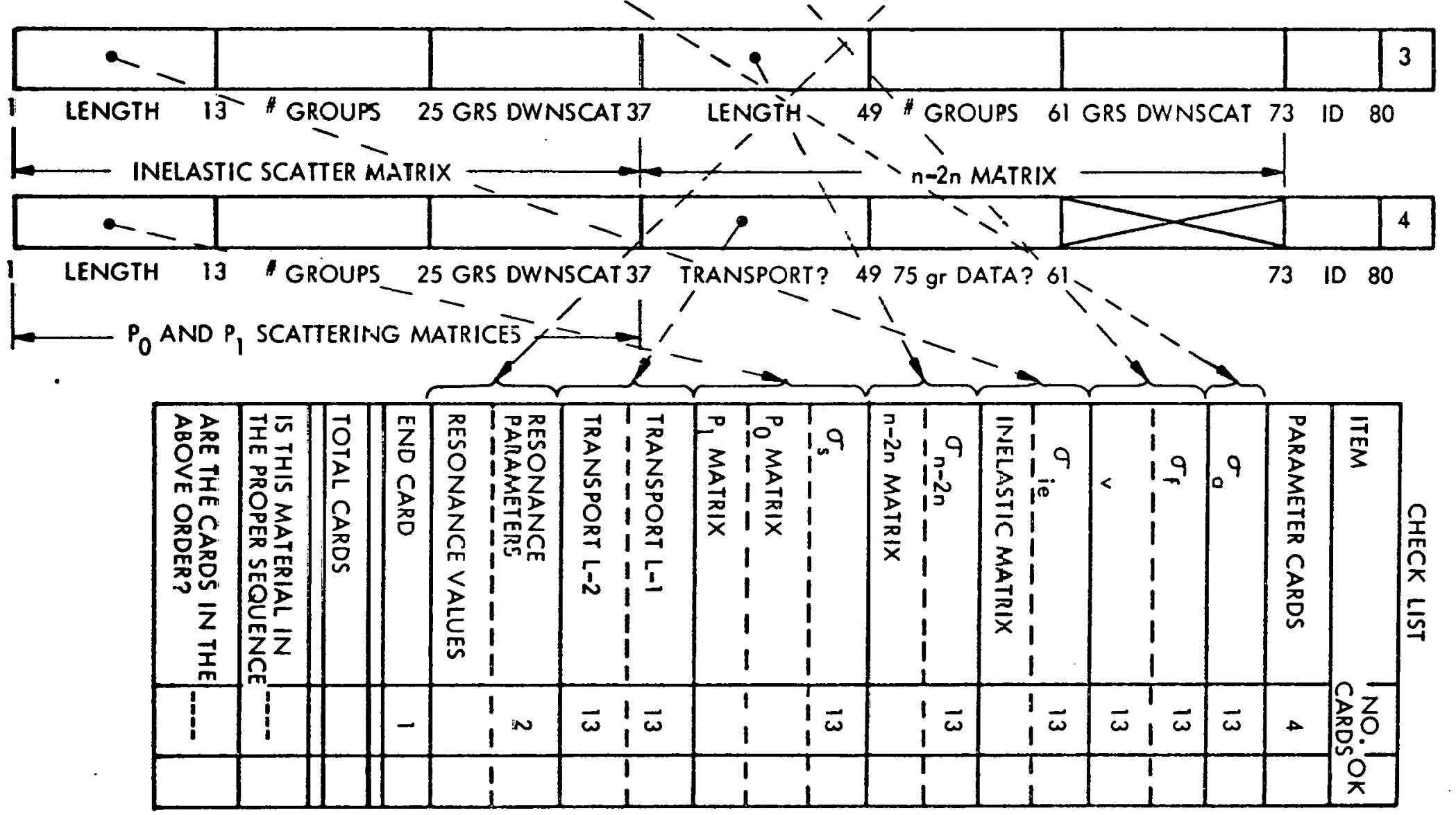

FIGURE E-2. PARAMETER CARD 
FOR QUESTIONS; YES $=1.0$, NO $=0.0$ (IF NO, STRIKE OUT CORRESPONDING BLOCK IN CHECK LIST).

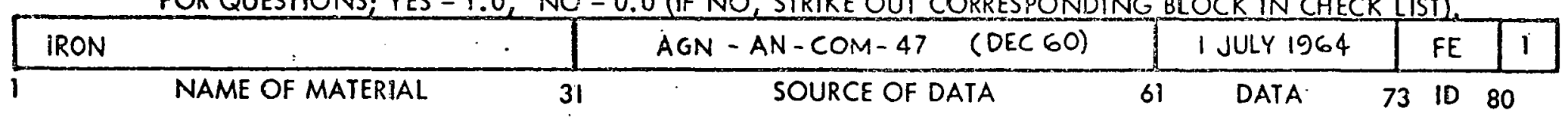

\begin{tabular}{|l|l|l|l|l|l|l|l|}
\hline+44.0 & +55.85 & +1.0 & +0.0 & +0.0 \\
\hline I MATERIAL ID 13 ATOMIC wt 25 ABSOFPTION?37 FISSION? 49 RESON ABS? 61 RESON FIS? 73 ID 80
\end{tabular}

\begin{tabular}{|l|l|l|l|l|l|l|l|l|}
\hline+280.0 & +10.0 & +2.0 & +0.0 & +0.0 & +0.0 \\
\hline LENGTH 13 & GROUPS 25 GRS DWNSCAT 37 LENGTH 49 \# GROUPS 61 GRS DWNSCAT 73 ID 80
\end{tabular}

$\longrightarrow$ INELASTIC SCATTER MATRIX $\longrightarrow n-2 n$ MATRIX $\longrightarrow$

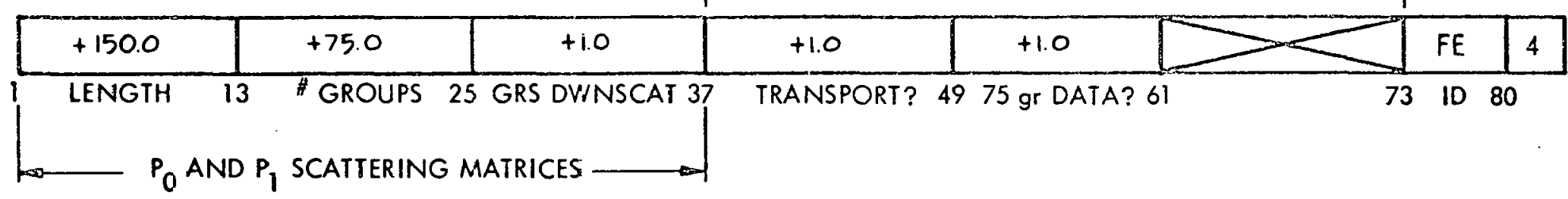

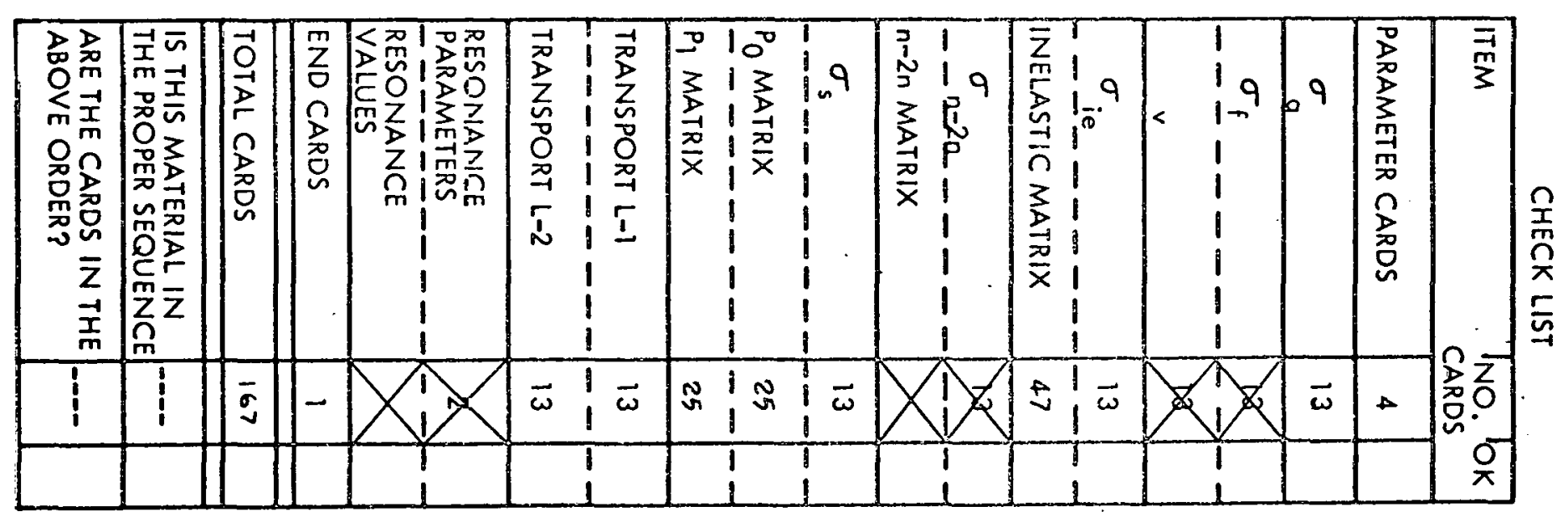

FIGURE E-3. FILLED-OUT PARAMETER CARD 
without blanks or spacing between groups, the total number of input cards for the matrix is equal to its length divided by six and rounded off to the next highest integer. Note that the terms to be input are the probabilities of scattering, not the product of cross-section and probability. If a scattering matrix is specified for groups in which a zero cross-section is then given, the SCR IBBLE program will disregard the zero values and shorten the stored matrix.

If the material has resonance absorption and/or resonance fission and the special resonance treatment is to be performed, additional input is necessary. First, two cards containing basic parameters and unresolved region data are required. These contain:

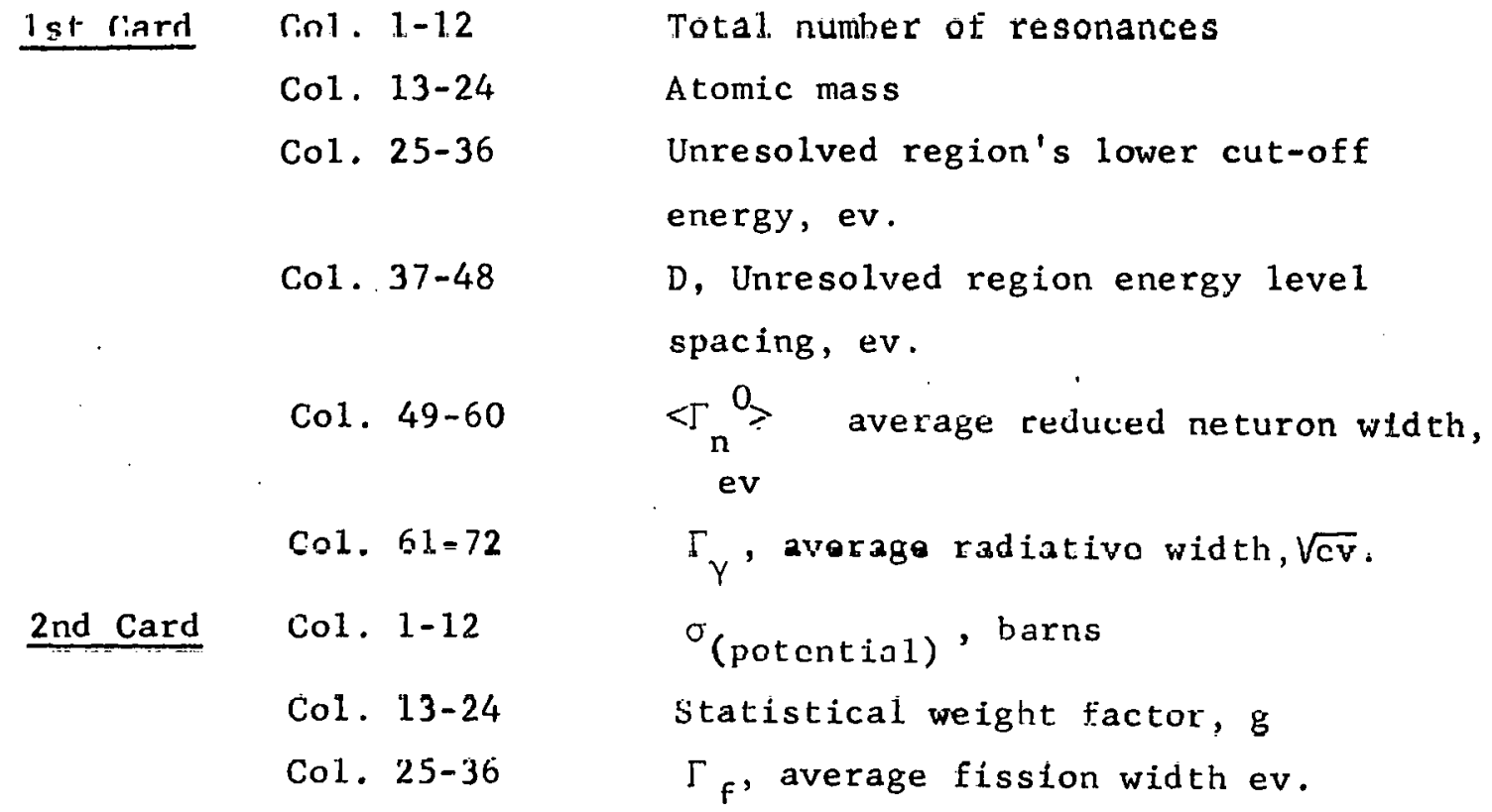

Following these cards are a series of cards describing the parameters for each resonance. Two cards per resonance are required.

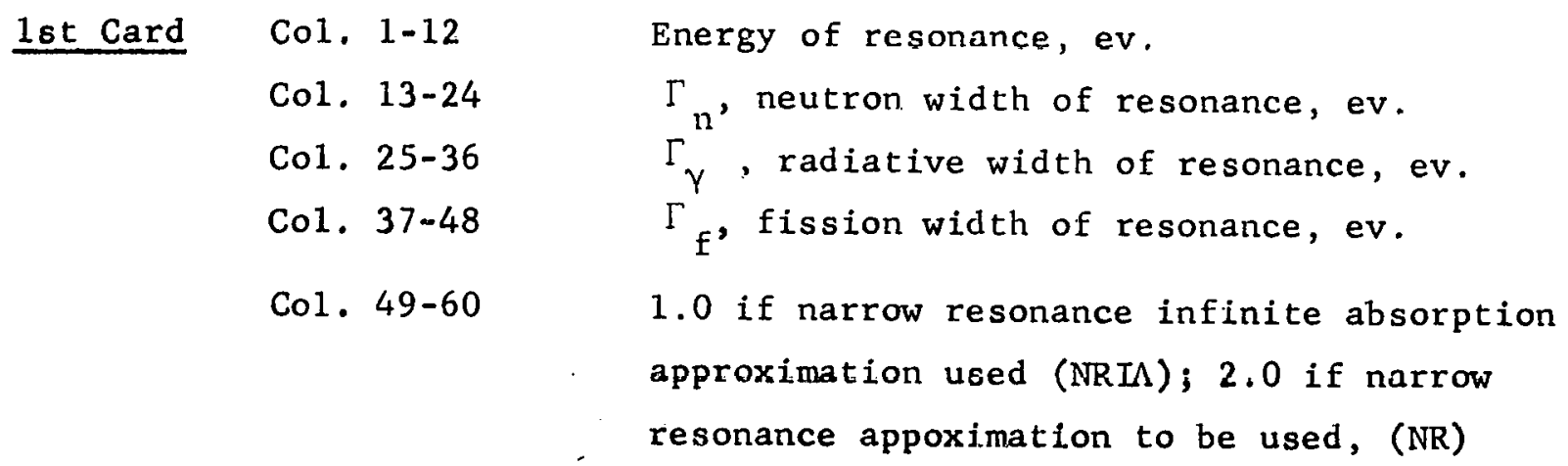


Co1. $61-72$

2nd Card Col. 1-12
Isotopic abundance of the isotope having this resonance (if a pure material, set equal to one).

Statistical weight factor, $g$.

The inputs for the material specified on Figure $E-4$ are shown in Figure $\mathrm{E}-5$, as an example of the format used to input cross-sections but not to specify particular cross-section data.

GROUP III, MIXED MATERIAL DEFINITIONS

One set of cards must be supplied for each material which is to be formed by mixing together materials already on the AGN-GAM library tape or materials that have been added as part of the Group II input. A mixed material is added to the tape either as a new material or an up-dated material. The number of mixed materials is given in Col. 13-24 of Card 1001 and one set of cards must be present for each of these. Omit all cards if no mixing is to be done.

\begin{tabular}{|c|c|c|}
\hline Card 非 & Co1. $1-30$ & Name of material \\
\hline & Co1. $31-60$ & Source of cross-section data \\
\hline & Col. $61-72$ & Date material added to tape \\
\hline Card 非 & Co1. $1-12$ & $\begin{array}{l}\text { Library tape ID number assigned to mixed } \\
\text { material. Must be equal to or less than } \\
\text { the maximum number of materials on this } \\
\text { tape. }\end{array}$ \\
\hline & Col. 13-24 & $\begin{array}{l}\text { Number of materials to be used to make the } \\
\text { mixture. }\end{array}$ \\
\hline & Col. 25-36 & $\begin{array}{l}+1.0 \text { if the mixed cross-section data is to } \\
\text { be considered valid for use in transport } \\
\text { codes; } 0.0 \text { otherwise. }\end{array}$ \\
\hline & Col. $37-48$ & $\begin{array}{l}+1.0 \text { if the mixed data is to be considered } \\
\text { to have valid data in all } 75 \text { groups. Set } \\
\text { equal to zero if on } 1 y \text { groups are valid. }\end{array}$ \\
\hline
\end{tabular}

Cards 非 3, 4, etc.

Col. $1-12$

Tape ID number of the first material in the mixture. If this material has just been 
read into the program (in Group II) for addition to the library, place a negative sign before the normal ID number.

Col. 13-24 The weight fraction of the first material in the mixture.

Col. 25-36 ID number of the second material. Weight fraction of the second material, etc:

GROUP IV, SOURCES

If the sources are to be read into the program and added to the library tape (option in Col. 61-72 of Card 非1001), they wil1 be placed into the input at this location. Since the total group of sources represents only a very small number of cards, it is necessary to.input the complete set of sources in order to change one source or to add a new source. The total number of sources is given in Col. 49-60 of Card 非1001. For each of these, the following set of cards must be supplied.

Card 非 Co1.1-72

Cards 非2-14

Card 非15
Hollerith description of source Seventy-five values of the source in each group, starting with the first (highest energy) group. Since the AGN-GAM program automatically normalizes the input source, no special normalization is necessary.

End Card, +99999.0 in Co1. 1-12

GROUP V, PRINTOUT OPTIONS

This group of cards defines the extent of the printout of the new AGN-GAM library tape. It is possible to obtain as little as the listing of one material or as much as all data on the entire tape. Special summary lists are available.

The first card describes the information wanted on general terms:

Col. $1-12$
$A+1.0$ if the resonance tables are to be printed. (These lists are finished tables with the proper description and coordinates. They are not just pages of unlabeled numbers.) 


$$
\begin{array}{ll}
\text { Col. 13-24 } & A+1.0 \text { if the sources are to be printed. } \\
\text { Co1. 25-36 } & A+1.0 \text { if there is to be a printout of a } \\
& \text { summary table of materials on the library } \\
& \text { tape. This table includes, in numerical } \\
& \text { order of the ID numbers, the name, atomic } \\
& \text { weight, date added, and source of the } \\
& \text { materials and an indication of what cross- } \\
& \text { section blocks are included. } \\
& \text { A }+1.0 \text { if summary cards are to be punched } \\
\text { Co1. 37-48 } & \text { for each material in the } 1 \text { ibrary. These } \\
& \text { cards are identical to the first card of } \\
& \text { the material input parameter cards (name, } \\
& \text { source, data added) with the material ID } \\
& \text { number punched into Col. } 72-80 .
\end{array}
$$

The following cards describe which materials on the library tape are to be printed.Each of these cards contains two numbers (in the first two fields). As many cards as necessary can be used. Each of the two numbers represents an ID number of a material on the tape. Printing will start at the first of these numbers and all materials up to and including the second of the ID numbers will be printed. The cards must be placed so that the ID numbers are in ascending order.

For example, if the information for materials 2, 7, 8, 15, 75 through 90, and 107 must be printed, the input cards to accomplish this would look as shown below:

$$
\begin{array}{ll}
+2.0 & +2.0 \\
+7.0 & +8.0 \\
+15.0 & +15.0 \\
+75.0 & +90.0 \\
+107.0 & +107.0
\end{array}
$$

At the end of this description, an end card (with a +99999.0 in the first field) will be added.

Figure E-5 gives a sample of the printout obtained from SCRIBBLE. 


\section{OPERATING INSTRUCTIONS}

SCRIBBLE is operated under MONITOR control. It is necessary to place the old AGN-GAM tape or logical tape number 1 , the new AGN-GAM tape (to be written) on tape number 6 , and erasable tapes on number 5 and 7 .

If an existing tape is just to be printed, it should be placed on tape number 6 with an erasable tape on number 1 .

There are a number of internal checks of input data. When appropriate, these checks result in error statements in the off-line printout and an automatic exit from the program. 


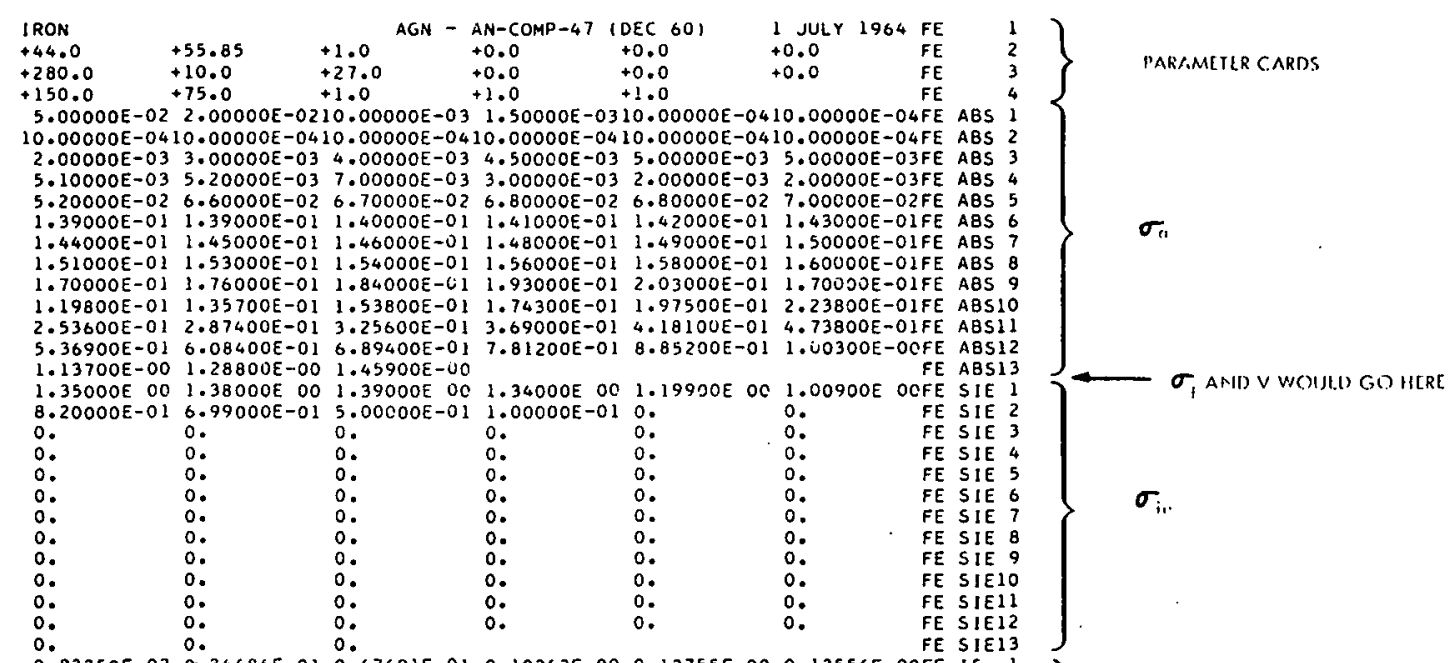

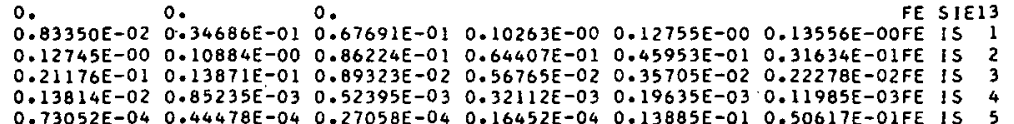

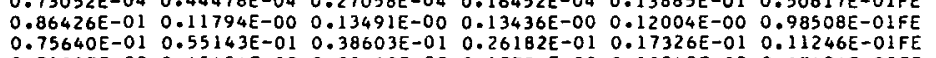

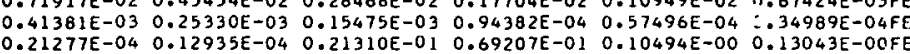

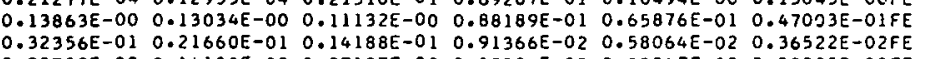

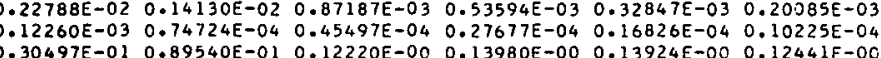

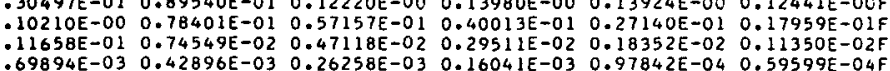

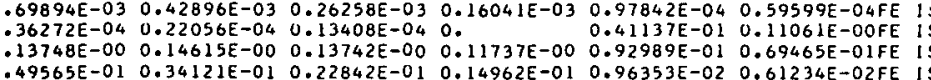

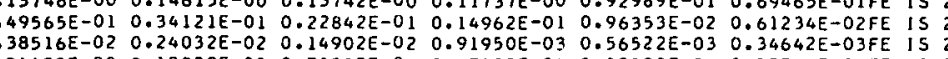

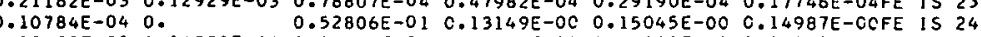

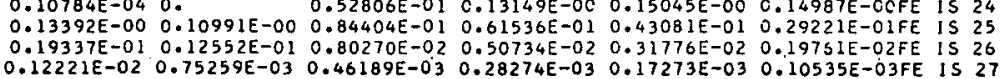

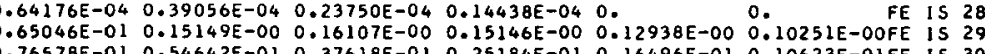
$0.76558 E-010.54642 E-010.37618 E-010.25184 E-010.16496 E-010.10623 E-01 F E$ is 30

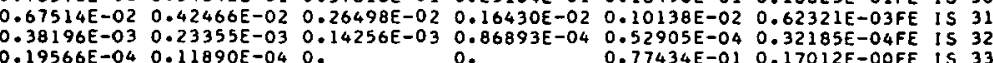

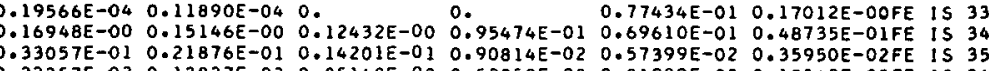

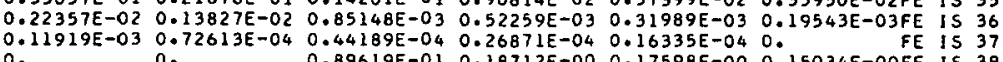

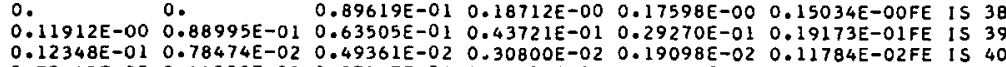

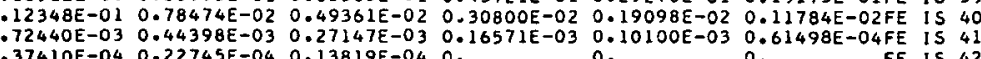

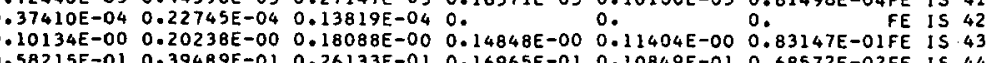

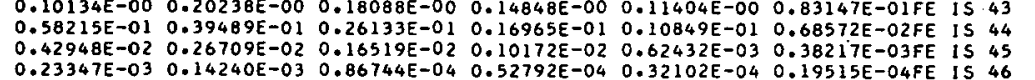

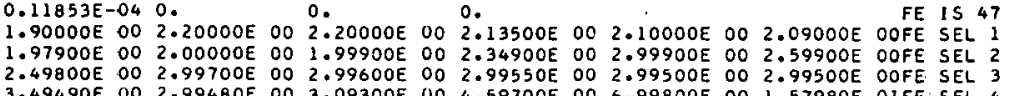

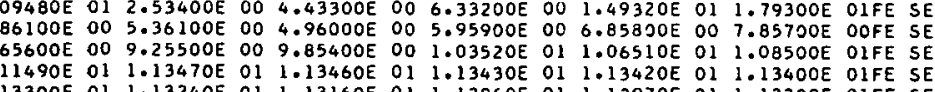
$\begin{array}{lllllll} & \end{array}$

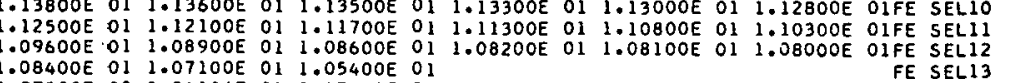

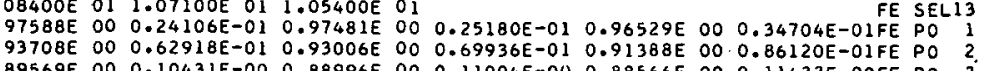

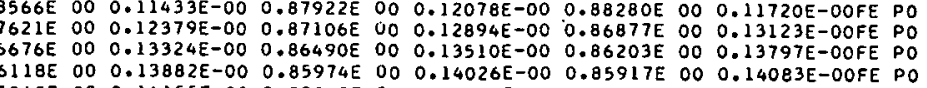

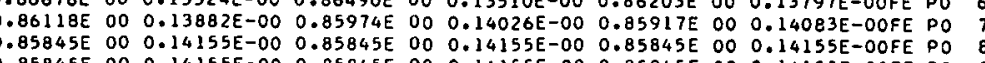

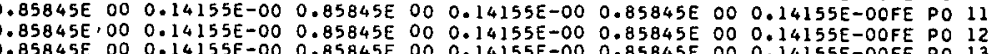

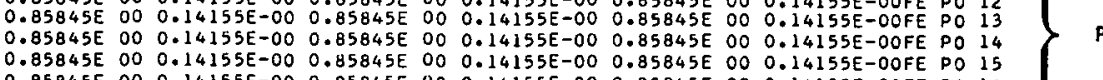

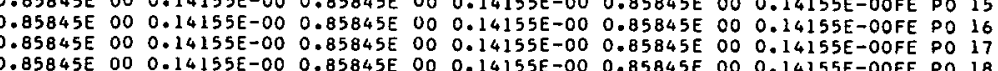

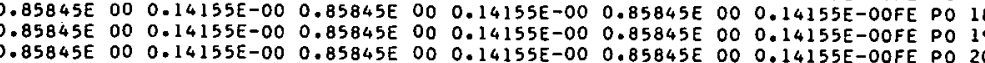

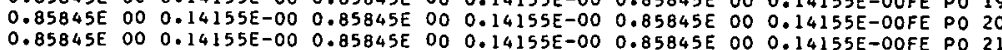

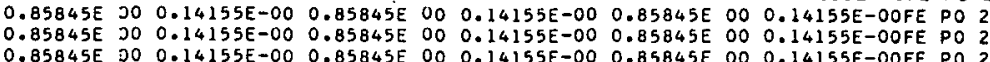

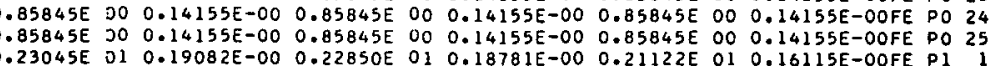
$\begin{array}{ll} & \end{array}$ 年

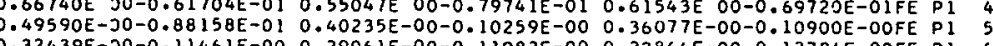

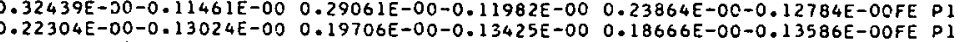

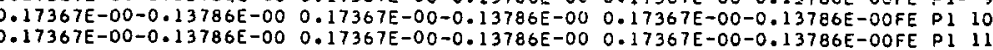

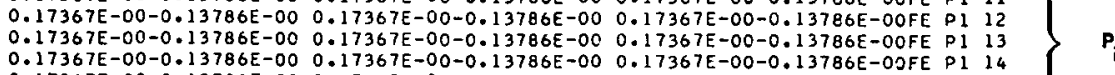

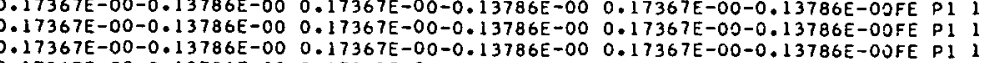

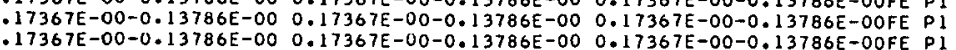

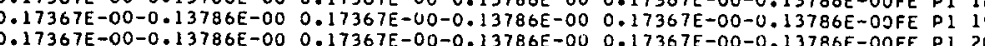
作

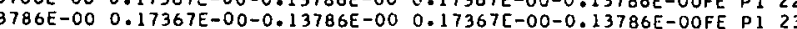

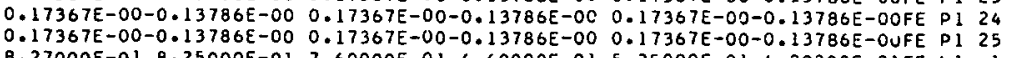

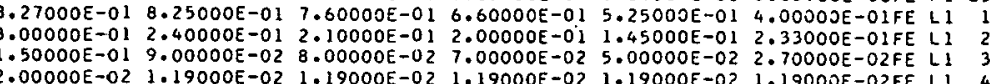

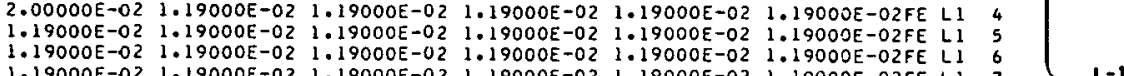

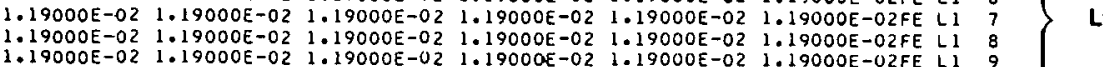

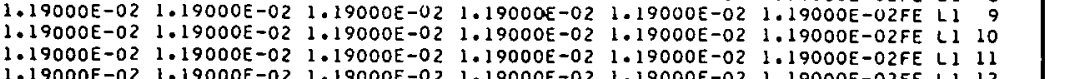




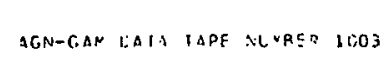
1 JUL 1954

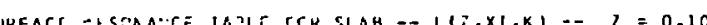

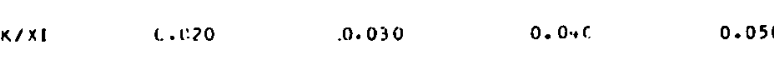

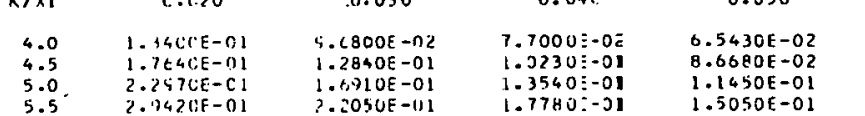

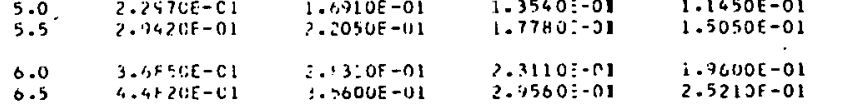

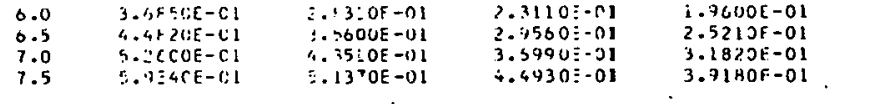

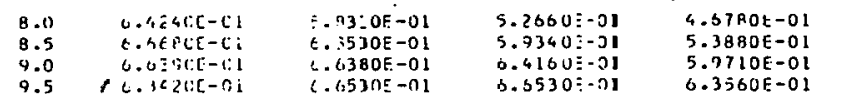

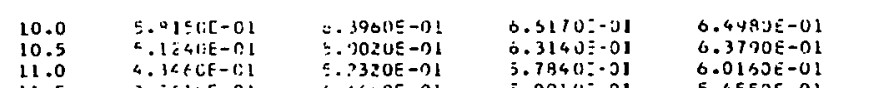

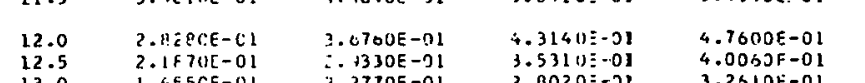

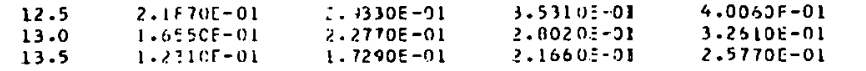

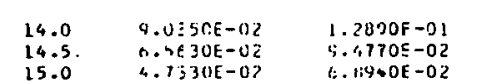

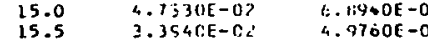

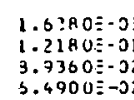

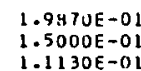

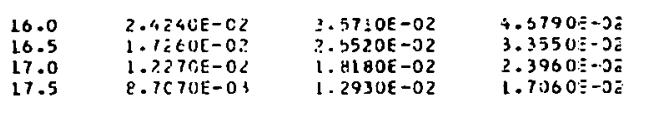

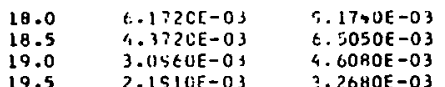

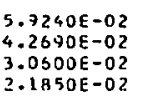

$1.556 J E-02$
$1.1060 E-02$
$7.8450 E-0$
$5.5610 E-03$

5.5610E-03

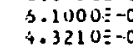

$3.0590 \div-0$
$4.2500 E-02$
$5.4930 E-02$

$\begin{array}{lll}1220 E-02 & 5.75300-02 & 5.1840 E-02 \\ .2 A 80 E-02 & 7.3430 E-02 & 6.4840 E-02\end{array}$

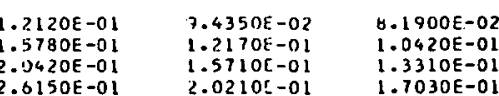

$\begin{array}{lll}3.2930 E-01 & 2.5770 L-01 & 2.1730 E-01 \\ 4.0480 E-01 & 3.2380 E-01 & 2.7500 E-01 \\ 4.8230 E-01 & 3.9780101 & 3.4260 E-01 \\ 5.5390 E-01 & 4.7410-01 & 4.1700 E-01\end{array}$

$\begin{array}{rll}6.1150 E-31 & 5.4530 E-01 \quad 4.9190 E-01\end{array}$

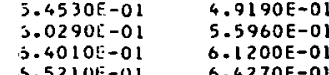

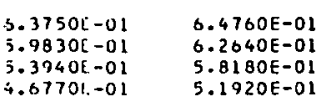

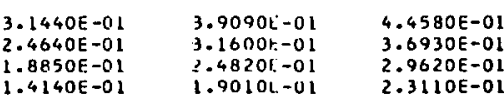

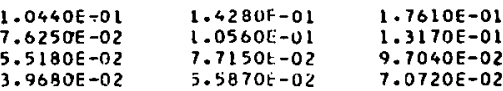

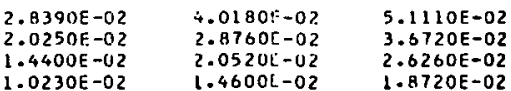

$7.2560 E-03$

$1.0370 \mathrm{k}-02$
AGN-GAR CATA TAPE NUPBER 1003

SURFACE RFSOAMAMCE TAMLE FOH SLAB -- LAPRIMEIK, K:I
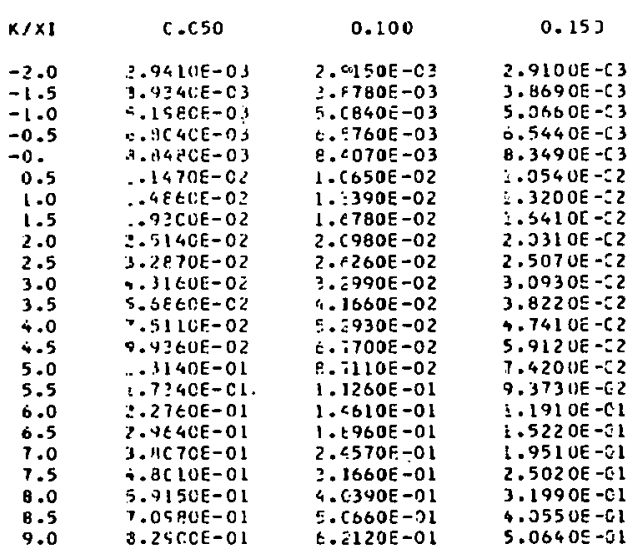

1 JUL 1964

0.203
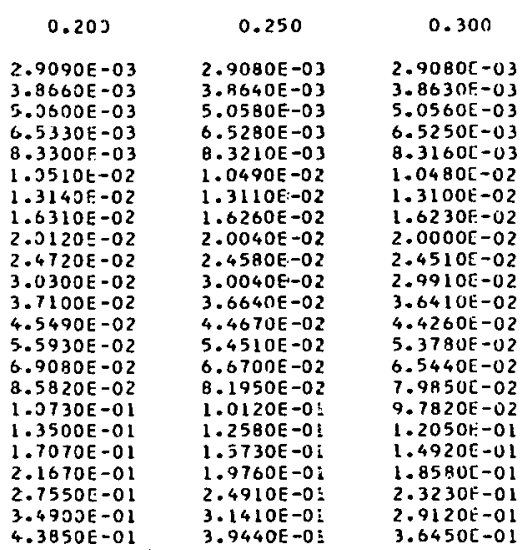

0.350

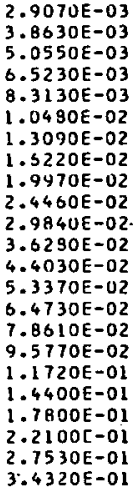

9.999

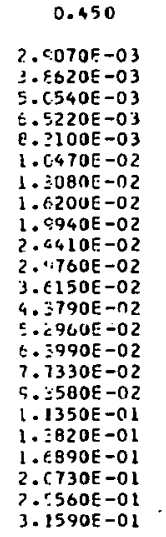

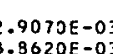
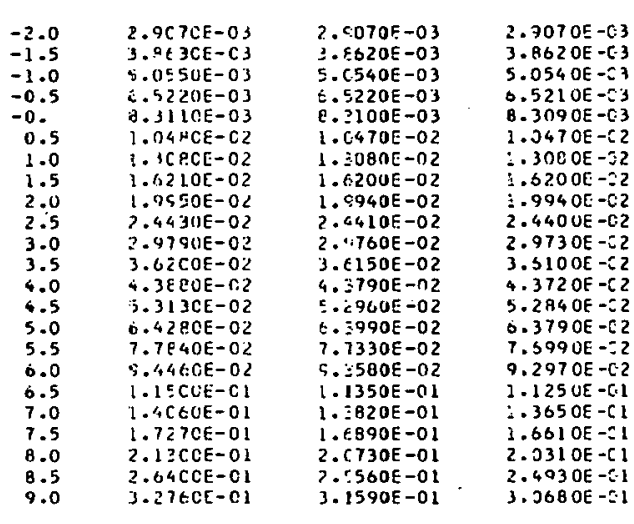

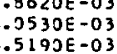

$8.3050 E-03$
$1.0470 E-02$
$1.3050 E-D 2$

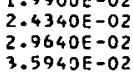

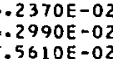

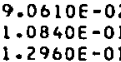

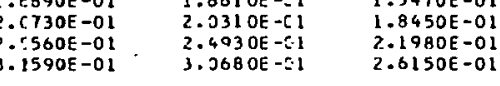

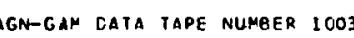

: JiL 1964
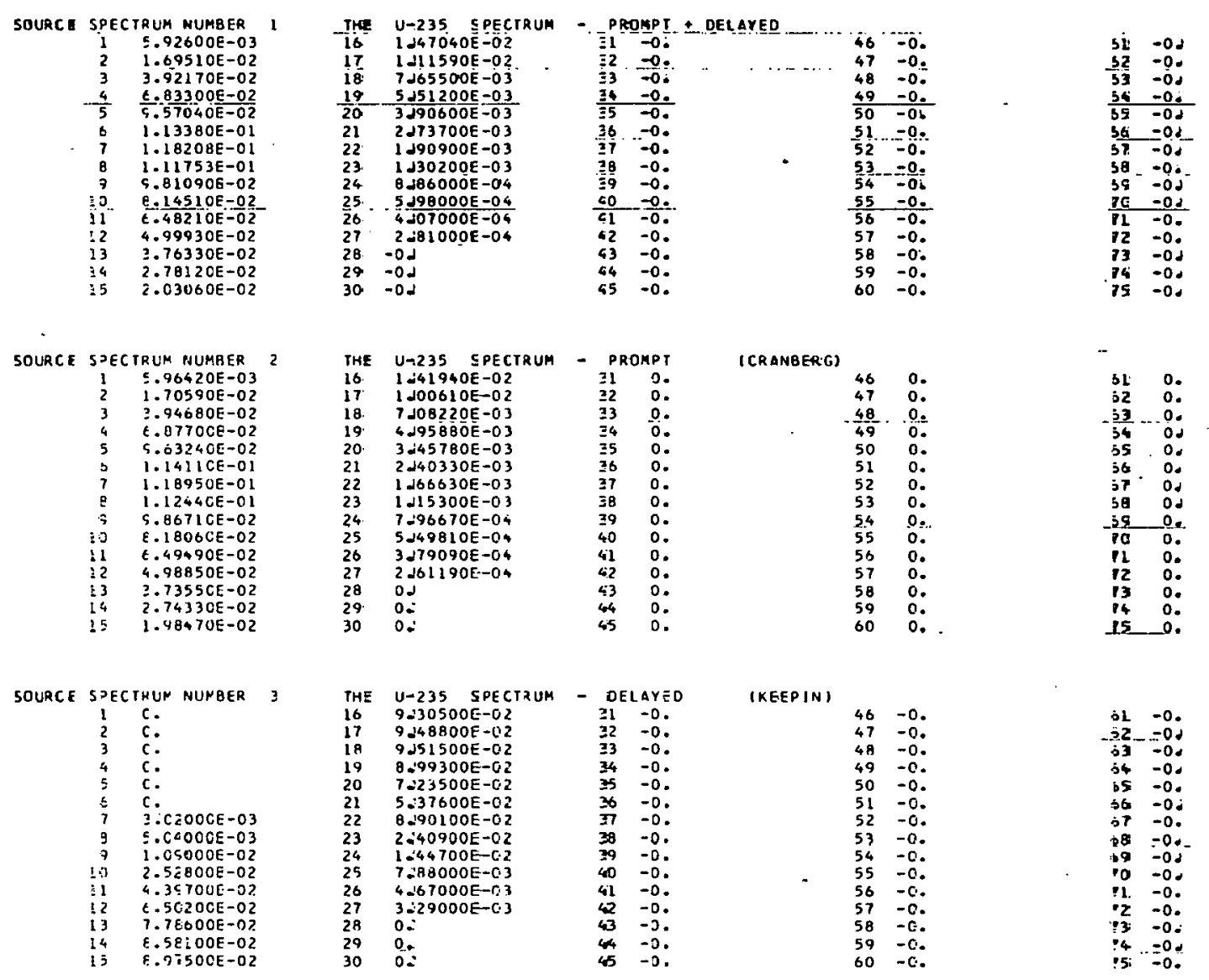


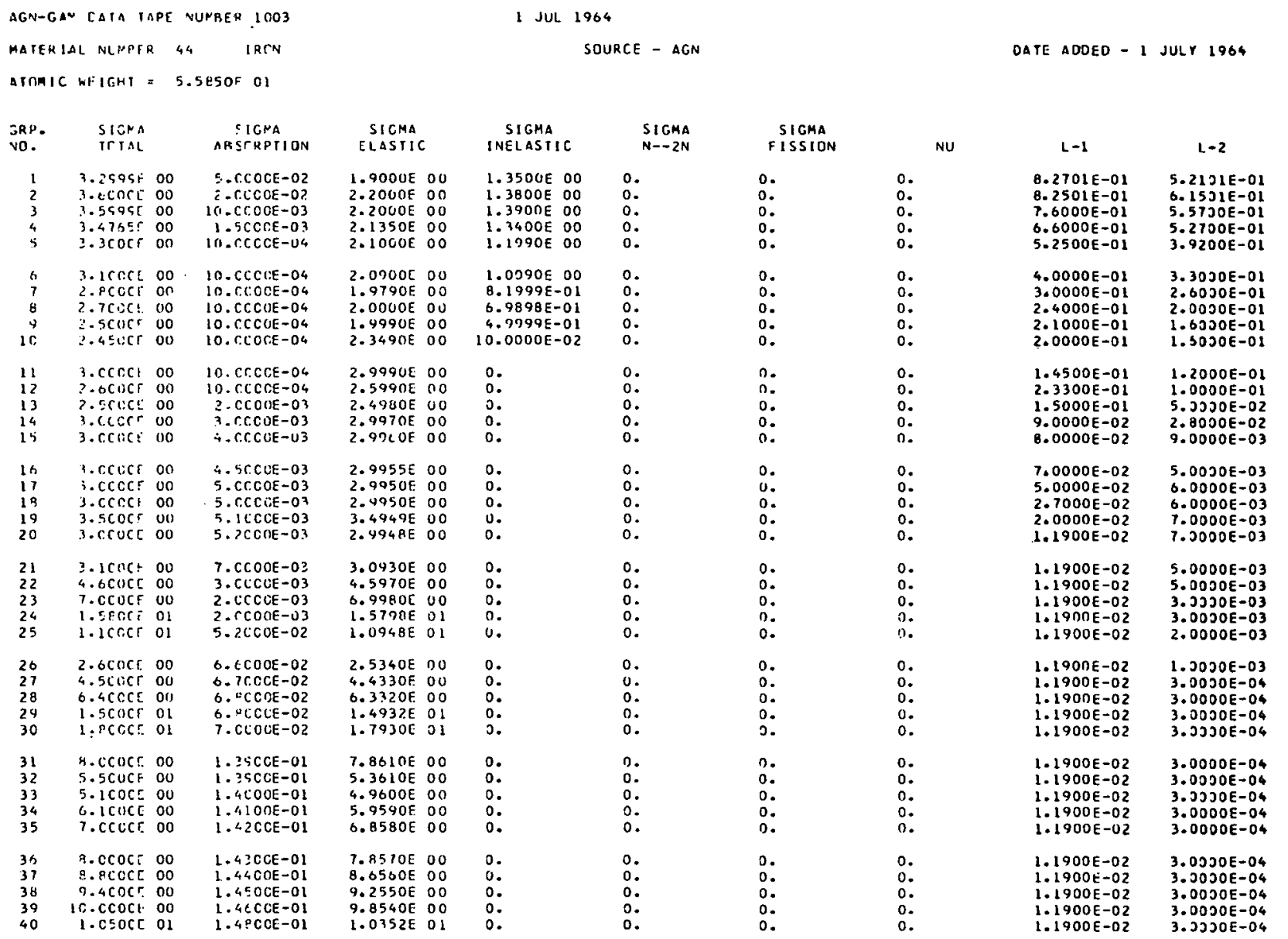

agn-gaN cata tape nUMBER ICOJ

MATER:AL NLMEER 44 IRCN
ATOMIC WEIGHT $=5.5850 F 01$

1 JUL 1964

GRPD SIGMA SIGNA
NO. TCIOL

SIGMA
ELASTIC INGA
SIGASTIC

SIGMA
$F 1 S S I O N$
$0:$
$0:$
$0:$
$0:$
$00:$
$0:$
$0:$
$0:$
$0:$
$0:$
$0:$
$0:$
$0:$
$0:$
$0:$
$0:$
$0:$
$0:$
$0:$
$0:$
$0:$
$0:$
$0:$
$0:$
$0:$
$0:$
$0:$
$0:$
$0:$
$0:$
0.

DATE AODED - I JULY 1964

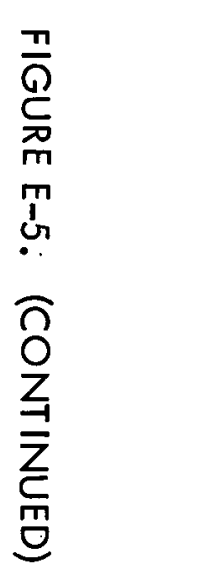

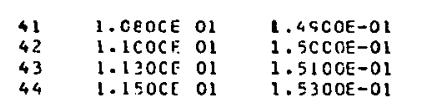

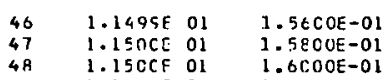

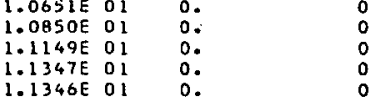

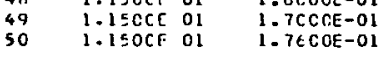

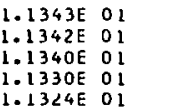

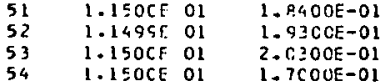

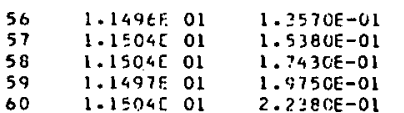

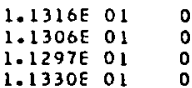

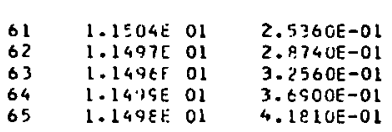

$\begin{array}{lll}1.1360 E & 01 & 0 \\ 111350 E & 01 & 0 \\ 1.13306 & 01 & 0 \\ 1.1300 \text { 01 } & 0 .\end{array}$

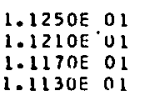

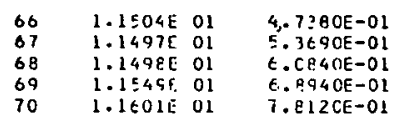

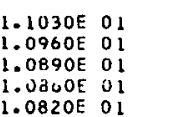

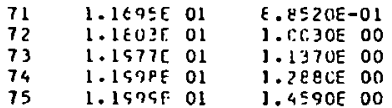

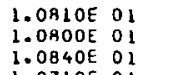

AGN-GAN TAAA TAPE NUPEEP 18003

1 JUL 1964

INELASIIC SCATIERING METRIX FOR Material MUMBER 44 IROU
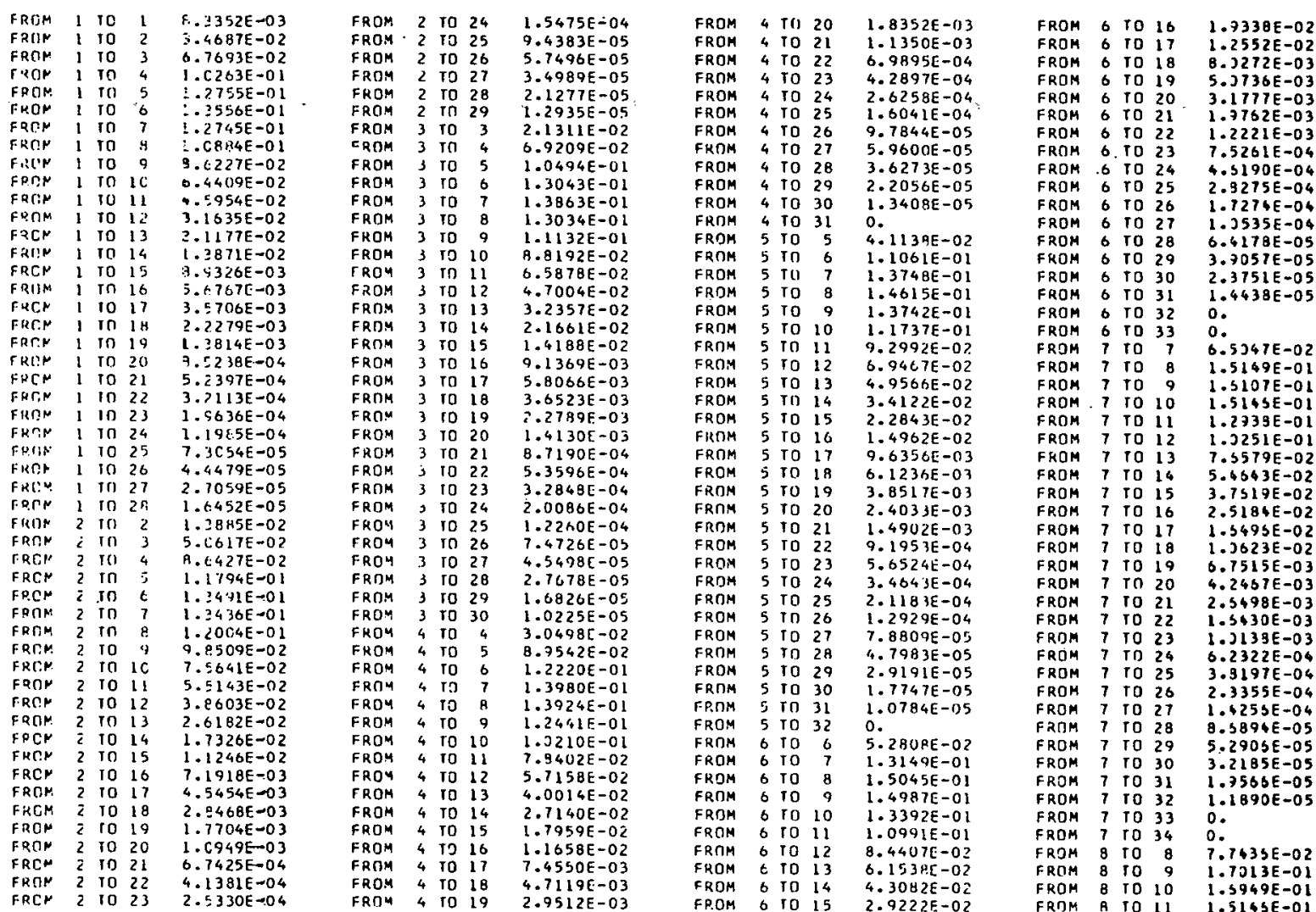

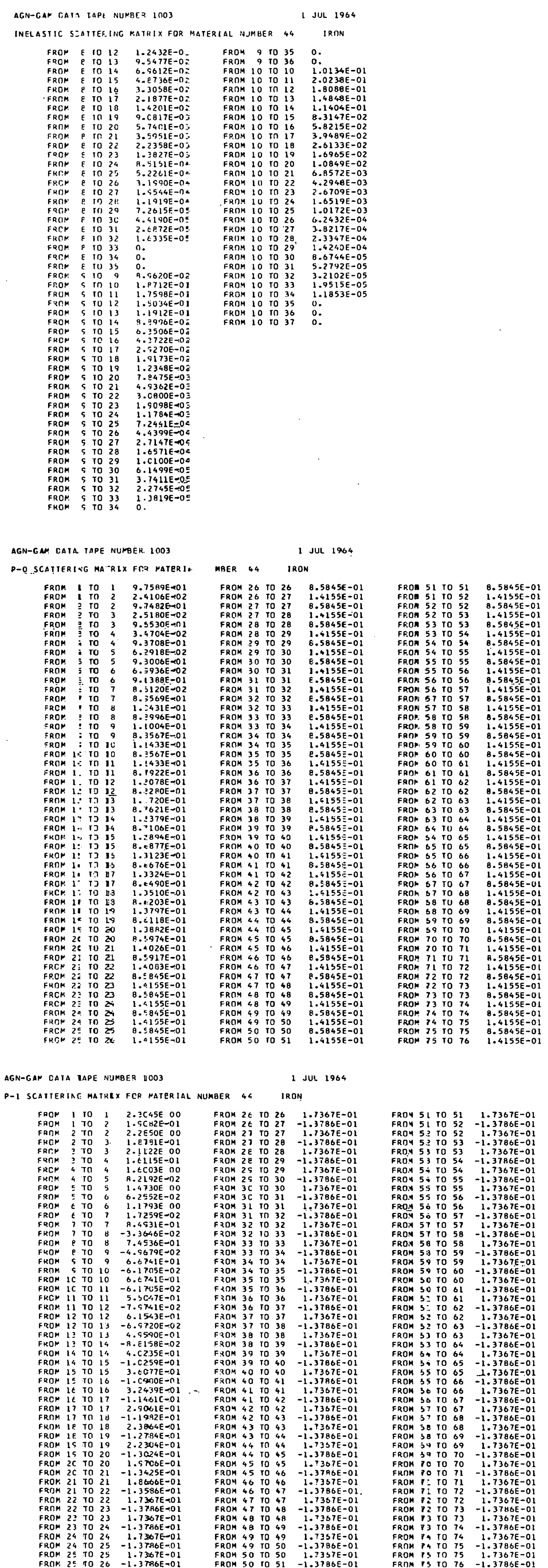


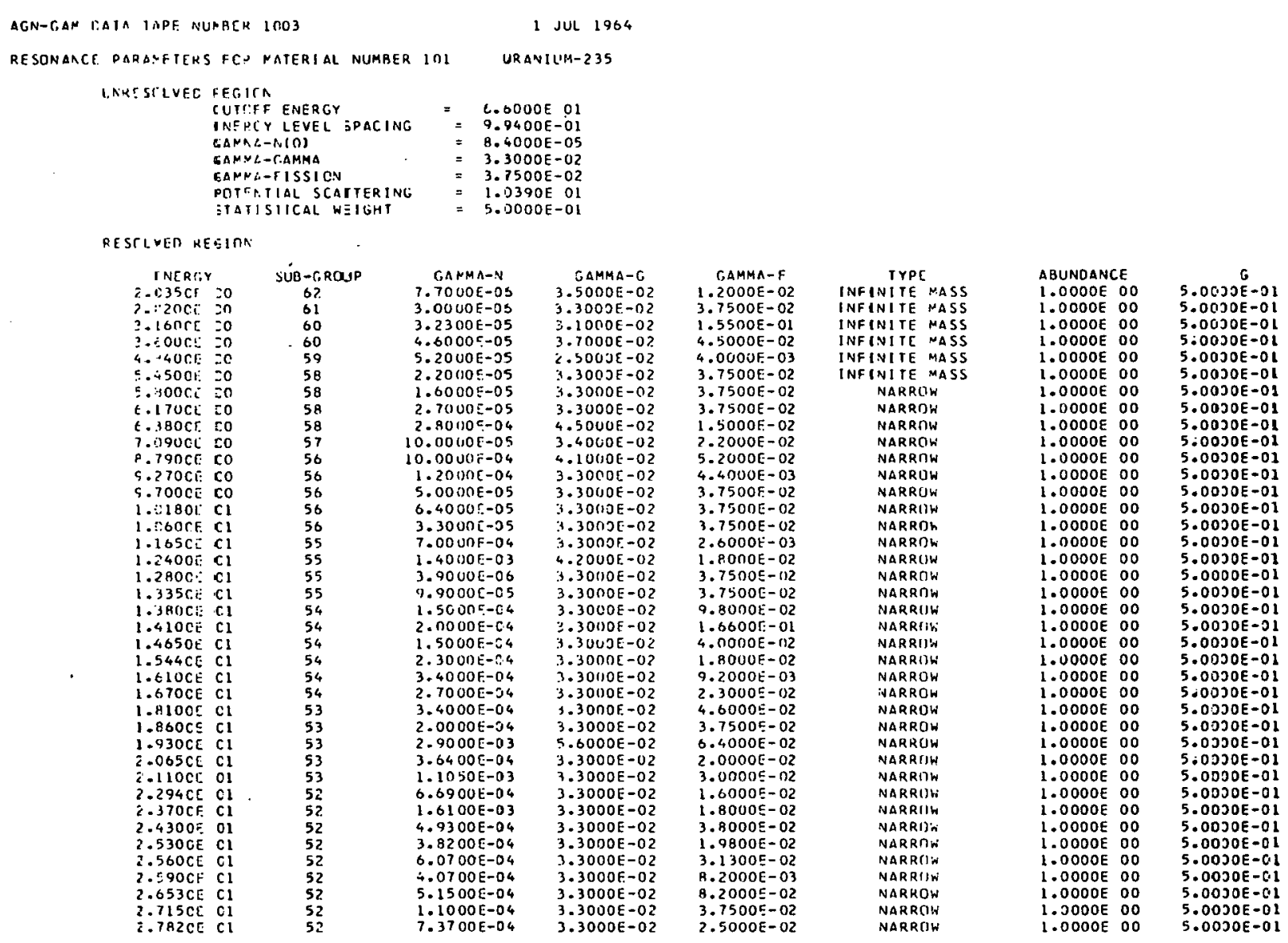

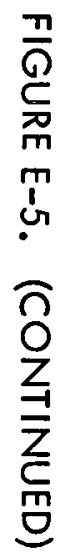

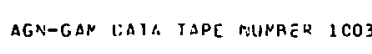
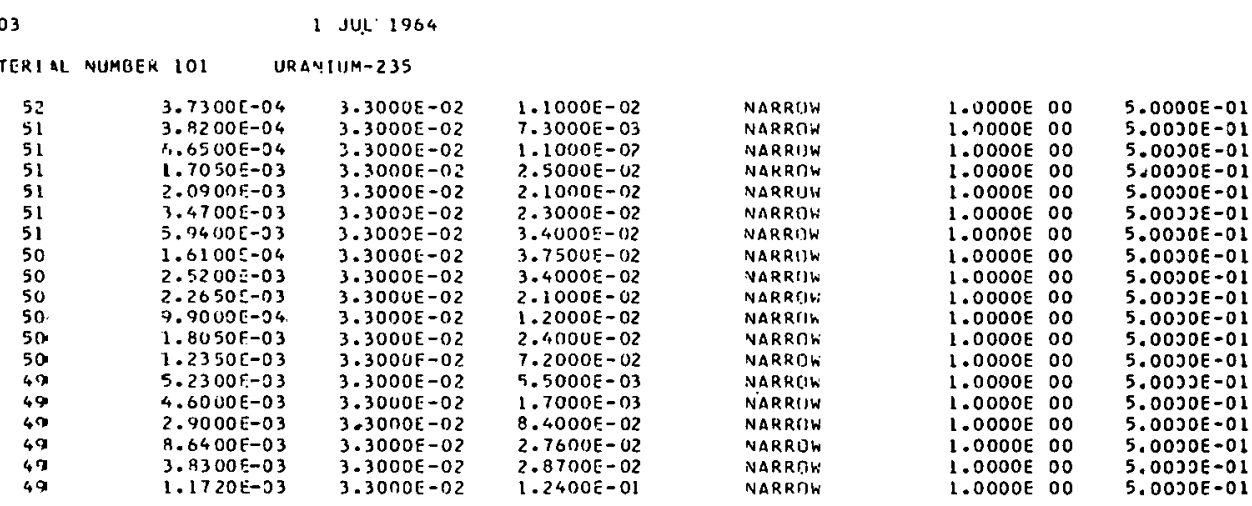

aGN-GAN CATA TAPE NLPBER 1003

SUMPARY TABLES

mat mategial description

42
43 Maromiun
4 Manganese

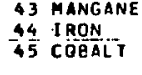

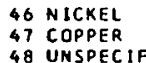

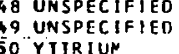

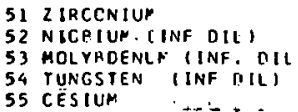

56 MERCURY

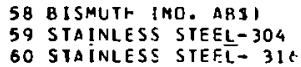

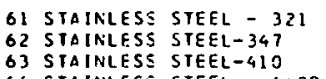

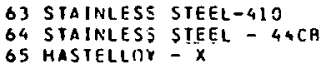

66 INCONEL
67 INCNEL - $x$
68 FECRAL

69 ALCALIML - 006
60 UNSPECIFIED

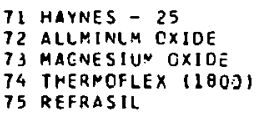

76 UNSPECIFIEC
77 UNSPECIFIEU

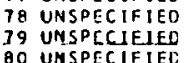

81 RORON
82 CACMIUN (INF OIL)

1 JUL 1964

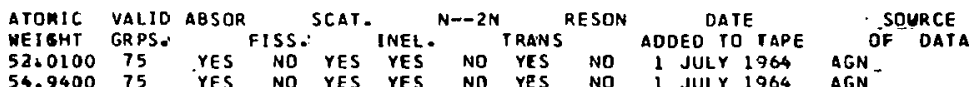

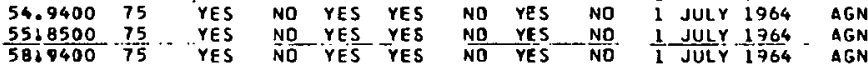

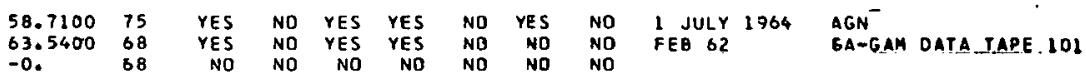

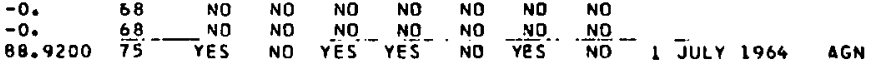

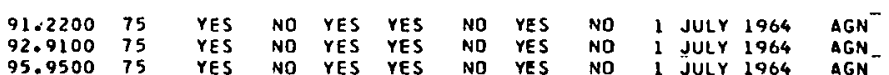

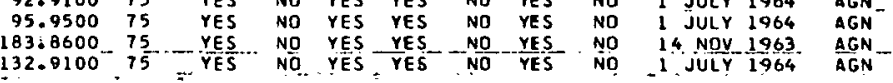

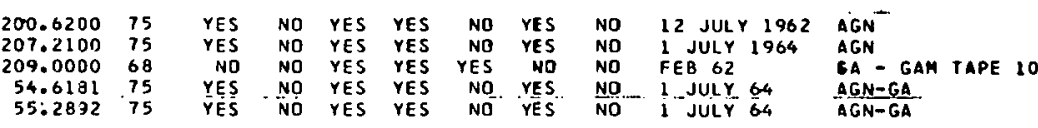

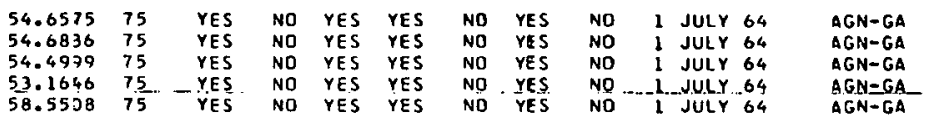

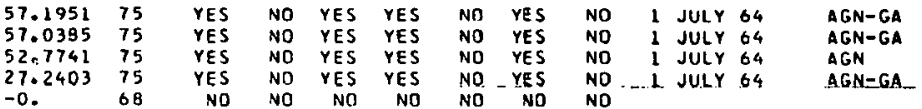

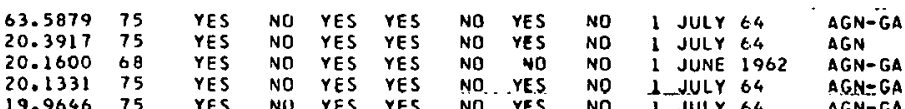

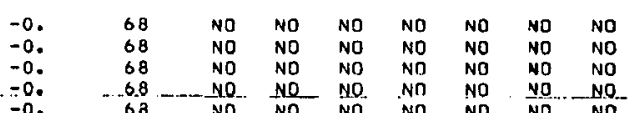




\section{AGN-GAM PROGRAM LISTING}

A simplified block diagram of the AGN-GAM code is shown in Figure F-1. Used with the program 1 isting, this diagram will he1p explain the overall operation of the code. The large number of comment cards inserted into the FORTRAN source program will also help to explain the operations being performed.

Since the listing of the program contains 51 pages and since this type of material is of interest to only a few who will read this document, the actual listing is omitted. However, it can be obtained from the Argonne Code Center.

Further explanations of the program, its operation, or other items concerning AGN-GAM may be obtained from the authors. 

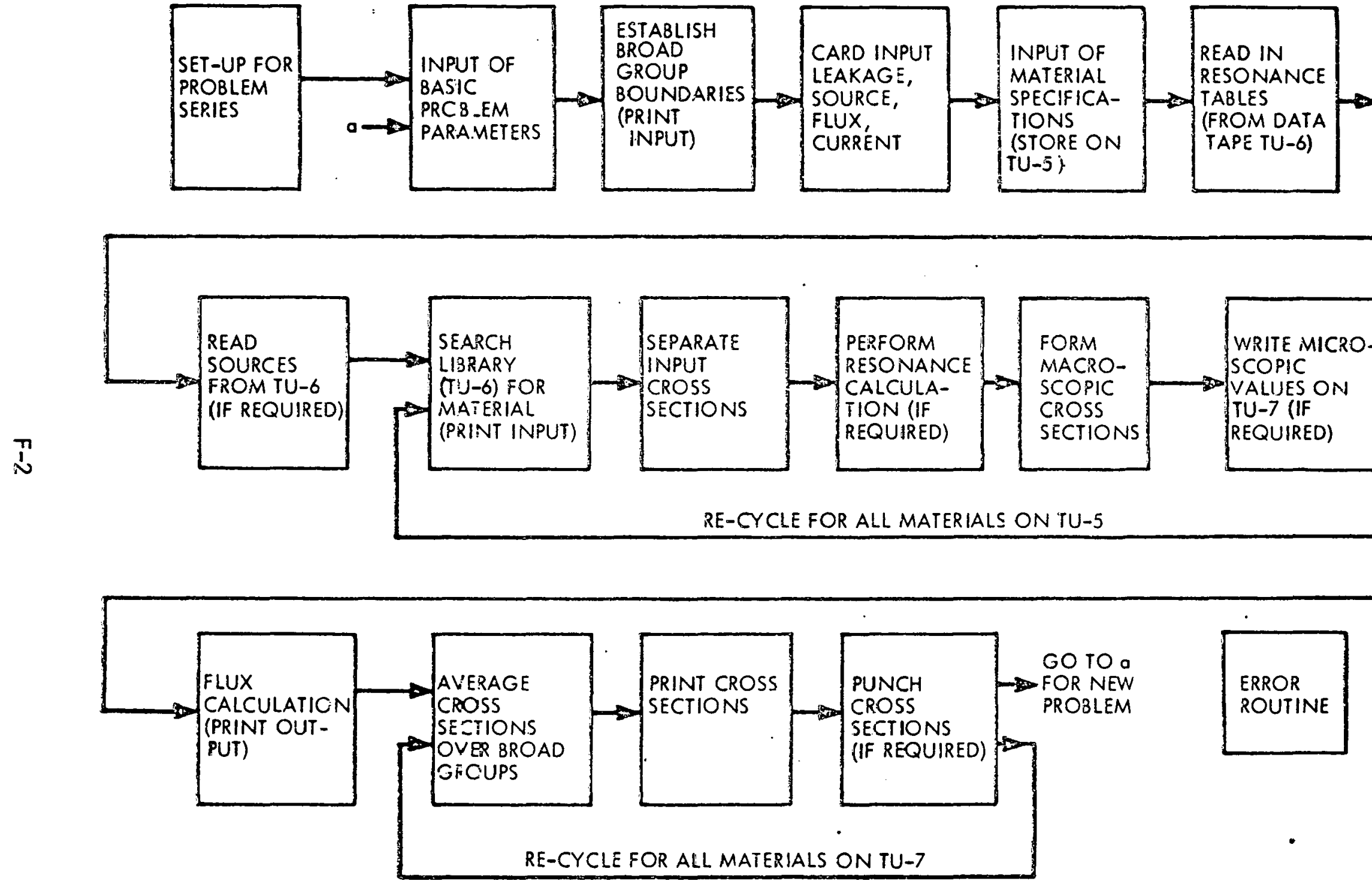

FIGURE $=-1$. SIMPLIFIED BLOCK DIAGRAM, AGN-GAM CODE 
Subgroup integrated quantities, such as the flux and current terms are designated by

$$
x_{i}=\int_{i} \mathrm{dE} X(E)
$$

The mean-value theorem is used to specify the pertinent subgroup constants

$$
Y_{i}=\frac{\int_{i} d E X(E) X(E)}{\int_{i} d E X(E)}
$$

Group transfer cross sections are specified in the usual (Section II-A-2 and Appendix B) manner with the $(n, 2 n)$ transfer probability normalized to unity. In addition, only isotropic inelastic and $(n, 2 n)$ reactions will be considered while elastic scattering may include components up to and including the linear anisotropic component.

\section{The $\mathrm{P}_{1}$ Equations}

a. The Subgroup Relations

The $P_{1}$ equations obtained (with Equations A-24 and A-25 of Appendix A) under the above assumptions are as follows:

$$
\begin{gathered}
\widetilde{J}(E)+\Sigma_{t}(E) \varphi(E)=\int_{E}^{E / \alpha} \mathrm{d} E^{\prime} \Sigma_{e 1 .}^{0}\left(E^{\prime}-E\right) \varphi\left(E^{\prime}\right)+\int_{E}^{\infty} d E^{\prime} \Sigma_{i e_{0}}^{0}\left(E^{\prime} \rightarrow E\right) \varphi\left(E^{\prime}\right) \\
+2 \int_{E}^{\infty} \mathrm{d} E^{\prime} \Sigma_{n, 2 n}^{0}\left(E^{\prime} \rightarrow E\right) \varphi\left(E^{\prime}\right)+s_{v}(E)+s_{s}(E) \\
\mathcal{L}(E) \varphi(E)+3 \Sigma_{t}(E) \widetilde{J}(E)=\int_{E}^{E / \alpha} d E^{\prime} \Sigma_{e l}^{l}\left(E^{\prime} \rightarrow E\right) \tilde{J}\left(E^{\prime}\right)
\end{gathered}
$$

where:

$$
\begin{aligned}
& s_{v} \text { is the volume source term } \\
& s_{s} \text { is the surface source term }
\end{aligned}
$$


These equations are now integrated over the $i^{\text {th }}$ subgroup. (Later on, the volume source term will be assumed proportional to a known, for example fission, spectrum.) If Equations (4) and (5) are used and if it is assumed that the intragroup flux and current spectra are similar, the following expressions are obtained when the intragroup transfer terms are moved to the left side of the equations.

$$
\begin{aligned}
& \tilde{J}_{i}+\left[\Sigma_{t_{i}}-\left(\Sigma_{e l_{i \rightarrow i}}^{0}+\Sigma_{i e_{i \rightarrow i}}^{0}+2 \Sigma_{n, 2 n_{i \rightarrow i}}^{0}\right)\right] \varphi_{i}=s_{v_{i}}+s_{s_{i}} \\
& +\sum_{j<i}\left(\Sigma_{e l_{j \rightarrow i}}^{0}+\Sigma_{i t_{j \rightarrow i}}^{0}+2 \Sigma_{n, 2 n_{j \rightarrow i}}^{0}\right) \varphi_{j} \\
& \mathcal{L}_{i} \varphi_{i}+\left(3 \Sigma_{t}-\Sigma_{e 1_{i} \rightarrow i}^{1}\right) \widetilde{J}_{i}=\sum_{j<i} \Sigma_{e l_{j \rightarrow i}}^{1} \tilde{J}_{j}
\end{aligned}
$$

The following definitions are now made:

$$
\begin{aligned}
& \Sigma_{0_{i}}=\Sigma_{t_{i}}-\left(\Sigma_{e 1_{i \rightarrow i}}^{0}+\Sigma_{i e_{i \rightarrow i}}^{0}+2 \Sigma_{n, 2 n_{i \rightarrow i}}^{0}\right) \\
& \Sigma_{1_{i}}=3 \Sigma_{t_{i}}-\Sigma_{e 1_{j \rightarrow i}}^{1} \\
& s_{i}^{0}=\sum_{j<i}\left(\Sigma_{e 1_{j \rightarrow i}}^{0}+\Sigma_{i e_{j \rightarrow i}}^{0}+2 \Sigma_{n, 2 n_{j \rightarrow i}}^{0}\right) \varphi_{j} \\
& s_{i}^{1}=\sum_{j<i} \Sigma_{e 1 . j \rightarrow i}^{1} \tilde{J}_{j} \\
& s_{i}=s_{v_{i}}+s_{s_{i}}
\end{aligned}
$$


Thus, the $P_{1}$ equations are:

$$
\begin{aligned}
& \widetilde{J}_{i}+\Sigma_{a_{i}} \varphi_{i}=s_{i}^{0}+s_{i} \\
& \mathcal{L}_{i} \varphi_{i}+\Sigma_{1_{i}} \widetilde{J}_{i}=s_{i}^{1}
\end{aligned}
$$

Solving Equation (12) for $\widetilde{J}_{i}$ and substituting into Equation (11) yields the $P_{1}$ difference equations:

$$
\begin{aligned}
& \varphi_{i}=\frac{\Sigma_{1}\left(s_{i}^{0}+s_{i}\right) s_{i}^{1}}{\Sigma_{0} \Sigma_{1}-\mathcal{L}_{i}} \\
& \tilde{J}_{i}=\frac{s_{i}^{1}-\mathcal{L}_{i} \varphi_{i}}{\Sigma_{1}}
\end{aligned}
$$

b. The Group Leakage Term, $\mathfrak{L}_{\mathbf{i}}$ The subgroup leakage parameter has been defined by Equation 5 as a flux weighted average of its energy dependent counterpart, i.e.:

$$
\mathcal{L}_{i}=\frac{\int \operatorname{div} \operatorname{grad} \varphi_{i}(\vec{r}) d v}{\varphi_{i}}
$$

Using the group form of Fick's law (Equation 43) along the same lines of Appendix A. IV-A., one obtains the two relationships:

$$
\mathcal{L}_{i}=-3 \Sigma_{\text {tr }_{i}} \frac{\mathrm{L}_{\text {out }}}{\varphi_{i}}
$$

and

$$
\mathcal{L}_{i}=\frac{\int \nabla^{2} \varphi_{i}(\vec{r}) d V}{\varphi_{i}}-3 \Sigma_{t r} \frac{L_{i}}{\varphi_{i}}
$$

where:

$$
\begin{aligned}
& \mathrm{L}_{\text {out }} \text { is the group integrated leakage out of the region } \\
& \mathrm{L}_{\text {in }} \text { is the equivalent leakage into the region. (Both } \mathrm{L}_{\text {out }} \text { and } \mathrm{L}_{\text {in }} \\
& \text { are positive quantities.) }
\end{aligned}
$$


Usually, only the multigroup (Section II.D.I) leakage parameter, $\mathfrak{L}_{\ell}$, is known. The multigroup and subgroup equations are selfconsistent and thus Equations (15) - (17) are satisfied by $\mathcal{L}_{\ell}$ (replacing subscript $i$ by $\ell$ ). From Equation (15), the relationship of the sub and multigroup leakage parameters is established:

$$
\mathcal{L}_{\ell}=\frac{\sum_{\text {in } \ell_{i}{ }^{\varphi_{i}}}}{\varphi_{\ell}}
$$

To estimate the energy (or lethargy) dependence of the subgroup leakage parameter, $\mathcal{L}_{i}$, the multigroup terms, $\mathcal{L}_{\ell}$, are plotted as a bar graph and a smooth curve is drawn through this graph. This reveals the gross structure of this dependence and subgroup values can be read off the curve.

If the multigroup leakage parameter is also not available, the one group theory (Section IV, Appendix A) can be used to estimate $\mathcal{L}$; the accuracy of the estimate is greater if the group diffusion coefficients are known.

\section{The $B_{1}$ Equations}

The pertinent $B_{1}$ equations are given by Equations (A-4.3) and (A-44) of Appendix A.

$$
\begin{aligned}
& \mathrm{BJ}(E)+\Sigma_{t}(E) \varphi(E)=\int_{E}^{E / Q^{\prime}} \mathrm{d} E^{\prime} \Sigma_{e l}^{0}\left(E^{\prime} \rightarrow E\right) \varphi\left(E^{\prime}\right)+\int_{E}^{\infty} \mathrm{d}^{\prime} \Sigma_{i e_{0}}^{0}\left(E^{\prime} \rightarrow E\right) \varphi\left(E^{\prime}\right) \\
& +2 \int_{E}^{\infty} d E^{\prime} \Sigma_{n, 2 n}^{0}\left(E^{\prime}-E\right)\left(p\left(E^{\prime}\right)+S(E)\right. \\
& -B \varphi(E)+3 \Sigma_{t}(E) \alpha(E) J(E)=\int_{E}^{E / \alpha} \mathrm{dE}^{\prime} \Sigma_{e 1}^{1}\left(E^{\prime} \rightarrow E\right) J\left(E^{\prime}\right)
\end{aligned}
$$

The argument $B$, which is inherent in all flux and current terms, has been omitted. 
If integration is performed over the $i^{\text {th }}$ subgroup, in the same fashion as the corresponding $P_{1}$ relations are reduced, and if the average of a product is assumed equal to the product of the averages, the following expressions are derived with definitions of Equation (10).

$$
\begin{aligned}
& \mathrm{BJ}_{i}+\Sigma_{0_{i}} \varphi_{i}=s_{i}^{0}+s_{i} \\
& -\mathrm{B} \varphi_{i}+\Sigma_{2_{i}} J_{i}=s_{i}^{1}
\end{aligned}
$$

where:

$$
\Sigma_{2_{i}}=3 \Sigma_{t_{i}} \alpha_{i}-\Sigma_{e l_{i \rightarrow i}}^{1}
$$

Solving Equation (22) for $\mathrm{J}_{i}$ and substituting into Equation (21) yields the $B_{1}$ difference equations:

$$
\begin{aligned}
& \varphi_{i}=\frac{\Sigma_{2}\left(s_{i}^{0}+s_{i}\right)-B s_{i}^{1}}{\Sigma_{0} \Sigma_{i}{ }_{2}+B^{2}} \\
& J_{i}=\frac{s_{i}^{1}+B \varphi_{i}}{\Sigma_{2}}
\end{aligned}
$$

4. The Combined $P_{1}-B_{1}$ Relations

The $P_{1}$ and $B_{1}$ equations can be combined into one set of

relations .

$$
\begin{aligned}
\varphi_{i} & =\frac{\Sigma_{2}\left(s_{i}^{0}+s_{i}\right)-a_{i} s_{i}^{1}}{\Sigma_{0} \Sigma_{i}{ }_{i}-b_{i}} \\
J_{i} & =\frac{s_{i}^{1}-c_{i} \varphi_{i}}{\Sigma_{2}}
\end{aligned}
$$


where:

$$
\mathbf{P}_{1} \text { Approx. } \quad \mathrm{B}_{1} \text { Approx. }
$$

$\begin{array}{ccc}a_{i} & 1.0 & B \\ b_{i} & \mathcal{L}_{i} & -B^{2} \\ c_{i} & \mathcal{L}_{i} & -B\end{array}$

$\alpha_{i}$ in Equation (23) is redefined as

$$
\left.\begin{array}{c}
\alpha_{i}=1.0 \text { for the } P_{1} \text { approximation } \\
\alpha_{i}=\frac{B}{\Sigma_{t}} \frac{\tan ^{-1}\left(\frac{B}{\Sigma_{t}}\right)}{\left.3^{\prime} 1-\frac{B}{\Sigma_{t}} \tan _{i}=1\left(\frac{B}{\Sigma_{t}}\right)\right)} \text { for the } B_{1} \text { apprnximation }
\end{array}\right\}
$$

$\Sigma_{0_{i}}$ as well as the source terms, are defined by Equation (10).

$$
\begin{aligned}
& \text { Finally, the volume source term, may be written as } \\
& s_{v_{i}}=k h_{i}
\end{aligned}
$$

where:

$k$ is the constant which normalizes the volume source to the surface source

$\mathrm{h}_{i}$ is the integral of a known spectrum nver the $i^{\text {th }}$ subgroup

$$
\text { For either a } P_{1} \text { problem without a surface source or a } B_{1}
$$

calculation, the normalization is arbitrary and $k$ is taken as unity.

\section{Current Calculation Using a Known Flux}

If the neutron flux and the sources are known, the current term (in the $\mathrm{P}_{1}$ sense) can be calculated directly from the conservation relation (Equation 11 ).

$$
J_{i}=s_{i}^{0}+s_{i}-\Sigma_{0} \varphi_{i}
$$

The calculation can be performed with both a volume and a surface source if the input flux is consistent with the source magnitudes. Specifically, this is accomplished by use of the constant in Equation (29). Since Equation (30) 
is an exact relation, the accuracy of the current term is equivalent to the accuracy of the original flux calculation.

\section{The Moment Equations}

The relevant moment equations (Equations A-55 through A-57 of Appendix A) are:

$$
\begin{aligned}
\Sigma_{t}(E) M_{00}(E) & =\int_{E}^{E / \alpha} d E^{\prime} \Sigma_{e l}^{0}\left(E^{\prime} \rightarrow E\right) M_{00}\left(E^{\prime}\right)+\int_{E}^{\infty} d E^{\prime} \Sigma_{i e_{0}}^{0}\left(E^{\prime} \rightarrow E\right) M_{00}\left(E^{\prime}\right) \\
& +2 \int_{E}^{\infty} d E^{\prime} \Sigma_{n, 2 n}^{0}\left(E^{\prime} \rightarrow E\right) M_{00}\left(E^{\prime}\right)+s(E) \\
\Sigma_{t}(E) M_{11}(E) & =\frac{1}{3} \int_{E}^{E / \alpha} d E^{\prime} \Sigma_{e 1 .}^{1}\left(E^{\prime} \rightarrow E\right) M_{11}\left(E^{\prime}\right)+M_{00}(E) \\
\Sigma_{t}(E) M_{20}(E) & =\int_{E}^{E / \alpha} d E^{\prime} \Sigma_{e 1}^{0}\left(E^{\prime} \rightarrow E\right) M_{20}\left(E^{\prime}\right)+\int_{E}^{\infty} d E^{\prime} \Sigma_{i e}^{0}\left(E^{\prime} \rightarrow E\right) M_{20}\left(E^{\prime}\right) \\
& +2 \int_{E}^{\infty} d E^{\prime} \Sigma_{n, 2 n}^{0}\left(E^{\prime} \rightarrow E\right) M_{20}\left(E^{\prime}\right)+\frac{1}{3} M_{11}(E)
\end{aligned}
$$

These relations are integrated over the $i^{\text {th }}$ subgroup, in the same fashion as the reduction of the $P_{1}$ relations was performed. The following definitions apply

$$
\begin{aligned}
& s_{00}=\sum_{j<i}\left[\Sigma_{e l_{j \rightarrow i}}^{0}+\Sigma_{i e_{j \rightarrow i}}^{0}+2 \Sigma_{n, 2 n_{j \rightarrow i}}^{0}\right]_{00}^{M_{j}}
\end{aligned}
$$

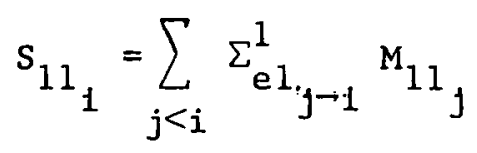

$$
\begin{aligned}
& s_{20}=\sum_{j<i}\left[\Sigma_{e l_{j \rightarrow i}}^{0}+\Sigma_{i e_{j \rightarrow i}}^{0}+2 \Sigma_{n, 2 n_{j \rightarrow i}}^{0}\right]_{20}^{M_{j}}
\end{aligned}
$$


The moments difference equations that are obtained can be solved successively for each subgroup.

$$
\begin{aligned}
& M_{00_{i}}=\frac{s_{00}+s_{i}}{\Sigma_{0}} \\
& M_{11_{i}}=\frac{s_{11_{i}}+3 M_{00}}{\Sigma_{1}} \\
& M_{20}=\frac{s_{20}+\frac{1}{3} M_{11}}{\Sigma_{0}}
\end{aligned}
$$

where the age is:

$$
\tau_{i}=\frac{M_{20}}{M_{00}}
$$

This age represents an average value for the $i^{\text {th }}$ subgroup.

D. MULTIGROUP CONSTANTS

\section{The Group Structure}

'l'he multigroup ctructurc is similar to the subysuup structure used in the development of the spectrum generation difference equations except that the differential energy elements are replaced by subgroups and the subgroups by groups. The assumption is made that there is an integer number of subgroups in a given group (Figure 2).

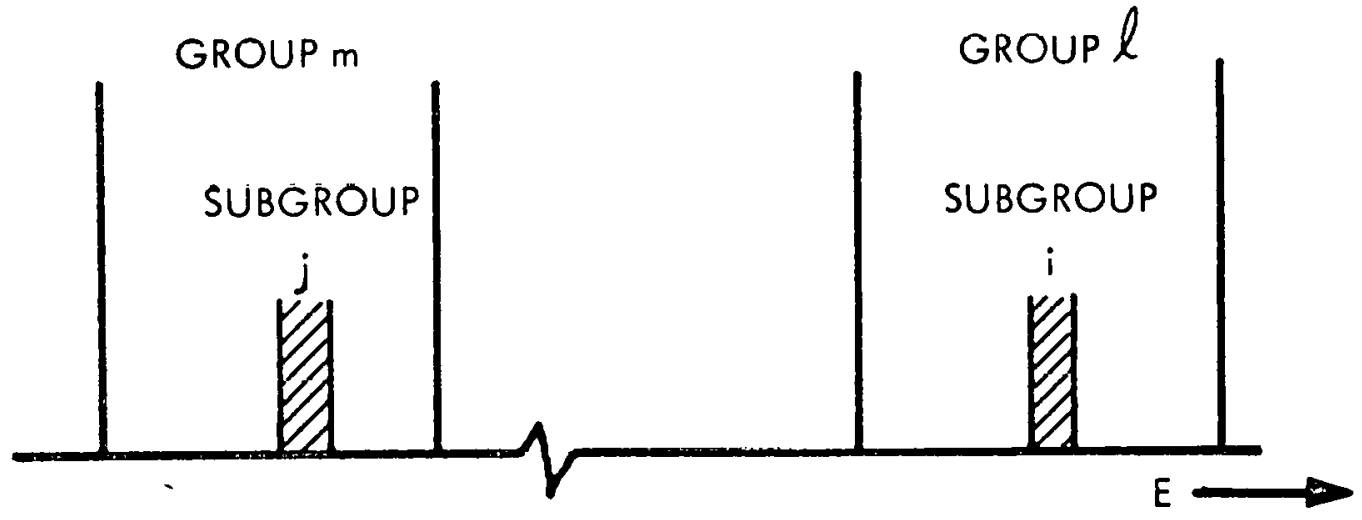

EIGURE 2. GROUP STRUCTURE 
The spectral weighing parameters are:

$$
\begin{aligned}
& \varphi_{\ell}=\sum_{i \text { in } \ell} \varphi_{i} \\
& J_{\ell}=\sum_{i \text { in } \ell} J_{i}
\end{aligned}
$$

The group source term is equal to

$$
s_{\ell}=\sum_{i=1} s_{i}
$$

\section{Group Averaged Parameters}

The group-averaged parameters are defined by the relation

$$
Y_{\ell}=\frac{1}{\varphi_{\ell}} \sum_{i \text { in } \ell} Y_{i} \varphi_{i}
$$

where $\mathrm{Y}$ is equal to the following cross sections

$$
Y=\Sigma_{t}, \Sigma_{s}, \Sigma_{a}, \Sigma_{f}, \nu \Sigma_{f}, \text { and } \Sigma_{c}
$$

and the corresponding microscopic quantities. The group averaged $\nu$ is:

$$
\nu_{\ell}=\frac{1}{\Sigma_{\mathrm{f}_{\ell} \varphi_{\ell}}} \sum_{i \text { in } l}\left(\nu \Sigma_{\mathrm{f}}\right)_{i} \varphi_{i}
$$

3. The Transport Cross Section and Diffusion Coefficient

a. Definition

The multigroup transport cross section and diffusion coefficient are defined by the multigroup Fick's law 


$$
\vec{J}_{\ell}(\vec{r})=\frac{1}{3 \Sigma_{t r_{\ell}}} \operatorname{grad} \varphi_{\ell}(\vec{r})
$$

and

$$
\mathrm{D}_{\ell} \equiv \frac{1}{3 \Sigma_{\mathrm{tr}_{\ell}}}
$$

Similar results are valid for the equivalent subgroup parameters.

The explicit form of the group transport cross section for the $P_{1}$ or $B_{1}$ approximations is obtained with the $P_{1}$ or $B_{1}$ group equation. This form is related to the cross sections of the medium. The corresponding microscopic cross section is obtained in a fashion similar to the energy dependent case (Appendix A). In fact, the group transport cross section is just a current term average of the corresponding energy dependent cross section over the group.

\section{b. The $\mathrm{P}_{1}$ Relation}

The multigroup form of Fick's law is obtained by integrating the divergence of Equation (43) over the volume.

$$
\Sigma_{t r_{\ell}}=-\frac{\tilde{I}_{\ell} \varphi_{l}}{3 \tilde{J}_{\ell}}
$$

Substituting for $\mathcal{L}_{\ell} \varphi_{\ell}$ in the multigroup equivalence of Equation (9) yields

$$
\Sigma_{t r_{l}}=<\Sigma_{t} z_{l}-\frac{\sum_{m b l} \Sigma_{m \rightarrow l}^{1} \tilde{J}_{m}}{3 \tilde{J}_{l}}
$$

where:

$$
\begin{aligned}
& \left.\Sigma_{t}\right\rangle_{l} \text { is the total cross section, averaged with respect to the } \\
& \text { current term }
\end{aligned}
$$

$$
\text { Because the equation is linear in the cross sections, }
$$
it can also be used for the microscopic transport cross section. The subgroup relations are equivalent to Equations (45) and (46). The connection between the sub and multigroup cross section is a current term average. 


$$
\Sigma_{\operatorname{tr}_{\ell}}=\frac{\sum_{i \text { inl }} \Sigma_{r_{i}} \tilde{J}_{i}}{\tilde{J}_{l}}
$$

Similarly, by integrating Equation (A-29) of Appendix A over the group, it develops that the group transport cross section is a current term average of its energy dependent equivalence.

\section{c. The $B_{1}$ Relation}

The multigroup Fick's law in the $B_{1}$ approximation is derived from Equation (43) in a fashion similar to the way the results leading up to Equation (A-48) of Appendix A were obtained.

$$
\Sigma_{t r_{\ell}}=\frac{B \varphi_{l}}{3 J_{l}}
$$

Substituting for $B_{\ell}$ in the multigroup equivalence of Equation (22) yields

$$
\Sigma_{t r_{\ell}}=\left\langle\Sigma_{t} \alpha\right\rangle_{\ell}-\frac{\sum_{m \leq l}^{1} \Sigma_{m-l}^{1} J_{m}}{3 J_{l}}
$$

where:

$$
\left.\Sigma_{t} \alpha\right\rangle_{\ell} \text { is current averaged over the subgroups. }
$$

This same equation may also be used for the microscopic cross section by taking $\alpha$ as an extensive property of the medium.

The subgroup relations are identical (except for changed subscripts) to Equation (48) and (49). The connection given by Equation (47) then follows.

d. The Monoenergetic Relation

The transport cross section relation in the monoenergetic approximation is:

$$
\Sigma_{t r_{l}}=\Sigma_{t}-\frac{1}{\varphi_{l}} \sum_{i \text { inl }} \Sigma_{e 1_{i}} L 1_{i} \varphi_{i}
$$

where:

L1 is the average $L$ system cosine for elastic scattering. 


\section{Scattering Matrices}

The isotropic elastic and the inelastic scattering matrices

are given by

$$
\Sigma_{x_{l-m}}^{0}=\frac{1}{\varphi_{l}} \sum_{i \text { in }} \varphi_{i} \sum_{\text {in } m} \Sigma_{x_{i \rightarrow j}}^{0}
$$

where:

$$
x=\text { el. or ie. }
$$

The $n, 2 n$ transfer matrix is given by

$$
\Sigma_{n, 2 n_{\ell-m}^{n}}^{n}=\frac{?}{\varphi_{l}} \quad \sum_{i \text { in } \ell} \varphi_{i} \sum_{j \text { in m }} \sum_{n, 2 n_{i \rightarrow j}}^{0}
$$

and the linear anisotropic elastic scattering matrix by

$$
\Sigma_{e l_{\ell-m}^{1}}^{l}=\frac{1}{3 J_{l}} \sum_{i \text { in } \ell} J_{i} \sum_{j \text { in } m}^{1} \Sigma_{e l_{i \rightarrow j}}^{1}
$$

The total isotropic scattering matrix is the sum

$$
\Sigma_{\ell \rightarrow \mathrm{m}}^{0^{a}}=\Sigma_{\mathrm{el}_{\ell \rightarrow \mathrm{m}}}^{0}+\Sigma_{\text {ie. }_{\ell-\mathrm{m}}}^{0}+\Sigma_{\mathrm{n}, 2 \mathrm{n}_{\ell \rightarrow \mathrm{m}}}^{0}
$$

The total isotropic transfer coefficients are:

$$
\mu_{l \rightarrow m}^{0}=\frac{\Sigma_{l-m}^{0}}{\Sigma_{s_{l}}}
$$

With the inclusion of the $n, 2 n$ reaction:

$$
\sum_{m \geq l} \mu_{l-m}^{0} \geq 1
$$

Two other cross sections which can be used in a few-group analysis are now defined; namely, $\Sigma_{\text {out }}$, the out of group scattering cross section, and $\Sigma_{r}$, the cross section for neutron removal. 


$$
\begin{aligned}
& \Sigma_{\text {out }}=\sum_{m>l} \Sigma_{l-m}^{0} \\
& \Sigma_{r_{\ell}}=\Sigma_{\text {out } l}+\Sigma_{a_{\ell}}
\end{aligned}
$$

\section{S Transport Theory Relations}

The transport approximation (Appendix C) is used to derive group constants for $S_{n}$ transport theory programs. The isotropic and linear anisotropic scattering are considered separately.

\section{a. Isotropic Theory}

A group "transport correcting" cross section is de-

fined in the multigroup approximation by:

$$
\Sigma_{\ell}^{1}=\frac{1}{3 \mathrm{~J}_{l}} \sum_{\mathrm{m} \leq \ell} \Sigma_{\mathrm{e} 1_{\mathrm{m} \rightarrow \ell}}^{1} \mathrm{~J}_{\mathrm{m}}
$$

Such a cross section in the monogroup approximation is:

$$
\Sigma_{l}^{1}=\frac{1}{\varphi_{l}} \cdot \sum_{i \text { in } l} \Sigma_{e 1_{i}} L_{i} \varphi_{i}
$$

The group cross section is:

$$
\Sigma_{\ell}=\Sigma_{t_{\ell}}-\Sigma_{\ell}^{1}
$$

The ingroup scattering term is:

$$
\Sigma_{l \rightarrow l}^{0}=\Sigma_{l \rightarrow l}^{0}\left(\text { From Eq. (54)) }-\Sigma_{\ell}^{1}\right.
$$

All other components of the transter matrix are obtained with Equation (54). b. Linear Anisotropic Theory The "transport correcting" cross section for this case is only used in the monogroup approximation: 


$$
\Sigma_{\ell}^{2}=\frac{1}{\varphi_{l}} \sum_{i \text { in } l} \sum_{e l_{i}} \mathrm{~L} 2 \varphi_{i}
$$

The group cross section is:

$$
\Sigma_{\ell}=\Sigma_{t_{\ell}}-\Sigma_{\ell}^{2}
$$

The ingroup scattering terms are:

$$
\begin{aligned}
& \Sigma_{\ell \rightarrow \ell}^{0}=\Sigma_{l \rightarrow l}^{0} \quad\left(\text { From Eq. (54)) }-\Sigma_{\ell}^{2}\right. \\
& \sum_{\ell \rightarrow \ell}^{1}=\Sigma_{\ell \rightarrow \ell}^{1} \quad \text { (From Eq. (53)) }-\Sigma_{\ell}^{2}
\end{aligned}
$$

The other elements of the isotropic matrix are obtained with Equation (54) and the other elements of the linear anisotropic matrix with Equation (53).

The Los Alamos discrete $s_{n}$ program, DTK; uses the absorption location of the anisotropic matrix in the material buckling calculation as follows:

$$
\mathrm{B}^{2}=\frac{j_{i} i_{i}\left(\nu \Sigma_{f_{\ell}}-\Sigma_{a_{\ell}}\right)_{i} v_{i} \varphi_{i \ell}}{\frac{1}{3} \sum_{\ell} \sum_{i} \frac{v_{i} \varphi_{i \ell}}{\left(\Sigma_{\ell}-\Sigma_{a_{\ell}}(\text { aniso })\right)_{i}}}
$$

where:

the subscript $i$ refers to volume increments and the subscript $l$ to the multigroup scheme. Thus, to obtain

$$
\Sigma_{t r_{\ell}}=\Sigma_{\ell}-\Sigma_{a_{\ell}} \text { (aniso) }
$$

the anisotropic absorption cross section must be defined:

$$
\Sigma_{a_{\ell}}(\text { aniso })=\Sigma_{\ell}^{2}-\Sigma_{\ell}^{1} \text { (From Equation (59)) }
$$

This cross section is not included in the printout but only in the punched card output. 
III. USE OF THE CODE

The AGN-GAM code was written to make the input as simple as possible. The first part of this section describes the input formats required for code operation. In the second part a sample problem is solved and the results are discussed, to classify the overal1 procedure..

\section{A. INPUT REQUIREMENTS}

For any machine code that offers both a wide choice in calculational methods and a great number of input options, the card input requirements can become quite complicated and confusing. To eliminate most of this confusion the sketch shown in Figure 3 was drawn. Each block of cards in this figure represents the input for a certain type of information. The blocks are input in the order given except when a complete block is omitted due to the type of calculation performed.

Table 3 lists the five possible types of problems and indicates which of the input blocks are required. Table 4 gives the "cook book" input formats for the data blocks themselves. 


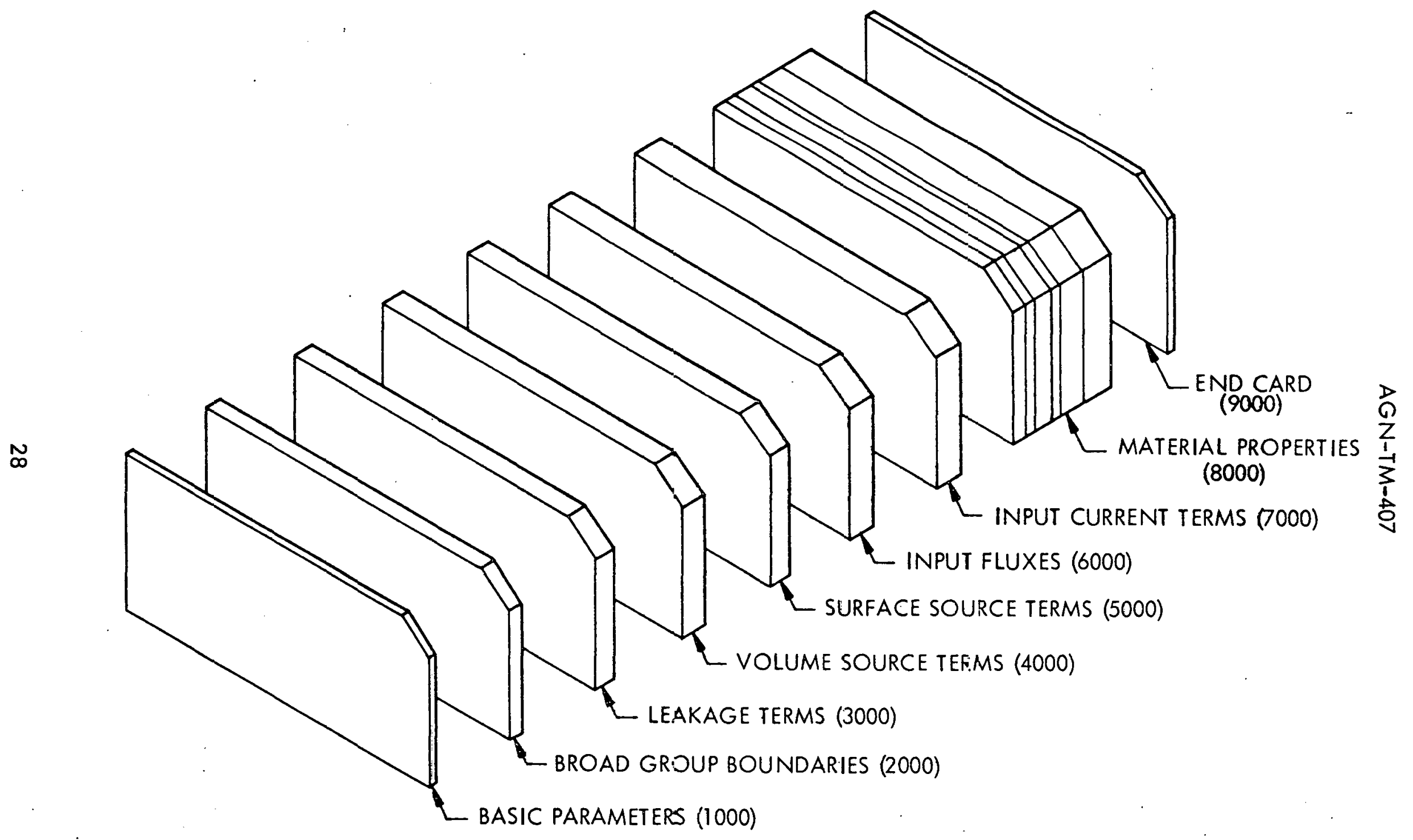

FIGURE 3. AGN-GAM INPUTS 
TABLE 4 - AGN-GAM PROBLEM TYPES AND REQUIRED INPUTS

\begin{tabular}{|c|c|c|c|c|c|c|c|c|c|c|}
\hline Type of Calculation & $\begin{array}{c}\text { Problem } \\
\text { Type }\end{array}$ & $\begin{array}{c}\text { Basic } \\
\text { Parameters } \\
(1000) \\
\end{array}$ & $\begin{array}{c}\text { Group } \\
\text { Boundaries } \\
(2000) \\
\end{array}$ & $\begin{array}{c}\text { Leakage } \\
\text { Terms } \\
(3000) \\
\end{array}$ & $\begin{array}{l}\text { Volume } \\
\text { Sources } \\
(4000) \\
\end{array}$ & $\begin{array}{r}\text { Surface } \\
\text { Sources } \\
(5000) \\
\end{array}$ & $\begin{array}{l}\text { Input } \\
\text { Flux } \\
(6000) \\
\end{array}$ & $\begin{array}{c}\text { Input } \\
\text { Current } \\
(7000)\end{array}$ & $\begin{array}{c}\text { Material } \\
\text { Properties } \\
(8000)\end{array}$ & $\begin{array}{l}\text { End } \\
\text { Card } \\
(9000) \\
\end{array}$ \\
\hline $\begin{aligned} P-1 ; & \text { Complete } \\
& \text { Calculation }\end{aligned}$ & 1.0 & $\mathrm{x}$ & $\mathrm{X}$ & $\mathrm{X}$ & $\mathrm{x}$ & $\mathrm{X}$ & No & No & $\mathrm{X}$ & $X$ \\
\hline $\begin{aligned} P-1 ; & \text { Flux Input } \\
& \text { but Current } \\
& \text { Calculated }\end{aligned}$ & 2.0 & $\mathrm{x}$ & $\mathrm{x}$ & No & $\mathrm{X}$ & $\mathrm{X}$ & $\mathrm{X}$ & No & $\mathrm{x}$ & $\mathrm{x}$ \\
\hline $\begin{array}{l}\text { Flux and Current } \\
\text { Eoth Input }\end{array}$ & 3.0 & $\mathrm{X}$ & $\mathrm{x}$ & No & No & No & $\mathrm{x}$ & $\mathrm{x}$ & $\mathrm{x}$ & $\mathrm{x}$ \\
\hline $\begin{aligned} \text { B - 1; } & \text { Complete } \\
& \text { Calculation }\end{aligned}$ & 4.0 & $\mathrm{X}$ & $\mathrm{x}$ & $x^{*}$ & $\mathrm{x}$ & No & No & No & $\mathrm{x}$ & $\mathrm{X}$ \\
\hline $\begin{array}{l}\text { Same flux and current } \\
\text { as previous problem }\end{array}$ & 5.0 & $\mathrm{x}$ & $\mathrm{x}$ & No & No. & No & No & No & $\mathrm{x}$ & $x$ \\
\hline
\end{tabular}

Notes: * Input one value of leakage for all 75 groups. This value is equal to-B ${ }^{2}$ 
TABLE 5 - INPUT FOR AGN-GAM CODE

NOTE: All cards, except the title card, have a (6E12.5) format.

\section{BASIC RARAMETERS (1000 Series Cards)}

Card \# 1000

Card \# 1001
$\operatorname{Col} \cdot 1-72$

Co1. 1-12

Co1. 13-24

Co1. 25-36
Problem description

Problem number

Type of flux solution desired ( 1.0 to 5.0). See Table 1 for description of the types available.

Type of cross section averaging to be used to obtain broad group constants.

$1.0=$ Diffusion theory

$2.0=$ Isotropic transport theory Type 1 (energy dependent)

$3.0=$ Isotropic transport theory Type 2 (monoenergetic)

$4.0=$ Anisotropic transport theory

Co1. 37-48 Number of broad groups desired $(\leq 32)$. This does not include a thermal group but only the "fast" groups included in the AGN-GAM energy range.

Co1. 49-60 Number of groups downscatter desired in broad group constants.

Co1. 61-72 Geometry to be used in resonance calculations. If no resonance materials are present in problem, leave blank;

$1.0=\mathrm{slab}$

$2.0=$ cylinder

$3.0=$ sphere

Set equal to 1.0 if it is desired to punch the calculated values of flux and current. 


\section{TABLE 5 - Continued}

Co1. 13-24 Option to punch calculated broad group macroscopic and microscopic (if applicable) cross sections;

$0.0=$ do not punch cross sections

$1.0=$ punch for input to DSN, TDC, or 2DXY codes

$2.0=$ punch for input to DTK or DDK codes

$3.0=$ punch for input to ZOOM code

$4.0=$ punch for input to ANGIE code

5.0 = punch for input to AIM- 6 code

$6.0=$ punch for input to $P D Q-2$ code

Col. 25-36 If cross sections are desired for the DSN, TDC, 2DXY, DTK, or DDK codes, input the number of activation cross sections desired in the cross section block. Zeros will be punched in the cards by AGN-GAM for these activation values.

Col. 37-48 For the same codes as above, indicate the number of groups up-scattering desired in the cross section block. Since there is no up-scattering considered in the AGN-GAM energy range, the values will also be punched as zeros.

\section{BROAD GROUP BOUNDARIES (2000 Series Cards)}

Cards \# 2000, 2001, etc.

The energy at the bottom of each of the broad groups is expressed in electronvolts and as many values as broad groups (Co1. 37-48 of Card 非1001) must be supplied. Start with the highest energy group on card 非2000 and proceed, in order, for the required number of groups. 


\section{TABLE 5 - Continued}

LEAKAGE TERMS (3000 Series Cards)

This data required only for certain type of problems; see Table 1.

Card 非 3000

$$
\begin{aligned}
& \text { Co1. 1-12 } \begin{aligned}
& \text { Method used to input values; } \\
& 1.0= \text { Single value to be used in all. } 75 \\
& \text { fine groups } \\
& 2.0= \text { Same value to be used in all the } \\
& \text { fine groups within a given broad } \\
& \text { group. } \\
& 3.0= \text { Values supplied for all } 75 \text { fine } \\
& \text { groups. }
\end{aligned}
\end{aligned}
$$

Col. 13-24 If the above option is set equal to 1.0 , input the single value of $\mathcal{L}$ to be used in this location and omit all the following cards in this set.

Cards 非 3001, 3002, etc.

Starting with the highest energy group, supply the needed values of $\mathcal{L}$. There will be the same number of values as there are the broad groups if option 2 (above) is chosen or 75 if option 3 is picked. VOLUME SOURCE TERM ( 4000 Series Cards)

This data required only for certain types of problems, see Table 1 . Card 非 4000 Col. 1-12 Type of method used to obtain volume source:

$$
\begin{aligned}
0.0= & \text { Set volume source equal to zero } \\
& \text { in all } 75 \text { fine groups } \\
1.0= & \text { read a single value of the volume } \\
& \text { source and use it in all fine } \\
& \text { groups. } \\
2.0= & \text { read a value of the volume source } \\
& \text { for each broad group and use it } \\
& \text { within each fine group within the } \\
& \text { broad group. }
\end{aligned}
$$




\section{TABLE 5 - Continued}

$3.0=$ read a value for each of the 75 fine groups

$4.0=$ read the volume source from the AGN-GAM data tape. The tape number of this source appears in Columns 13-24.

$5.0=$ place $a$ unit source in one fine group only. The number of this group appears in Columns 13-24.

$6.0=$ use the same source as the previous problem.

Col.13-24 Either the source number of the source requested from the data tape (option 4.0 above) or the fine group into which a unit source is to be specified (option 5.0 above). Otherwise, leave blank. Col. 25-36 Normalization constant for the volume source. If this number is left blank or set to zero, it will automatically be made equal to one.

Cards \# 4001,4002 , etc.

If input values are required beyond those given on Card \# 4000, they are input on these cards starting with the highest energy group. SURFACE SOURCE TERM (5000 Series Cards)

This data required only for certain types of problems, see Table 1. Card 非 5000

Co1. $1-12$ Type of method used to obtain the surface source:

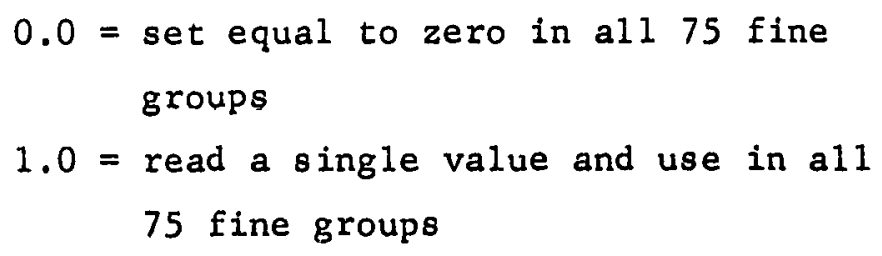


TABLE 5 - Continued

$2.0=$ read a value for each broad group
and use in each fine group within
the broad group.
$3.0=$ read a value for each fine group
Col. 13-24 Single value of surface source if above
option is equal to 1.0 . Skip remaining
cards in this section if this option is
used.

Cards 非 5001, 5002, etc.

Specify required surface șources, if necessary, on these cards starting with highest energy term.

INPUT FLUX (6000 Series Cards)

This data required only for certain types of problems, see Table 1. Card \# 6000 Co1. 1-12 Same method of input as is used for surface source. See 5000 series inputs

\section{Co1. 13=2/ Ditto}

Cards \# 6001, 6002, etc. Ditto

INPUT CURRENT TERMS (7000 Series Cards)

This data required only for certain types of problems, see Table 1. Card \# 7000 Co1. 1-12 Same method of input as is used for surface source, see 5000 series inputs

Col. 13-24 Ditto

Cards \# 7001, 7002, etc. Ditto

MATERIAL PROPERTIES (8000 Series Cards)

Supply one set of 8000 series cards for each material in the problem. If desired, the card number may be prefixed by a material identification number or symbol. Each material requires from 1 to 15 cards to describe it depending upon the use of self-shielding factors and the special resonance treatment. It is not necessary to place the materials in any particular order. 


\section{TABLE 5 - Continued}

Card 非 8000

Col $1-12$

AGN-GAM Tape ID number of the material

Co1. 13-24

Number density of the material (atoms/cc $\times 10^{-24}$ )

Co1. 25-36 Physical density of the material $(\mathrm{gm} / \mathrm{cc})$

NOTE:

Either the number density or the physical density must be input. If both are given, the number density will be used in the problem and the corresponding physical density calculated. It is per.missible to leave blank the one quantity that is not supplied.

Col. 37-48 Option for self-shielding factors.

0.0 If no self-shielding exists (i.e., the values are all one) omit cards 非3001 - 8013 .

1.0 If factors are supplied by broad groups. The one value per broad group will then be used in each fine group within that broad group. In this case, use as many of the 8001 8013 cards as are necessary.

\subsection{If the factors are supplied for all} 75 fine groups.

Col. 49-60 Set equal to 1.0 if microscopic cross sections are wanted.

Cards 非 $8001-8013$

These cards contain the self-shielding tactors requested by the option in Col. 37-48 of Card 非 8000. Start with the highest energy group in the first location. If there is no-self-shielding, these cards must ald be omitted. 


\section{TABLE 5 - Continued}

\section{Card 非 8014}

Required only for those materials which compute resonance absorption and fission from individual resonance parameters.

\begin{tabular}{|c|c|}
\hline Col. $1-12$ & $\begin{array}{l}\text { Number density (atoms/cc } \times 10^{-24} \text { ) of the } \\
\text { resonance material within the "lump" }\end{array}$ \\
\hline Col. 13-24 & $\begin{array}{l}\text { Dimension (cm) of the "lump". Thickness } \\
\text { of a slab, radius of a cylinder or } \\
\text { sphere. Equivalent dimension may be } \\
\text { usen fnr hollow sylinders, pin bundlee, } \\
\text { etc. }\end{array}$ \\
\hline Col. $25-36$ & Physical temperature of the material $\left({ }^{\circ} \mathrm{K}\right)$ \\
\hline $\operatorname{col} \cdot 37-48$ & $\begin{array}{l}0_{m} \text {, the scattering cross section of all } \\
\text { other materials within the "lump". In } \\
\text { barns per atom of the resonance material. }\end{array}$ \\
\hline Co $1 \cdot 49-60$ & $\begin{array}{l}\sigma_{\mathrm{p}} \text {, the total scattering cross section } \\
\text { of all materials within the "lump". In } \\
\text { barns per atom of the resonance material. }\end{array}$ \\
\hline
\end{tabular}

END CARD (9000 Series Card)

NOTE: The end card must be supplied in each problem
Card 非 9000
Co1. $1-12$
$"+99999.0 "$ 


\section{B. SAMPLE PROBLEM}

To illustrate the use of the AGN-GAM code, a sample problem is defined and solved. The problem is designed to show how the code functions, not to convey "magic" numbers, constants, or methods.

For the sample problem it is desired to calculate fast group cross sections for a system composed of Hastelloy $X$ clad fuel pins arranged in a triangular lattice and in a water moderator. Each fuel pin contains fully enriched $\mathrm{UO}_{2}-\mathrm{BeO}$ fuel with a U-235 loading of 1.616 grams/inch. The dimensions of the lattice and pins are given in Figure 4. Results are to be used in a 16 group DSN code calculation using anisotropic transport theory. Resonance calculations are performed for U-235 only. The composition of the unit cell is calculated on a purely geometric basis and to permit greater accuracy, the U-235 density is derived from known fuel loadings, rather than volume fractions. It is assumed that all the materials in the cell "see" the same flux (i.e., there is no self-shielding to permit the flux, at any energy, to be higher in one material than in another). Table 6 shows the results obtained.

A P-1 calculation is performed. The completed basic parameter cards are listed in Figure 5. The following comments apply to these inputs.

1) The problem number is assigned for reference purposes only. 2) Fifteen groups are specified; the code calculates only fast group constants; the constants for the sixteenth (therma1) group must be obtained from other sources. However, scattering into the sixteenth group (defined with energy limits from the bottom of the fifteenth group to zero) is calculated.

3) Five broad groups of downscattering are desired. All scattering to groups below this point are added to the last group considered. 4) Since more than one type of resonance geometry cannot be used and since cylindrical fuel pins are involved, a cylindrical geometry is selected for the resonance calculations. The choice of geometry defines which of three possible tables of $L(t, \xi, \beta)$ must be used in the machine. 


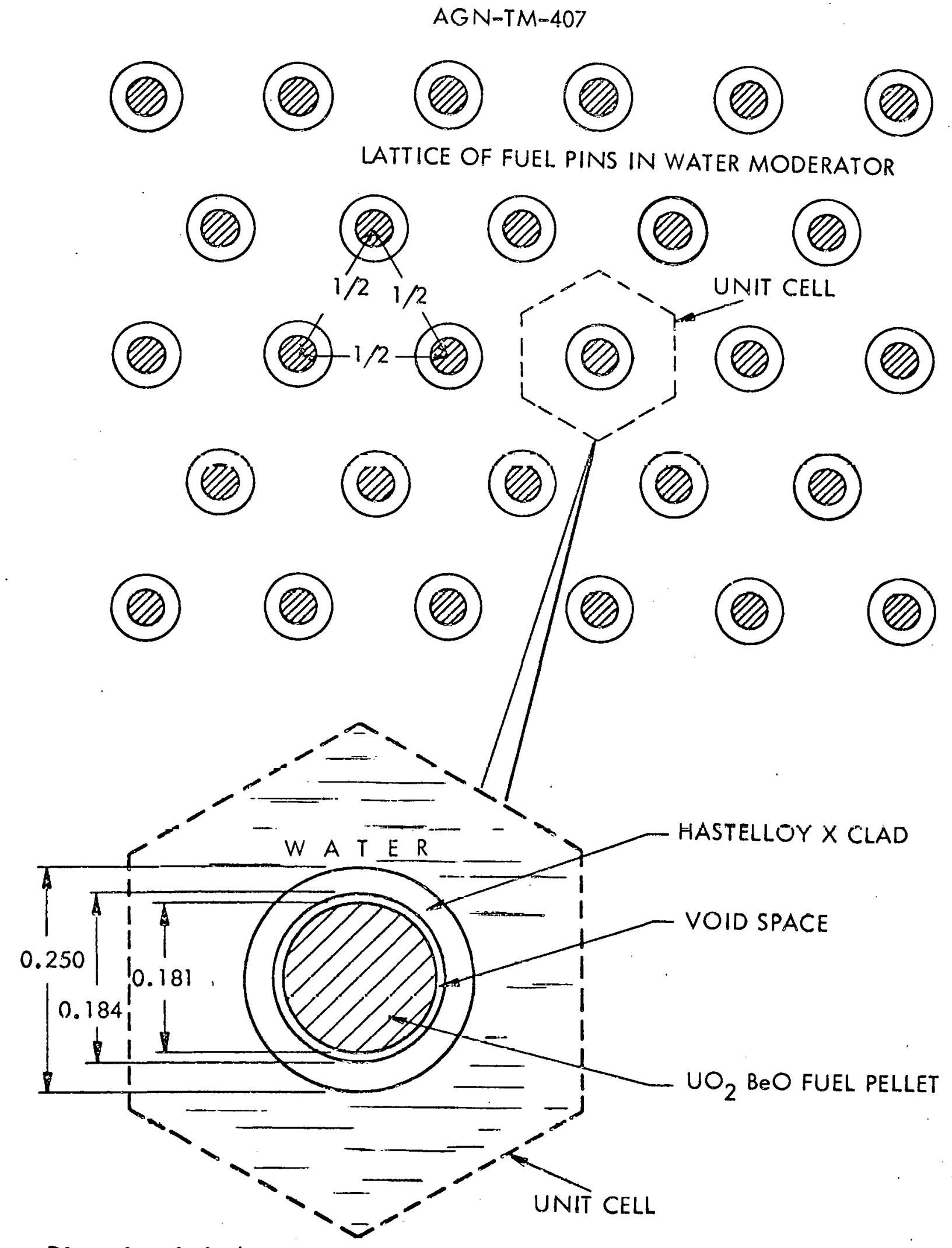

Dimensions in inches 


\begin{tabular}{ll}
\multicolumn{3}{c}{ EXAMPLE PROBLEM } \\
+7.0001 & $E+00+1.0$ \\
+0.0 & $E+00+1.0$ \\
+3.0 & $E+06+1.4$ \\
+3.0 & $E+03+4.54$ \\
+1.1256 & $E+00+4.141$ \\
+2.0 & $E+00$ \\
-6.91 & $E-03-7.82$ \\
-1.125 & $E-02-1.129$ \\
-1.132 & $E-02-1.140$ \\
+4.0 & $E+00+1.0$ \\
+0.0 & $E+00$ \\
+6.0 & $E+00$ \\
+6.5 & $E+01$ \\
+8.0 & $E+00$ \\
+1.01 & $E+02$ \\
+9.8 & $E-03+2.09$ \\
+1.7 & $E+01$ \\
+3.2 & $E+01$ \\
+3.0 \\
+4.3 & $E+01+0.0$ \\
+1.10 & $E+00+1.05$ \\
+1.00 & $E+00+1.00$ \\
+0.95 & $E+00+0.91$ \\
+9.9999 & $E+04$
\end{tabular}

FOR AGN-TM-407 $E+00+4.0$ $E+00+1.0$ $E+06+9.0$ $E+02+6.144$ $E-01+1.523$

$E-03-9.21$ $E-02-1.129$ $E-02-1.178$ $E+00+1.0$ $+7.73$ $+8.55$ $+1.82$ $+4.55$

$E-01+2.93$ $+3.40$ $+6.70$

$E+00+0.0$

$E+00+1.03$

$E+00+1.00$

$E+00+C .85$

$\begin{array}{llll}E+01+5.0 & E+00+2.0 & E+00 & 1000 \\ E+00 & & & 1001 \\ E+05+1.0 & E+05+1.7 & E+04 & 2002 \\ E+01+8.315 & E+00+3.059 & E+00 & 2001 \\ & & & \\ & & & 2002 \\ & & & 3000 \\ E-02-1.058 & E-02-1.105 & E-02 & 3001 \\ E-02-1.130 & E-02-1.130 & E-02 & 3002 \\ & & & 3003 \\ & & & 4000 \\ & & & 5000 \\ E+00+0.0 & E+00 & H 20 & 8000 \\ E+00+0.0 & E+00 & H X & 8000 \\ E+00+0.0 & E+00 & B E O & 8000 \\ E+00+1.0 & E+00 & U 35 & 8000 \\ E+01+5.58 & E+01 & U 35 & 8014 \\ E+00+0.0 & E+00 & U 38 & 8000 \\ E+00+0.0 & E+00 & O X & 8000 \\ E+00+1.0 & E+00 & M N & 8000 \\ E+00+1.00 & E+00+1.00 & E+00 M N & 8001 \\ E+00+1.00 & E+00+0.98 & E+00 M N & 8002 \\ & & M N & 8003 \\ & & & 9000\end{array}$

FIGURE 5. LIST OF INPUT CARDS FOR SAMPLE PROBLEM 


\section{TABLE 6 - COMPOSITION OF SAMPLE PROBLEM}

\section{Material}

Water

Hastelloy- $\mathrm{X}$

Void

Fuel Pellet

$\mathrm{BeO}$

$\mathrm{UO}_{2}$
a) U-235
b) $\mathrm{U}-238$
c) Oxygen

Volume Fraction

0.7732

0.1039

0.0040

$$
0.0648
$$

0.0541

$\overline{1.0000}$

\section{Pure Material}

Density $(g / c c)$

1.00

8.23

$-\cdots$

2.81

8.41

0.63

1.23
Ce11

Density $(g / c c)$

0.773

0.855

-...

0.182

0.455

0.034

0.067

2.366

5) No punched fluxes and currents are requested.

6) Punched cross sections for the DSN code are requested. Macroscopic results for the mixture are provided in addition to the microscopic values for any material indicated later in the input.

7) In the punched cross section block, room for one activation cross section is left (it is punched as a zero). No up-scattering on the transfer matrices is provided for.

Tho cnergy brcako betwecn the broad groups correspund wilh lle common LASL values. These specified energies do not have to correspond with the one quarter lethargy values used with the library data tape; the code will find the nearest division on the library tape and use it.

Leakage terms are calculated by cstimating the buckling for a bare cylinderical core $56 \mathrm{~cm}$ high and $25 \mathrm{~cm}$ in radius. A U-235 fission source on the AGN-GAM data tape is selected for the volume source. The surface source is set to zero.

Material constants are input as previously specified. Identification numbers for the data tape are obtained from Table D-IV in Appendix D. Microscopic cross sections for U-235 are calculated with the resonance treatment, and therefore, an extra card containing the appropriate parameters is supplied. Table 7 shows how the needed values are obtained. It is assumed that the pins are at a physical temperature of $20^{\circ} \mathrm{C}$. 
TABLE 7 - CALCULATION OF PARAMETERS FOR RESONANCE CALCULATION

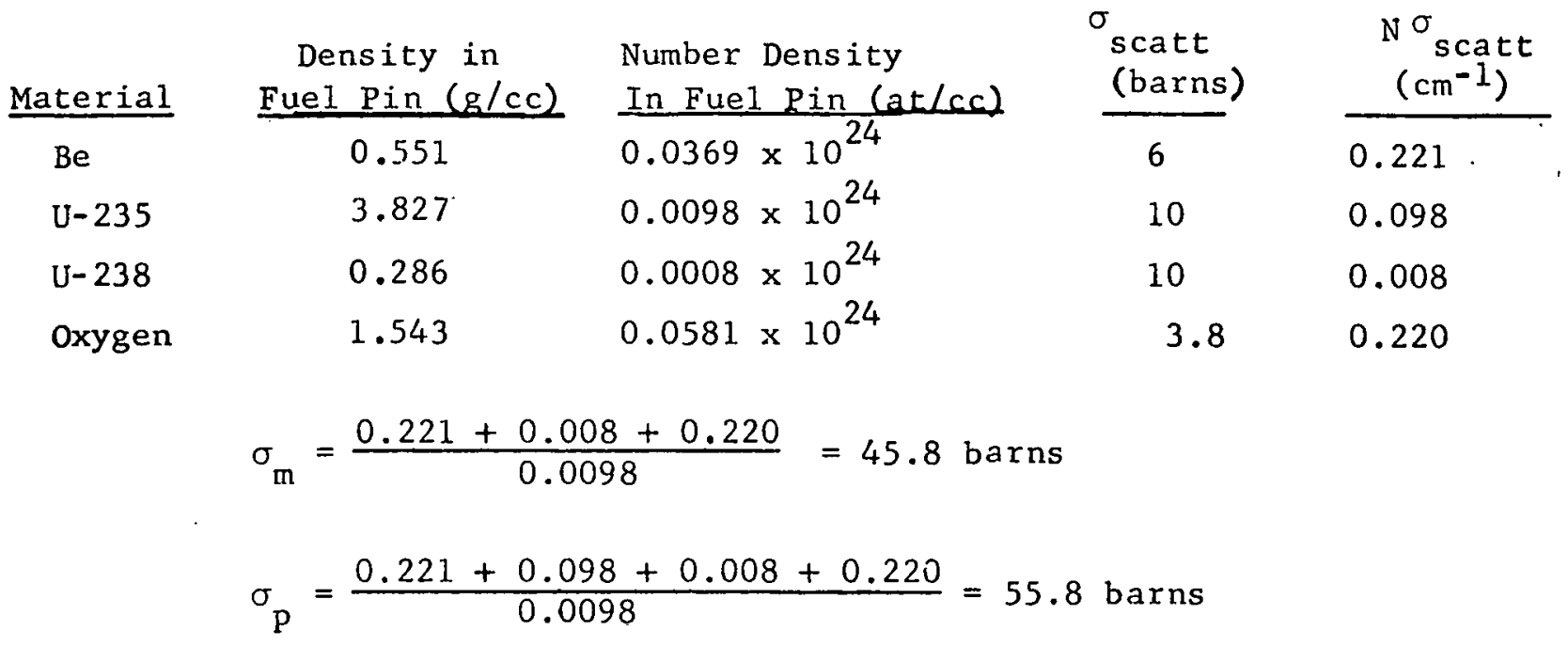

As an added complication, it is assumed that a manganese wire exists in the system for experimental purposes, and that cross sections for this wire are desired. The assumption is made that self-shielding factors are known for the manganese by broad groups. The manganese is added with zero density, which will cause it not to be considered in the calculation of the macroscopic cross sections but will permit calculation of microscopic values. The self-shielding factors are automatically included in these microscopic values.

Figure 6 shows the output from this problem. Note the energy sperifirations and hov thcy have leell aljusted to tall on the one quarter. lethargy values. In addition it is apparent that the materials have been placed according to ID numbers (in ascending order). Self-shielding factors are printed only when they were input. Results of the resonance calculations are shown with totals; following the input quantities, the calculated flux, current, and ages appear. Listed next are the averaged macroscopic cross sections for the specified mixture (in $\mathrm{cm}^{-1}$ ), followed by the requested microscopic values (in barns).

Figure 7 shows a listing of part of the punched card outputs for input to the DSN code; the meaning of the ID field symbols are indicated on this figure. Values for the thermal group have been punched as zeros and must be replaced with the correct values. 


\section{THIS PAGE \\ WAS INTENTIONALLY \\ LEFT BLANK}




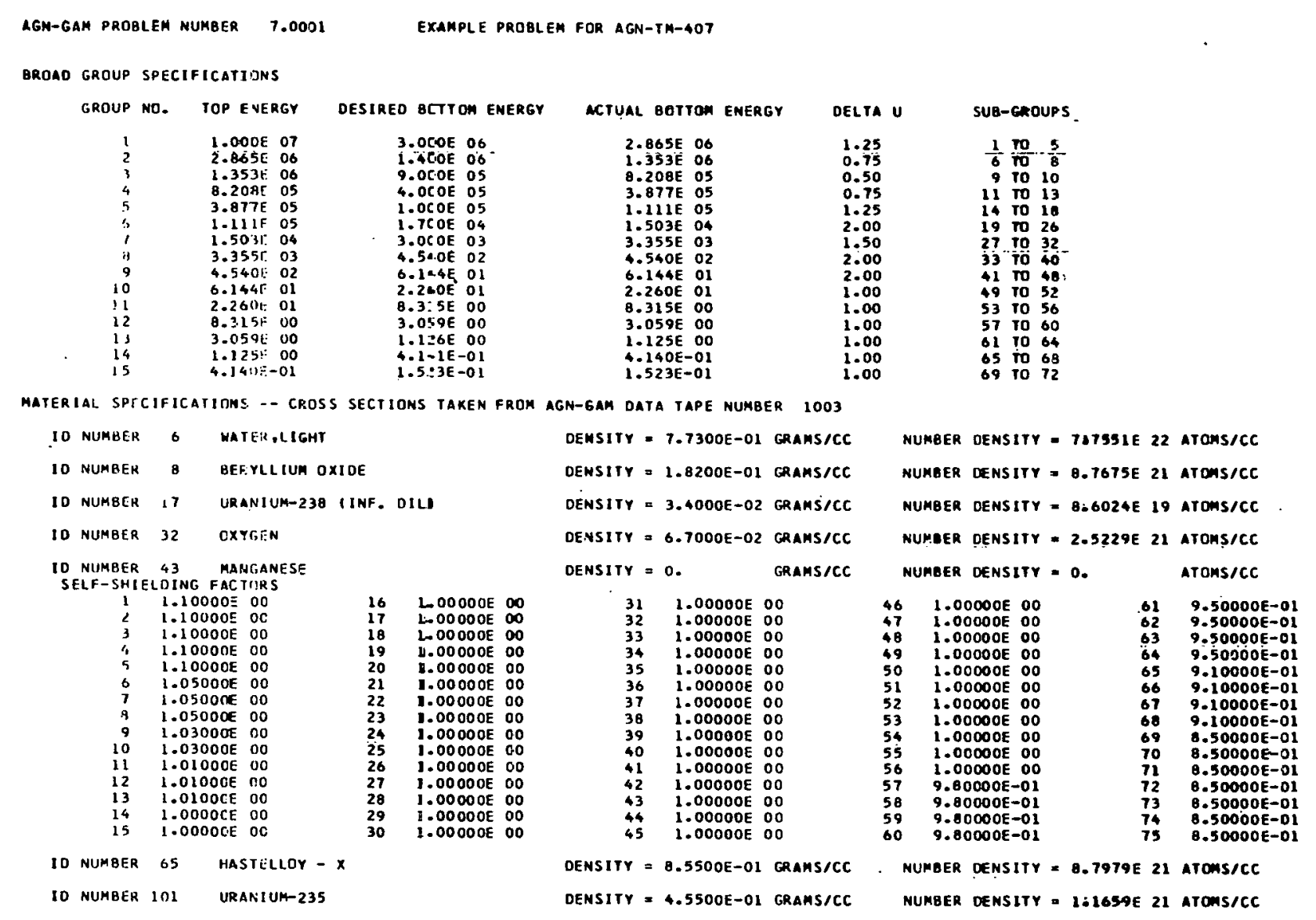

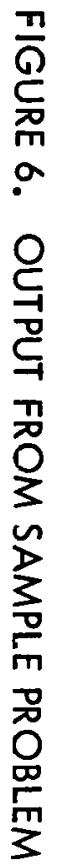

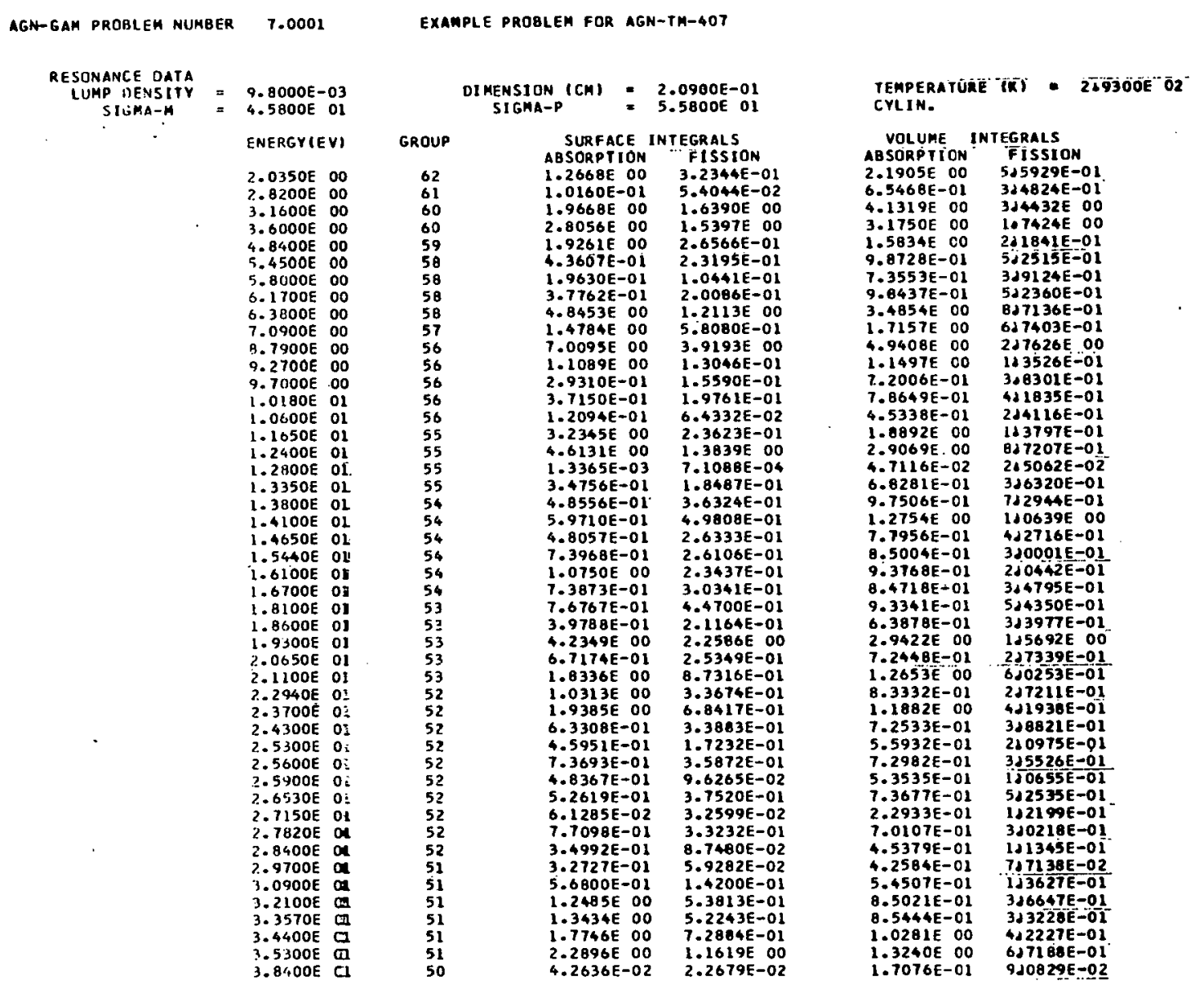

EXAMPLE PROBLEM FOR AGN-TM-407

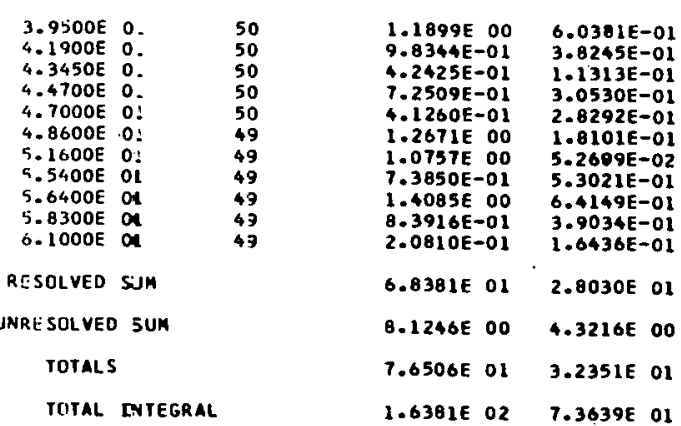

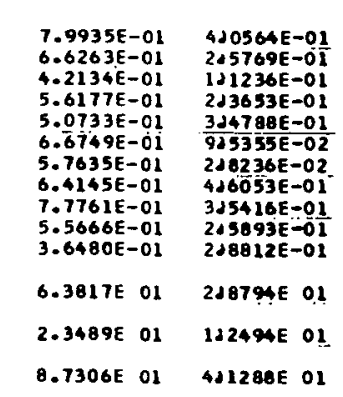


AGN-GAM Problem NUHBER T.0001 EXaMple Problem FOR AGN-TM-407

flux AND CURzent Calculated using th: P-1 methor

LEAKAGE TEKM

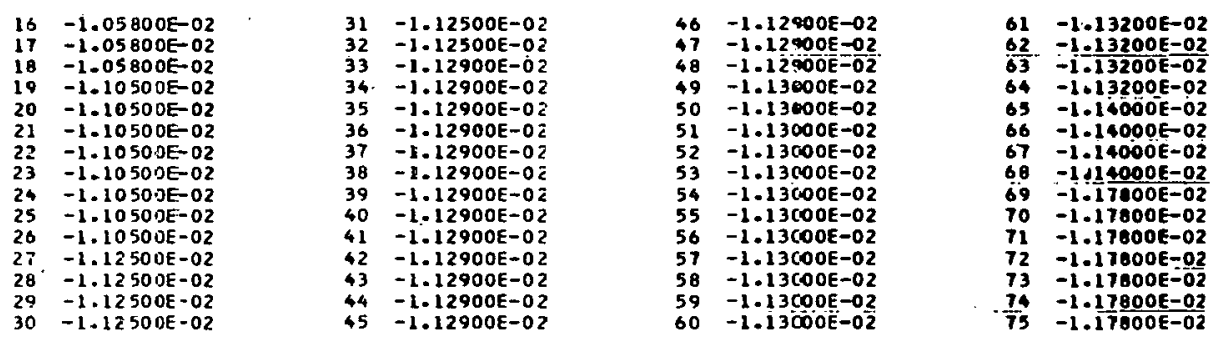

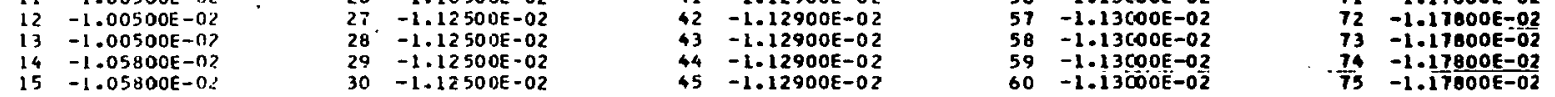

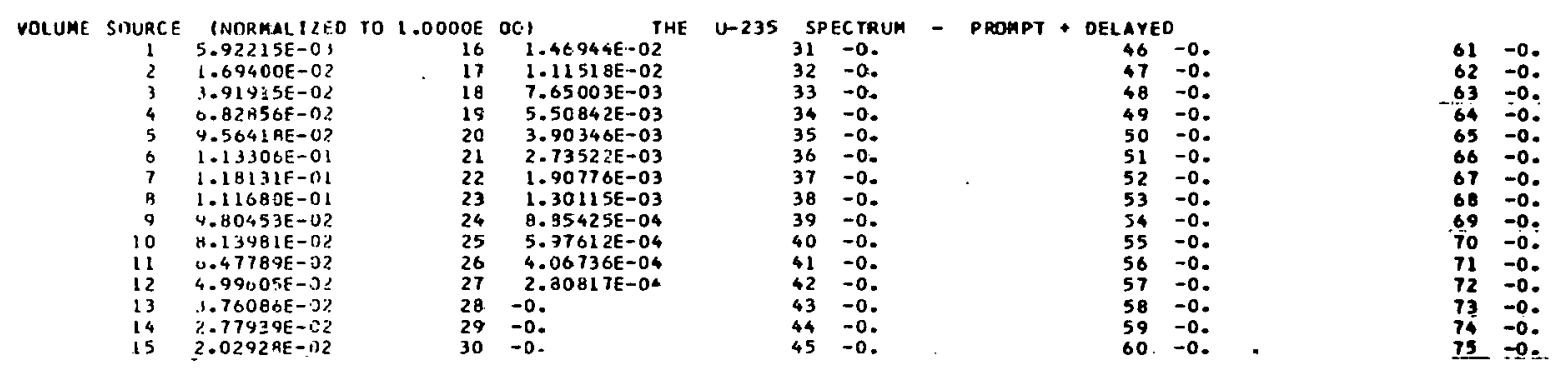

SURFACE SOURCE
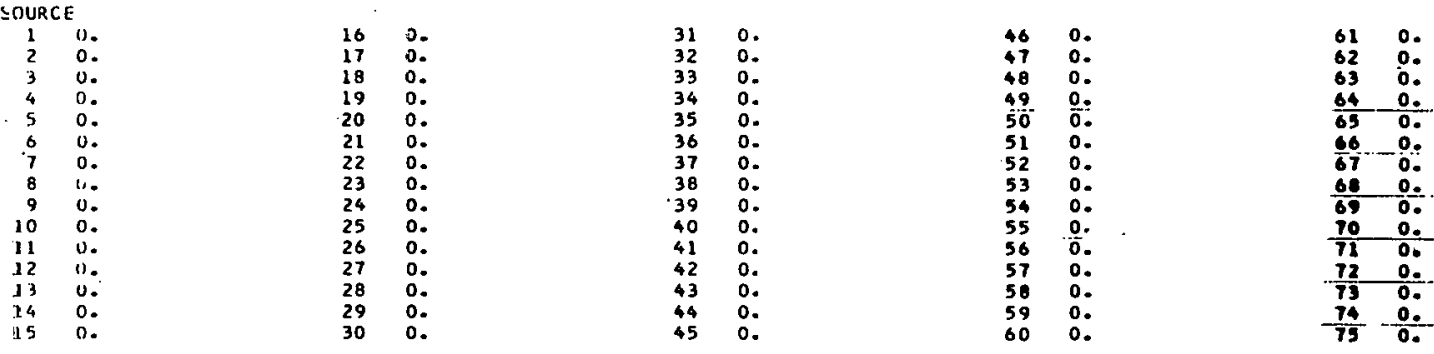

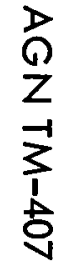

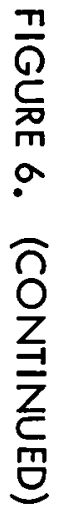
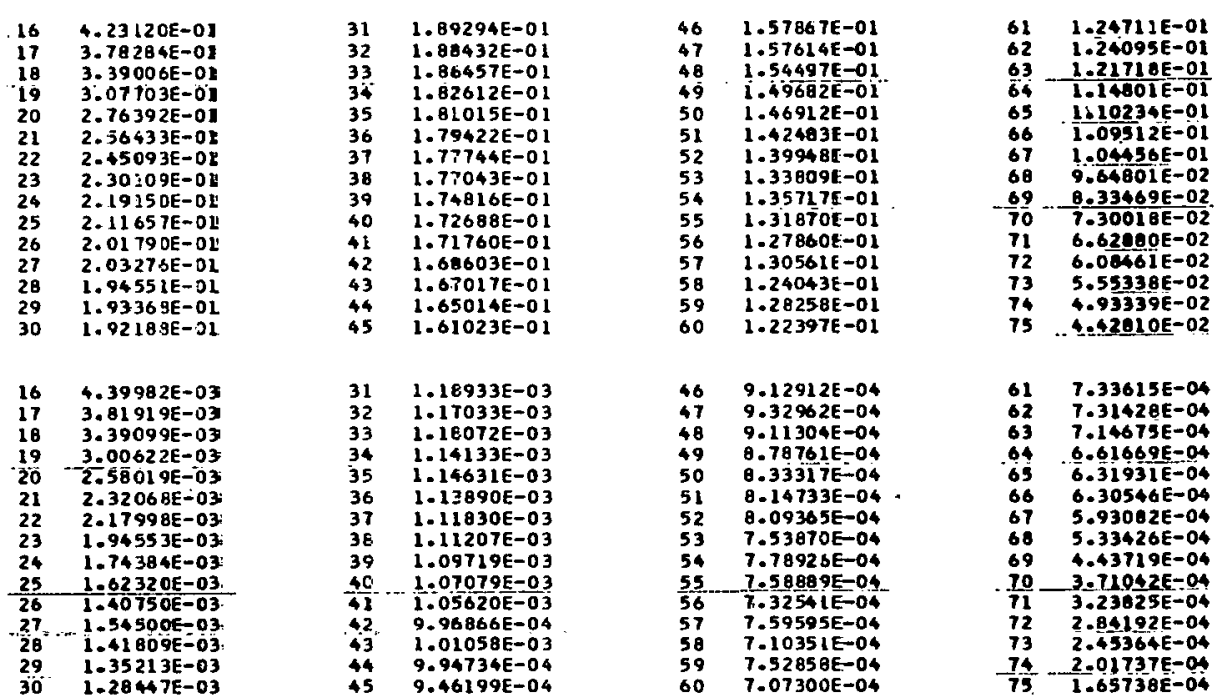

AGN-GAM PROBLEM NUMBER 7.0002

EXAYPLE PROELEM FOB AGM-TM-4OT
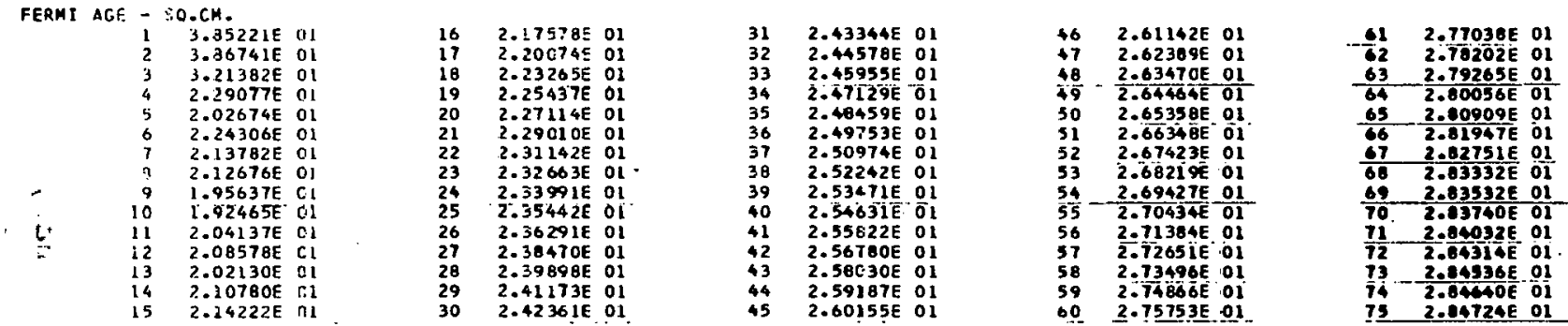

AGM-GAM PROPLEM NUMEER 7.0001

EXAMPLE PROBSEM FOL AGN-TM-407

BROAO GROUP MACROSCOPIC CROSS SECTIONS
IAVERAGEG FOR USE IN ANISOT ROPIC TRANSPORT CODES,

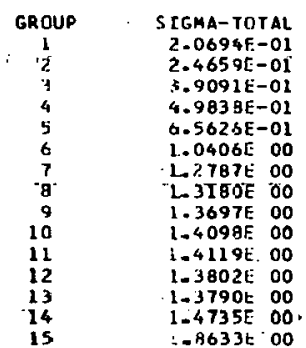
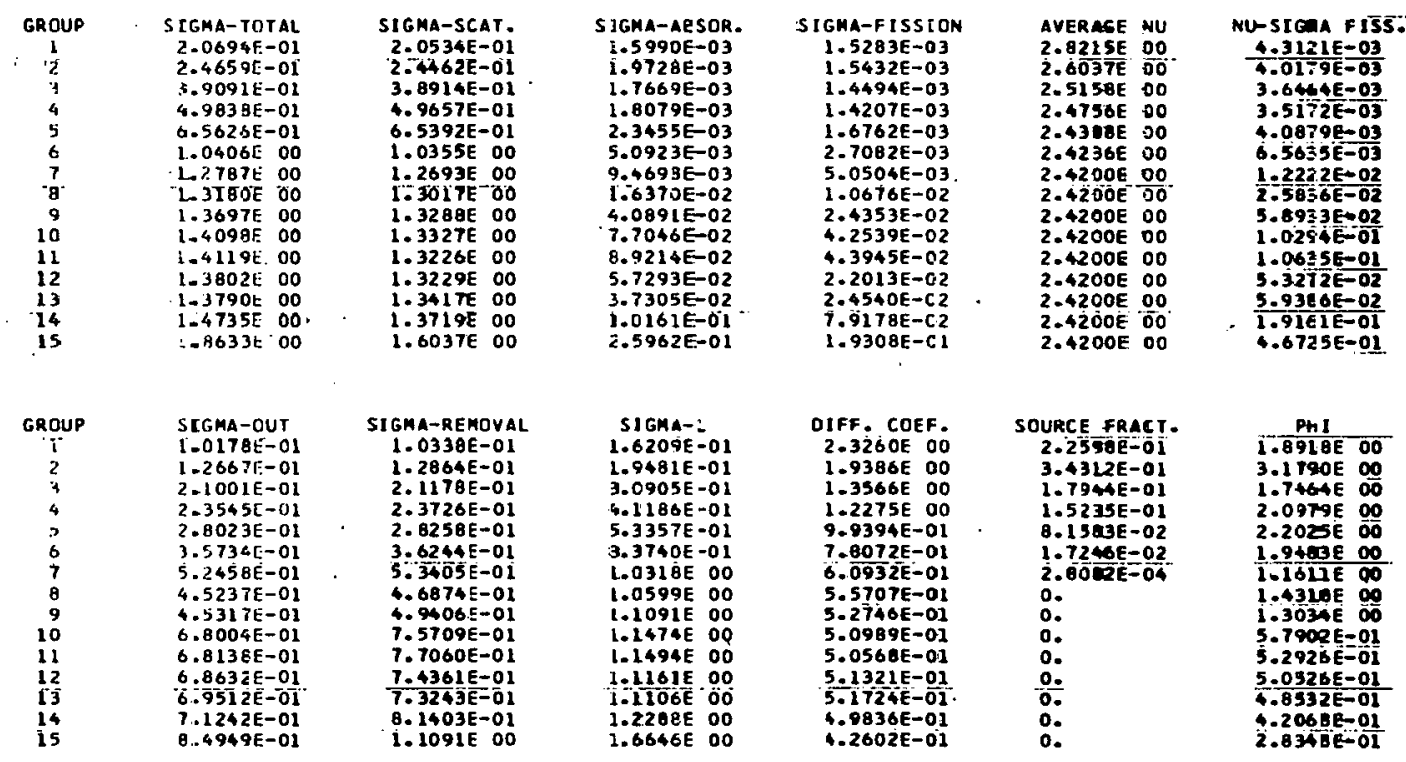

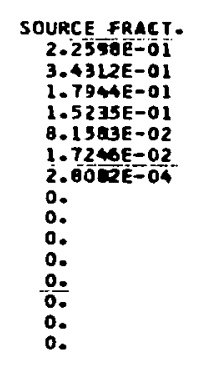

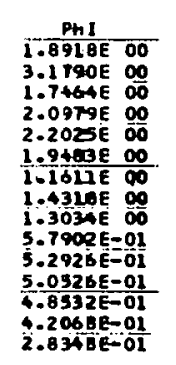
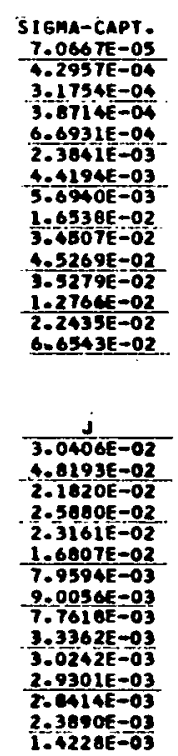


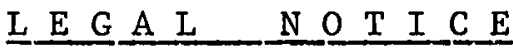

This report was prepared as an account of Government sponsored work. Neither the United States, nor the Commission, nor any person acting on behalf of the Commission:

A. Makes any warranty or representation, expressed or implied, with respect to the accuracy, completeness, or usefulness of the information contained in this report, or that the use of any information, apparatus,method, or process disclosed in this report may not infringe privately owned rights; or,

B. Assumes any liabilities with respect to the use of, or for damages resulting from the use of any information, apparatus, method, or process disclosed in this report.

As used in the above, "person acting on behalf of the Commission" includes any employee or contractor of the Commission, or : employee of such contractor to the extent that such employee or contractor of the Commission, or employee of such contractor prepares, disseminates, or provides access to, any information pursuant to his employment or contract with the Commission, or his employment with such contractor.

The information herein is regarded as preliminary and subject to further checking, verification and analysis. 
AEROJET - GENERAL NUCLEONICS 